ESCOLA POLITÉCNICA DA UNIVERSIDADE DE SÃO PAULO

JUAN CARLOS CEBRIAN AMASIFEN

METODOLOGIAS PARA AVALIAÇÃO DE RISCOS E DOS CUSTOS DE INTERRUPÇÕES EM PROCESSOS CAUSADOS POR FALTAS EM SISTEMAS DE DISTRIBUIÇÃO DE ENERGIA ELÉTRICA

São Paulo

2008 


\title{
METODOLOGIAS PARA AVALIAÇÃO DE RISCOS E DOS CUSTOS DE INTERRUPÇÕES EM PROCESSOS CAUSADOS POR FALTAS EM SISTEMAS DE DISTRIBUIÇÃO DE ENERGIA ELÉTRICA
}

\author{
Tese apresentada à Escola Politécnica da \\ Universidade de São Paulo para obtenção de \\ título de Doutor em Engenharia Elétrica \\ Área de concentração: \\ Sistemas de Potência
}

Orientador: Prof. Doutor Nelson Kagan

São Paulo 
Este exemplar foi revisado e alterado em relação à versão original, sob responsabilidade única do autor e com a anuência de seu orientador.

São Paulo, de julho de 2008.

Assinatura do autor

Assinatura do orientador

FICHA CATALOGRÁFICA

Amasifen, Juan Carlos Cebrian

Metodologias para avaliação de riscos e dos custos de interrupções em processos causados por faltas em sistemas de distribuição de energia elétrica / J.C.C. Amasifen. -- ed.rev. -- São Paulo, 2008.

$184 \mathrm{p}$.

Tese (Doutorado) - Escola Politécnica da Universidade de São Paulo. Departamento de Engenharia de Energia e Automação Elétricas.

1.Redes de distribuição de energia elétrica (Metodologia) 2.Risco (Avaliação) I.Universidade de São Paulo. Escola Politécnica. Departamento de Engenharia de Energia e Automação Elétricas II.t. 
Dedicado a Jessyca, pelo amor, carinho, apoio, compreensão, e por tudo o que ela significa para mim. 


\section{Agradecimentos}

Em primeiro lugar a Deus por mais esta conquista em minha vida

Aos meus pais Teodosia e Alex e aos meus irmãos Alejandro e Mercedes pelo carinho e incentivo em todas as etapas da minha vida.

Ao Prof.Dr.Nelson Kagan pela orientação e também pela confiança, sugestões, leituras e pelo brilhantismo e entusiasmo com que cria seus projetos.

Aos meus colegas Nelson Massakuzu Matsuo e João Carlos Guaraldo pelas valiosas contribuições em várias etapas desta tese.

Ao apoio e amizade que sempre me foram dados pelos demais colegas do ENERQ. 


\section{RESUMO}

Nesta tese, foram desenvolvidas três metodologias para análise dos riscos de interrupções em processos eletro-eletrônicos provocadas por faltas nos sistemas de distribuição de energia elétrica. Estas metodologias são: Monte Carlo, Enumeração de Estados e Híbrido.

Com a utilização destas metodologias, são avaliados índices relativos às interrupções de longa duração e às variações de tensão de curta duração (afundamentos, elevações e disrupções de tensão) em cada consumidor da rede de distribuição de energia elétrica. Em cada barra do sistema, as freqüências de ocorrências de cada índice são obtidas, classificadas por faixas de magnitude e duração dos eventos.

Conhecendo informações sobre a configuração e parâmetros de rede e sobre os dispositivos de proteção, através de um conjunto de simulações, é possível mapear as áreas de risco relativas aos fenômenos de interrupção e variações de tensão de curta duração (VTCDs). Dispondo ainda do conjunto de curvas de sensibilidade dos processos industriais, avaliam-se as freqüências de disrupções de processos, esperadas por ano no ponto analisado, isto é, o número de vezes que um processo apresenta mau funcionamento e possivelmente interrupção devido a uma VTCD.

Também é apresentada nesta tese uma formulação matemática que permite realizar a inclusão do custo do prejuízo pela falta da qualidade de energia nos consumidores em modelos clássicos para o tratamento de problemas de planejamento da operação e da expansão de sistemas de distribuição de energia elétrica.

Os métodos para avaliação das áreas de risco e custos de interrupção de processos por faltas nas redes de distribuição foram implementados em um sistema computacional. Resultados da aplicação em redes de distribuição reais permitem avaliar vantagens e desvantagens de cada um dos métodos.

Para observar o impacto do prejuízo nos consumidores, são utilizados resultados obtidos na literatura para realizar a comparação e obter o custo total envolvendo custos de investimento de novas obras, custo de perdas de energia e custo do prejuízo pela falta da qualidade de energia nos consumidores existentes na rede de distribuição de energia elétrica. 


\section{ABSTRACT}

Three methodologies for risk assessment of interruptions in electrical and electronic sensitive devices are herein developed. These interruptions are mainly due to faults in electric power distribution systems. The methodologies are herein named Monte Carlo Method, State Enumerating Method and Hybrid Method.

These methods allow for the evaluation of indices related to long duration interruptions and voltages sags and swells in each customer supplied by the distribution network. The power quality indices (expected number of events per year) are classified according to voltage amplitude and event duration.

The information regarding network configuration and parameters as well as protection devices are input for a set of simulations that result in mapping the indices related to long duration interruptions and short duration voltage variations along the network. By considering the sensitivity curves for industrial processes, the method determines the frequency of process disruptions, i.e. the number of events in which the customer process malfunctions, or it is damaged or it is interrupted due to voltage sags or swells.

This thesis also shows a mathematical formulation that includes costs regarding customer losses caused by poor power quality to conventional models that deal with operation and expansion planning of electric power distribution systems.

The proposed methods for assessing risks and interruption costs in customer processes due to faults in distribution networks were implemented in a computational system. Case studies in real distribution networks show advantages and disadvantages of each method.

In order to determine losses in customer processes, some literature results are taken as a basis to determine the total planning costs, that include the parcels corresponding to the reinforcement capital, power losses and power quality costs, that consider customer interruptions and disruptions due to voltage sags and swells. 


\section{SUMÁRIO}

1 - INTRODUÇÃO

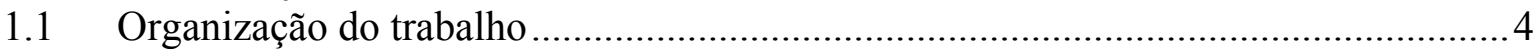

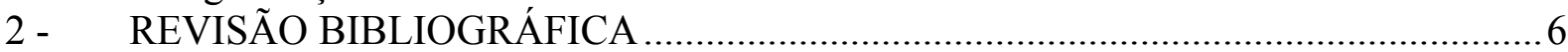

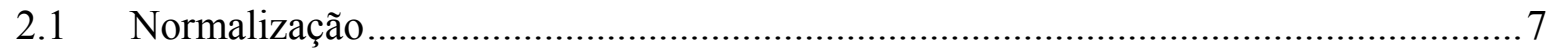

2.2 Impactos da Qualidade de Energia sobre as Cargas .......................................... 10

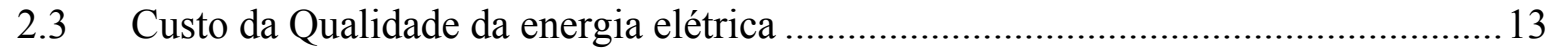

2.4 Avaliação das VTCDs nas redes elétricas e seus impactos sobre os consumidores.. 14

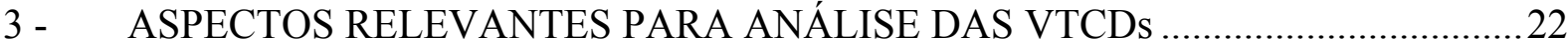

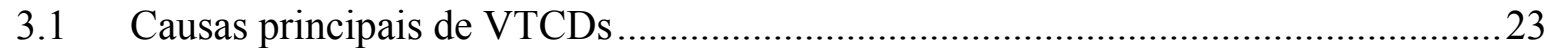

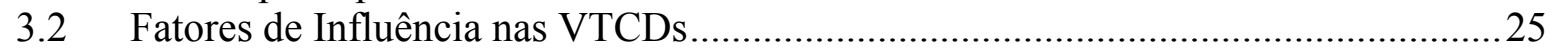

3.3 Sensibilidade de equipamentos ou processos industriais .......................................... 31

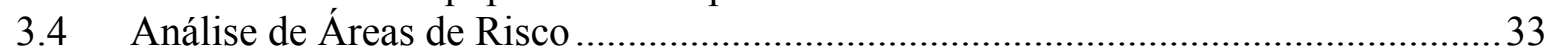

4 - $\quad$ MODELOS PARA ANÁLISE DE ÁREAS DE RISCO.............................................. 36

4.1 Obtenção de Condições de Curto-Circuito na rede de Distribuição............................36

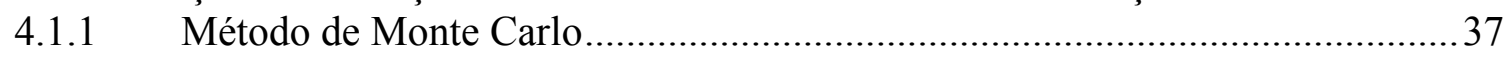

4.1.1.1 Aplicação ao problema de Análise de Risco de VTCDs ....................................38

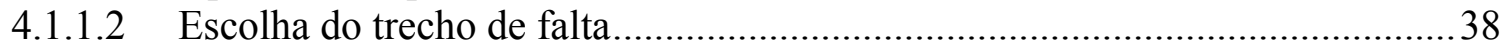

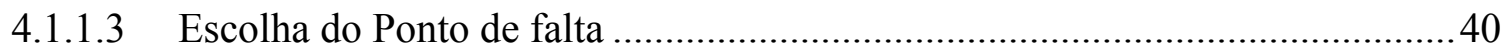

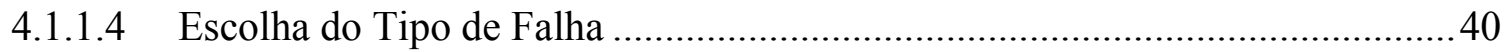

4.1.1.5 Escolha da Resistência de Falta..................................................................... 41

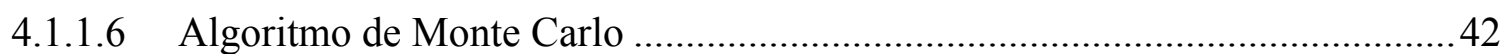

4.1.2 Método de Enumeração de Estados.................................................................... 43

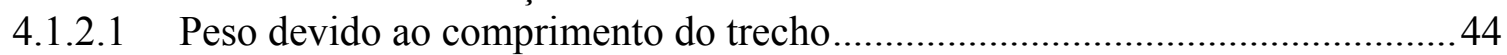

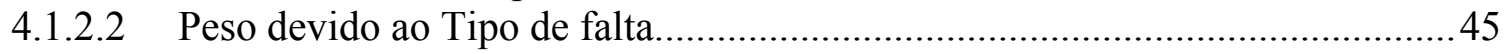

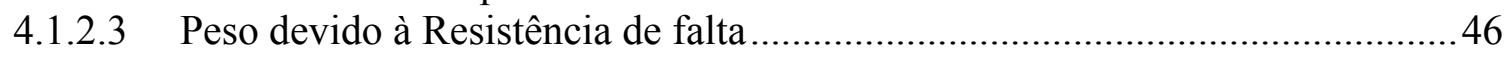

4.1.2.4 Peso total para uma condição de Curto-Circuito .............................................. 46

4.1.2.5 Algoritmo do Método de Enumeração de estados.............................................47

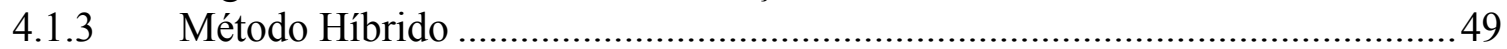

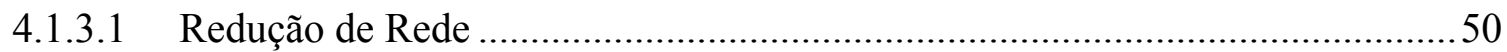

4.1.3.2 Agrupamento em função do comprimento ..........................................................51

4.1.3.3 Grupos mais predominantes e menos predominantes......................................52

4.1.3.4 Obtenção do conjunto de condições de Curtos-Circuitos...................................54

4.1.3.4.1 Grupos Mais Predominantes........................................................................... 54

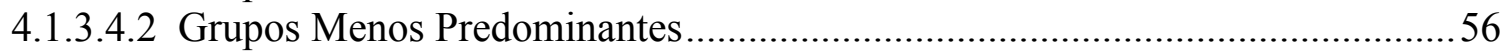

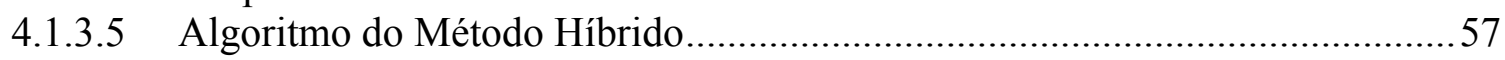

4.2 Determinação do Número de Condições de Curtos-Circuitos para cada Método .....60

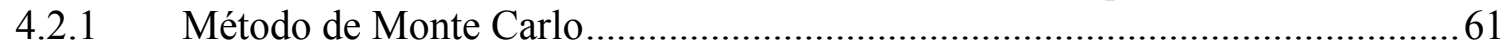

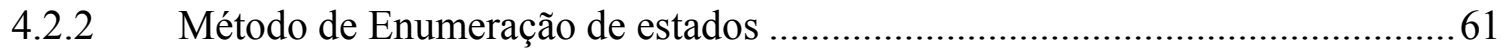

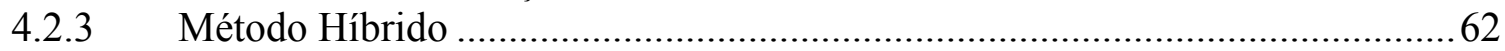

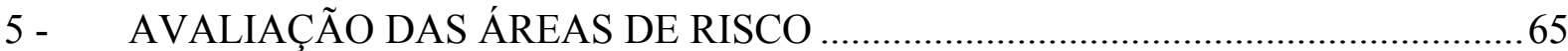

5.1 Cálculo das Grandezas Elétricas durante um Curto-Circuito ....................................65

5.2 Coordenação dos dispositivos de proteção ..............................................................66

5.3 Distribuição de probabilidade do tempo da extinção da falta ..................................68

5.4 Determinação da Probabilidade de ocorrência VTCDs ou Interrupções....................69

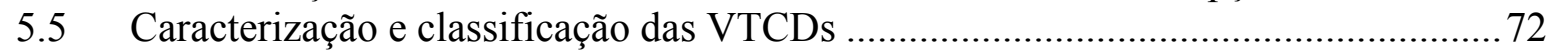

5.6 Caracterização e classificação das Disrupções de equipamentos eletro-eletrônicos.75

5.7 Contribuição de outros alimentadores nas VTCDs ................................................. 77 
5.8 Determinação da freqüência anual de ocorrência de VTCDs e Interrupções............78

5.9 Determinação dos Custos de Interrupção e Disrupção ............................................... 80

5.10 Algoritmo Utilizado para análise de Áreas de Risco................................................ 82

6 - PLANEJAMENTO DE SISTEMAS DE DISTRIBUIÇÃO CONSIDERANDO

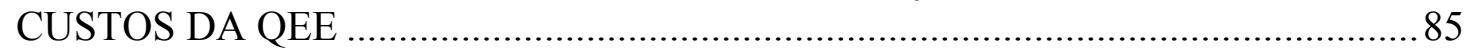

6.1 Inclusão do Custo da QEE no Planejamento de Operação ....................................... 86

6.1.1 Formulação Clássica do Problema de Reconfiguração …………......................... 87

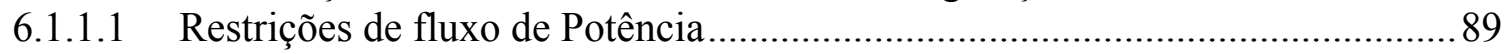

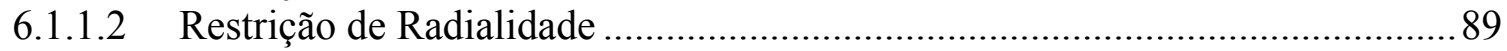

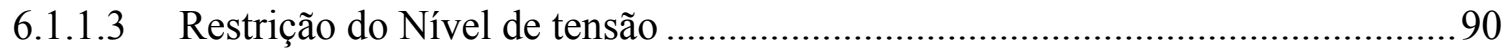

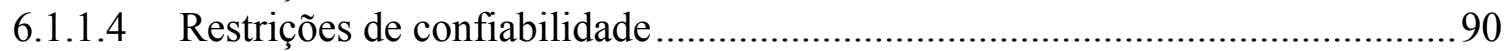

6.1.1.5 Restrições de balanço de carga entre os alimentadores .................................. 91

6.1.1.6 Restrições de fluxo de potência nos Trechos...................................................92

6.1.2 Formulação do Problema de Reconfiguração considerando Custos da QEE...92

6.1.3 Inclusão Prática dos Custos da QEE no Problema de Reconfiguração .............93

6.2 Inclusão do Custo da QEE no Planejamento da Expansão........................................94

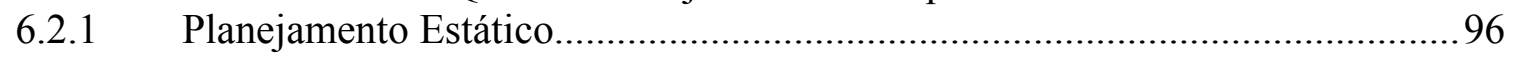

6.2.2 Planejamento Multi-Estágios (Dinâmico) ....................................................... 96

6.2.3 Planejamento Pseudo-dinâmico.......................................................................98

6.2.4 Formulação Clássica do Problema de Planejamento de Expansão....................98

6.2.4.1 Função objetivo - Planejamento ótimo estático Clássico ..................................99

6.2.4.2 Função objetivo - Planejamento ótimo Dinâmico clássico ...............................99

6.2.4.3 Ações durante o Planejamento de Expansão .................................................... 100

6.2.5 Formulação considerando Custo da QEE no Planejamento de Expansão....... 102

6.2.5.1 Função objetivo - Planejamento ótimo estático incluindo custo da QEE....... 102

6.2.5.2 Função objetivo - Planejamento ótimo Dinâmico incluindo custo da QEE ... 103

6.2.6 Inclusão Prática do custo da QEE no Problema de Planejamento da Expansão

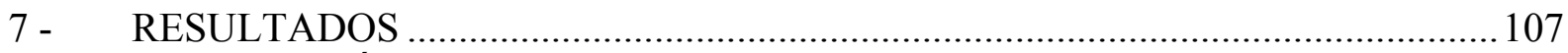

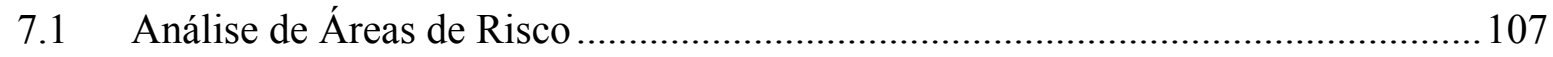

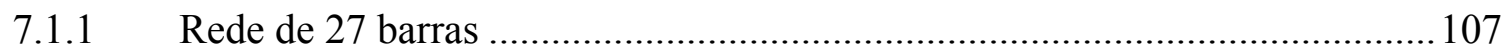

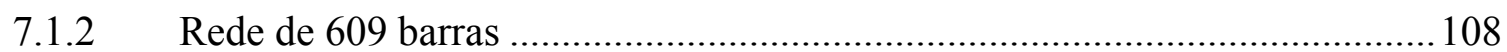

7.1.3 Parâmetros Para as Simulações ..................................................................... 109

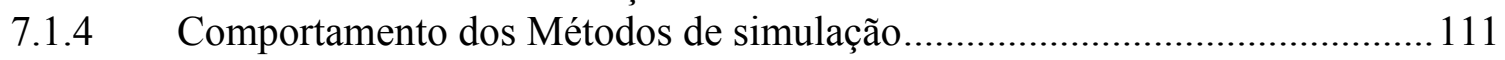

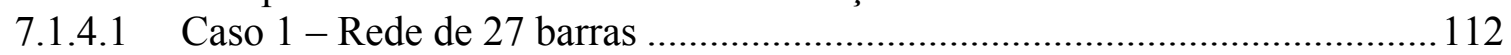

7.1.4.1.1 Método de Monte Carlo............................................................................... 112

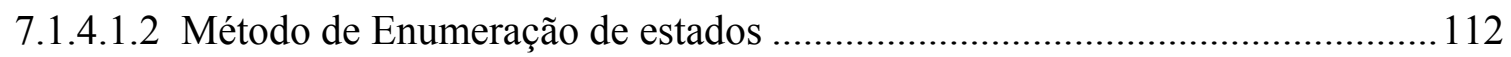

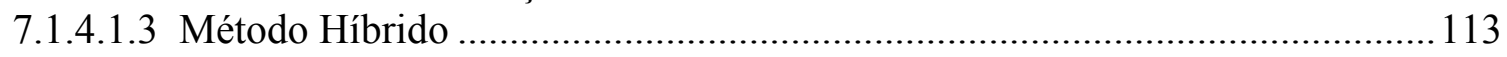

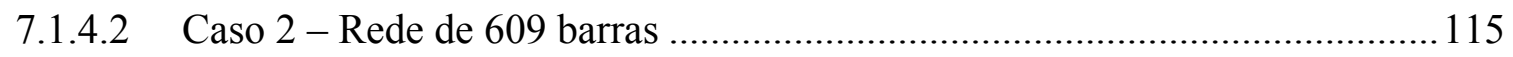

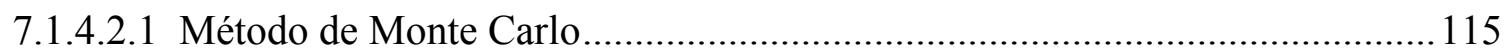

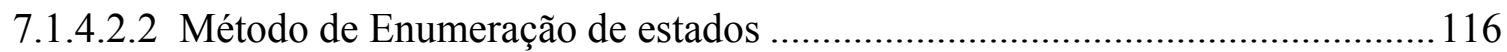

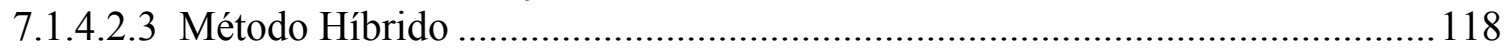

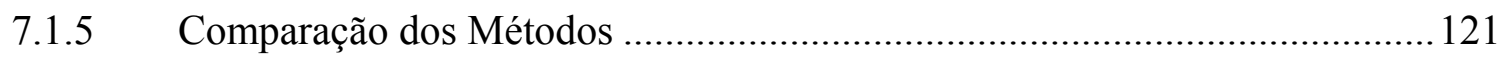

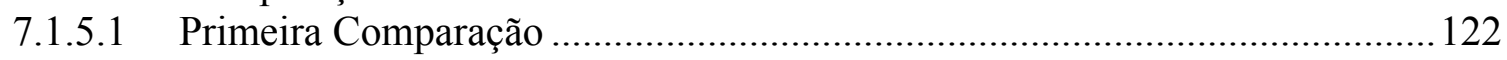

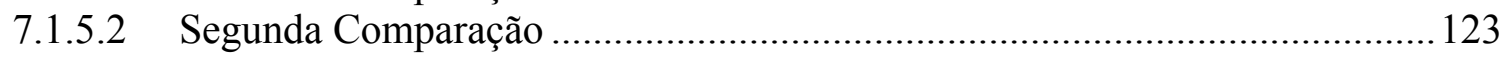

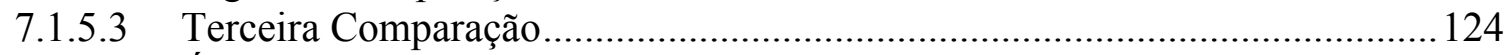

7.1.6 Áreas de Risco utilizando os diferentes métodos de simulação ....................... 127

7.1.6.1 Análise de Afundamentos de Tensão ............................................................. 128

7.1.6.2 Análise de Interrupções de longa duração................................................... 129 
7.1.6.3 Análise de Afundamentos mais Interrupções ............................................... 130

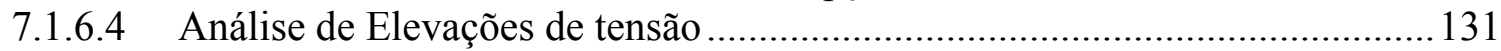

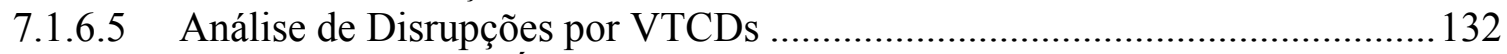

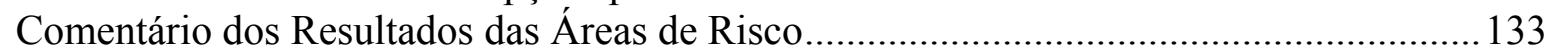

7.2 Inclusão do Custo de QEE no Planejamento de Operação - Reconfiguração de

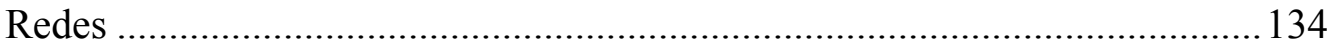

7.2.1 Inclusão dos Custos de interrupção de longa duração e de disrupção por VTCDs nas configurações com menores perdas ...........................................137

7.2.2 Análise de VTCDs para um consumidor particular.....................................139

7.3 Inclusão do custo da QEE no Planejamento de Expansão....................................... 143

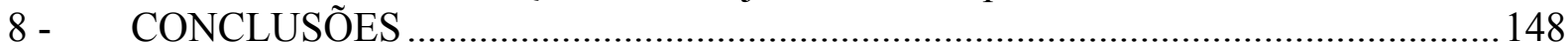

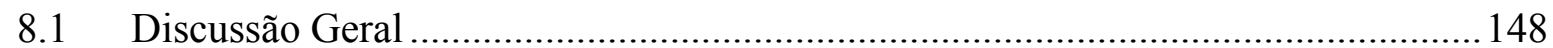

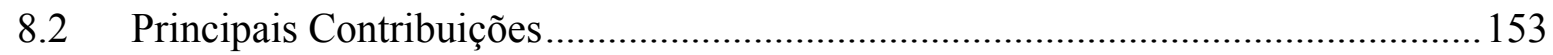

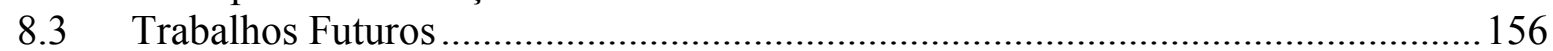

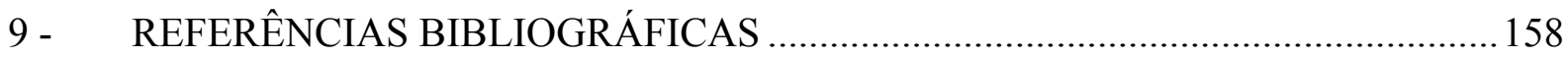

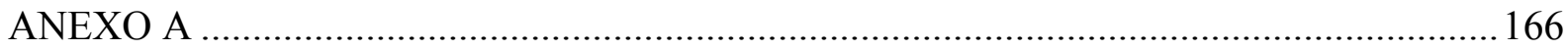

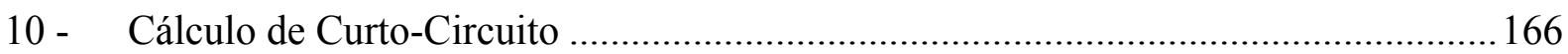

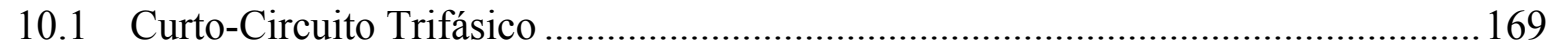

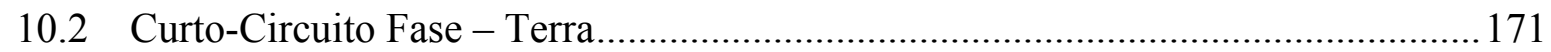

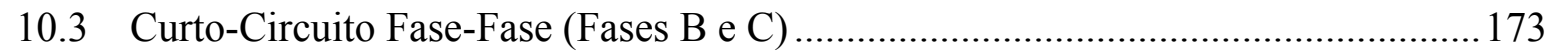

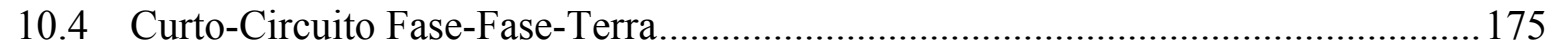




\section{LISTA DE FIGURAS}

Figura 3-1 - Influência do tipo de conexão do transformador: Conexão DYt e YtYt.

Figura 3-2 -Obtenção da Impedância própria de seqüência zero, considerando tipo de conexão

do transformador.

Figura 3-3 - Efeito da conexão dos transformadores na obtenção das impedâncias de

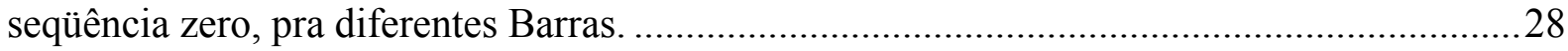

Figura 3-4 Curva de Sensibilidade por afundamentos de tensão.......................................... 35

Figura 4-1 - Probabilidade acumulada vs taxa de falha por ano para cada trecho ...................3 39

Figura 4-2 - Distribuição Acumulada vs Comprimento do trecho de falha .............................40

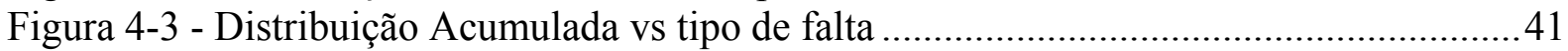

Figura 4-4 - Distribuição Acumulada vs impedância de falta ................................................42

Figura 4-5 - Algoritmo utilizado no método de Monte Carlo para a obtenção de condições de

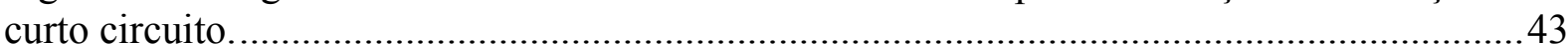

Figura 4-6 - Distribuição das faixas da cada variável envolvida no método de Enumeração de

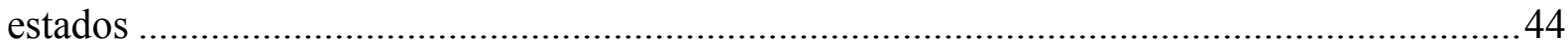

Figura 4-7 - Exemplo do peso devido ao tipo de curto ......................................................... 45

Figura 4-8 - Algoritmo utilizado no método de Enumeração de estados para a obtenção de

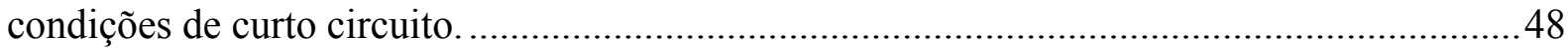

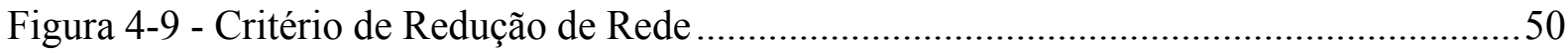

Figura 4-10 - Exemplo de redução de rede: (a) rede completa, (b) rede reduzida. .................51

Figura 4-11 - Exemplo de uma rede com seus respectivos comprimentos ............................52

Figura 4-12 - Obtenção do ponto de falta utilizando o método Híbrido ...................................56

Figura 4-13 - Algoritmo utilizado no método Híbrido para a obtenção de condições de curto

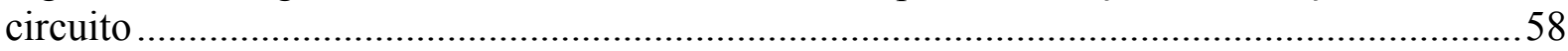

Figura 4-14 - Algoritmo do Método Híbrido - Grupos Mais Predominantes .........................59

Figura 4-15 - Algoritmo do Método Híbrido - Grupos Menos Predominantes ........................60

Figura 5-1 - Representação da Rede: Blocos de carga e Dispositivos de Proteção...................66

Figura 5-2 - Distribuição Acumulada vs Tempo de Extinção da Falta .....................................68

Figura 5-3 - Representação da Rede: Ponto de Falta e as respectivas curvas de proteção........70

Figura 5-4 - Dispositivos de proteção envolvidos durante uma falta ......................................70

Figura 5-5 - Obtenção da Probabilidade de VTCD e interrupção utilizando as curvas de proteção e probabilidade acumulada dada uma corrente de falta ............................................. 71

Figura 5-6 - Valor das Probabilidades de VTCD e interrupção para diferentes blocos de consumidores em função da sua posição ............................................................................ 72

Figura 5-7 - Faixas de tensão e tempo, $\mathrm{N}$ faixas de tempo e $\mathrm{M}$ faixas de tensão.................... 75

Figura 5-8 - Faixas de tensão e tempo para análise de Disrupções, $N$ faixas de tempo e $M$

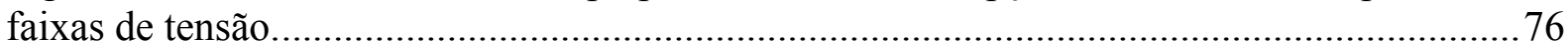

Figura 5-9 - Contribuição de Faltas em outros alimentadores.................................................77

Figura 5-10 - Diagrama de blocos Utilizado na obtenção de índices de VTCDs e Análise de

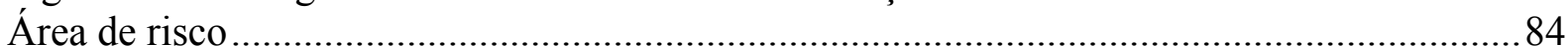

Figura 6-1 - Exemplo do planejamento de investimentos com $\mathrm{n}$ estágios ..............................97

Figura 7-1 -Diagrama Unifilar - Rede de 27 barras ................................................................ 108

Figura 7-2 - Diagrama Unifilar - Rede de 609 barras utilizada nas simulações..................... 109

Figura 7-3 - Curva de sensibilidade representativa utilizada na análise de áreas de risco para

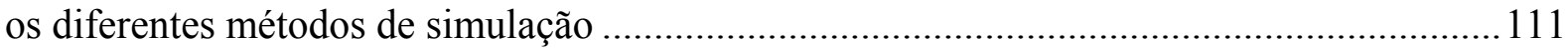

Figura 7-4 - \% Coeficiente de variação vs Número de Faltas- Método Monte Carlo ............ 115

Figura 7-5 - Custos anualizados vs Número de Faltas - Método Monte Carlo ...................... 116

Figura 7-6 - Rede de 609 barras (reduzida para 323 barras)............................................... 117 
Figura 7-7 - \% coeficiente de variação vs Número de faixas mínimas - Método Híbrido ..... 119

Figura 7-8 - Custo anualizados vs Número de faixas mínimas - Método Híbrido................. 120

Figura 7-9 - \% coeficiente de variação vs Número de Curtos-Circuitos - Método Híbrido... 121

Figura 7-10 - Custos Anualizados vs Número de Curtos-circuitos - Método Híbrido ........... 121

Figura 7-11 - Custo total médio vs tempo de processamento para os três métodos.............. 124

Figura 7-12 - Custo Anualizado vs Tempo de Número de Curtos-Circuitos ......................... 125

Figura 7-13 - \% Coeficiente de variação vs Número de Curtos-Circuitos............................. 125

Figura 7-14 - \% Coeficiente de variação vs Número de curtos-circuitos para o método Monte

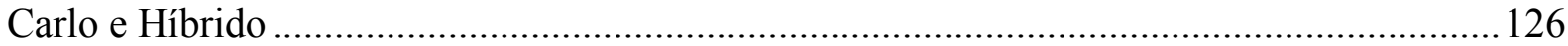

Figura 7-15- Áreas de Risco referente a afundamentos de tensão: (a) Método Monte Carlo, (b)

Método Enumeração de estados, (c) Método Híbrido........................................................... 128

Figura 7-16 - Áreas de Risco referente a Interrupções: (a) Método Monte Carlo, (b) Método

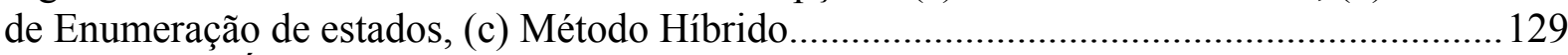

Figura 7-17 - Áreas de Risco referente a afundamentos de tensão mais Interrupções: (a)

Método Monte Carlo, (b) Método de Enumeração de estados, (c) Método Híbrido............... 130

Figura 7-18 - Áreas de Risco referente a elevações de tensão: (a) Método Monte Carlo, (b)

Método de Enumeração de estados, (c) Método Híbrido

Figura 7-19 - Áreas de Risco referente à Disrupções de tensão: (a) Método Monte Carlo, (b)

Método de Enumeração de estados, (c) Método Híbrido..................................................... 132

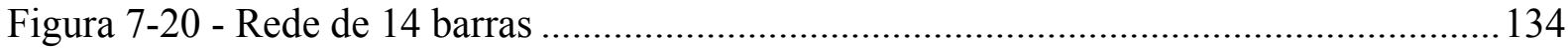

Figura 7-21 - Melhores Configurações - Rede 14 barras. ................................................. 135

Figura 7-22 - Curva de sensibilidade para os consumidores do exemplo ............................. 136

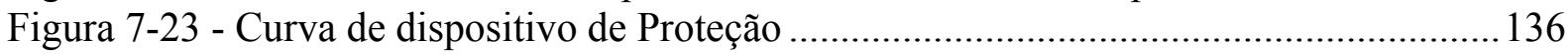

Figura 7-24 - Contribuição de cada custo por categoria vs melhores configurações ............. 138

Figura 7-25 - Resultados do custo total vs melhores configurações...................................... 139

Figura 7-26 - Histograma dos índices de Afundamentos: (a) Histograma, (b) Eventos/ano vs

tempo(ms) e Eventos/ano vs tensão pu, (c) Dados do histograma. ........................................ 140

Figura 7-27 - Histograma dos índices de Elevação: (a) Histograma, (b) Eventos/ano vs

tempo(ms) e Eventos/ano vs tensão pu, (c) Dados do histograma. ......................................... 141

Figura 7-28 - Histograma dos índices de disrupção por afundamentos de tensão: (a)

Histograma, (b) Eventos/ano vs tempo(ms) e Eventos/ano vs tensão pu, (c) Dados do

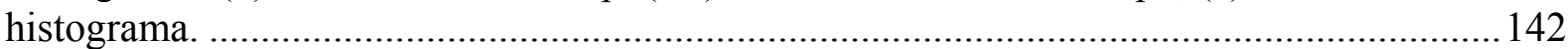

Figura 7-29- Rede de 12 barras para análise da inclusão do custo da QEE no planejamento de

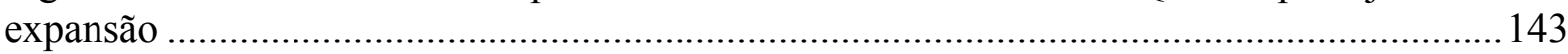

Figura 7-30 - Configurações para os três estágios do planejamento dinâmico: (a) Primeiro

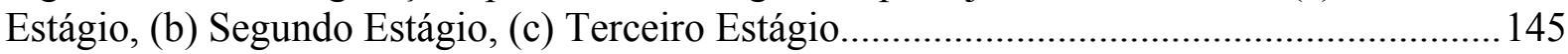

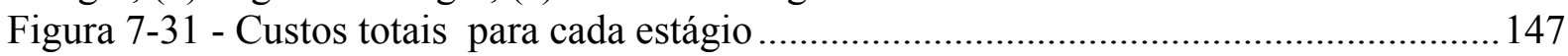

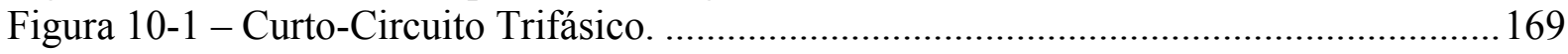

Figura 10-2 - Diagrama Trifilar - Curto-Circuito trifásico ........................................... 170

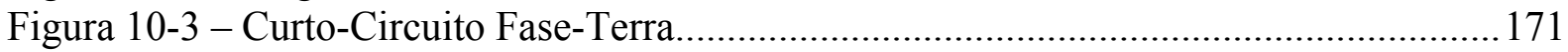

Figura 10-4 - Equivalente Thévenin para o Curto-Circuito fase-terra................................ 172

Figura 10-5 - Diagrama de seqüência para o Curto-Circuito fase-terra................................. 173

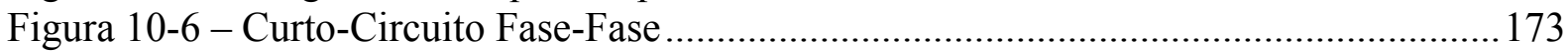

Figura 10-7 - Equivalente Thévenin para o Curto-Circuito fase-fase................................. 175

Figura 10-8 - Diagrama de seqüência para o Curto-Circuito fase-fase. .............................. 175

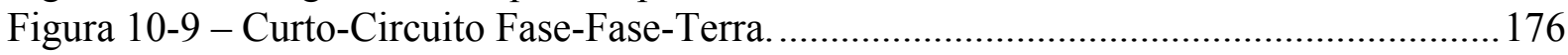

Figura 10-10 - Equivalente Thévenin para o Curto-Circuito fase-fase-terra......................... 176

Figura 10-11 - Diagrama de seqüência para o Curto-Circuito fase-fase-terra........................ 178 


\section{LISTA DE TABELAS}

Tabela 5-1 Tabela de Coordenação da Proteção

Tabela 5-2 Faixas de magnitudes e durações para a classificação dos afundamentos de tensão

Tabela 5-3 Faixas de magnitudes e durações para a classificação das elevações

Tabela 5-4 - Custos de Interrupção para cada evento em diferentes categorias de consumidor

Tabela 7-1 - Resultados para diferentes números totais de faltas-Método Monte Carlo - Rede

27 Barras

Tabela 7-2 - Resultados para diferentes números de faixas - Método de Enumeração de estados - Rede 27 Barras.

Tabela 7-3-Resultados para diferentes faixas mínimas - Método Híbrido - Rede 27 Barras 114

Tabela 7-4 - Resultados para diferentes números de faltas - Método Híbrido - Rede 27 Barras

Tabela 7-5 - Resultados Para diferentes Números de Curtos-Circuitos - Método Monte Carlo

Tabela 7-6 - Resultados para diferentes números de faixas - Método de Enumeração de estados

Tabela 7-7 - Resultados para diferentes valores de faixas de comprimento, utilizando uma rede reduzida - Método de Enumeração de estados....

Tabela 7-8 - Resultados Para diferentes valores de faixas de impedância de falta, utilizando uma rede reduzida - Método de Enumeração de estados

Tabela 7-9 - Resultados Para diferentes valores de faixas de impedância de falta terra,

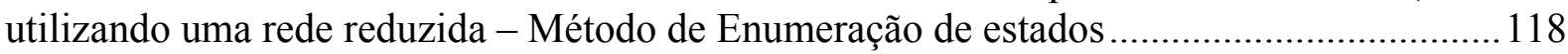

Tabela 7-10-Resultados para diferentes números de faixas mínimas - Método Híbrido....... 119

Tabela 7-11 - Resultados para diferentes Números de faltas - Método Híbrido ................... 120

Tabela 7-12 - Comparação dos Três Métodos de simulação - Rede 27 Barras ..................... 122

Tabela 7-13 - Comparação dos Três Métodos de simulação - Rede 609 Barras ..................... 122

Tabela 7-14 - Comparação do Método Monte Carlo e Híbrido - Rede 609 Barras................ 123

Tabela 7-15 - Custo Total médio vs tempo para os três métodos ......................................... 123

Tabela 7-16 - Comparação Método Híbrido e Monte Carlo - custo médio total e \% coeficiente

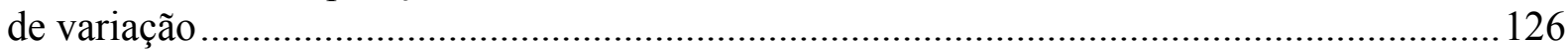

Tabela 7-17- Configurações com menores valores de Perdas de Potência - Rede 14 barras 134

Tabela 7-18 - Resultados dos Custos de Disrupção por barra para as 4 Configurações........ 137

Tabela 7-19 - Resultados dos Custos da interrupção por barra para as 4 Configurações....... 137

Tabela 7-20 - Comparação dos Custos para as Melhores configurações ................................ 138

Tabela 7-21 - Dados das Demandas dos nós para três estágios de planejamento................... 144

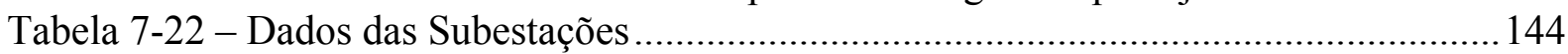

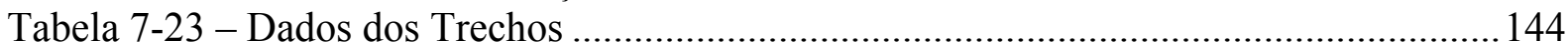

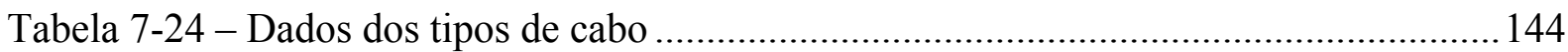

Tabela 7-25 - Custo Unitário das Interrupções e Disrupções ................................................ 144

Tabela 7-26 - Custos de investimento, perdas, interrupção e disrupção para cada estágio de

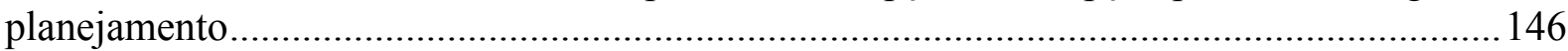

Tabela 7-27 - Resultados dos Custos de Disrupção por barra para os três estágios de planejamento............................................................................................................... 146

Tabela 7-28 - Resultados dos Custos de Interrupção por barra para os três estágios de planejamento. 


\section{1 - INTRODUÇÃO}

É cada vez maior o nível de exigência dos consumidores quanto aos problemas com a qualidade da energia fornecida pelas concessionárias de distribuição. Este fato deve-se a vários fatores: a lei de defesa do consumidor, aspectos regulatórios / institucionais e o pouco conhecimento do mercado sobre o nível de sensibilidade dos equipamentos utilizados nas instalações dos consumidores, que historicamente eram em larga predominância eletromecânicos, mas passaram nas duas últimas décadas a ser eletro-eletrônicos.

No Brasil, a tendência à modernidade industrial vem seguindo os padrões de competividade mundial. Esta é uma realidade vivida pela indústria no Brasil desde a abertura dos mercados a partir do ano de 1990. Este crescimento deu origem à necessidade de grandes investimentos em meios de produção modernos, com máquinas mais sofisticadas e altamente automatizadas, o que gerou mudanças nas exigências quanto à energia elétrica fornecida. Os grandes impulsos ligados a essas significativas mudanças representam: Ganhos de eficiência na produtividade industrial, modernização e sofisticação nas instalações de comércio e serviço, e oferta de produtos de consumo que incorporam essas tecnologias voltadas ao conforto nas residências. No entanto, estas novas tecnologias, baseadas em equipamentos eletro-eletrônicos, são mais sensíveis às perturbações no fornecimento de energia e, ao mesmo tempo, de modo geral, injetam correntes distorcidas nas redes elétricas. Pequenas falhas, antes sem qualquer efeito tangível, passam a representar grandes prejuízos, aumentando as exigências dos consumidores em todos os níveis na cadeia de produção. O comportamento do PIB, principal indicador de riqueza gerada por uma sociedade, está condicionado, cada vez mais, a decisões empresariais que levam em conta a disponibilidade de energia elétrica tanto na qualidade como no preço [61].

Desde 1990, com a edição da lei 8078, mais conhecida como Código de Defesa do Consumidor, a questão dos danos causados a clientes em decorrência de distúrbios causados na rede elétrica vem causando preocupação às concessionárias. Estes problemas relacionados com a qualidade de energia elétrica podem ser causados no sistema da concessionária de energia em seus diversos níveis de tensão ou mesmo no consumidor final. No caso da concessionária de energia elétrica ser a responsável pelo distúrbio, este poderá ter causas 
naturais (Curtos-Circuitos), operacionais (chaveamentos de grandes blocos de carga) ou mesmo por defeitos em equipamentos (transformadores, geradores de tensão, entre outros). Por outro lado, distúrbios na qualidade de energia elétrica causados pelo consumidor final estão em sua maioria associados a injeções de correntes harmonicas (normalmente causadas pela carga), partida de grandes motores, ou falhas internas em sua instalação elétrica [37].

Dentre os diferentes fenômenos relacionados à Qualidade de Energia Elétrica (QEE), os de mais difícil tratamento são os resultantes de fenômenos transitórios, como as variações de tensão de curta duração (VTCDs). Seguindo a tendência mundial, o Operador Nacional do Sistema (ONS) declara: “As variações de tensão de curta duração constituem-se em um dos principais fenômenos a serem tratados no âmbito da QEE, tendo em vista os prejuízos que podem causar aos agentes consumidores, sendo um assunto que vem ganhando importância em função do crescente número de cargas sensíveis a este efeito" (Operador Nacional do Sistema - ONS, em sua página na internet, fevereiro 2002).

As Variações de Tensão de Curta Duração, conforme anteriormente apresentado, podem ser consideradas como ocorrências de alteração temporária da magnitude ou do valor eficaz da forma de onda.

Assim sendo, é possível considerar tais fenômenos como redução ou aumento do valor eficaz da tensão de curta duração e cuja ocorrência normalmente está vinculada a curtoscircuitos, sobrecargas ou partidas de motores.

O interesse neste fenômeno está relacionado aos problemas ocasionados em diversos tipos de equipamentos utilizados por clientes de empresas distribuidoras de energia elétrica, em função de sua maior ou menor sensibilidade, dentre os quais se consideram: os sistemas de controle da velocidade de motores, sistemas de controle de processos microprocessados, micro-computadores e eletro-eletrônicos em geral.

Após a criação da Agência Nacional de Energia Elétrica (ANEEL) e das agências reguladoras estaduais, um esforço muito grande tem sido feito pelos vários agentes envolvidos para definir medidas e estabelecer procedimentos que visam garantir os direitos dos consumidores, melhorando a qualidade do serviço e do produto, além de preservar os sistemas elétricos de fornecimento de energia. Embora a definição desses procedimentos seja uma tarefa bastante difícil, devido aos interesses conflitantes entre os agentes envolvidos, esses procedimentos são de fundamental importância para garantir a regulação dos serviços, através da criação, supervisão e controle de indicadores da qualidade da prestação de serviços e do produto de fornecimento da energia elétrica. Neste sentido, a exigência de índices de qualidade adequados, por parte dos órgãos reguladores, cria condições para preservar e 
melhorar a qualidade do serviço e a qualidade do produto de fornecimento de energia elétrica e, a par disso, preservar as empresas de serviços públicos sob controle do capital privado, garantindo, em conseqüência, um atendimento adequado aos clientes.

$\mathrm{Na}$ procura da obtenção de índices de qualidade nas redes elétricas, existem na literatura trabalhos que permitem a avaliação de áreas de vulnerabilidade, principalmente abrangentes nos sistemas de transmissão. Nestes casos, são geralmente realizadas grandes campanhas de medição, em diferentes pontos da rede para a obtenção de índices representativos, estas campanhas de medição geram grandes investimentos na compra de equipamentos de medição QEE, que alem de ser relativamente caros, demandam de um período de tempo muito grande, que pode levar anos de estudo.

Visando a diminuição do custo e do tempo necessários para a obtenção destes índices de QEE, muitos autores adotam métodos de simulação computacional. Estes métodos existentes são ferramentas de bastante interes já que permitem antecipar os problemas de QEE ocasionadas por fenômenos intempestivos.

É nesse contexto que este trabalho propõe aprofundar o desenvolvimento de modelos e ferramentas específicas para estudo de VTCDs em sistemas de distribuição de energia elétrica. Serão consideradas neste trabalho as particularidades do sistema de distribuição em estudo, as taxas de falha distintas (por região, por tipo de sistema, etc.), sistemas de proteção utilizados (fusíveis, disjuntores nas subestações, etc.) e, em especial, que a maior parte das faltas nos sistemas de distribuição aéreos é temporária, não causando interrupção do fornecimento de longa duração, mas ocasionando VTCDs (Afundamentos, Elevações e Disrupções de tensão). Assim também, sendo obtidos os índices de VTCDs é possível obter, o custo relativo às Interrupções de longa duração e o custo relativo às Disrupções de tensão por VTCDs, para cada consumidor existente na rede elétrica.

Será comentado também neste trabalho, a possibilidade da inclusão destes índices dentro dos estudos de planejamento clássico. Dado que muitos autores tratam os problemas de planejamento como a diminuição dos custos de investimento e custos operacionais, sendo desconsiderado o custo relativo às VTCDs. Com a inclusão deste valor de custo, pode-se obter o valor total anualizado que a concessionária terá que enfrentar não somente pela operação e/ou expansão da sua rede, mas também pelos prejuízos imputados aos consumidores existentes nas suas redes elétricas. 


\subsection{Organização do trabalho}

O presente documento de Tese foi organizado da seguinte forma:

No capítulo 0é apresentado uma introdução que mostra a importância do estudo da qualidade de energia e seu efeito nos diferentes consumidores. Também é apresentada a organização do trabalho desenvolvido.

No capítulo 2 - é apresentada uma revisão bibliográfica que abrange um panorama de diferentes estudos realizados no mundo e no Brasil, sobre temas referentes a qualidade de energia. Também apresentada uma revisão das normas técnicas existentes, e trabalhos referentes ao efeito das VTCDs relativo aos afundamentos de tensão sobre as cargas elétricas e o custo da qualidade de energia.

No capítulo 3 - são apresentados aspectos relevantes para as análises de VTCDs. São apresentadas neste capítulo as causas e efeitos das VTCDs, assim como os fatores que influenciam os parâmetros do afundamento de tensão. O conceito de área de risco a Disrupções por VTCDs é definido e comentado também neste capítulo.

No capítulo 4 - são apresentados três metodologias para a obtenção do conjunto de simulações de curto-circuito necessárias para a obtenção dos índices de VTCDs em cada consumidor existente na rede de distribuição elétrica. As metodologias são: Método de Monte Carlo, Enumeração de estados e Híbrido, explicadas em detalhe no capítulo.

No capítulo 5 - é apresentado o procedimento para a classificação e caracterização dos fenômenos de VTCDs para cada condição de curto-circuito obtido pelos diferentes métodos apresentados no capítulo anterior. Para classificar os índices de VTCDs é importante a obtenção de magnitude e duração dos eventos.A metodologia para obtenção da duração das VTCDs e seu tratamento probabilístico é descrita em detalhes. Neste capítulo será descrito também a formulação necessária para a obtenção dos índices de VTCDs anualizados, tanto para Afundamentos, Elevações e Disrupções de tensão como para as Interrupções de longa duração.

No capítulo 6 é apresentada uma revisão de trabalhos referentes ao planejamento de operação e planejamento de expansão, assim como as formulações clássicas existentes para a solução destes problemas. Também é apresentado uma formulação matemática quer permite incluir o custo dos índices de VTCDs, obtidos no capítulo anterior, na formulação clássica do problema de planejamento de operação (Reconfiguração) e planejamento de expansão de sistemas de distribuição de energia elétrica. 
No capítulo 7 - são apresentados os resultados obtidos, utilizando as três metodologias apresentadas no capítulo 4 - (Monte Carlo, Enumeração de Estados e Híbrido), sendo comparadas estas metodologias tanto na qualidade dos resultados obtidos como no tempo de processamento para avaliar qual metodologia poderia ser aplicada a redes de distribuição de grande porte. Também são observados resultados dos custos totais considerando,as parcelas de custo do investimento na expansão de redes de distribuição, custo da operação (perdas de energia) e custo da qualidade de energia dos consumidores. Pode-se então comparar o efeito da inclusão do custo da qualidade de energia nos resultados nas formulações clássicas, para a solução de problemas do planejamento da operação e planejamento da expansão de sistemas de distribuição de energia elétrica.

No capítulo 8 - são apresentados as conclusões finais deste trabalho, assim como as suas principais contribuições. Trabalhos futuros também são comentados e apresentados na parte final deste capítulo.

No ANEXO A são apresentadas as formulações básicas utilizadas para o cálculo das correntes e tensões em condições de curto-circuito, para diferentes pontos na rede de distribuição. A formulação inclui o critério de componentes simétricas para redes trifásicas. 


\section{2 - REVISÃO BIBLIOGRÁFICA}

No Brasil, a grande disponibilidade de força hidráulica e a localização remota da geração, distante dos grandes centros de consumo, determinam a configuração do sistema elétrico nacional, dependente de longas linhas de transmissão. Esta topologia, exigida pelas grandes distâncias, expõe o sistema elétrico, tornando-o assim muito mais vulnerável aos efeitos de Curtos-Circuitos.

Vários são os fenômenos considerados na avaliação da qualidade de energia elétrica, os quais podem ser identificados ou classificados, segundo a sua magnitude e sua duração.

Os fenômenos transitórios são os que possuem as menores durações, em geral na faixa de alguns micro-segundos a alguns milésimos de segundos. De acordo com a sua natureza ou sua forma de onda, esses fenômenos podem ser divididos em impulsivos (geralmente de origem atmosférica) e oscilatórios (geralmente resultados de chaveamentos ou outras situações em que há uma mudança súbita no regime permanente) [49].

Entende-se como variação de tensão de curta duração (VTCD) a variação no valor eficaz do sinal de tensão com duração compreendida entre $8,33 \mathrm{~ms}(0,5$ ciclo de um sinal com freqüência fundamental de $60 \mathrm{~Hz}$ ) e 1 minuto [ 15]. Geralmente, essa variação no valor eficaz é resultado da variação na amplitude da forma de onda. Essas variações são capazes de sensibilizar dispositivos de proteção, desligando processos, ou afetar o funcionamento de equipamentos, podendo provocar grandes prejuízos a clientes conectados ao sistema de fornecimento de energia, devido à parada na produção ou comprometimento da qualidade da produção.

Os fenômenos de longa duração, ou comumente denominados de regime permanente, incluem as variações lentas nas amplitudes das tensões e variações nas formas de onda das tensões. Desses tipos de variações originam-se os fenômenos como variação dos níveis de tensão, distorção harmônica de tensão e desequilíbrio de tensão. Os fenômenos de longa duração também são caracterizados por valores eficazes. A forma de tratar os valores eficazes ao longo do tempo tenta representar efeitos de aquecimento térmico em equipamentos elétricos submetidos a condições não adequadas de fornecimento. As medições e apurações de indicadores relacionados a esses fenômenos considerando intervalos de tempo apropriados 
possibilitam avaliar os efeitos térmicos dos fenômenos sobre equipamentos elétricos com constantes de tempo térmicas bem diferentes, como equipamentos eletrônicos com constantes de tempo de $600 \mathrm{~ms}$, pequenos transformadores ou motores com constantes de tempo da ordem de 2 minutos e transformadores ou motores de maior porte com constantes de tempo térmica da ordem de 20 minutos a horas.

Uma outra categoria de indicadores é definida para flutuações rápidas na amplitude da tensão (modulação na amplitude da tensão com freqüências entre 0 e $30 \mathrm{~Hz}$ ). Essas flutuações dão origem a um fenômeno conhecido como cintilação (Flicker), que é o resultado da variação na luminância de lâmpadas elétricas, principalmente as incandescentes. Esse fenômeno relaciona-se à percepção visual do olho humano quando de oscilações da intensidade luminosa emitida por uma lâmpada incandescente, quando a amplitude de sua tensão de alimentação está sujeita a flutuações rápidas. Além do efeito de cintilação, as flutuações rápidas na amplitude da tensão causam também efeitos danosos sobre motores elétricos. Dentro do contexto de qualidade de energia, especialmente no sistema elétrico brasileiro, variações de tensão de curta duração são de grande destaque devido a que as linhas aéreas de transmissão e distribuição, possuem uma vasta extensão, o que faz que estes tipos de distúrbios sejam inevitáveis e inerentes à operação do sistema.

Do ponto de vista dos consumidores industriais, estes fenômenos também são de grande destaque, já que seus processos produtivos possuem objetivos que visam atingir metas de produtividade e qualidade cada vez maiores. Os processos industriais modernos têm se tornado mais rápidos e precisos. Acionamentos com velocidade variável e controles microprocessados tornaram-se ferramentas imprescindíveis para alcançar tais metas, não obstante sejam cargas extremamente sensíveis a variações de tensão. Custos associados às Interrupções nos processos, perdas de matéria prima e custos de possíveis reparos em equipamentos danificados prejudicam crescentemente os consumidores. As concessionárias vêm sofrendo perdas de sua imagem e, em alguns casos, processos judiciais para ressarcimento das perdas.

\subsection{Normalização}

A normalização de qualidade de energia vem percorrendo um longo percurso. Cronologicamente, Deloux (1974)[ 32] alegou que dentro da normalização internacional não foram elaborados requisitos necessários para garantir a compatibilidade eletromagnética entre 
a rede e as cargas conectadas, em caso de perturbação da tensão. Sob este ponto de vista, a situação foi mudando consideravelmente, como foi relatado no Comitê Europeu de Normalização Electrotécnica (CENELEC). Era necessário definir critérios de qualidade, assim como desenvolver meios adequados de medição da qualidade para poder ratificar recomendações e normas como descrito por Lonngren (1974)[ 64].

A União Internacional dos Produtores e Distribuidores de Energia Elétrica (UNIPEDE) emitiram uma das primeiras normas sobre qualidade de energia. Em um relatório apresentado por Colding (1982)[ 27] descreve a qualidade do fornecimento de eletricidade frente a variação dos níveis de tensão e do conteúdo de áudio e rádio freqüência.

Um estudo realizado por McEachern (1993)[ 72] alegou a necessidade de normas relativas à qualidade de energia, a fim de determinar o estado normativo nos sistemas de distribuição, mas, infelizmente, concluiu-se a falta da existência de normas, pelo menos até 1993. Muitos grupos diferentes estavam trabalhando para atingir esse objetivo, incluindo IEEE, JEC (Comissão Electrotécnica Internacional), ANSI (American National Standards Institute), CBEMA (Computer and Business Equipment Manufacturers Association), e EPRI.

Como resenha histórica sobre as normas relacionadas com a qualidade do fornecimento no IEEE (Institute of Electrical and Electronic Engineers), pode-se mostrar os mais relevantes:

- IEEE Std C62.48-1995 " Guia IEEE sobre interações entre os distúrbios do sistema de potência e dispositivos de proteção";

- IEEE Std 1159-1995, "Prática IEEE recomendada para a monitoração da qualidade de energia elétrica";

- IEEE Std 1250-1995 "Guia IEEE de serviços para equipamentos sensíveis a distúrbios momentâneos de tensão";

- IEEE Std 493-1997 "Prática IEEE recomendada para a concepção de sistemas industriais e comerciais" capítulo 9;

- IEEE Std 1346-1998 "Prática IEEE recomendada para verificar a compatibilidade dos equipamentos eletrônicos dos processos com o sistema de energia elétrica";

- IEEE Std 1100-1999 "Prática IEEE recomendada para alimentação e aterramento de equipamentos eletrônicos";

- IEEE Std 1564, "Prática recomendada para o Estabelecimento de índices de afundamentos de tensão". 
Como comentário, a norma IEEE Std 1346-1998 indica procedimentos para que se planeje a aplicação de equipamentos sensíveis a partir do mapeamento e um sistema de energia elétrica, permitindo estudar a compatibilidade entre os equipamentos eletrônicos de diferentes processos com o sistema de potência, o que seria a tolerância de equipamentos vulneráveis aos afundamentos de tensão. Esta norma possibilita observar a área ou região em que o equipamento é afetado pelo afundamento e aquela que é tolerada pelo equipamento.

De um levantamento das normas nacionais e internacionais dedicadas à qualidade de energia, especificamente no tocante à normalização de VTCDs e à terminologia aplicada aos principais fenômenos envolvidos, destacam-se os seguintes comentários:

\section{Normalização proposta pelo IEEE [ 52]}

Nesta norma americana, o fenômeno está inserido na categoria de variações de tensão de curta duração, que engloba tempos desde 0,5 ciclos da freqüência fundamental até 1 minuto. O afundamento de tensão, em inglês "sag", é reservado para redução a tensões compreendidas entre 0,1 e 0,9 pu. Para redução a tensões inferiores a 0,1 pu, o fenômeno é classificado como interrupção de curta duração. A elevação de tensão, em inglês "swell", é caracterizada por identificar elevações de tensão de curta duração a níveis acima de 1,1 pu.

\section{Normalização proposta pela IEC/CENELEC [ 23$]$}

Nesta norma européia, o termo em inglês usado para afundamentos de tensão é "dip" e refere-se a reduções a valores entre 0,01 e 0,9 pu da tensão de fornecimento, durante uma duração ou período de tempo compreendido entre 0,5 ciclo a 1 minutos. Para valores inferiores a $0,01 \mathrm{pu}$, esta norma considera o fenômeno como sendo uma interrupção.

\section{Normalização utilizada pela ONS/PRODIST [ 85][ 4]}

No Brasil, a resolução $\mathrm{N}^{0} 24$ de janeiro 2000, e a resolução $\mathrm{N}^{\mathrm{o}} 505$ de novembro 2001, estabelecidas pela ANEEL (Agência Nacional de Energia Elétrica) estabelecem indicadores e metas de qualidade relativa à continuidade de fornecimento de energia elétrica para agentes distribuidores. Visando oferecer medidas de desempenho da rede básica compatíveis com tais indicadores, a resolução estabelece indicadores de continuidade para a fronteira, que deverão ser apurados e divulgados pelo ONS.

Esta resolução apresenta indicadores de duração e freqüência de interrupção referente às barras de conexão da rede básica com os demais agentes. Ao operador nacional do sistema 
(ONS) cabe a apuração e divulgação de tais indicadores, bem como a proposição de padrões de desempenho.

Para atender a atribuição recebida do órgão regulador, os procedimentos necessários na rede de distribuição podem ser observados na publicação feita pela ANEEL em setembro do 2007 dentro do PRODIST (Procedimentos de Distribuição de Energia Elétrica no Sistema Elétrico Nacional) no Item 7 do Módulo 8 [ 4], que estabelecem padrões de desempenho da rede de distribuição conforme definidos a seguir.

Para as Variações de tensão de curta duração (VTCD), estabelece:

-VMT (variações momentâneas de tensão):

$\begin{array}{lrr}\text { Interrupção } & \mathrm{t} \leq 3 \mathrm{~s} & \mathrm{~V}<0,1 \mathrm{pu} \\ \text { Afundamento } & 1 \text { ciclo } \leq \mathrm{t} \leq 3 \mathrm{~s} & 0,1 \leq \mathrm{V}<0,9 \mathrm{pu} \\ \text { Elevação } & 1 \text { ciclo } \leq \mathrm{t} \leq 3 \mathrm{~s} & \mathrm{~V}>1,1 \mathrm{pu}\end{array}$

- VTT (variação temporária de tensão):

$\begin{array}{llr}\text { Interrupção } & 3 \mathrm{~s}<\mathrm{t} \leq 1 \mathrm{~min} & \mathrm{~V}<0,1 \mathrm{pu} \\ \text { Afundamento } & 3 \mathrm{~s}<\mathrm{t} \leq 1 \mathrm{~min} & 0,1 \leq \mathrm{V}<0,9 \mathrm{pu} \\ \text { Elevação } & 3 \mathrm{~s}<\mathrm{t} \leq 1 \mathrm{~min} & \mathrm{~V}>1,1 \mathrm{pu}\end{array}$

\subsection{Impactos da Qualidade de Energia sobre as Cargas}

A melhoria da eficiência energética e da produtividade das instalações industriais e comerciais por vezes pode resultar na utilização de novas tecnologias sensíveis a problemas de qualidade de energia devido a sua sensibilidade às variações de tensão. No ambiente desregulamentado, as responsabilidades pela qualidade do fornecimento da energia não ficam bem definidas. Quem será responsável pela qualidade da energia fornecida nas indústrias no ambiente desregulamentado? Quais são os requisitos de qualidade de energia na interface entre a empresa de transmissão e a empresa de distribuição? Qual é o nível de qualidade que devem ser fornecidos pela empresa de distribuição para seus clientes finais? Que tipos de serviços por parte da distribuidora podem melhorar o nível de qualidade utilizada pelos seus clientes finais? Uma vertente tem como respostas a todas estas questões como sendo desenvolvidas em termos dos contratos entre as diferentes entidades participantes envolvidas na regulamentação, como mostra o trabalho de McGranaghan e Kennedy (1998) [ 76]. 
Nos últimos anos, duas tendências simultâneas na tecnologia das empresas industriais e comerciais fizeram com que um conceito simples de fornecimento de energia se tornasse uma abordagem cada vez mais complicada. A primeira tendência foi o enorme crescimento no uso de energia elétrica no setor industrial em geral. As antigas instalações começaram a operar além das suas capacidades, geralmente com conseqüências adversas para o seu desempenho cujas mudanças foram não só qualitativas, mas também quantitativas. Em muitas plantas se deu início ao grande crescimento do uso de carga elétrica, com utilização de: fornos à arco elétricos de arco, retificadores, conversores a tiristores, e outros equipamentos que contribuem para deterioração da qualidade de energia. A segunda tendência foi a utilização, pelos consumidores, de máquinas e ferramentas tecnológicas que exigem alta qualidade, devido a seu alta precisão e desempenho como mostra no trabalho de Gruzs (1989)[ 45].

Uma característica importante dos consumidores é a sua dependência de sistemas eletrônicos sensíveis que desenvolvem funções importantes dentro de cada empresa tais como: tratamento de dados, comunicações e controle do processo de produção, que pode ocorrer em diferentes tipos de consumidores, sejam eles comerciais, industriais e residenciais, etc. Esta dependência criou uma nova preocupação em relação às perturbações no fornecimento de energia. Qualquer ruptura no fornecimento pode causar parada de produção e perdas financeiras, o que mostra a grande importância do estudo para determinar as ações corretivas mais apropriadas.

Um trabalho que analisa os efeitos dos afundamentos nos processos industriais é apresentado por McGranaghan (1995) [ 74]. O autor descreve os impactos dos afundamentos de tensão sobre equipamentos utilizados em processos industriais. Este trabalho centra-se em faltas elétricas no sistema como a principal causa de afundamentos. Assim também estudam a sensibilidade de diferentes tipos de processos e equipamentos industriais, incluindo dispositivos de acionamento de motores com velocidade variável, controladores lógicos programáveis e contatores.

Uma interrupção no fornecimento de energia elétrica pode causar diferentes modalidades de transtornos e prejuízos ao consumidor. Como por exemplo, podem-se citar perdas na produção, em oportunidades de negócios, de lazer, dentre outros. A interpretação, a avaliação e o tratamento das informações obtidas a partir de dados junto ao consumidor permitem estimar o custo da interrupção do fornecimento de energia elétrica, também, conhecido como "custo social da interrupção". Tais custos refletem os custos diretos e indiretos de curto prazo, suportados pelo consumidor, causados por uma interrupção de energia elétrica, como analisado por Magalhães (2001) [ 66]. 
Uma ampla pesquisa realizada no Canadá mostra como os grandes consumidores industriais são mais afetados por eventos de curta duração, em contraste com os consumidores residenciais, que praticamente são insensíveis a eventos rápidos. Para consumidores que são afetados por Interrupções de curta duração e afundamentos momentâneos de tensão, Wacker \& Billinton (1989a, 1989b) [ 109] [ 110] sugerem considerar o custo por evento pela demanda de ponta $(\$ / \mathrm{kW})$.

O trabalho apresentado por Reis (2000) [ 93] e discutido por Leitão (2002) [ 61] relata que no Brasil em 1996 as classes de consumo da energia elétrica estavam divididas nas seguintes porcentagens: Industrial 46,7\%, Residencial 24,9\%, Comercial 12,6\%, Público $8,7 \%$, Outros 7,1\%. Os impactos das Interrupções do serviço e da degradação de sua qualidade variam para cada tipo de consumidor. Os residenciais são mais sensíveis aos aspectos de confiabilidade, os ligados ao conforto e de conveniência, enquanto os industriais estão mais ligados aos aspectos de custos, volume de produção, qualidade e eficiência. Os consumidores comerciais situam-se em uma faixa intermediária, valorizando tanto os aspectos ligados a custo como o conforto.

É comentado no trabalho de Leitão (2002) [ 61] que para o consumidor, o custo do serviço é composto de duas parcelas: a primeira, do custo do serviço recebido, que é cobrado na tarifa; e a segunda, do prejuízo decorrente do uso do produto fornecido. Os custos associados a cada distúrbio dependem não somente das perdas e danos causados pela falha, mas também, do tipo de atividade desenvolvida, da natureza e do grau de dependência da atividade em relação à energia elétrica, da disponibilidade de uma fonte alternativa e da capacidade de retomada ao nível de atividade após a normalização da eletricidade.

Trabalhos recentemente desenvolvidos por pesquisadores nacionais, entre eles Carvalho (2000)[ 19] permitem a obtenção de estimativas mais confiáveis para a ocorrência de desligamentos nos processos industriais, por afundamentos de tensão, associados a uma metodologia para estimativa de custos devidos a Interrupções de processo.

Seguindo esta base de pesquisa o trabalho desenvolvido por Gomes da Costa (2003) [ 39] permite mostrar três importantes contribuições. A primeira é a obtenção de estimativas a serem utilizadas com o intuito de auxiliar os estudos de planejamento e mudanças no sistema elétrico por parte da concessionária de energia. A segunda é a obtenção de estimativas a serem utilizados pelos consumidores industriais, possuidores de cargas sensíveis, de forma a auxiliar a tomada de decisão de investimento em equipamentos e mitigação das conseqüências do distúrbio. A terceira é a avaliação do desempenho do sistema de distribuição do consumidor industrial, permitindo a execução de estudos de viabilidade econômica para a 
mudança de filosofia de concepção de projeto de sistemas industriais, especificação e aquisição de equipamentos eletro-eletrônicos menos vulneráveis a afundamentos de tensão.

\subsection{Custo da Qualidade da energia elétrica}

Desde a década de 80 são desenvolvidas contribuições sobre a definição de teorias e modelos de custos de interrupção de energia elétrica, também utilizadas para a avaliação da confiabilidade do sistema elétrico e conseqüentemente para o seu planejamento.

Subramaniam, Billinton e Wacker (1985) [ 101] elaboraram um estudo a fim de obter os custos advindos de Interrupções de energia elétrica para os consumidores do setor industrial com e sem sistema standby, assim também, referentes as variações dos custos de interrupção com o período anual, semanal e diário. O mesmos autores em Wacker e Billinton (1989) [ 109] desenvolveram uma metodologia para a obtenção do valor aproximado do custo de Interrupções de energia elétrica.

Já a partir da década de 90, observa-se a crescente preocupação não só com a confiabilidade dos sistemas elétricos de potência, mas também com os efeitos que distúrbios na qualidade da energia elétrica causam aos consumidores, sendo o impacto econômico um destes efeitos.

Massaud, Schilling e Hernandez (1994) [ 71] realizaram uma pesquisa no Brasil para se estimar os custos das Interrupções utilizando-se para isto a investigação direta realizada junto aos consumidores residenciais, comerciais e industriais de energia elétrica.

Neudorf et al (1995) [ 82] analisaram o custo-benefício em relação à melhoria da confiabilidade do sistema elétrico de potência e os custos com o não fornecimento de energia elétrica por meio de dois estudos de caso. No mesmo ano Gates et al (1995) [ 38] apresenta uma metodologia desenvolvida para avaliar os custos e as perdas incorridas por consumidores de energia durante Interrupções no sistema elétrico de potência.

Sullivan et al (1996) [ 102] avaliam o custo de interrupção para os desligamentos momentâneos e os distúrbios de tensão, abordando também, indicadores econômicos e expectativas dos consumidores em relação ao sistema elétrico de potência americano e sua qualidade de energia elétrica. No mesmo ano Sarkar (1996) [98] desenvolveu uma ferramenta para a avaliação do custo da Qualidade de Energia Elétrica (QEE), em relação às Interrupções mostrando os resultados destes custos para diferentes setores de consumidores de energia elétrica na Índia. 
Sullivan, Vardell e Johnson (1997) [ 103] apresentaram os resultados de uma pesquisa realizada com 210 grandes clientes comerciais e industriais dos Estados Unidos e Canadá a fim de obter descrições detalhadas dos componentes de custo das Interrupções de energia elétrica. No Brasil, no mesmo ano, Gomes e Schilling (1997) [ 42] publicaram um artigo que trata dos custos de interrupção baseados em métodos probabilísticos permitindo às concessionárias planejarem os seus sistemas dentro de níveis de confiabilidade de acordo com aquilo que os consumidores estariam dispostos a pagar.

McGranaghan e Roettger (2002) [ 75] descreveram um método para a avaliação econômica da qualidade de energia, que é subdividido em quatro etapas: caracterização do desempenho da QEE do sistema elétrico de potência, estimativa de custos associados às variações de QEE, caracterização das alternativas de soluções em termos de custos e benefícios, e execução da análise comparativa econômica destes custos.

Magalhães et al (2001)[ 66], no Brasil, analisaram as diferentes modalidades de transtornos e prejuízos ao consumidor em relação à avaliação do custo social, devido à interrupção de energia elétrica. Também no Brasil, Alves, Costa e Fonseca (2003)[ 3] publicaram um artigo que trata dos problemas associados à ocorrência dos distúrbios da QEE, em especial aos afundamento de tensão, apresentando uma metodologia que calcula os prejuízos associados a este fenômeno. Melo e Cavalcanti (2003)[77] propuseram uma nova metodologia de avaliação da QEE fornecida às indústrias, analisando e definindo novos indicadores de energia elétrica, além dos já utilizados pelo setor elétrico brasileiro.

\subsection{Avaliação das VTCDs nas redes elétricas e seus impactos sobre os consumidores}

Dentro da literatura, podem ser encontrados diferentes trabalhos significativos referentes ao efeito da qualidade de energia sobre equipamentos eletrônicos. Do ponto de vista cronológico, podemos encontrar o primeiro trabalho publicado por Kajihara (1968) [ 56] sobre o efeito da qualidade da energia nos dispositivos eletrônicos, mas a partir dos anos 80 surge uma preocupação generalizada sobre a qualidade da energia. Em 1985, no Congresso de Atenas, a associação de empresas de energia elétrica na Europa, UNIPEDE (hoje EURELECTRIC), nomeou um grupo de peritos para melhorar o conhecimento da gravidade das taxas de ocorrência dos afundamentos de tensão nas redes elétricas. Deste estudo um relatório foi lançado por Davenport (1991) [ 31]. Entre as conclusões, o relatório destaca que: 
Os afundamentos na faixa de $0-60 \%$ e até $500 \mathrm{~ms}$ são resultado de falhas transitórias nos sistemas de alta tensão, principalmente no sistema de transmissão. Este relatório foi apresentado à IEC (Comissão Internacional Electrotec), para permitir estabelecer níveis e limites de imunidade e compatibilidade.

Em resposta à falta de informações sobre a natureza e magnitude das perturbações em sistemas de baixa tensão, o NPL (National Power Laboratory) iniciou em 1990 um estudo da qualidade de energia desenvolvida por Dorr (1992) [ 34]. Centenas de distúrbios foram acumuladas. Os afundamentos de tensão no sistema de $120 \mathrm{~V}$ (nominal) foram limitados a 104V com uma duração de até 30 ciclos (1/2 segundo). Este estudo apresenta resultados de 600 medições e compara os distúrbios registrados com a curva CBEMA. O autor conclui que o grande número de distúrbios encontrados sugere a utilização de sistemas de proteção juntos aos equipamentos e processos industriais sensíveis.

O EPRI (Electric Power Research Institute) também se mostrou interessado em avaliar o efeito dos afundamentos de tensão nas redes elétricas, encomendando um estudo intitulado "Uma Avaliação da qualidade da energia em sistemas de Distribuição" relatado em Dorr (1996) [ 33]. De junho de 1993 a setembro de 1995, foram monitorados um total de 227 pontos em sistema com tensão nominal variando de $4,16 \mathrm{kV}$ a $34,5 \mathrm{kV}$. Um terço das medições foram realizadas nas subestações. Para os alimentadores, as instalações dos medidores foram localizadas de forma aleatória.

Nos E.U.A. e Canadá, na década de 1990, também foram realizadas três grandes e importantes campanhas de medição. Desta maneira, foi possível montar um relatório sobre o perfil da qualidade de energia nas redes monitoradas, como comentado em Carvalho (2000)[ 19].

Existe também, na literatura científica, uma grande quantidade de trabalhos que focalizam o efeito de afundamentos de tensão nas redes elétricas. Estes fenômenos são importantes para a confiabilidade dos processos industriais. Processos produtivos atuais que utilizam sofisticados controles são freqüentemente sensíveis às variações de tensão de curta duração. O efeito de afundamentos de tensão sobre cargas sensíveis pode causar a parada de diversos processos. Alguns equipamentos menos sensíveis a estes eventos estão disponíveis no mercado. Porém, os fabricantes deveriam ter alguma idéia das características dos afundamentos de tensão na rede elétrica para fazer a melhor escolha, considerando confiabilidade e custo, como foi discutido no trabalho de Becker (1994) [ 9]. Sabe-se que o custo de um afundamento de tensão é na maioria das vezes, equivalente a uma interrupção no fornecimento de energia. 
Um trabalhos apresentado por Dugan et al (1999) [ 36], mostra uma metodologia para estimar índices de qualidade de energia relativos aos afundamentos de tensão e Interrupções. É discutida a importância da influência destes índices, sob o ponto de vista econômica a tomada de decisões nos investimentos futuros no âmbito da expansão. Este mesmo autor, em Dugan et al (2002) [ 35], mostra a necessidade de se estudar o comportamento das VTCDs, principalmente porque são eventos que ocorrem com maior freqüência do que as Interrupções.

Dada a necessidade de poder caracterizar o comportamento das redes de distribuição, subtransmissão e transmissão frente a fenômenos de VTCDs, foram desenvolvidos aplicativos computacionais de simulação de forma a estimar o número de eventos de VTCDs nos quais estes sistemas estão submetidos.

O primeiro trabalho sobre este tema foi publicado em 1991, pelo norte-americano Larry Conrad (1991) [ 28]. O método proposto, conhecido como método das posições de falta consiste em calcular o número de eventos esperados para cada elemento da rede e classificálos em uma tabela, pela sua duração e amplitude.

Outro método bastante difundido na literatura, com bastante influência no cálculo dos valores esperados de VTCDs nas redes elétricas, é o método das distâncias críticas, proposto por Bollen (1996) [ 11] e comentado pelo mesmo autor em Bollen (1998a, 1998b)[ 12][ 13]. É um método deduzido e aplicável para redes radiais, mas pode ser estendido a redes malhadas. O método das distâncias criticas não determina a tensão do afundamento, mas sim a posição da falta para determinado valor esperado de tensão. Inicialmente calcula-se para todos os PAC (pontos de acoplamento comum), os níveis de tensão esperados e, em seguida, qual o valor da distância (elétrica) necessária para que um determinado ponto seja sensibilizado para os valores esperados de tensão.

Em McGranaghan et al (1991) [ 73] é apresentado um trabalho que segue a mesma tendência mostrada nas publicações anteriores combinando taxa de falha para a estimação de afundamentos de tensão. Um novo conceito é introduzido, denominado área de vulnerabilidade, que diz respeito à sensibilidade das cargas frente a falhas elétricas em determinadas regiões que podem causar afundamentos de tensão com valor inferior a uma determinada magnitude.

O método de posições de falta é aplicado por Qade, Bollen e Allar (1999) [ 88] para determinar o número esperado de afundamentos de tensão nas barras, em um grande sistema de transmissão. Este trabalho mostra de forma gráfica, as áreas expostas (ou áreas de vulnerabilidade), nas quais faltas produzidas na rede irão provocar afundamentos de tensão inferior a um determinado valor. Nas conclusões, os autores, levantam algumas questões, 
principalmente que o número esperado de afundamentos de tensão varia significativamente em todo o sistema mostrando que um número médio de afundamentos de tensão não pode ser utilizado para caracterizar qualquer consumidor.

Uma outra linha de trabalho é a desenvolvida por Pohjanheimo e Lehtonen (2004) [ 87]. Neste trabalho são calculados, de forma analítica, os afundamentos de tensão esperados para uma determinada barra do sistema elétrico, sem a necessidade de diversas simulações. Ao invés disto, são utilizados equacionamentos a partir de curvas de probabilidade de distribuição das ocorrências de falta ao longo da rede, para cada conjunto de linhas do sistema. O resultado final é a obtenção de uma curva de probabilidade de distribuição da amplitude do afundamento de tensão para esta barra. O inconveniente deste trabalho é ignorar a duração dos afundamentos.

Carvalho (2000)[ 19] apresenta uma visão geral dos métodos e ferramentas computacionais que estão atualmente em uso para simulação de afundamentos de tensão. Os métodos de posições de faltas e distâncias críticas são apresentados e discutidos em seis ferramentas computacionais: VSAT (EPRI / ELEKTROTEK, E.U.A.); VSAG (Pacific Gas \& Energy, E.U.A.); PTI (Power Technology Inc., E.U.A.); ANAQUALI (CEPEL, Brasil); software da PUC-BH (Universidade Católica de Belo Horizonte, Brasil) e VISAGE (Universidade Federal de Itajubá). Somente os dois últimos instrumentos, desenvolvidos nas universidades brasileiras, incluem a estimação da duração dos afundamentos. Em geral, todas as ferramentas computacionais utilizam a teoria de avaliação de Curto-Circuito em redes elétricas para calcular a tensão durante a falta. Em seguida, os métodos combinam as informações estocásticas dadas pela taxa de falta para obter uma estimativa do número esperado de afundamentos de tensão e as suas características de magnitude e duração.

Um trabalho desenvolvido no Brasil por Marques (2006) [ 70] propõe um método para a estimação da perda de produção relacionada à energia elétrica, levando em consideração a freqüência de ocorrência dos fenômenos que causam prejuízos para as indústrias, a duração dos mesmos e o número de linhas de produção afetadas em cada distúrbio. O método é de baixo custo de implementação, dado que o levantamento de informações é realizado por questionários quem apresentam conjuntos de cenários que descrevem distúrbios elétricos passiveis ocorridos na indústria, em um tempo específico, com certa duração, com e sem notificação prévia pela concessionária. A estimação do custo das variações de tensão de curta duração sobre a produção das indústrias é obtida por meio de uma ferramenta computacional desenvolvida em Visual Basic ${ }^{\circledR}$ e Excel ${ }^{\circledR}$. Além do custo individual de cada indústria, a ferramenta desenvolvida permite a comparação do impacto da qualidade da energia entre 
empresas, permitindo avaliar as variáveis de custo de maior impacto e os setores de maior sensibilidade. Os distúrbios elétricos podem ter significantes conseqüências econômicas para muitos tipos diferentes de negócios; conhecer a dimensão do problema é o primeiro passo para solucioná-lo de forma adequada.

Um trabalho que tem que ser destacado é apresentado por Olguin (2005) [ 83], onde o autor apresenta um método para estimar os afundamentos de tensão a partir de resultados de medições realizadas em diferentes barras do sistema. Este trabalho também usa o método de posição da falta para observar o efeito dos afundamentos de tensão na rede elétrica estudada. Também faz uso do método de simulação de Monte Carlo para calcular o perfil da rede frente a afundamentos de tensão. Além disso, apresenta um método para monitoração ótima (modelo de otimização que utiliza programação inteira) que permite conhecer o número e o local de instalação dos medidores, e permite estimar o perfil do efeito dos afundamentos de tensão nas barras não monitoradas.

No trabalho de Oliveira et al (2005) [ 84] é apresentado também uma aplicação do método de simulação de Monte Carlo aplicado ao cálculo dos índices de VTCDs nas redes elétricas. Este método, a partir de simulações de Monte Carlo, onde são sorteados os parâmetros do local esperado do defeito, a impedância esperada do defeito e o tipo do defeito, é feito um levantamento estatístico das variações de tensão de curta duração. Para calcular o valor esperado de afundamentos de tensão por ano, o autor utiliza o comprimento total da rede de distribuição multiplicado pelo valor da taxa de falha dos trechos. Com este número, determina quantas simulações de Monte Carlo o método desenvolvido deve simular para representar, anualmente, os afundamentos de tensão para cada barra. O método ainda propõe fazer simulações para anos futuros, indicando o valor de afundamentos de tensão, distribuído em faixas, para cada uma das barras da rede. Evidentemente, até pela natureza aleatória do processo, cada ano apresenta um valor diferente. Com um tratamento estatístico e assumindo uma distribuição normal dos afundamentos de tensão ao longo dos anos, o processo calcula o valor médio dos afundamentos de tensão e a confiabilidade do resultado, a partir de médias e desvios padrões ao longo dos diversos anos calculados.

O trabalho de Aung et al (2004) [ 6] descreve um método para calcular áreas de observabilidade e cita o conceito de área das barras afetadas por um determinado afundamento de tensão. Estas diferentes áreas representam os Curtos-Circuitos ocorridos em qualquer ponto da rede, que poderiam gerar um valor no nível de tensão da barra estudado inferior a um valor pré-estabelecido. Este conceito é extremamente importante quando se pretende mapear a rede quanto ao risco de mau funcionamento de equipamentos ou processos 
e pode ser estendidos para contemplar, além de valores de amplitude do afundamento de tensão, os valores de duração do mesmo.

Um trabalho recente apresentado por Camilo (2007) [18] discute duas metodologias de estimação para realizar o cálculo dos indicadores de alguns fenômenos que impactam os processos industriais: afundamentos de tensão, elevações de tensão e Interrupções de fornecimento de energia. A primeira metodologia baseia-se em simulações de Monte Carlo. Para tal, são utilizados parâmetros reais da rede elétrica, permitindo ao analista determinar, com confiança, quais os valores em risco para cada um dos pontos de carga do sistema. A segunda metodologia utiliza o conceito estatístico de função de distribuição de probabilidades acumulada. Esta metodologia consiste em ordenar as amostras obtidas na simulação e buscar os elementos que se encontram na posição de menor valor em risco e na posição de maior valor em risco. Desta maneira é realizada, uma aproximação com uma curva normal dos resultados obtidos das simulações aplicando o teorema de limite central.

Por outro lado, é sabido que os afundamentos de tensão são altamente dependentes das características da rede, como pode ser observado no trabalho de Heine et al (2003) [ 47], onde o efeito do afundamento de tensão no consumidor teria sua origem em outros níveis de tensão, vindos da transmissão. Heine mostra a importância da influência das faltas na transmissão sobre os afundamentos de tensão em áreas urbanas. O mesmo autor, Heine et al (2001a) [ 46], apresenta uma análise do efeito da configuração dos sistemas de distribuição nos afundamentos de tensão. No entanto, este trabalho é centrado na comparação entre redes urbanas e rurais. Como conclusões tem-se que consumidores urbanos apresentam menos freqüência de afundamentos de tensão quando comparados com os consumidores rurais, devido ao menor comprimento total das redes urbanas.

Outro trabalho que relaciona o impacto dos afundamentos de tensão nos consumidores é apresentado por Sang-Yun Yun et al (2000) [ 95]. Este trabalho utiliza uma curva de sensibilidade típica conhecida como CBEMA para analisar o comportamento das cargas dos consumidores. Este trabalho apresenta um método para mitigar o número de afundamentos de tensão. Este método propõe transferir o fornecimento de energia de um consumidor para outros alimentadores. Para este fim, utiliza o método de simulação de Monte Carlo, assim como dados históricos nas escolhas das chaves seccionadoras para a mudança de fornecimento dos consumidores.

O trabalho de Lakervi et al (2000) [ 60] comenta o efeito da queda de um raio sobre o alimentador e os seus respectivos consumidores, e discute a diminuição do número de 
afundamentos de tensão, utilizando vários transformadores para a alimentação dos diferentes circuitos de uma rede de distribuição.

Do mesmo modo, o trabalho de Chen et al (2002) [24] propõe estratégias de reconfiguração para melhora dos índices de afundamentos de tensão na rede. Estas estratégias são as seguintes: melhora do nível de tensão de fornecimento, alteração da rede radial para rede em malha, mudança das instalações aéreas por subterrâneas, e alimentação das cargas por subestações mais próximas. Estas estratégias conseguem melhoria dos índices de afundamentos de tensão na rede de distribuição, assim como conseguem melhorar os índices de sensibilidade dos equipamentos e processos industriais dos consumidores.

$\mathrm{Na}$ literatura podemos encontrar trabalhos que mostram que a Geração Distribuída podem melhorar índices de VTCDs. Entre eles, podemos encontrar o trabalho de Macken et al (2004) [ 65], que apresenta duas soluções para diminuir o efeito dos afundamentos de tensão nos equipamentos eletroeletrônicos. As suas soluções, compensação em série e transferência para MicroGrid durante os afundamentos de tensão, utilizam sistemas de geração distribuída para manter o nível de tensão frente a afundamentos de tensão no fornecimento. Nos resultados, estas duas opções se mostraram eficientes durante a mitigação dos afundamentos de tensão.

Em Gomez e Campetelli (2000) [ 40] se propõe a atenuação dos afundamentos usando fusíveis limitador de corrente. Os autores, neste trabalho, analisaram a coordenação das curvas de susceptibilidade dos equipamentos frente a um afundamento de tensão. Existem no mercado vários tipos de fusíveis, que permitem uma melhor escolha para a redução das durações do afundamento de tensão.

Tosato e Quaia (2000) [ 107] apresentaram também uma solução na atenuação da severidade dos afundamentos de tensão pela redução do tempo de abertura dos dispositivos de proteção. A redução do tempo pode levar a uma substancial melhoria da qualidade, porque a maioria dos processos industriais sensíveis são capazes de operar através de um afundamento de tensão de menor duração, tipicamente inferiores a meio ciclo. Esta redução na duração é possível com as modernas tecnologias. Mais tarde, o mesmo autor Tosato (2001) [ 108] apresentou uma limitação da corrente de falta como uma forma de limitar a amplitude do afundamento, considerando que a magnitude afundamento é proporcional à corrente de falha. Este trabalho propõe limitar a corrente de falta por meio de um dispositivo conectado no início dos alimentadores radiais, de modo a melhorar a qualidade do sistema.

O trabalho de Heine et al (2001b) [ 48], estima a freqüência anual e o custo dos afundamentos de tensão para consumidores de concessionárias diferentes. Neste trabalho, 
estima-se, para os consumidores industriais, o custo por perda de produção, desde a parada até o reinício das operações, provocados por mau funcionamento de seus equipamentos eletroeletrônicos, quando submetidos a afundamentos de tensão durante a sua operação.

Finalmente, a presente Revisão Bibliográfica visa apresentar os estudos referentes a variações de tensão de curta duração (VTCDs) e seu impacto nas redes de distribuição das concessionárias de energia e seus efeitos sobre os consumidores. Tais estudos compreendem as bases utilizadas no delineamento do trabalho de pesquisa realizado nesta tese, tanto para o cálculo dos índices de VTCDs (afundamentos de tensão, elevações de tensão e Interrupções) como critérios para a melhoria destes índices visando à diminuição do impacto nos consumidores secundários. 


\section{3 - ASPECTOS RELEVANTES PARA ANÁLISE DAS VTCDS}

As VTCDs (Variações de tensão de curta duração) constituem um problema sério nos consumidores existentes nas redes de distribuição. No caso dos consumidores indústrias, para melhorar a eficiência e qualidade de seus processos precisam de uma grande quantidade de equipamentos eletro-eletrônicos cada vez mais sofisticados e precisos de alta tecnologia.

As conseqüências destes fenômenos produzem grandes preocupações principalmente nos processos industriais e nas instalações comerciais, especialmente os mais modernos, o que se reflete na importância dada a estes fenômenos na literatura técnica especializada.

Para sistemas trifásicos pode-se ter, em determinados casos, afundamento e elevação de tensão em fases diferentes durante uma ocorrência de perturbação, dependendo das fases envolvidas, do grau de aterramento do sistema, do local da origem da ocorrência, da topologia da rede, dos equipamentos existentes e do tipo de ligação dos transformadores.

$\mathrm{Na}$ literatura e em trabalhos anteriores levantados, Souza (2002)[ 100], encontra-se argumentação de que, no atual cenário do setor elétrico, em termos internacionais, o comportamento das concessionárias frente aos fenômenos de qualidade de energia é dividido em duas vertentes: a competitiva e a regulatória.

$\mathrm{Na}$ vertente competitiva, a concessionária busca constantemente oferecer melhores condições de fornecimento para cativar clientes, sendo a qualidade de energia um potêncial valor a ser agregado nessa postura. Gerenciar a qualidade implica tanto conhecimento do lado do sistema, como da sensibilidade de equipamentos e processos dos consumidores por parte da concessionária.

$\mathrm{Na}$ vertente regulatória, a concessionária evitar violar limitados índices estabelecidos pela legislação e, portanto, evitar pagar multas. Conhecer e gerenciar os níveis de qualidade e seus impactos nesses índices é necessário também neste caso.

Desenvolver ferramentas para avaliar graus de exposição de consumidores, estimar número de VTCDs, localizar faltas no sistema (assim com sua causa), avaliar quais áreas do sistema são mais expostas, passam a ser importantes atividades tanto para a operação e planejamento de expansão, como para planejamento de manutenção, proteção e investimentos da área comercial visando fidelidade e conquista de clientes. 
Por fim, a questão da definição da origem das perturbações é fundamental nos processos de estabelecimento de responsabilidades entre o agente distribuidor, transmissor, gerador, o operador do sistema e os próprios consumidores.

\subsection{Causas principais de VTCDs}

São dois os principais fenômenos desencadeadores de VTCDs: ocorrência de faltas e manobras de grandes cargas na rede, principalmente partida de grandes motores.

Durante a partida de grandes motores de indução, a corrente de partida pode alcançar valores bastante elevados quando não devidamente compensados, expondo a rede a esta situação durante períodos que podem alcançar 1 minuto. A queda de tensão depende fortemente dos parâmetros associados à rede supridora e do ponto em análise.

A partida de motores, em geral provoca afundamentos de tensão menos profundos e com maior duração. Como os cabos dos alimentadores são dimensionados para a corrente nominal, a corrente de partida será responsável por uma maior queda de tensão no alimentador. Como o tempo de partida é de alguns segundos e a corrente desta varia de um valor de 6 a 8 vezes a corrente nominal, a queda de tensão terá duração de alguns segundos e será variável neste intervalo de tempo (afundamento não retangular).

A magnitude do afundamento depende da intensidade da corrente de partida do motor e das características da rede como um todo. Uma rede forte é aquela de baixa impedância equivalente no ponto de acoplamento comum e baixa impedância dos cabos da instalação que supre o motor. A queda de tensão será função do produto de toda a impedância entre a carga e o barramento a ser estudado, pela corrente de partida. Quanto mais forte a rede, menor obviamente será a queda de tensão.

Na maioria dos casos, durante o planejamento da instalação é considerado um valor máximo para a queda de tensão na partida dos motores (tipicamente entre 10 a $12 \%$ da tensão nominal do secundário do transformador). Para compatibilizar esta queda de tensão com os valores estipulados, existem diversas formas, tais como aumentar a seção nominal dos condutores, utilizar um ramal exclusivo para a carga, instalar métodos de partida suave (como chaves eletrônicas de partida, conhecidas como "soft start"), solicitar da concessionária um reforço da rede de alimentação ou utilizar restauradores dinâmicos de tensão. 
Sendo assim, as VTCDs causados por partidas de motores são, na maioria dos casos, facilmente controlados e limitados a valores que não causem problema a instalação como um todo.

A maioria das VTCDs que ocorrem no sistema elétrico está diretamente relacionada a Curtos-Circuitos. Estes são praticamente inevitáveis em um sistema elétrico de grande porte. A circulação da corrente de Curto-Circuito através das impedâncias do sistema causa quedas (afundamentos) de tensão ao longo da rede. A extensão da VTCD depende da topologia da rede e de suas impedâncias, tanto no ponto de falta quanto ao longo dos ramais. Por outro lado, a duração da VTCD está diretamente relacionada com dois tipos de tempos: i) O Tempo de atuação do relé mais o tempo de abertura do disjuntor, neste caso a atuação dos dispositivos de proteção provocariam interrupções de curta ou de longa duração, e ii) Tempo da extinção natural da falta, este tempo refere se a efeito de faltas de curtíssima duração nos quais os dispositivos de proteção não são sensibilizados.

Dentre todas as causas de Curto-Circuito, as maiores responsáveis são as descargas atmosféricas. Seus efeitos são sentidos principalmente na rede de distribuição de energia elétrica, pois o seu nível de isolamento é bem inferior ao de linhas de transmissão.

Apesar destes distúrbios (Curto-Circuito e partida de motores) acima mencionados estarem limitados a um intervalo de tempo inferior a um minuto, todos podem ser responsáveis por graves problemas para o consumidor, principalmente na área industrial onde estão concentrados os equipamentos mais sensíveis a estas variações de tensão de curta duração, tais como acionamentos de motores, equipamentos de processamento de dados e de controle, Farqui (2005)[ 37].

Os diversos tipos de VTCDs que ocorrem nos pontos da rede, devido à ocorrência de uma falta, estão diretamente relacionados a cada tipo de falta, que pode ser trifásica, faseterra, dupla-fase ou dupla fase - terra. Como as faltas não são previsíveis, o fenômeno de VTCDs tem caráter aleatório e, portanto, seu tratamento deve incluir abordagem estatística.

Dos diferentes tipos de faltas existentes no sistema elétrico, aquele geralmente produz maior severidade no afundamento de tensão é a falta trifásica, entretanto esta representa apenas cerca de 5\% do total de ocorrências. Por outro lado, faltas monofásicas (fase-terra) são as que apresentam menor severidade e maior índice de incidência (aproximadamente 70\%) Santos e Silva (2003) [ 96]. Considerando a ocorrência de defeito monofásico, há o surgimento de um transitório de curta duração (alguns ciclos, no máximo), seguido de uma redução da tensão na fase defeituosa e geralmente de uma elevação de tensão nas demais fases (em função da relação entre as impedâncias de seqüência zero e positiva). Verifica-se 
este comportamento não só no alimentador onde se dá o defeito, mas também em todos aqueles alimentados da mesma subestação supridora, perdurando até que seja acionada a proteção da rede.

Em uma análise global destas causas, é necessária a identificação do sistema onde se deu o evento e de sua abrangência. Sendo assim, pode-se considerar o envolvimento dos Sistemas de Transmissão, Subtransmissão e Sistema de Distribuição de Energia Elétrica ou mesmo dos Consumidores circunvizinhos ao ponto em análise. Tal identificação permite a avaliação da abrangência sistêmica da perturbação e, por conseqüência, a identificação de recursos adequados para a melhoria do desempenho da qualidade para o fenômeno em pauta.

\subsection{Fatores de Influência nas VTCDs}

A magnitude das VTCDs está associada à configuração da rede em estudo e, portanto, depende da determinação do local da incidência do defeito. Ou seja, para os casos aplicáveis a sistemas de transmissão, deve-se ter em conta a configuração em anel em algumas condições normais operativas, diferente da configuração radial. No caso de sistemas de subtransmissão, existe o recurso de paralelismos temporários para emergências ou para manobras de transferência de cargas entre subestações adjacentes. Nas redes de distribuição, também é interessante a análise das possíveis configurações adotadas em caráter permanente e as que caracterizam a sua flexibilidade operativa em manobras para atendimento das cargas.

De qualquer forma, a avaliação de VTCDs e de seus impactos depende de uma avaliação global das redes envolvidas, tendo em vista a verificação dos parâmetros magnitude e duração.

Entre os principais fatores que influenciam as VTCDs estão: Tipo de Falta, Localização da Falta, Impedância de Falta, Conexão dos Transformadores, Tensão Pré-falta, Desempenho do Sistema de Proteção e Outros Fatores, Farqui (2005)[37].

\section{- Tipo de Falta}

Um dos fatores mais importantes para se determinar a magnitude da VTCD é o tipo de falta que ocorreu no sistema. Em ordem decrescente, as faltas que causam os afundamentos mais severos são: trifásica, trifásica-terra, fase-fase, fase-fase-terra e fase-terra. 
As duas primeiras são simétricas causando consequentemente afundamentos trifásicos simétricos mais severos, porém são as que apresentam menor índice de ocorrência. Todos os outros são desequilibrados, necessitando do auxílio das ferramentas de componentes simétricos para determinar suas magnitudes. Correspondem também aos eventos de maior incidência, principalmente os Curtos-Circuitos fase-terra em linhas de transmissão.

\section{- Localização da Falta}

A localização da falta determina o número de consumidores que são afetados pela VTCD. Como exemplo, existem registros nos EUA, referentes a uma falta sobre um sistema de transmissão de $230 \mathrm{kV}$ pode ser percebida, sob forma de afundamento de tensão, por equipamentos instalados a aproximadamente $160 \mathrm{~km}$. Para um sistema de subtransmissão 100 $\mathrm{kV}$ o raio de ação é de aproximadamente $80 \mathrm{~km}$, Abreu (2000)[ 1]. Entretanto, conforme comentado anteriormente, faltas em sistemas de distribuição são responsáveis por afundamentos mais severos aos consumidores ligados ao ramal atingido e ramais adjacentes.

\section{- Impedância de Falta}

A impedância de falta, em geral, e constituída pela resistência de arco ou resistência de contato entre condutores ou mesmo a resistência de terra, no caso de uma falta fase-terra. Dificilmente a impedância de falta é igual a zero (caso onde suas conseqüências são mais severas). $\mathrm{O}$ arco ocorre com a ionização do ar no local da falta causada pelo aquecimento provocado pela elevada corrente de Curto-Circuito.

Desprezando a impedância de falta, encontrar-se-ão valores maiores (máximos) de correntes de Curto-Circuito e, conseqüentemente uma maior severidade na VTCD.

\section{- Conexão dos Transformadores}

A influência da conexão do transformador na VTCD é significativa quando este está localizado entre o ponto de falta e a barra que está sendo analisado. Esta influência ocorre tanto sobre a magnitude como sobre o ângulo. Existem diversos tipos de conexão com diferentes conseqüências para a propagação das VTCDs. Como exemplo as conexões $Y$ - $D, Y$ $Y$, dentre outros, cada uma com diversas possibilidades de defasamento. 

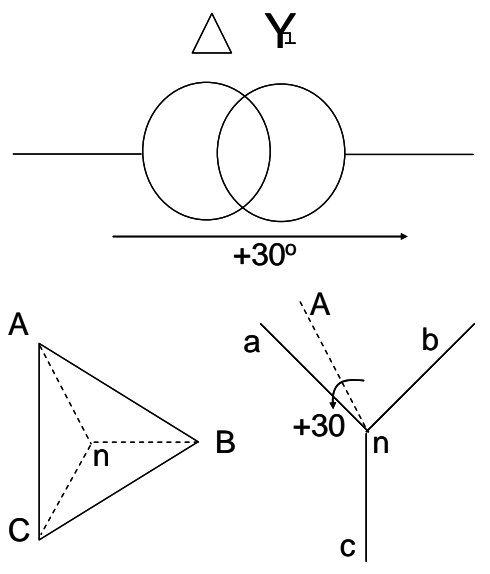
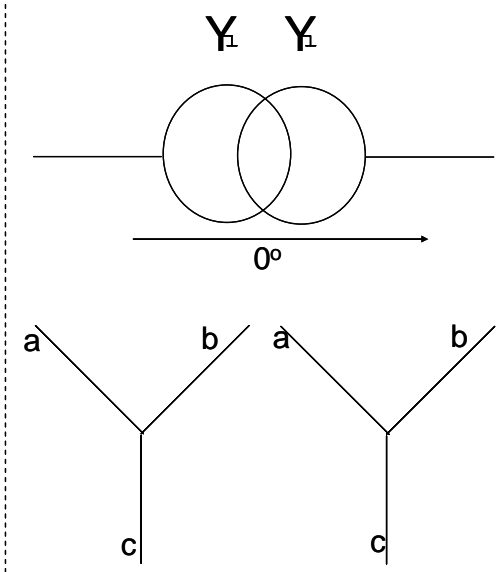

Figura 3-1 - Influência do tipo de conexão do transformador: Conexão DYt e YtYt

Na Figura 3-1 são apresentados exemplos da influência do tipo de conexão dos transformadores na defasagem dos fasores. No caso da conexão $\operatorname{Delta}(D)$-Estrela Aterrado $(Y t)$ mostrado na figura a defasagem é de $+30^{\circ}$ nos fasores de tensão para todas as barras localizadas no lado Estrela aterrado. No caso da conexão Estrela Aterrado(Yt)-Estrela $\operatorname{Aterrado}(Y t)$ a defasagem é de $0^{\circ}$.

Neste trabalho as conexões utilizadas são $D-Y t$ e $Y t-Y t$, já que são as mais freqüentemente encontradas nas redes testadas pela metodologia proposta. Para os outros tipos de conexão tem que ser obtido o valor da defasagem dos fasores de tensão para as barras que se deseja simular e analisar.

Outra grande influência do tipo de conexão dos transformadores se reflete também na obtenção das impedâncias próprias de seqüência zero do ponto de falta.

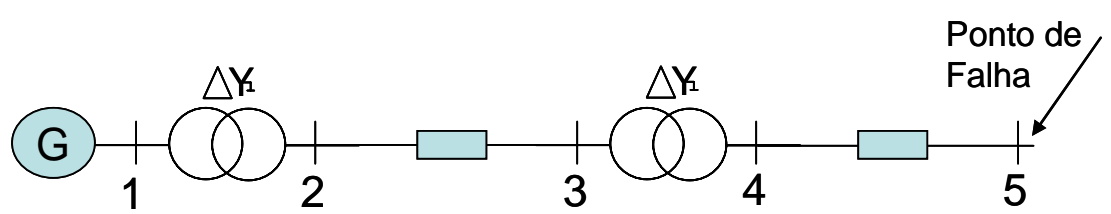

Equivalente Seqüência Zero

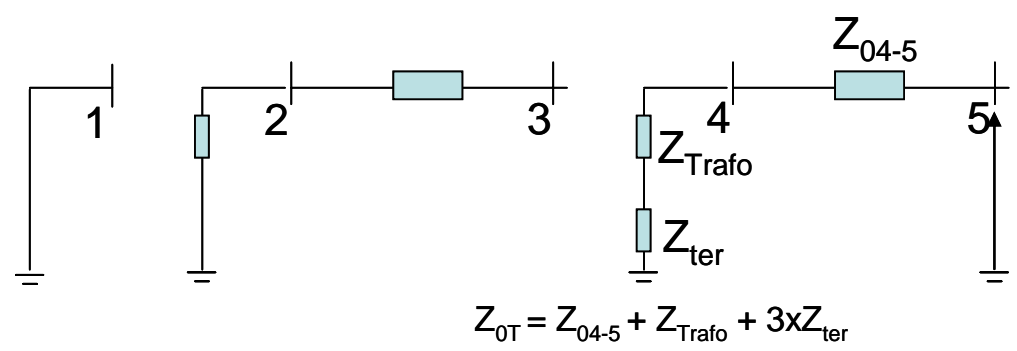

Figura 3-2 -Obtenção da Impedância própria de seqüência zero, considerando tipo de conexão do transformador 
Pode ser observado na Figura 3-2 que no caminho da corrente de falta desde sua origem até a Subestação, existem dois transformadores de tipo $D$ - $Y t$ (delta estrela aterrado). Para a obtenção da impedância própria de seqüência zero é colocado o modelo de seqüência zero para cada componente elétrico existente na rede estudada. Do exemplo da Figura 3-2 pode ser observada que o efeito da conexão $D-Y t$ produz uma diminuição do valor da impedância própria de seqüência zero. Isto se reflete diretamente na corrente de CurtoCircuito e no nível de VTCD no quais os consumidores estarão submetidos. A impedância Zter representa a impedância da malha de terra existente na subestação a qual o neutro do transformador é conectado.

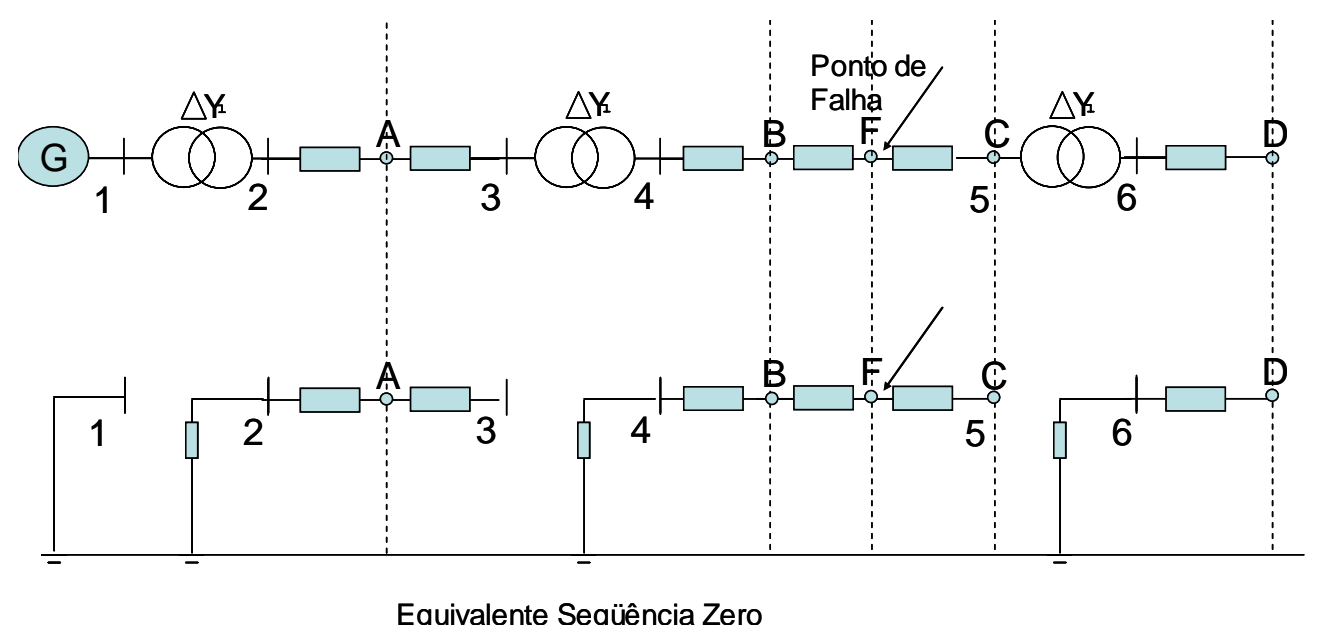

Figura 3-3 - Efeito da conexão dos transformadores na obtenção das impedâncias de seqüência zero, pra diferentes Barras.

Na Figura 3-3 pode ser observado o modelo de seqüência zero para os diferentes elementos da rede, considerando que a falta foi originada na barra $F$. A impedância mútua de transferência em seqüência zero para diferentes barras da rede pode ser obtida seguindo os seguintes equacionamentos:

Sendo $F$ barra de falta;

Barra A: $V_{0 A}=0$;

Barra B: $V_{0 B} \neq 0 ; Z_{m B}=Z_{04 B}+Z_{0 T 4}$;

Barra C: $V_{0 C} \neq 0 ; Z_{m C}=Z_{0 B F}+Z_{04 B}+Z_{0 T 4}$;

Barra D: $V_{O D}=0$;

Em que:

$V_{O A}, V_{O B}, V_{O C}, V_{O D}$ : Tensão de Curto-Circuito de seqüencia zero nas barras A, B, C, D respectivamente; durante a falta na barra $\mathrm{F}$; 
$Z_{m B}, Z_{m C}$ : Impedância mutua de transferência em seqüência zero nas barras $\mathrm{B}$ e $\mathrm{C}$ respectivamente;

$Z_{04 B}$ : Impedância de seqüência zero no trecho 4-B;

$Z_{O B F}$ : Impedância se seqüência zero no trecho B-F;

$Z_{\text {0T4: }}$ Impedância de seqüência zero entre a barra 4 e terra.

\section{- Tensão Pré-falta}

Sob condições normais de operação, a tensão do sistema elétrico pode variar entre 0,95 e 1,05 pu da tensão contratada, de acordo com o nível de demanda durante o ciclo diário de carga. Em estudos de Curtos-Circuitos, base do cálculo das VTCDs, é em geral aceitável considerar a tensão pré-falta como sendo igual a $1 \mathrm{pu}$.

Entretanto, esta consideração implicará em um erro, normalmente tolerável. Torna-se importante ressaltar que esta é uma simplificação nos cálculos que fará o valor calculado ser ligeiramente diferente do valor real. O valor da defasagem de cada barra será obtido considerando o tipo de conexão dos transformadores existentes na rede.

\section{- Desempenho do Sistema de Proteção}

O sistema de proteção é o responsável por isolar os elementos do sistema elétrico que estejam operando sob condições anormais, tais como sobrecarga ou Curto-Circuito.

A duração da VTCD está diretamente relacionada ao tempo de atuação deste sistema. Este não é apenas o tempo de processamento dos relés somado ao tempo de abertura do disjuntor, mas também a retardos intencionais para garantir seletividade entre proteções (sobrecorrente).

Linhas de transmissão são, em sua grande maioria, protegidas por relés de distância (função ANSI / 21) associados ou não a tele-proteção. Este é um sistema de comunicação entre relés (em diferentes subestações) com o objetivo de minimizar o tempo de atuação da proteção. Caso o sistema de proteção não utilize a tele-proteção, deve-se utilizar proteções com zonas da atuação do relé de distância com tempos distintos.

Em sistemas de subtransmissão $(69,88$ e $138 \mathrm{kV})$ o esquema de proteção é mais simplificado do que nos de transmissão. Raramente utiliza-se tele-proteção nestes níveis de tensão. Quando utilizada será apenas em sistemas mais importantes de $138 \mathrm{kV}$. As proteções 
mais utilizadas na subtransmissão são de sobrecorrente (50/51) de fase e neutro, direcional e diferencial (para equipamentos específicos).

Nas redes de distribuição (tensão até $34,5 \mathrm{kV}$ ), relés de sobrecorrente e fusíveis são muito utilizados. Alimentadores principais utilizam religadores o que faz com que a tensão seja rapidamente restabelecida para todos os consumidores. Entretanto a utilização destes dispositivos faz com que ocorram diversos VTCDs consecutivos para consumidores de outros ramais em caso de falta permanente.

A lista abaixo apresenta alguns tempos típicos de eliminação de defeitos por tipo de proteção utilizada.

Fusível Limitador de Corrente: inferior a um ciclo

Fusível de Expulsão: 10 --1000 ms

Proteção de Distância: 50 ---500 ms

Proteção Diferencial: 100 ---300 ms

Proteção de Sobre-corrente: 200 ---2000 ms

Como a duração da VTCDs está associada ao equipamento de proteção que elimina o defeito, a sua identificação permite de forma recursiva identificar a sua origem. Isso possibilita o mapeamento de medidas a serem aplicadas para melhoria do desempenho de todo o sistema de forma a minorar os efeitos de tais eventos.

\section{- Outros Fatores}

Outros fatores que interferem nas VTCDs estão associados àqueles causadores de faltas no sistema elétrico, tais como:

- Poluição: a poluição depositada nos isoladores ou mesmo a maresia diminuem a isolação facilitando assim a ocorrência de faltas fase-terra;

- Raios causam sobretensões que podem romper a isolação da cadeia de isoladores causando Curtos-Circuitos;

- Interferências públicas: acidentes rodoviários, queimadas, contatos acidentais e vandalismo entre outros, estão relacionados à ocorrência de faltas nos sistemas elétricos, principalmente de distribuição. 
O sistema de proteção com seus diversos dispositivos serão responsáveis por isolar os elementos do sistema elétrico que estejam operando sob condições anormais, tais como sobrecarga ou Curto-Circuito.

\subsection{Sensibilidade de equipamentos ou processos industriais}

A sensibilidade dos equipamentos eletroeletrônicos frente às VTCDs varia de equipamento para equipamento, sendo que, mesmo dentro de uma categoria (por exemplo, acionamentos de motores), pode-se encontrar diferentes reações, dependendo do modelo e do fabricante. Com isso, torna-se difícil normalizar um padrão único para se definir a sensibilidade dos diversos equipamentos.

Entretanto, de uma forma geral, pode-se constatar que a utilização cada vez maior de equipamentos eletrônicos no controle de processos, tais como PLCs (Controladores Lógicos Programáveis) e ASDs (Acionamentos de Velocidade Variável), que são vulneráveis a variações de tensão, torna a questão do controle e limitação das VTCDs fundamental na eficiência do processo produtivo.

Uma questão que tem preocupado a indústria eletrônica ultimamente, especificamente a de informática, refere-se aos prejuízos que uma variação de tensão pode causar durante a execução de um software. As primeiras referências a este tipo de fenômeno estão contidas na norma do IEEE (Std 446 de 1987 e atualizada em 1995 - Orange Book) e também nas curvas da CBEMA (Computer Business Equipment Manufacturers Association), atualmente denominada ITI (Information Technology International Council)[ 72].

Além destes efeitos das VTCDs sobre equipamentos eletrônicos e de informática, pode-se citar outros equipamentos e processos industriais mais tradicionais afetados, tais como:

- $\quad$ Extinção de lâmpadas de descarga, que necessitam de uma tensão mínima para seu funcionamento;

- Variação na velocidade de motores;

- Atuação indevida de contatores e relés auxiliares, devido à falha de energização das bobinas;

- $\quad$ Perda de sincronismo de máquinas síncronas;

- $\quad$ Falha de comutação em pontes de tiristores. 
Conhecendo as características da VTCD a que o equipamento está submetido pode-se optar pela melhor solução a fim de elevar a imunidade do mesmo com a melhor relação custo $\mathrm{x}$ beneficio. Para isso é necessária a utilização de modernos programas para cálculo e simulação de Curto-Circuito e partidas de motores. Com os resultados, pequenas mudanças nas especificações de equipamentos podem, na maioria dos casos, reduzir os problemas relacionados à sensibilidade dos mesmos perante VTCDs.

Alguns trabalhos abrangendo equipamentos em processos industriais, como por exemplo, o trabalho de Santos et al (2001) [ 97], demonstra através de medições em diversos tipos de clientes que os níveis de sensibilidade dos processos não observam uma relação direta com a severidade da VTCD, considerando somente a sua amplitude e duração. Uma análise mais aprofundada mostrou que o número de fases envolvidas com o afundamento de tensão é importante para a avaliação da severidade do fenômeno e sensibilidade naqueles processos.

Na busca de possíveis soluções para aliviar o impacto das VTCDs na sensibilidade dos diferentes equipamentos eletrônicos, deve-se levar em conta que quanto mais generalista é a solução, maior será seu custo. Como exemplo, tem-se o DVR (Dynamic Voltage Regulator) que costuma ser considerado como a solução para todo e qualquer problema envolvendo afundamentos de tensão. Entretanto, além de seu custo de aquisição ser extremamente elevado, apresenta consideráveis custos de manutenção, instalação e, em alguns casos, elevada taxa de falha. Sendo assim, pode ser que existam soluções mais simples e econômicas para solucionar o problema de forma mais eficiente e localizada.

Existem basicamente duas vertentes de atuação para mitigar os problemas associados às VTCDs para evitar a ocorrência e minimizar seus impactos. A primeira compreende medidas preventivas, que contribuem para a eliminação ou diminuição das taxas de ocorrência dos afundamentos de tensão como apresentado por Gomes e Schilling (1997) [ 42]. Entre as principais, pode-se mencionar:

- Para falha nos equipamentos: Cuidado na especificação, compra, armazenagem e manutenção;

- Para Descargas Atmosféricas: Proteção e blindagem de equipamentos, linhas de transmissão e de distribuição;

- Para Contato com árvores: Limpeza de faixa de servidão das linhas de transmissão e de distribuição e poda das árvores

- Para Contato com animais; Análise de riscos, isolamento e identificação de áreas de perigo; 
- Para Interferências Públicas: Análise de riscos, isolamento e identificação de áreas de perigo associadas a campanhas educativas;

- $\quad$ Para Poluição: Limpeza/lavagem das cadeias de isoladores;

- $\quad$ Para Falha Humana; Treinamento da mão de obra, modernização e automação.

A outra vertente considera medidas corretivas que analisam basicamente a mitigação dos problemas associados às VTCDs, alcançada seguindo as três formas seguintes:

- Diminuir o impacto da VTCD reduzindo sua magnitude, duração ou taxa de ocorrência;

- Diminuir a sensibilidade dos equipamentos sensíveis, aumentando sua robustez e tolerância a VTCDs;

- Instalar equipamentos condicionadores de energia como UPS (estáticos ou rotativos) e DVRs (Dynamic Voltage Regulator), dentre outros.

Deve ser ressaltado que o custo da solução adotada cresce com a abrangência, ou seja, uma solução utilizada especificamente em um equipamento considerado crítico é economicamente mais viável que uma envolvendo toda a planta ou o sistema elétrico que alimenta.

Soluções mais abrangentes variam de acordo com a configuração do sistema elétrico estudado e mesmo com as características do distúrbio, entretanto, constituem-se geralmente em alterações na configuração do sistema elétrico, no sistema de proteção ou mesmo a instalação de equipamentos condicionadores de energia.

\subsection{Análise de Áreas de Risco}

A Análise de Áreas de Risco (AR) abrange um conjunto de metodologias destinadas a apoiar a tomada de decisões em ambientes afetados por incertezas.

Para poder simular os eventos que acontecem no sistema de distribuição de energia elétrica frente a fenômenos de VTCDs e observar o efeito nas cargas sensíveis dos clientes é necessário definir as características que devem ser levadas em consideração, isto é:

i) A VTCD decorre de uma anormalidade verificada em algum ponto da rede, como uma descarga elétrica ou rajada de vento que causa o contato de galhos de árvores nos condutores ou ainda o contato entre condutores. 
ii) $\mathrm{O}$ efeito destes fenômenos depende muito do tipo de rede (aérea, nu, semi-isolada, compacta, etc.), mas em última instância, quando se manifesta, pode ser modelado como uma "falta shunt", isto é, impedâncias de falta ligando uma ou mais fases e, em certos casos, a terra.

iii) O efeito de uma certa VTCD no ponto de acoplamento sobre o cliente conectado depende, por sua vez, de quanto a carga é sensível a afundamentos de tensão, incluindo assimetria de módulo e/ou fase. Isto é descrito como a sensibilidade ou susceptibilidade da carga, sendo bastante comum representar esta característica (ou seu dual, a "suportabilidade") como uma probabilidade de disrupção.

iv) Para evitar danos, tanto à rede elétrica como às unidades consumidoras, sistemas de proteção são dimensionados para reagir às anormalidades de tensão e corrente. As características destes sistemas de proteção relacionam os seus tempos de atuação, determinando o tipo de eventualidade que vai afetar a rede e/ou o cliente.

Devido à grande quantidade de informações e da complexidade de um sistema real de distribuição, alguns parâmetros utilizados nas simulações assumem valores julgados mais adequados. A arma essencial para a análise de áreas de risco é a simulação de experimentos com base a certas hipóteses estatísticas. Para isto, uma das técnicas mais populares hoje em dia é a simulação Monte Carlo, como foi apresentado no trabalho de Camilo e Silva (2007)[ 18] e Kagan (2004)[ 55].

Este trabalho tem como objetivo desenvolver modelos de AR aplicável à estimação de VTCDs capaz de subsidiar decisões de operação e planejamento da qualidade de energia elétrica nas empresas concessionárias, assim como apresentar testes preliminares sobre o funcionamento do modelo e aderência à realidade. Em ausência de dados mais detalhados sobre os eventos causadores de VTCDs na rede da empresa, são assumidos os valores mais aderentes à realidade.

Um modelo para AR na estimação de VTCDs deve levar em consideração diversos subsistemas cujo comportamento seja relevante à ocorrência e ao impacto, tanto técnico quanto econômico, das VTCDs. Entre outros, tem-se: a rede elétrica, as cargas dos clientes, os "estados da natureza" que causam as VTCDs e influem nas suas características e os subsistemas de proteção.

Assim também, neste trabalho tem-se como foco a avaliação do impacto que os fenômenos de VTCDs podem produzir ao consumidor. Assim é definido o conceito de Disrupção nos processos ou equipamentos eletro-eletrônicos nos consumidores. 
O termo "Disrupção" é um termo genérico que descreve o caso de existir algum defeito adverso no desempenho da carga de um consumidor com interrupção de um processo de produção devido a um afundamento de tensão, ou ainda "queima" de equipamentos associado a uma elevação da tensão.

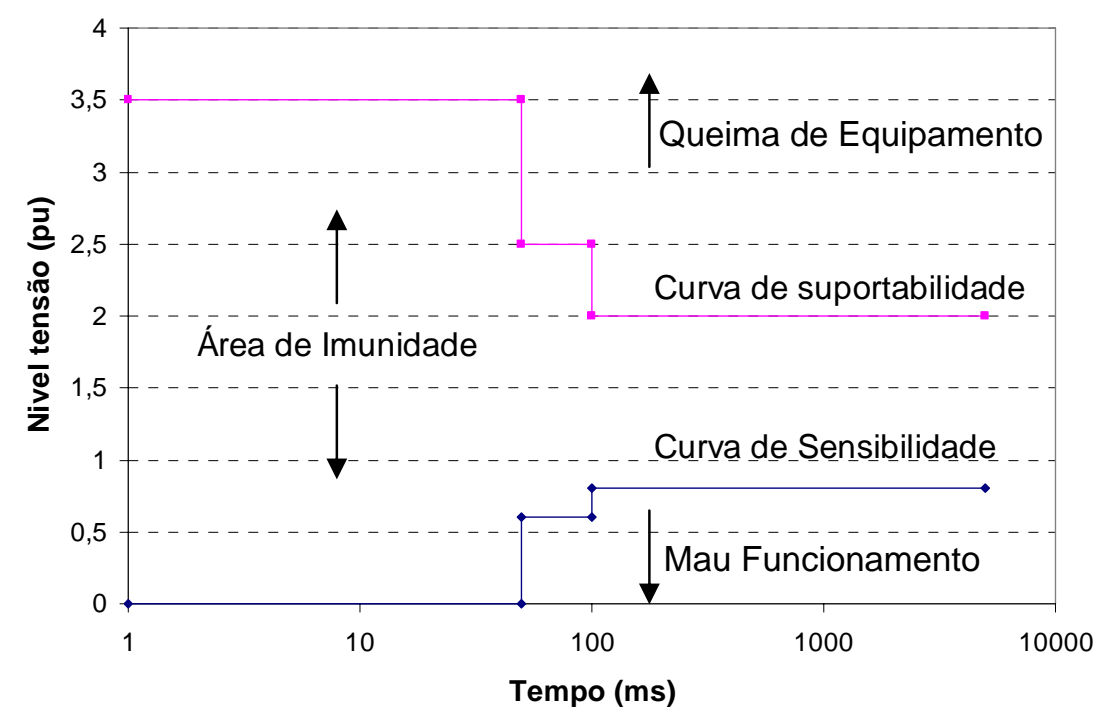

Figura 3-4 Curva de Sensibilidade por afundamentos de tensão.

Pode-se observar na Figura 3-4 uma curva representativa de um consumidor. Nesta figura nota-se que diferentes faltas na rede podem produzir diferentes níveis de variações de tensão de curta duração na barra do consumidor.

Em função da curva representativa e da variação de tensão produzida, pode-se conhecer o impacto da falta, no consumidor. Da Figura 3-4, afundamentos de tensão na parte inferior da curva de sensibilidade ocasionarão mau funcionamento no processo do consumidor em análise, enquanto elevações de tensão, em geral, resultam em queima de equipamentos.

Isto mostra a importância de conhecer e caracterizar o comportamento do processo do consumidor frente a diferentes níveis de tensão. O comportamento destas curvas frente a fenômenos de VTCDs será discutido e comentado nos próximos capítulos. 


\section{4 - MODELOS PARA ANÁLISE DE ÁREAS DE RISCO}

Neste capítulo descreve-se a concepção dos modelos utilizados durante a análise de áreas de risco aplicados ao problema das variações de tensão de curta duração (VTCDs) em um sistema de distribuição.

A preocupação com os eventos de qualidade de energia elétrica e os efeitos disruptivos que provocam sobre a empresa e seus clientes faz necessário o emprego de várias técnicas e métodos de natureza diversa, abrangendo tanto o aspecto técnico quanto as implicações econômico-financeiras sobre a sociedade, empresa e consumidor, bem como da imagem da empresa que a ocorrência das VTCDs traz consigo.

\subsection{Obtenção de Condições de Curto-Circuito na rede de Distribuição}

No presente capítulo serão apresentados diferentes métodos para a obtenção de parâmetros de Curtos-Circuitos ao longo da rede. Estes métodos utilizam diferentes critérios e tentam percorrer todas as possíveis combinações de parâmetros que influem nos CurtosCircuitos, envolvendo variáveis definidas, tais como: ponto de falta, tipo de falta e impedância de falta. A qualidade na construção do conjunto das possíveis combinações de parâmetros é refletido diretamente na obtenção dos índices de VTCDs para cada uma das barras e consumidores, permitindo realizar um estudo de áreas de risco na rede de distribuição.

Neste item são apresentadas três metodologias. A primeira, baseada no Método de Monte Carlo, utiliza um critério de seleção estatística na obtenção do conjunto de combinações de parâmetros, em que a seleção dos valores das variáveis é realizada de forma aleatória. A segunda metodologia, baseada no método de Enumeração de estados deixa de realizar a seleção das variáveis de forma aleatória para utilizar critérios determinísticos, dividindo os valores das variáveis em faixas definidas na obtenção do conjunto de combinações. E a terceira metodologia chamada de Híbrida utiliza as vantagens dos dois métodos anteriores já que, durante a seleção, algumas das variáveis envolvidas são selecionadas de forma aleatória e outras de forma determinística. 


\subsubsection{Método de Monte Carlo}

O nome "Monte Carlo" teve origem durante a Segunda Guerra Mundial, quando tal abordagem foi aplicada a problemas relacionados com o desenvolvimento da bomba atômica, principalmente na resolução de integrais de funções matemáticas de difícil solução analítica.

Só com o aparecimento dos rápidos computadores modernos é que o método de simulação de Monte Carlo ganhou ímpeto como método científico, pois para conseguir toda sua potencialidade é preciso gerar e processar uma grande quantidade de procedimentos aleatórios. O método de Monte Carlo pode ser usado com vários graus de sofisticação, mas para a sua utilização mais conveniente e eficiente dependerá largamente do problema considerado, Burato (2005)[ 17].

O método de Monte Carlo baseia-se em processo de geração de números aleatórios a partir de uma dada função de distribuição de probabilidades. Também se fundamenta em um processo de imitar a realidade, com modelos que podem conservar ou não as características físicas e lógicas do sistema real. Isso faz do método uma das ferramentas mais poderosas disponíveis para analisar projetos e operação de processos complexos.

Este método permite simular modelos que apresentem o maior número possível de características de sistemas reais e, desta maneira, chegar a resultados precisos em um tempo extremamente inferior ao da ocorrência do processo real. Estudar um sistema real por meio de uma representação artificial do processo requer a construção de um modelo de simulação que, através de ajustes adequados, pode levar a resultados satisfatórios, Sato (1995)[ 99].

A simulação pelo método de Monte Carlo pode ser classificada em dois tipos:

I. Simulação de problemas determinísticos;

II. Simulação de problemas estocásticos e probabilísticos.

A simulação de problemas determinísticos se refere à resolução de tipos de problemas, tais como integrais, derivadas, equações diferenciais, matrizes, etc., através de modelagem conveniente. Por outro lado a simulação de problemas estocásticos e probabilísticos abrange os casos em que por sua natureza estocástica ou probabilística não podem ser resolvidos através de métodos matemáticos usuais e a simulação é o melhor ou muitas vezes o único método de resolução. Este processo de simulação é feito através da geração de números denominados aleatórios ou randômicos, os quais podem apresentar as ocorrências aleatórias que caracterizam os problemas a serem resolvidos pelo método de Monte Carlo. 
Partindo da premissa de que os números aleatórios devem se comportar segundo a mesma distribuição de probabilidade do fenômeno físico dos eventos aleatórios simulados, cabe um questionamento: estes números são realmente aleatórios? A resposta a esta questão é que testes estatísticos são feitos com os números aleatórios gerados de modo a garantir o seu caráter aleatório. Entretanto, seria necessário gerar infinitos números aleatórios por um mesmo processo e submetê-los a um número infinito de testes estatísticos. Nesse sentido, jamais poderíamos ter números aleatórios genuínos, mas sim números pseudo-aleatórios. Os números pseudo-aleatórios gerados por um computador constituem em uma seqüência de números calculados matematicamente por uma regra pré-fixada e são aprovados em testes estatísticos de aleatoriedade porque são gerados em quantidade extremamente grande, antes de ser iniciada a geração da mesma seqüência, Sato (1995)[ 99].

\subsubsection{Aplicação ao problema de Análise de Risco de VTCDs}

Para utilizar o método de Monte Carlo, é necessário realizar uma grande quantidade de sorteios, obtendo-se, no final, resultados estatísticos das grandezas de interesse para o estudo de áreas de risco.

Para o problema de Análise de Riscos de Disrupções por VTCDs, cada sorteio é caracterizado por parâmetros que simulam um evento de VTCD originado na rede de distribuição elétrica, Mamede (2004)[ 67]. O critério para escolher cada um deles será explicado nos itens seguintes com mais detalhe.

\subsubsection{Escolha do trecho de falta}

Curtos-Circuitos, que originam VTCDs, são fenômenos aleatórios, ou seja, que podem acontecer em qualquer trecho da rede de distribuição.

Neste trabalho, para a escolha do trecho de falta, são levados em consideração todos os trechos da rede; sendo que a probabilidade da seleção do trecho é proporcional ao comprimento do trecho, e à sua respectiva taxa de falta.

Estas considerações tentam incluir a influência do comprimento dos trechos para estudos das áreas de risco, ou seja, trechos com maiores comprimentos têm maior probabilidade de sofrer um Curto-Circuito.

Do mesmo modo, as taxas de falta dos trechos são informações que cada concessionária de distribuição possui ou tende a possuir em função, dentre outros, de estudos 
de confiabilidade. Assim, incluindo estas considerações, tenta-se modelar o comportamento de cada rede específica ao estudo de simulação.

Pelas equações (1) (2) pode-se obter, respectivamente, o número de falhas totais na rede em estudo, e o número de falhas para cada trecho.

$$
\begin{gathered}
N F_{T}=\sum_{i=1}^{n} N F_{i} \\
N F_{i}=T x_{i} \times \text { Comp }_{i}
\end{gathered}
$$

Em que:

$N F_{T}$ : Número de falhas por ano totais em toda a rede estudada (Falhas/ano);

$N F_{i}$ : Número de falhas por ano para o trecho i (Falhas/ano);

$T x_{i}$ : Taxa de falhas para o trecho i (Falhas/km.ano);

Comp $_{i}$ : Comprimento do trecho i $(\mathrm{km})$.

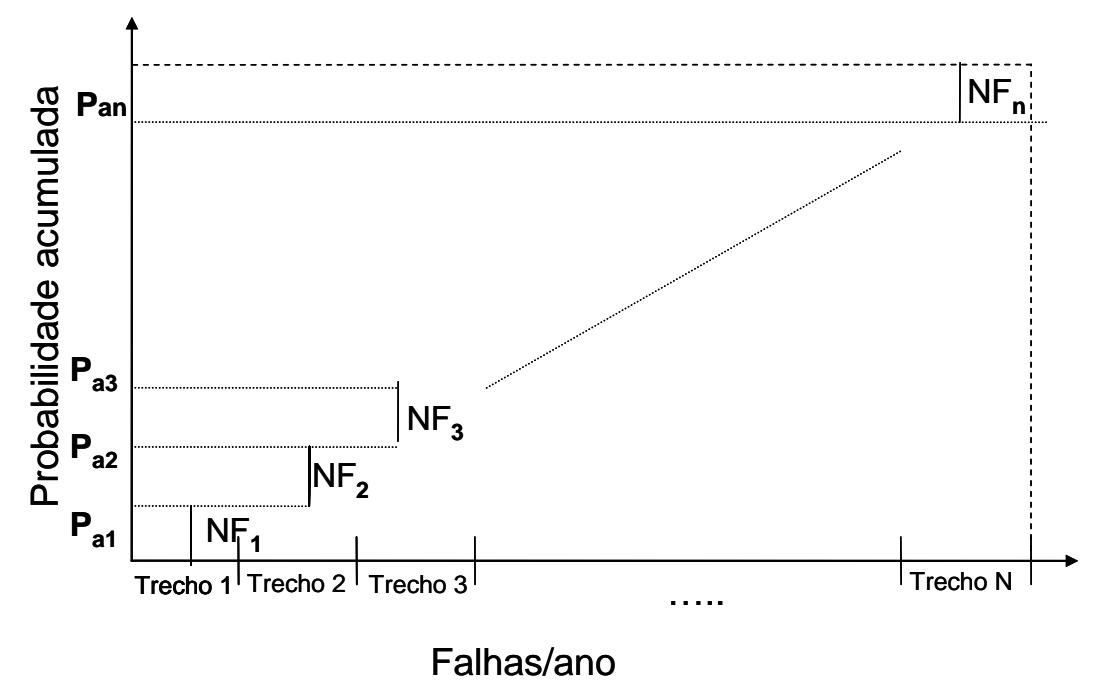

Figura 4-1 - Probabilidade acumulada vs taxa de falha por ano para cada trecho

Pode-se observar na Figura 4-1 uma função linear entre a distribuição de probabilidades acumulada e a taxa de falha para cada trecho. Para realizar a escolha do trecho em falta é realizado um sorteio aleatório entre 0 e 1. Na Figura 4-1 o valor sorteado de probabilidade acumulada $\mathrm{Pa}_{3}$, representaria que o trecho de falta é o $\mathrm{N}^{\mathrm{o}} 3$. Realizando múltiplos sorteios com a mesma curva de probabilidade acumulada é possível conhecer o número de faltas que corresponderia a cada trecho. 


\subsubsection{Escolha do Ponto de falta}

Depois de conhecer o trecho de falta, logo após o sorteio, é importante conhecer o ponto onde acontece a falta dentro deste trecho.

Considera-se, neste trabalho, que a condição para ocorrer uma falta em qualquer ponto deste trecho está associada à probabilidade acumulada de distribuição uniforme, cujo valor é o proporcional ao próprio comprimento, conforme Figura 4-2.

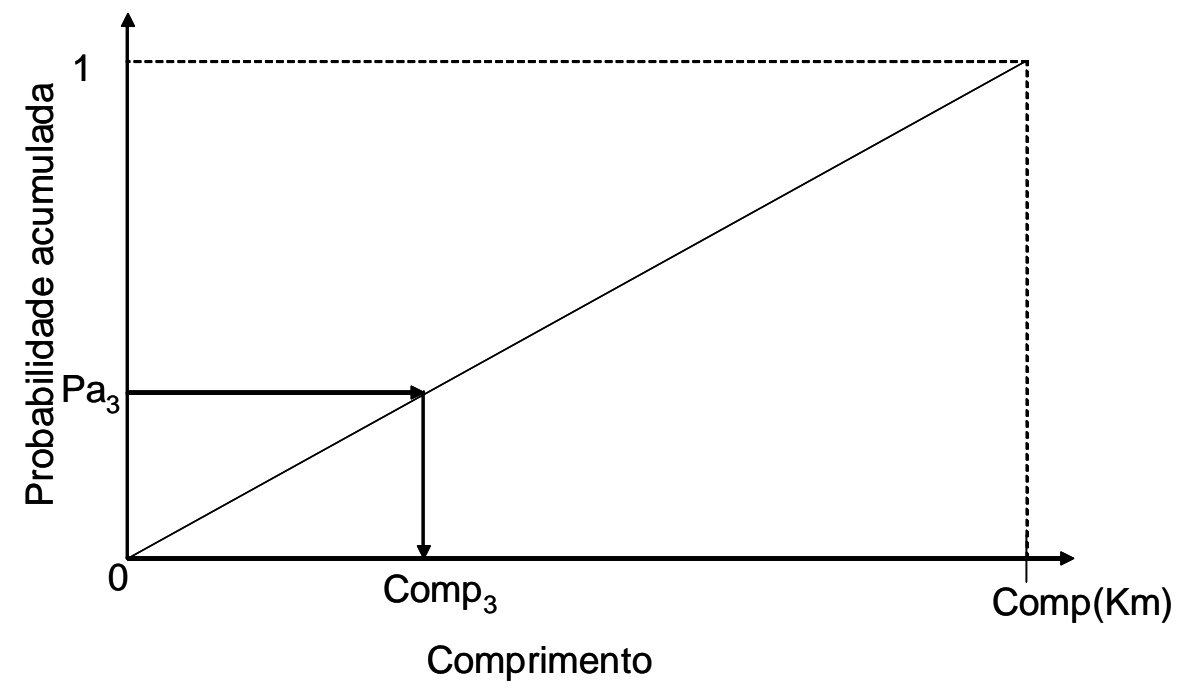

Figura 4-2 - Distribuição Acumulada vs Comprimento do trecho de falha

Obedecendo a um comprimento de valor crescente a partir de uma das barras extremas do trecho, como uma função de probabilidade contínua, calcula-se um ponto interno no trecho através da equação:

$$
\operatorname{CompFal}_{i}=\mathrm{Comp}_{i} \times \text { Rnd }
$$

Sendo:

$\mathrm{CompFal}_{\mathrm{i}}$ : Valor do comprimento da barra extrema até o ponto de falha para o $i$-ésimo trecho $(\mathrm{km})$;

Comp $_{i}$ : Valor do comprimento total do $i$-ésimo trecho $(\mathrm{km})$;

Rnd: é um número real aleatório no intervalo $[0,1]$.

\subsubsection{Escolha do Tipo de Falha}

Neste trabalho será levado em conta o cálculo dos valores das correntes de CurtoCircuito para os seguintes tipos de falta: trifásica (CC3f), dupla-fase (CCff), fase-terra (CCft), e dupla fase - terra (CCfft). A escolha de um desses tipos é aleatória, considerando a 
probabilidade de ocorrência por tipo de Curto-Circuito que é função do comportamento da rede de concessionária de distribuição em estudo.

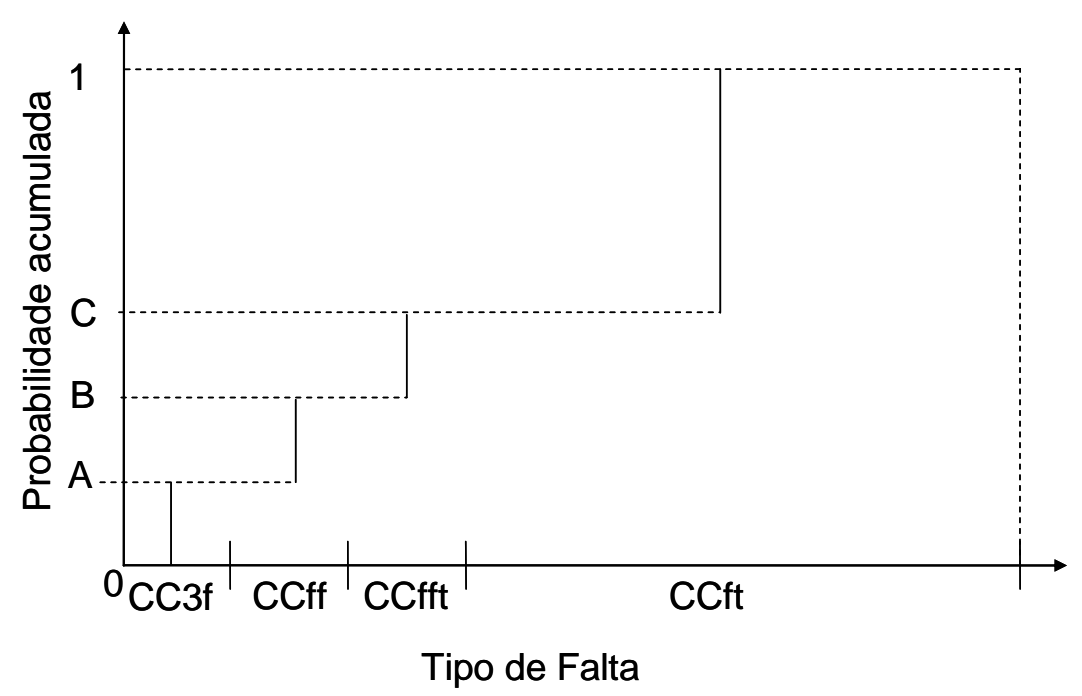

Figura 4-3 - Distribuição Acumulada vs tipo de falta

Para facilitar a escolha do tipo de Curto-Circuito, criam-se quatro faixas em uma graduação contínua de zero até $100 \%$, segundo o critério: de zero a um valor A é a proporção para o tipo de Curto-Circuito trifásico; de um valor A até B, é o intervalo para Curto-Circuito dupla fase, de um valor B até C, é o intervalo para dupla fase-terra e acima de C até $100 \%$, é Curto-Circuito fase-terra. O procedimento é baseado na geração de um número aleatório entre zero e um e, em seguida, avalia-se o tipo de Curto-Circuito associado a esse número, conforme ilustrado na Figura 4-3. Estes valores podem ser obtidos seguindo os registros de ocorrências de cada concessionária de energia.

\subsubsection{Escolha da Resistência de Falta}

A escolha da resistência de falta entre fases e a terra é efetuada segundo uma função de distribuição acumulada dentro de um intervalo pré-determinado. Para o desenvolvimento deste trabalho será considerada uma distribuição acumulada uniforme como mostra a Figura 4-4. Para aumentar a precisão durante a obtenção dos índices de VTCDs é necessário um maior conhecimento da distribuição destas variáveis, o que pode ser obtido realizando um levantamento de campo para cada concessionária de energia. 


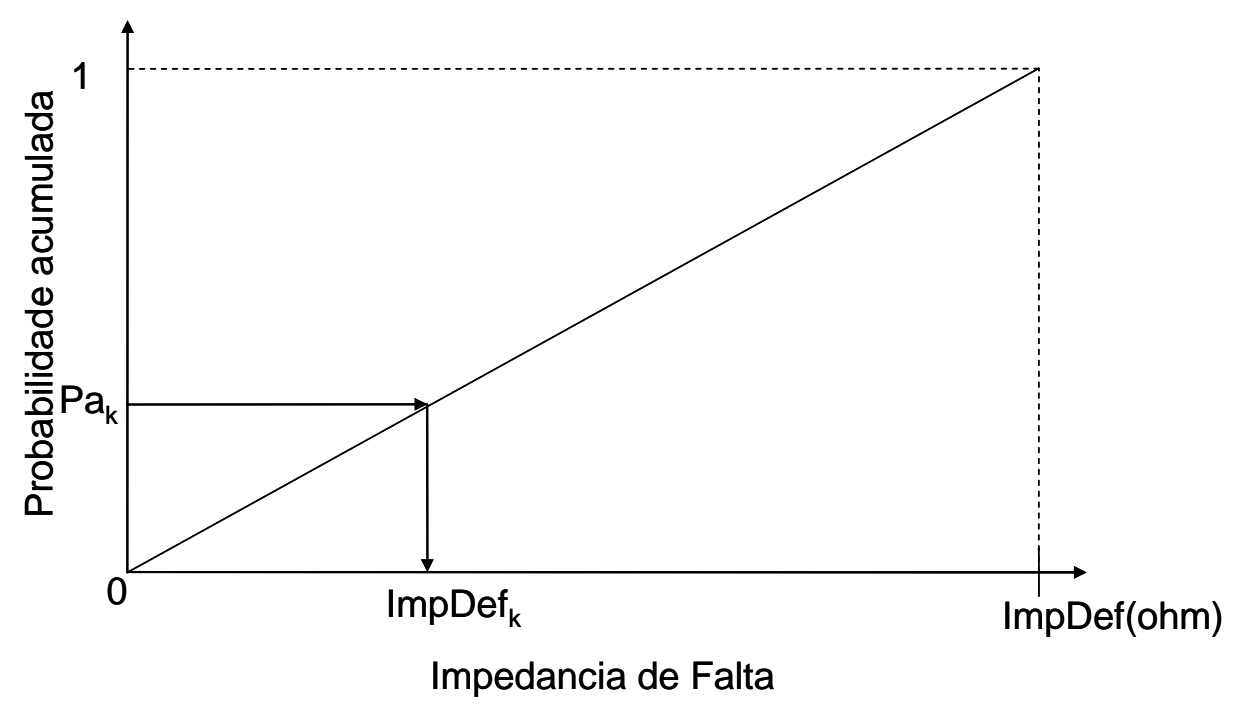

Figura 4-4 - Distribuição Acumulada vs impedância de falta

Para o cálculo da impedância de falta, conforme Figura 4-4 geram-se valores aleatórios entre zero e um, que guarda proporção com o valor máximo por tipo de falta, desta maneira é determinado o valor da provável resistência de falta, que será utilizada para o cálculo do Curto-Circuito no ponto de falta.

$$
\operatorname{ImpDef}_{k}=\operatorname{ImpMax}_{k} \times \text { Rnd }
$$

Sendo:

$K$ : tipo de falta (trifásico, fase terra, dupla fase e dupla fase terra);

$\operatorname{ImpDef}_{k}$ : Valor da impedância de falta para o tipo de falta $\mathrm{k}(\mathrm{ohm})$;

$\operatorname{ImpMax}_{k}$ : Valor da impedância máxima para o tipo de falta $\mathrm{k}(\mathrm{ohm})$;

Rnd: é um número real aleatório no intervalo $[0,1]$.

\subsubsection{Algoritmo de Monte Carlo}

Na Figura 4-5 é apresentado o algoritmo utilizado pelo método de Monte Carlo durante a obtenção de condições de curto-circuito necessárias para a avaliação das áreas de risco. 


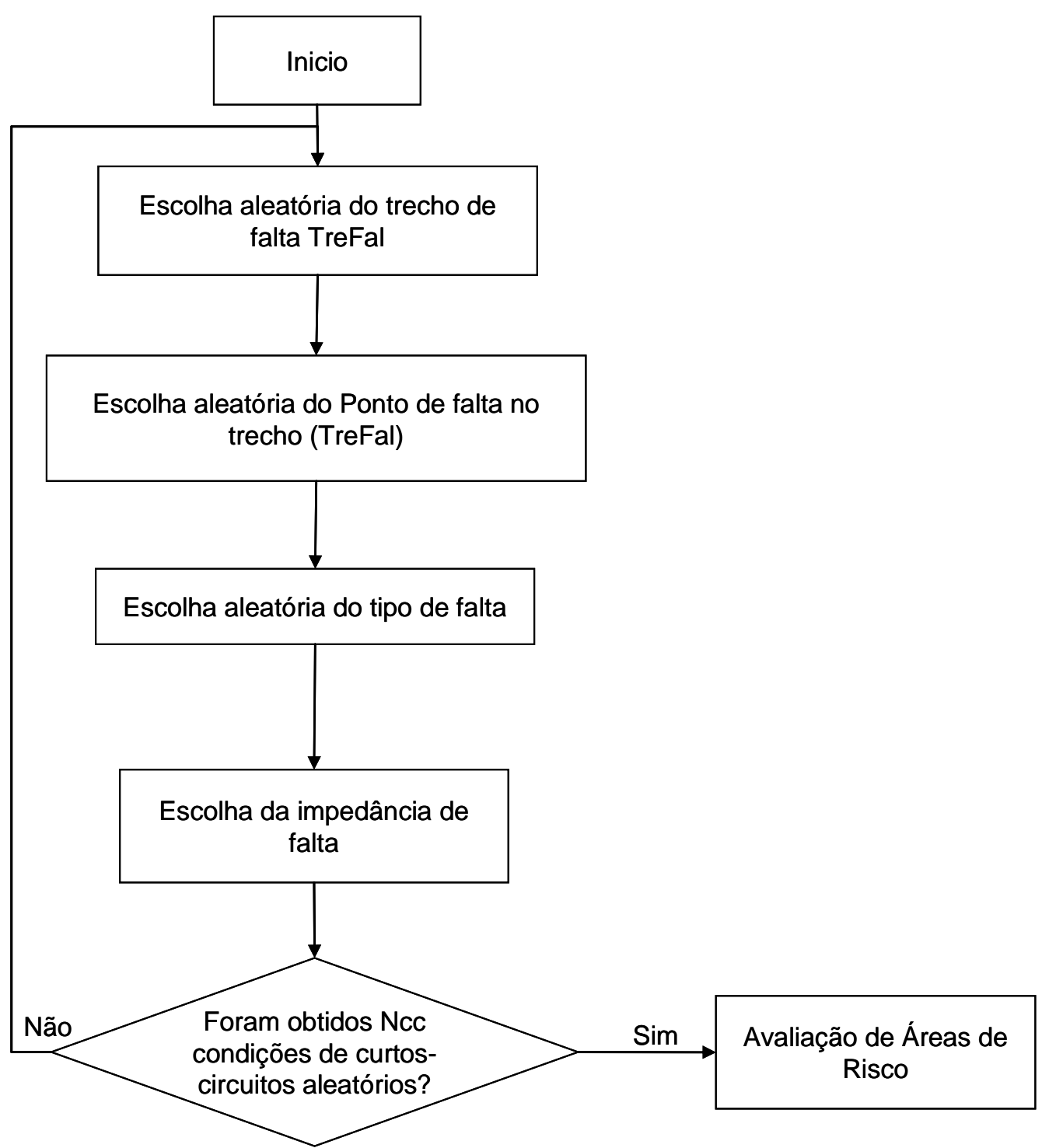

Figura 4-5 - Algoritmo utilizado no método de Monte Carlo para a obtenção de condições de curto circuito.

Como pode ser observado na Figura 4-5, o método de Monte Carlo precisa realizar uma quantidade de sorteios aleatórios para cada variável envolvida respeitando suas respectivas distribuições de probabilidade. Com isto é possível obter um conjunto de condições de curtos-circuitos e assim poder avaliar as Áreas de Risco para uma rede de distribuição elétrica.

\subsubsection{Método de Enumeração de Estados}

Uma das preocupações ao executar o método de Monte Carlo, por ser um método estatístico, concentra-se em conhecer a qualidade das variáveis estatísticas envolvidas na simulação, como também conhecer o número de simulações necessário para obter a 
estabilidade do método Monte Carlo. Apesar de este método tender-se percorrer todas as possíveis opções dentro do conjunto de variáveis envolvidas na simulação, este percurso fica diretamente relacionado com o número de simulações escolhido, dada a sua natureza aleatória, correspondendo para o caso, número de Curtos-Circuitos. Isto faz que quando escolhido um número de simulações reduzido, muitas opções de Curtos-Circuitos não sejam selecionadas, o que poderia influenciar no resultado final.

A nova metodologia, batizada de Metodologia de Enumeração de estados, é uma modelagem não aleatória, que consiste em executar todos os tipos de Curtos-Circuitos, para todos os trechos da rede, variando em faixas de comprimento, tipos de Curto-Circuito e impedâncias de defeito (e impedância entre fases no caso do curto dupla-fase a terra), sendo que cada uma destas combinações de local-tipo-impedância teria associado um peso final na contribuição do perfil da variação da tensão obtida.

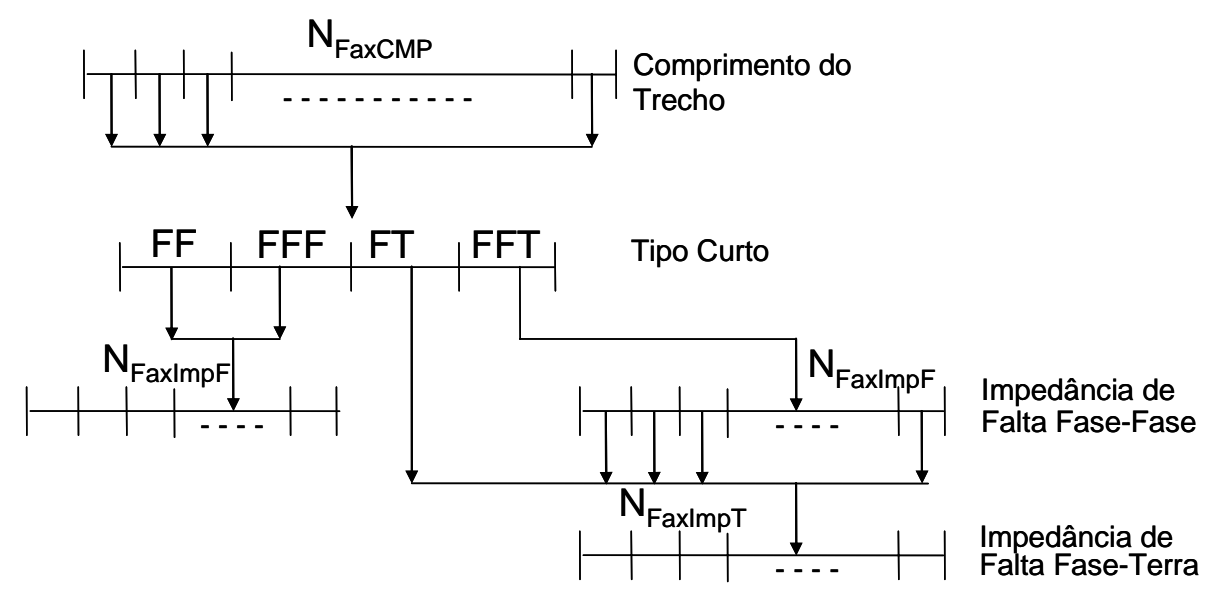

Figura 4-6 - Distribuição das faixas da cada variável envolvida no método de Enumeração de estados

Na Figura 4-6 podem ser observadas, de forma gráfica, as possíveis combinações das faixas para cada variável envolvida na simulação do método de Enumeração de estados. Cada combinação da origem a uma condição de Curto-Circuito que envolve posição de curto, tipo de curto, e impedância da falha (fase-fase, fase-terra). Cada faixa de cada variável possui um peso, assim o valor do peso total de cada combinação seria a multiplicação de todos estes pesos.

\subsubsection{Peso devido ao comprimento do trecho}

Para realizar o cálculo do peso devido ao comprimento $\left(P_{1 i}\right)$ para cada trecho $i$ existente na rede, é necessário considerar não somente o valor do seu comprimento, mas 
também a sua respectiva taxa de falha. Por se tratar de uma rede radial, ordenou-se a rede armazenando em cada trecho a sua barra inicial e a barra final. Entende-se como barra inicial aquela barra do trecho que fica mais perto da subestação e barra final aquela barra mais afastada da subestação. O valor de $P_{1 i}$ será obtido seguindo o equacionamento:

$$
\begin{gathered}
F l h_{i}=\operatorname{comp}_{i} \times \lambda_{i} \\
F l h_{\text {totais }}=\sum_{i=1}^{N_{t}} F l h_{i} \\
P_{1 i}=\frac{F l h_{i}}{F l h_{\text {totais }}}
\end{gathered}
$$

Em que:

$i$ : índice do trecho

$N t$ : Número total de trechos;

$F l h_{i}$ : Número de falhas do $i$-ésimo trecho;

$F l h_{\text {totais }}$ : Número de falhas para toda a rede;

comp $_{i}$ : Comprimento $(\mathrm{km})$ do $i$-ésimo trecho;

$\lambda_{i}$ : Taxa de falha (falhas $/ \mathrm{km}$-ano) do $i$-ésimo trecho;

$P_{1 i}$ : Peso devido ao comprimento para o $i$-ésimo trecho;

\subsubsection{Peso devido ao Tipo de falta}

Para realizar o cálculo de peso devido aos tipos de falta $\left(P_{2 F}\right)$, foi realizada a divisão em quatro tipos de defeitos: trifásico, dupla-fase, fase-terra, e dupla fase terra. Suas probabilidades de ocorrência consideram o número de ocorrências percentual por tipo de Curto-Circuito, representando o comportamento da rede de cada concessionária de distribuição.

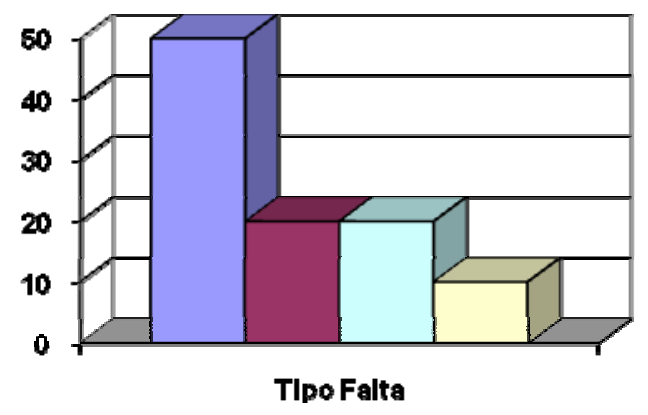

口Fase Terra(b0\%)

QFase Fase(20\%)

口Dupla Fase Terra(20\%)

口Trifasica(10\%)

Figura 4-7 - Exemplo do peso devido ao tipo de curto 
Na Figura 4-7 é observado um exemplo da freqüência de ocorrências de tipos de Curto-Circuito em uma rede elétrica qualquer. Neste exemplo, $P_{2}$ assumirá os seguintes valores: Para Fase Terra $P_{2 F}=1 / 2(50 \%)$, para Fase Fase $P_{2 F}=1 / 5(20 \%)$, para Dupla Fase Terra $P_{2 F}=1 / 5(20 \%)$ e para Trifásico $P_{2 F}=1 / 10(10 \%)$.

\subsubsection{Peso devido à Resistência de falta}

Para a obtenção do peso devido à resistência de Falta $\mathrm{R}\left(P_{3 R}\right)$ foram considerados os dois tipos de impedâncias de defeito: entre fase e terra e entre fases. No cálculo deste peso, o intervalo considerado vai desde zero a um valor de impedância máxima, desta forma foi realizado uma divisão em $N_{\text {FaxImpF }}$ faixas para as impedâncias de falta entre fases e em $N_{\text {FaxImpT }}$ faixas para as impedâncias de falta entre fase e terra. O peso pode ser obtido seguindo os equacionamentos:

i) Para as falhas do tipo trifásica e fase-fase:

$$
P_{3 R}=P_{3 R F}=\frac{1}{\left(N_{\text {FaxImpF }}+1\right)}
$$

Em que:

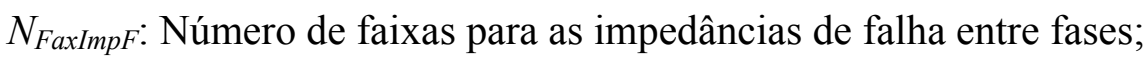

ii) Para as falhas do tipo fase terra:

$$
P_{3 R}=P_{3 R T}=\frac{1}{\left(N_{\text {FaxImp } T}+1\right)}
$$

Em que:

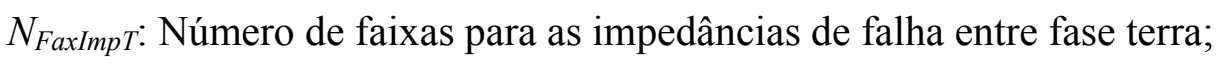

iii) Para as falhas do tipo dupla fase terra:

$$
P_{3}=P_{3 R F} \times P_{3 R T}
$$

\subsubsection{Peso total para uma condição de Curto-Circuito}

Sendo já calculado o valor do peso que representa cada variável, a obtenção do peso total para cada condição de curto é obtida desta forma:

$$
P_{T k}=P_{1 i} \times P_{2 F} \times P_{3 R}
$$


$i=1, \ldots, n$ trechos;

$\mathrm{F} \in\{\mathrm{FF}, \mathrm{FT}, \mathrm{FFT}, \mathrm{FFF}\}$

Em que:

$F F, F T, F F T, F F F$ : Tipo de falta: fase-fase, fase-terra, dupla fase-terra e trifásico, respectivamente;

$P_{1 i}$ : Peso devido ao comprimento do trecho i;

$P_{2}$ : Peso devido ao tipo de falta;

$P_{3}$ : Peso devido à impedância da falta;

$P_{T K}$ : Peso total para a condição de curto k;

Efetua-se o cálculo de todas as combinações possíveis, considerando-se seus respectivos pesos (e não o número de ocorrências, como no método de Monte Carlo), e multiplica-se cada resultado obtido por seu respectivo peso, para realizar a sua integração sucessiva. Desta forma é possível obter um perfil representativo da rede para cada índice de VTCD analisado.

\subsubsection{Algoritmo do Método de Enumeração de estados}

Na Figura 4-8 é apresentada o algoritmo utilizado pelo método de Enumeração de estados durante a obtenção de condições de curto circuito necessárias para a avaliação das áreas de risco.

Este método divide em faixas definidas cada uma das suas variáveis (ponto de falta, impedância de falta fase-fase e impedância de falta fase-terra), obtendo combinações de localtipo-impendancia como seus respectivos pesos. Estas combinações serão armazenadas para serem utilizadas durante a análise de Áreas de Risco. 


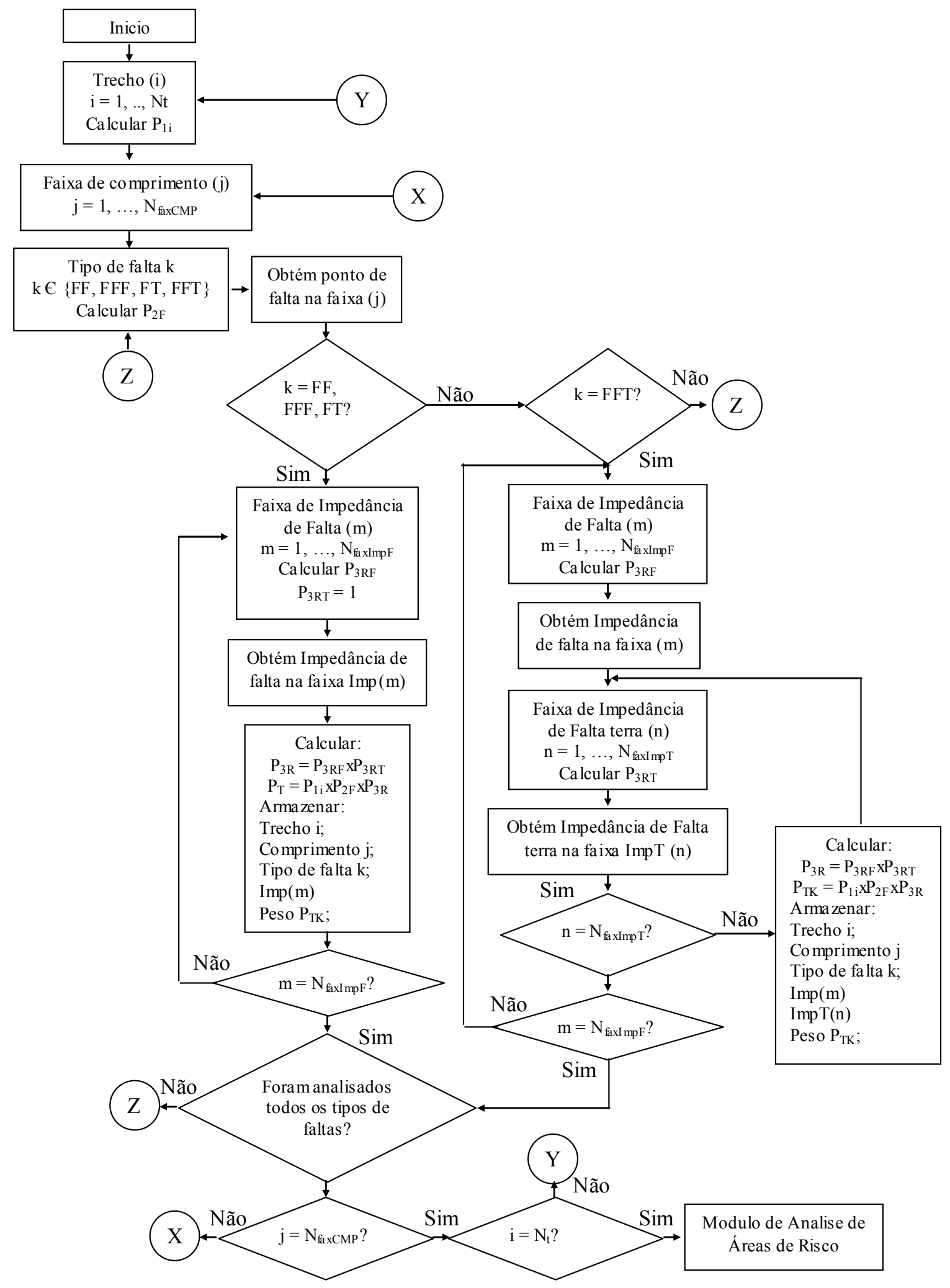

Figura 4-8 - Algoritmo utilizado no método de Enumeração de estados para a obtenção de condições de curto circuito. 


\subsubsection{Método Híbrido}

Como foi observado nos itens anteriores, o método de Monte Carlo utiliza um critério estatístico que abrange todas as variáveis envolvidas considerando suas respectivas distribuições de probabilidade. Por outro lado, o método de Enumeração de estados tenta realizar todas as possíveis combinações, dividindo cada variável em faixas definidas, sendo que, cada uma das combinações obtidas possui um peso ou probabilidade de ocorrências definida.

A vantagem de se utilizar o método de Monte Carlo consiste em que, definindo um número de combinações iniciais (número de Curtos-Circuitos), é possível obter um conjunto de combinações de forma rápida que mantenha as condições de distribuição de probabilidade de cada variável envolvida. A principal desvantagem deste método consiste na sua dependência do número de combinações iniciais, já que precisa de um grande número para que se obtenha a sua estabilidade. Quando o número de combinações é pequeno, a qualidade das amostras é deficiente, já que possíveis combinações não estão sendo consideradas.

Quando é utilizado o Método de Enumeração de estados o número de combinações é definido pelo número de faixas de cada variável envolvida. Neste método, é necessário definir, para cada variável, seu respectivo número de faixas. A principal vantagem deste método consiste na possibilita de obtenção de um conjunto de combinações muito mais definida. A principal desvantagem deste método parte na dependência do número de faixas para cada variável, ou seja, quanto maior a número de faixas, maior o número de combinações, o que poderia acarretar um valor muito alto, com reflexo direto no tempo de processamento. Por outro lado, um número pequeno de faixas pode não representar convenientemente o problema.

De forma a absorver as vantagens do Método de Monte Carlo e do Método de Enumeração de estados, foi concebido um terceiro método, intitulado de "Método Híbrido". Este método utiliza os dois critérios dos métodos anteriores para a obtenção das combinações de variáveis, ou seja, para algumas variáveis serão realizadas as escolhas aleatórias, como no método Monte Carlo e para outras variáveis será definido um número de faixas com enumeração como o método de Enumeração de estados. Desta maneira junta-se a rápida obtenção do conjunto de combinações realizada pelo método de Monte Carlo com a vantagem da observabilidade definida usada no método de Enumeração de estados. 
O conceito do método Híbrido baseia-se em, sendo fixado inicialmente um número preestabelecido de condições de curtos circuitos, distribuir este número de forma uniforme para todas as variáveis envolvidas respeitando suas respectivas distribuições de probabilidade.

Neste método, será estabelecida uma série de critérios de procedimentos para obtenção dos índices de área de risco com um esforço e tempo computacional aceitáveis. Estes critérios serão apresentados nos próximos itens.

\subsubsection{Redução de Rede}

A Redução de rede é um procedimento para agrupamento de vários conjuntos de trechos em um só representativo. Desta forma, diminui-se o número de barras e trechos do sistema, sem comprometer o resultado final na obtenção dos índices de VTCDs e análise de áreas de risco.

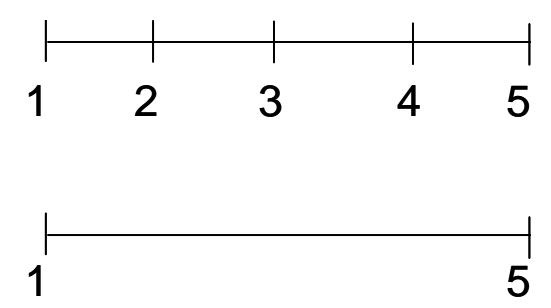

Figura 4-9 - Critério de Redução de Rede

O critério utilizado para a redução de rede pode ser observado no exemplo da Figura 4-9 em que um conjunto de trechos: 1-2, 2-3, 3-4, 4-5, é reduzido a um único trecho 1-5. Os valores do comprimento, impedância e taxa de falha equivalente são obtidos seguindo as fórmulas:

$$
\begin{gathered}
\operatorname{Comp}_{1-5}=\operatorname{Comp}_{1-2}+\operatorname{Comp}_{2-3}+\operatorname{Comp}_{3-4}+\operatorname{Comp}_{4-5} \\
\operatorname{Imp}_{1-5}=\operatorname{Imp}_{1-2}+\operatorname{Imp}_{2-3}+\operatorname{Imp}_{3-4}+\operatorname{Imp}_{4-5} \\
\mathrm{Tx}_{1-5}=\frac{\left(\mathrm{Tx}_{1-2} \times \operatorname{Comp}_{1-2}+\mathrm{Tx}_{2-3} \times \operatorname{Comp}_{2-3}+\mathrm{Tx}_{3-4} \times \operatorname{Comp}_{3-4}+\mathrm{Tx}_{4-5} \times \operatorname{Comp}_{4-5}\right)}{\operatorname{Comp}_{1-5}}
\end{gathered}
$$

Em que:

$\operatorname{Comp}_{1-5}$ : Comprimento do trecho equivalente entre as barras 1-5;

Comp $_{1-2}$, Comp 2-3, Comp $3-4$, Comp $_{4-5}$ : Comprimento dos trechos entre as barras 1-2, 2-3, 3-4 e 4-5 respectivamente;

$\operatorname{Imp}_{1-5}$ : Impedância do trecho equivalente entre as barras 1-5;

$\operatorname{Imp}_{1-2}, \operatorname{Imp}_{2-3}, \operatorname{Im}_{p 3-4}, \operatorname{Imp}_{4-5}$ : Impedância dos trechos entre as barras 1-2, 2-3, 3-4 e 4-5 respectivamente; 
$T x_{1-5}$ : Taxa de falha equivalente entre a barra 1-5;

$T x_{1-2}, T x_{2-3}, T x_{3-4}, T x_{4-5}$ : Impedância dos trechos entre as barras 1-2, 2-3. 3-4, 4-5 respectivamente;

A redução da rede também respeita algumas considerações:

i) Os transformadores e suas respectivas barras são mantidos;

ii) As barras de derivação são mantidas;

iii) As barras de suprimento e barras de carga são mantidas;

iv) As barras com dois trechos incidentes com bitolas diferentes são mantidas;

Para todos os outros casos, as barras que contém trechos comuns são agrupadas.

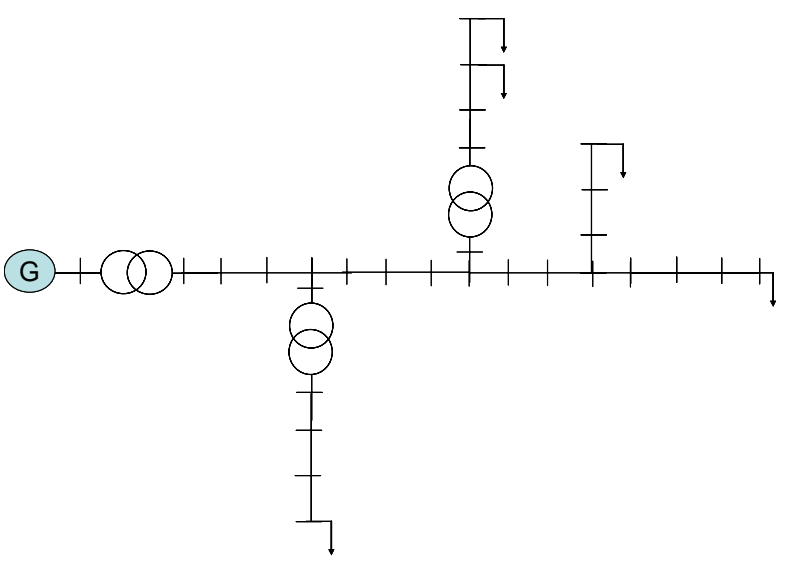

(a)

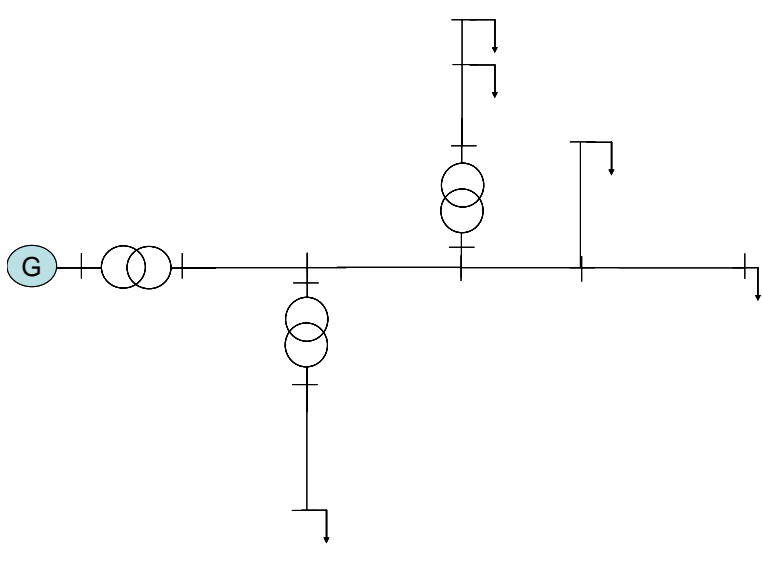

(b)

Figura 4-10 - Exemplo de redução de rede: (a) rede completa, (b) rede reduzida.

Na Figura 4-10 pode ser observada graficamente como é realizada a redução de rede. A rede da Figura 4-10 (a), possui na sua estrutura: 29 barras, 3 transformadores, 25 linhas e 5 cargas. Depois de realizada a redução, a nova estrutura possui: 14 barras, 3 transformadores, 10 trechos e 5 cargas. Com isto, o número de trechos e barras é reduzido significativamente o que se reflete na diminuição dos tempos computacionais.

\subsubsection{Agrupamento em função do comprimento}

Depois de ser feita a redução de rede, é aplicando um procedimento de agrupamento relacionado aos comprimentos dos trechos da nova rede reduzida. Este critério agrupa todos os trechos reduzidos com os mesmos comprimentos dentro de uma tolerância dada. Cada grupo será adicionando a uma lista chamada de (LGrupos). 


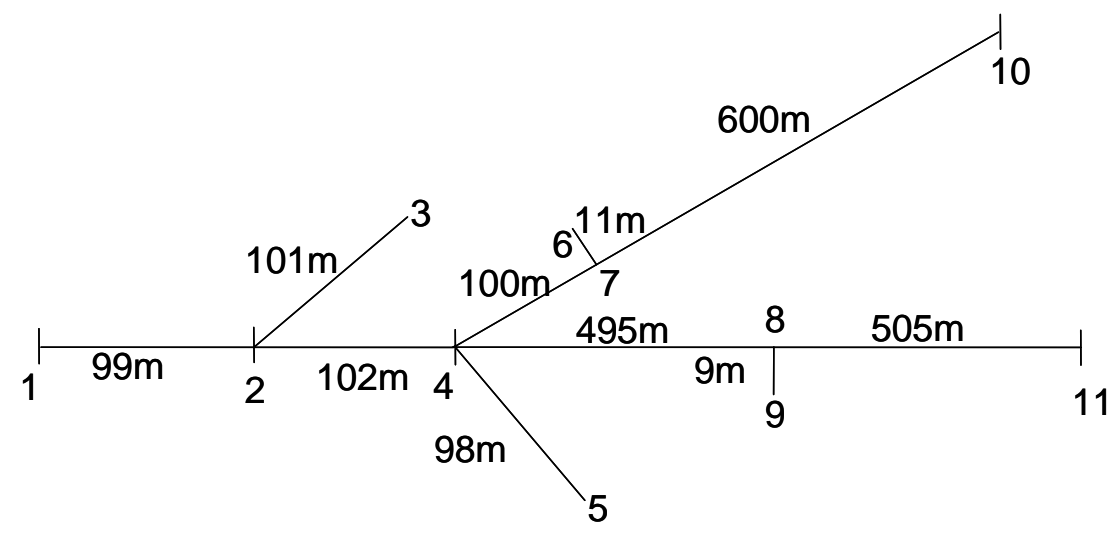

Figura 4-11 - Exemplo de uma rede com seus respectivos comprimentos

Da rede apresentada na Figura 4-11 o agrupamento é realizado em função dos trechos com comprimento igual dentro de uma tolerância de $5 \mathrm{~m}$. A seguir, são apresentados os trechos agrupados:

Grupo 1 = Tre1-2, Tre2-3, Tre2-4, Tre4-7, Tre4-5, (Trechos de aproximadamente 100 metros);

Grupo 2 = Tre4-8, Tre8-11, (Trechos de aproximadamente 500 metros);

Grupo 3 = Tre 7-10 (Trecho de 600 metros);

Grupo 4 = Tre6-7, Tre8-9 (Trechos de aproximadamente 10 metros).

Para este exemplo LGrupos estará constituído por (Grupo 1, Grupo2, Grupo 3, Grupo 4).

\subsubsection{Grupos mais predominantes e menos predominantes}

Como foi observado no Item 4.1.3.2, o agrupamento é realizado em função dos comprimentos com o mesmo valor dentro de uma tolerância. Existem casos em que o comprimento do grupo é um valor muito baixo em comparação com o comprimento total da rede. O impacto destes grupos será muito baixo em comparação com grupos de maior valor. Com o intuito de diminuir o esforço computacional, os grupos pertencentes à lista (LGrupos) serão realocados em duas listas diferentes chamadas LGrupos $_{\text {Predom }}$ e LGrupos NaoPredom $_{\text {L }}$ relativos aos grupos predominantes e menos predominantes respectivamente. $\mathrm{O}$ critério para realizar a realocação será explicado a seguir.

O valor do comprimento de cada grupo é obtido da seguinte forma:

$$
\operatorname{Comp}_{\operatorname{Grupo(i)}}=\sum_{i=1}^{N_{\text {Grupo }(i)}} \operatorname{Comp}_{(i)}
$$


Em que:

Comp $_{\text {Grupo(i) }}$ : Valor do comprimento total do grupo i;

$\operatorname{Comp}_{(i)}$ : Comprimento médio do grupo i;

$N_{\text {Grupo(i) }}$ : Número de elementos do grupo i;

Para o exemplo da Figura 4-11:

Comp $_{\text {Grupo } 1}=99+101+102+98+100=500$;

Comp $_{\text {Grupo } 2}=495+505=1000$;

Comp $_{\text {Grupo3 }}=600$

Comp $_{\text {Grupo } 4}=9+11=20$

Logo depois de realizado o cálculo dos valores de comprimento de cada grupo, é realizada uma ordenação em forma crescente, em função do valor total dos comprimentos de cada grupo. Do exemplo da Figura 4-11.

Comp $_{\text {Grupo } 4}=20$;

Comp $_{\text {Grupo1 }}=500$

Comp $_{\text {Grupo3 }}=600$

Comp $_{\text {Grupo2 }}=1000$

Para a realização desta nova seleção seguindo o critério de predominância no valor do comprimento dos grupos, é utilizado um critério que analisa a relação do valor de cada grupo com o valor do comprimento total da rede seguindo o equacionamento:

$$
\begin{gathered}
\text { Comp }_{\text {GrupoMinimo }}=P_{\min } \% \times \operatorname{Comp}_{\text {GrupoTotal }} \\
\text { Comp }_{\text {GrupoTotal }}=\sum_{i=1}^{n} \operatorname{Comp}_{\text {Grupo }(i)}
\end{gathered}
$$

Em que:

Comp $_{\text {GrupoMinimo: }}$ Comprimento mínimo para o qual o grupo seja considerado predominante; $n$ : Número total de grupos;

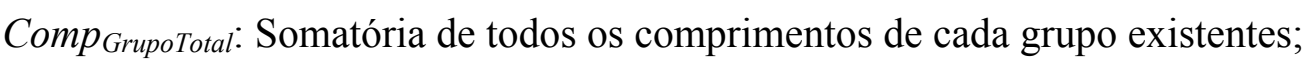

$P_{\min } \%$ : Porcentagem mínima da somatória total dos comprimentos dos grupos existentes.

Aqueles grupos pertencentes à lista LGrupos cujo comprimento seja menor que Comp $_{\text {GrupoMinimo }}$ serão realocados para a lista LGrupos $_{\text {NaoPredom, }}$ e aqueles com comprimento

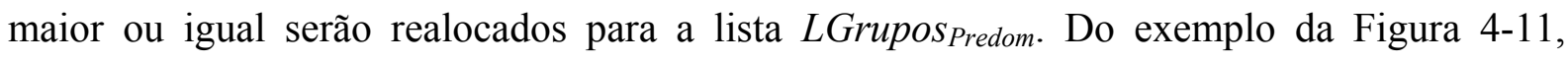
considerando $P_{\min } \%=1 \%$.

Comp $_{\text {GrupoTotal }}=20+500+600+1000=2120$; 
Comp $_{\text {GrupoMinimo }}=1 \% \mathrm{x} 2120=21,20$;

Então, o valor do comprimento mínimo é 21.20, o que faz com que o grupo 4 (trechos

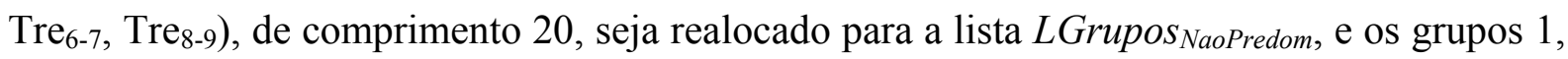
2 e 3 sejam realocados para a lista LGrupos $_{\text {Predom. }}$.

\subsubsection{Obtenção do conjunto de condições de Curtos-Circuitos}

Após conhecer as listas de grupos LGrupos $_{\text {Predom }}$ e LGrupos $_{\text {NaoPredom }}$ é necessário distribuir o número total de simulações (Curtos-Circuitos) para cada elemento pertencente a cada grupo. Para tal distribuição, a seguir são utilizados critérios diferentes em função da sua predominância.

\subsection{Grupos Mais Predominantes}

Sendo já conhecido a lista de grupos de trechos reduzidos LGrupos Predom $_{\text {que entrarão }}$ na análise da seleção de condições de Curto-Circuito, após realizado o agrupamento considerando a predominância dos grupos, o passo seguinte será escolher a melhor distribuição do número total de Curtos-Circuitos, mantendo os critérios de distribuição de probabilidade.

\section{a) Número de Curtos-Circuitos para cada Grupo;}

Sendo conhecido o número de Curtos-Circuitos que se deseja simular, a distribuição destes defeitos para cada grupo pertencente à lista LGrupos $_{\text {Predom }}$ fica dependente da relação do valor do comprimento de cada grupo em relação ao valor do comprimento total dos grupos existentes na lista LGrupos.

$$
N_{\text {Curtos-Grupo(i) }}=N_{\text {Total-Curtos }} \times \frac{\operatorname{Comp}_{\text {Grupo }(i)}}{\operatorname{Comp} p_{\text {GrupoTotal }}}
$$

Em que:

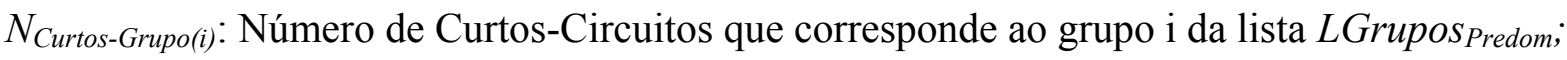

$N_{\text {Total-Curtos: }}$ Número total de Curtos-Circuitos a distribuir em cada grupo existente na lista LGrupos Predom;

$\operatorname{Comp}_{\text {Grupo(i) }}$ : Valor do comprimento do grupo i;

Comp $_{\text {GrupoTotal }}$ : Valor dos comprimentos de todos os grupos pertencentes à lista LGrupos. 


\section{b) Número de Curtos-Circuitos por tipo de falta;}

Sendo conhecido o número de Curtos-Circuitos para cada grupo $\left(N_{\text {Curtos-Grupo }}\right)$, o passo seguinte é distribuir estes número em função do tipo de falta. Neste caso, é considerada a distribuição de probabilidade para cada falta.

$$
N_{\text {Curtos-TipoFalta(f)(i) }}=N_{\text {Curtos-Grupo(i) }} \times \operatorname{Prob}_{(f)}
$$

Em que:

$f:$ Índice que indica o tipo de falha (trifásica, fase terra, dupla fase terra, fase fase);

$N_{\text {Curtos-TipoFalta(f)(i) }}$ : Número de Curtos-Circuitos para o tipo de falta $f$ correspondente ao grupo i; $\operatorname{Prob}_{(j)}$ : Distribuição de probabilidade para o tipo de falta $f$.

\section{c) Obtenção da impedância de falta;}

Sendo conhecido o valor do número de Curtos-Circuitos para cada grupo por tipo de falta ( $N_{\text {Curtos-TipoFalta }}$, o passo seguinte é obter o valor da impedância da falta. Para tal, é utilizado o critério utilizado no Método de Enumeração de estados, explicado no Item 4.1.2. Este critério realiza o fracionamento desta variável em faixas definidas desde zero até um valor máximo condicionado ao tipo de falta.

$$
\operatorname{Imp} F_{\text {TipoFalta }(f)}=\frac{(k-1)}{N_{\text {Curtos-TipoFalta }(f)(i)}} \times \operatorname{Imp} F_{\operatorname{Max}(f)}
$$

Em que:

$i$ : Índice do grupo;

$f$ : Índice do tipo $f$ de falta;

k: Índice da faixa k $\in\left[1, N_{\text {Curtos-TipoFalta(f)(i) }}+1\right]$

$\operatorname{Imp} F_{\operatorname{Max}(f j)}$ : Valor da impedância de falha máxima para o tipo de falta $f(\Omega)$;

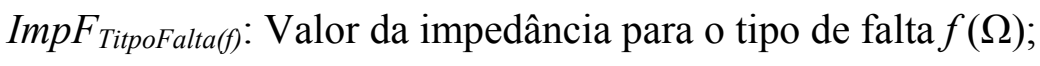

Para o caso das faltas duplas fases terra, em que existem as impedâncias de defeito entre fases e entre fase a terra, o valor da impedância de falta entre fases seguirá o mesmo critério explicado anteriormente. Para as impedâncias de falta entre fase e terra, o valor será obtido aleatoriamente entre o zero e o valor máximo. 


\section{d) Obtenção da Posição do Ponto de Falta;}

Para obtenção do ponto de falta é necessário escolher o trecho reduzido onde acontecerá a falta dentro do grupo (predominante ou menos predominante) que esta sendo analisado. Esta escolha é feita de forma aleatória. Já que os trechos reduzidos contêm, dentro deles, conjuntos de trechos originais, a escolha do trecho original também é realizada aleatoriamente. Logo após conhecido o trecho original a escolha do ponto de falta dentro deste trecho, será também de forma aleatória, mantendo os mesmos critérios de aleatoriedade utilizados no método de Monte Carlo, explicado no item 4.1.1.

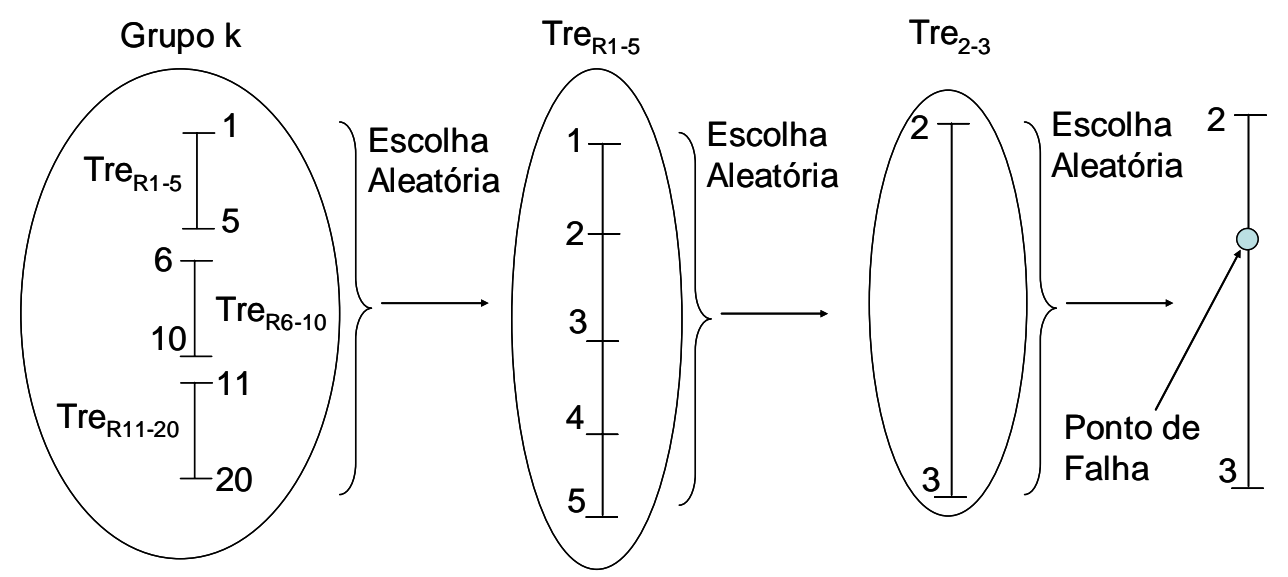

Figura 4-12 - Obtenção do ponto de falta utilizando o método Híbrido

Na Figura 4-12 pode ser observado que para um Grupo de trechos reduzido $\mathrm{k}$ foi escolhido aleatoriamente o trecho reduzido $\operatorname{Tr}_{R 1-5}$. Na rede original foi escolhido aleatoriamente o trecho original $\operatorname{Tre}_{2-3}$. A escolha do ponto de falha será realizada também de forma aleatória dentro do trecho $\operatorname{Tre}_{2-3}$.

Desta maneira, conhecidos os parâmetros para cada falta como: Tipo, faixa de impedância e posição, é possível executar um módulo de cálculo de Curto-Circuito e avaliar o efeito deste defeito em toda a rede, possibilitando a obtenção dos índices de VTCDs e a análise de áreas de risco.

\subsection{Grupos Menos Predominantes}

Foi observado no item 4.1.3.3 o agrupamento em função da predominância de cada grupo, os grupos chamados menos predominantes agrupados em LGrupos $_{\text {NaoPredom }}$ possuem um valor de comprimento muito baixo em relação ao comprimento total da rede, dado que o impacto destes grupos na obtenção de índices de VTCDs é relativamente baixo. Mesmo assim, estes grupos não podem ser excluídos na distribuição de condições de Curto-Circuito, 
dado que a somatória dos comprimentos de todos estes grupos menos predominantes muitas vezes representa um valor significativo.

Para realizar a distribuição no número de condições de Curto-Circuito nos grupos pertencentes à lista LGrupos $_{\text {NaoPredom }}$ poderá ser utilizado algum critério anteriormente apresentado no item 4.1.3.4., mas com algumas variações.

i) Número de Curtos-Circuitos Para cada grupo menos predominante: o critério será o mesmo apresentando no item 4.1.3.4, em que será obtido, para cada grupo menos predominante, seu respectivo número de condições de Curto-Circuito;

ii) Número de Curtos-Circuitos por tipo de falta, o critério será o mesmo apresentado no item 4.1.3.4 (b), Neste caso também é considerada a distribuição de probabilidade para cada tipo de falta.

iii)Obtenção da impedância de falta e posição do Ponto de Falta, a impedância de falta, assim como o ponto de falta serão obtidas de forma aleatória, no caso da impedância de falta a variação será desde zero até um valor máximo que depende do tipo de falta. Para o ponto de falta será utilizado o critério apresentado no item 4.1.3.4.1 (d) dentro dos trechos existentes na lista LGrupos $_{\text {NaoPredom. }}$ O número de sorteios será o mesmo obtido no passo ii.

\subsubsection{Algoritmo do Método Híbrido}

Na Figura 4-13, Figura 4-14, Figura 4-15 são apresentados os algoritmos utilizados pelo método Híbrido durante a obtenção de condições de curto circuito necessárias para a avaliação das áreas de risco.

Este método distribui um número de curtos-circuitos para uma das variáveis envolvidas, respeitando suas distribuição de probabilidade respectiva. Na Figura 4-14, é apresentado o critério utilizado para realizar a distribuição dentro dos grupos chamados Mais Predominantes, já na Figura 4-15 será apresentado o critério utilizado para os grupos menos predominantes. Durante a distribuição de curtos-circuitos, será armazenada cada combinação de local-tipo-impedância obtidos pelo método Híbrido para realizar a análise de Áreas de Risco. 


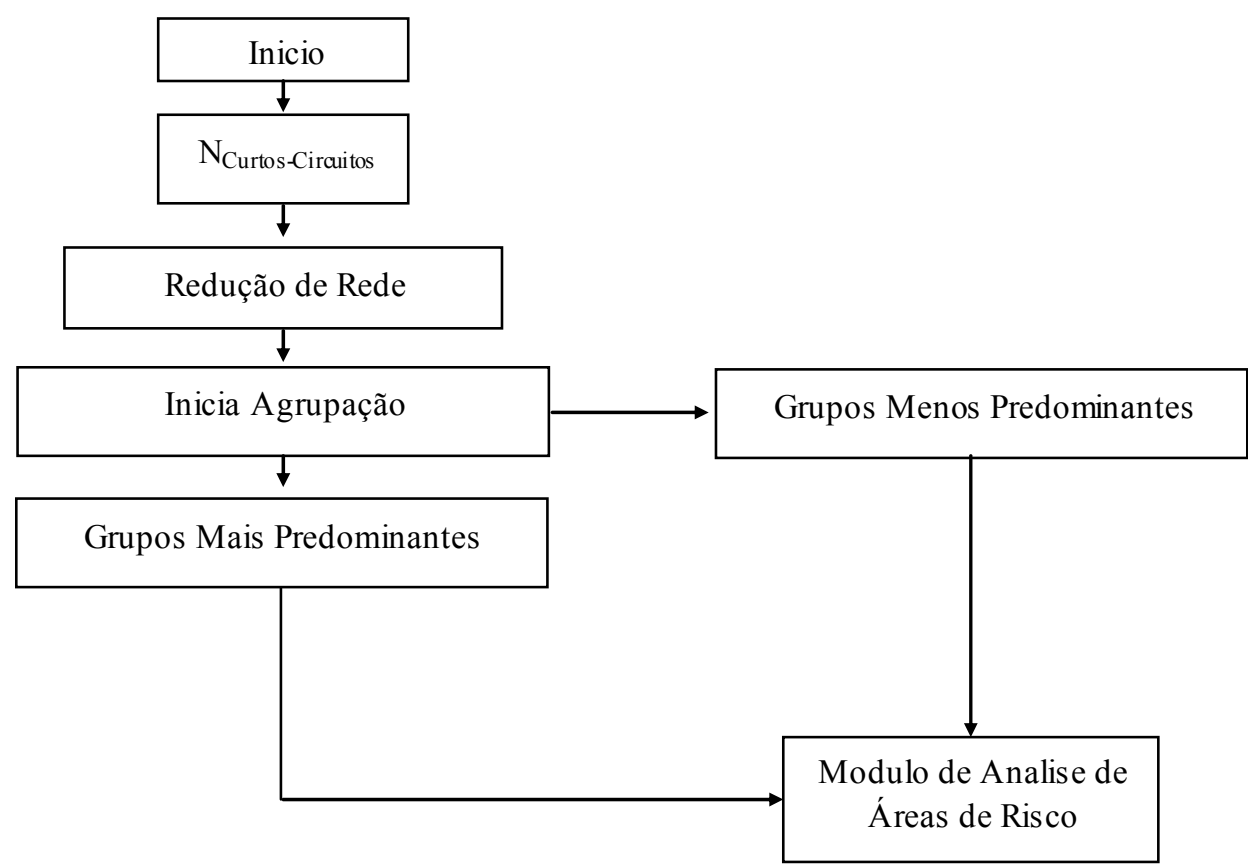

Figura 4-13 - Algoritmo utilizado no método Híbrido para a obtenção de condições de curto circuito 


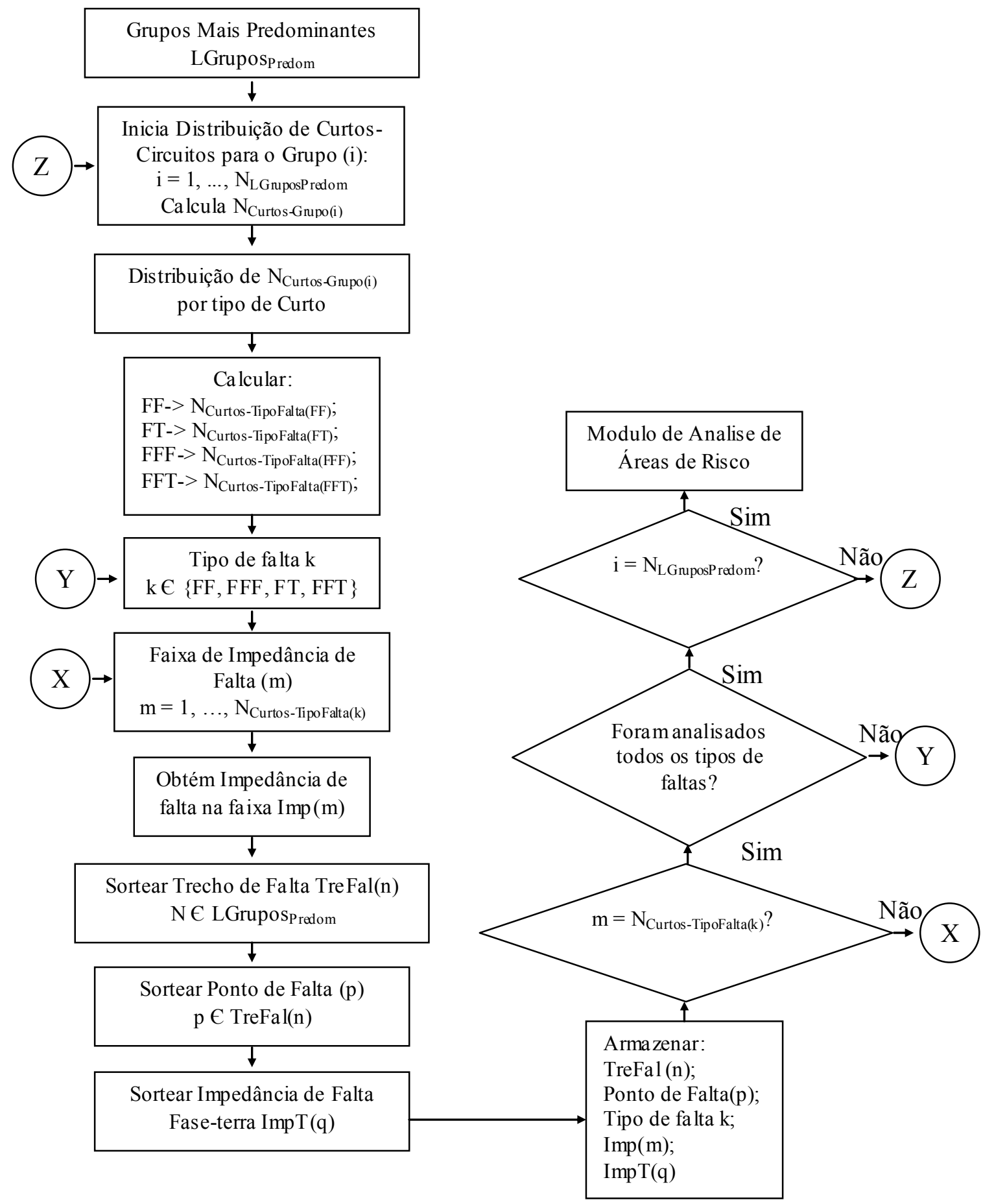

Figura 4-14 - Algoritmo do Método Híbrido - Grupos Mais Predominantes 


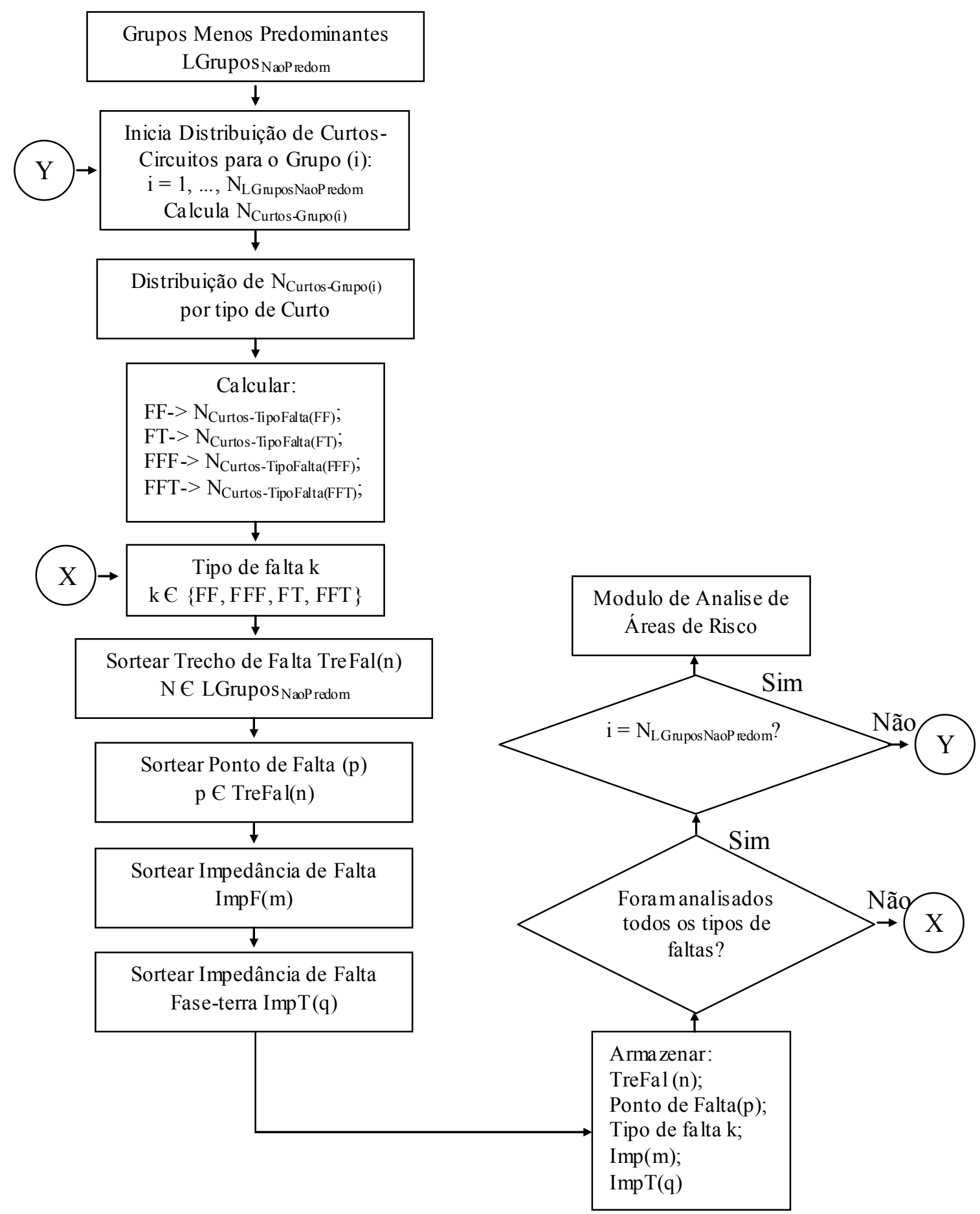

Figura 4-15 - Algoritmo do Método Híbrido - Grupos Menos Predominantes

\subsection{Determinação do Número de Condições de Curtos-Circuitos para cada Método}

O Número de simulações necessário durante o estudo de áreas de risco está diretamente relacionado ao número de Curtos-Circuitos que serão analisados ao longo da rede de distribuição. 
No item 4.1 foram apresentadas 3 metodologias para a obtenção do conjunto de combinações de Curtos-Circuitos. Cada uma delas utiliza um critério para a obtenção do número de simulações necessário. Já que este valor se reflete na qualidade dos resultados obtidos para cada método, a seguir serão apresentados os critérios e formulações necessárias para a obtenção deste valor.

\subsubsection{Método de Monte Carlo}

O método de Monte Carlo utiliza um critério que se baseia em escolher um número muito grande de simulações, já que é um método estatístico em que as variáveis são escolhidas aleatoriamente. Neste método várias iterações devem ser realizadas. Em cada iteração os índices desejados são recalculados até que o método consiga a sua estabilidade, chamada também de estabilidade de Monte Carlo.

\subsubsection{Método de Enumeração de estados}

O método de Enumeração de estados, em comparação com o método de Monte Carlo não utiliza critérios aleatórios, e sim determinísticos. Por tanto é possível obter uma equação para o número de simulações de Curto-Circuito que o método irá utilizar. O número de faltas a serem analisadas em um trecho da rede será:

$N_{F l h(i)}=N_{F x \operatorname{Comp}(i)} \times\left(N_{F x \operatorname{lmpFFF(i)}}+N_{F x \operatorname{lmpFF}(i)}+N_{F x \operatorname{lmpFT}(i)}+N_{F x \operatorname{lmpFFT-F(i)}} \times N_{F x I m p F F T-T(i)}\right)$

Em que:

$N_{F l h(i)}$ : Número de faltas correspondente ao $i$-ésimo trecho;

$N_{F x \text { Comp(i) }}$ : Número de faixas devido ao comprimento do $i$-ésimo trecho;

$N_{F x I m p F F F(i)}$ : Número de faixas devido à impedância de falta trifásica para o $i$-ésimo trecho;

$N_{F x I m p F F(i)}$ : Número de faixas devido à impedância de falta fase-fase para o $i$-ésimo trecho;

$N_{F x I m p F T(i)}$ : Número de faixas devido à impedância de falta fase-terra para o $i$-ésimo trecho;

$N_{F x I m p F F T-F(i)}$ : Número de faixas devido à impedância de falta dupla fase terra, impedância entre fases para trecho $i$

$N_{F x I m p F F T-T(i)}$ : Número de faixas devido à impedância de falta dupla fase terra, impedância entre fase e terra para trecho $i$;

Dado que:

$N_{F x I m p F F(i)}=N_{F x I m p F F(i)}=N_{F x I m p F T(i)}=N_{F x I m p F F T-F(i)}=N_{F x I m p}$ 
O equacionamento fica resumido a:

$$
N_{F l h(i)}=N_{F x \operatorname{Comp}(i)} \times N_{F x I m p} \times\left(3+N_{F x I m p F F T-T(i)}\right)
$$

Considerando que todos os trechos possuem a mesma quantidade de faixas para cada tipo de falta, o número de Curtos-Circuitos para toda a rede é obtido seguindo a formula:

$$
N_{\text {Curtos-Rede }}=N_{\text {Tre }} \times N_{\text {Flh(i) }}
$$

Em que:

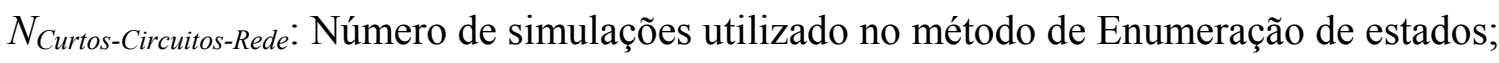

$N_{\text {Tre }}$ : Número de trechos existentes na rede;

$N_{F l h(i)}$ : Número de falhas correspondente a um trecho representativo $i$;

Como exemplo de um caso, considerando os seguintes valores:

$N_{F x \operatorname{Comp}(i)}=N_{F x I m p F F F(i)}=N_{F x I m p F F(i)}=N_{F x I m p F T(i)}=N_{F x I m p F F T-F(i)}=N_{F x I m p}=10$

Para uma rede que possui 100 trechos, o valor do número de simulações resultaria:

$N_{\text {Curtos-Circuitos-Rede }}=100 \times 10 \times 10 \times(3+10)=130,000$ simulações ou condições de Curto-Circuito a serem analisadas.

\subsubsection{Método Híbrido}

Para a obtenção do número de simulações necessário para que o método Híbrido obtenha resultados satisfatórios durante a análise de áreas de risco, é necessária a montagem de uma formulação que consiga obter um valor mínimo de condições de curto-circuito que permita fazer uma distribuição necessária para cada variável considerada.

No Item 4.1.3.1 foi apresentado um procedimento que permite reduzir a rede, simplificando os trechos originais em trechos reduzidos com características elétricas que não interferem na obtenção das condições da rede durante um Curto-Circuito. No Item 4.1.3.2 é apresentado um procedimento de agrupamento dos trechos reduzidos em função de comprimentos similares. Logo após, no Item 4.1.3.3, é apresentado outro critério que permite agrupar trechos reduzidos com comprimentos similares em grupos mais predominantes e grupos menos predominantes, estes últimos teriam um peso menor durante a análise de área de risco.

Seja:

$$
\operatorname{Comp}_{\text {Total-Grupos }}=\sum_{i=1}^{N} \operatorname{Comp}_{\text {Grupo(i) }}
$$




$$
\begin{gathered}
\text { Comp }_{\text {min-GrupoPredom }}=\operatorname{Min}_{j=1}^{\text {Npre }}\left(\operatorname{Comp}_{\text {GrupoPredom }(j)}\right) \\
\text { Fator }_{\text {Comp-Min }}=\frac{\operatorname{Comp}_{\text {min-GrupoPredom }}}{\operatorname{Comp}_{\text {Total-Grupos }}} \\
\text { Fator }_{\text {Prob-Min }}=\operatorname{Min}_{k=1}^{4}\left(\text { Prob }_{(k)}\right) \\
N_{\text {Curtos-Rede }}=\frac{N_{\text {Fx-Min }}}{\text { Fator }_{\text {Comp-min }} \times \text { Fator }_{\text {Prob-Min }}}
\end{gathered}
$$

Em que:

N: Número de Grupos existente na lista LGrupos;

$N_{\text {pre: }}$ Número de Grupos existentes na lista LGrupos Predom; $_{\text {; }}$

Comp $_{\text {Grupo }(i)}$ : Comprimento total para o grupo $i$;

Comp $_{\text {GrupoPredom(j): }}$ : Comprimento total para o grupo predominante $j$;

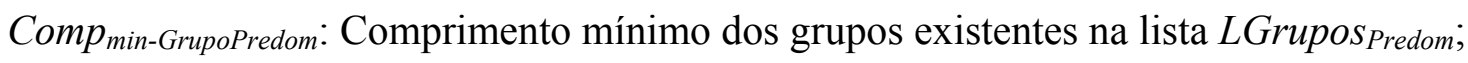

Comp $_{\text {Total-Grupos: }}$ Comprimento total resultante da soma de todos os grupos existentes;

Fator $_{\text {Comp-Min }}$ : Fator para o comprimento mínimo;

$\operatorname{Prob}_{(k)}$ : Distribuição de probabilidade para o tipo de falta $k$;

Fator $_{\text {Prob-Min: }}$ Fator para a probabilidade mínima por tipo de falta;

$N_{F x-M i n}$ : Número mínimo de faixas para o fracionamento da impedância de falta;

$N_{\text {Curtos-Rede }}$ : Número de simulações ou condições de curto circuito utilizada no método

Híbrido;

Seguindo o exemplo apresentado na Figura 4-11, os grupos pertencentes à lista LGrupos serão Grupo 1, Grupo 2, Grupo 3, Grupo 4.

Grupo 4: 2 elementos $=20$ metros;

Grupo 1: 5 elementos $=500$ metros;

Grupo 3: 1 elemento $=600$ metros;

Grupo 2: 2 elementos $=1000$ metros;

Com isto:

Comp $_{\text {Total-Grupos }}=2120$ metros;

Os grupos pertencentes à lista LGrupos Predom serão Grupo 1, Grupo 2, Grupo 3, então:

Comp $_{\text {min-Ter }}=500$ metros;

Fator $_{\text {Comp-Min }}=500 / 2120$;

Considerando a distribuição de probabilidade apresentada na Figura 4-7:

Fator $_{\text {Prob-Min }}=10 \%=1 / 10$; 
Escolhendo um valor adequando para $N_{F x-M i n}=5$. O valor para o número de simulações utilizada no método Híbrido resultará:

$$
N_{\text {Curtos-Rede }}=\frac{5}{\frac{500}{2120} \times \frac{1}{10}}=212
$$

Dado que o valor dos comprimentos dos trechos e a probabilidade dos tipos de falta é um valor fixo, o número de simulações necessário para o método Híbrido fica diretamente relacionado com o número de faixas mínimo escolhido para o fracionamento das impedâncias de falta. Quanto maior o número de faixas mínimo, maior o número de simulações, o que ajuda na precisão dos índices de VTCDs e análise de áreas de risco. 
5 - AVALIAÇÃO DAS ÁREAS DE RISCO

Sendo já conhecidas às informações da rede de distribuição em estudo, assim como os parâmetros da falta, quais sejam: o trecho de falta, ponto da falta, tipo de falta e impedância da falta, explicado no capítulo anterior, o próximo passo seria utilizar um módulo que permita avaliar cada combinação de curto-circuito obtida pelos métodos anteriores, e assim obter os índices de VTCDs para cada consumidor existente na rede de distribuição.

Neste capítulo serão apresentados os procedimentos necessários para poder avaliar cada índice representativo relativo às VTCDs.

\subsection{Cálculo das Grandezas Elétricas durante um Curto-Circuito}

Os modelos anteriormente apresentados possibilitam a obtenção do número de curtoscircuitos representativos. Cada combinação de tipo-posição-impedância de falta precisa ser avaliada para verificar seu efeito na rede de distribuição elétrica. Para tal finalidade é implementado um módulo de cálculo de curto-circuito. Este módulo permite calcular as grandezas elétricas da rede de distribuição durante a falta.

Dentre as grandezas obtidas, o valor da corrente de curto tem grande importância no estudo, já que com ela podem ser analisados os tempos de atuação dos dispositivos de proteção distribuídos em toda a rede elétrica. Para o cálculo da corrente de Curto-Circuito é utilizado o método de componentes simétricas, analisando redes trifásicas desequilibradas. A formulação desta metodologia para diferentes tipos de Curto-Circuito (fase terra, dupla fase, trifásico, dupla fase terra) será explicado com mais detalhe no Anexo A.

Este módulo para cálculo de curto-circuito também será utilizado para obter o valor do nível de tensão em todas as barras durante um falta. Com isto é possível avaliar o nível de afundamento e elevação da tensão a tensão nas fases envolvidas pela falta.

Durante o cálculo da tensão nas barras durante a falta, será considerado que o valor da tensão pré-falta será de 1 pu. Como foi comentado no Item 3.2, em condições normais de operação de sistemas de distribuição, os valores das tensões variam entre 0,95 e 1,05 pu, 
considerando a tensão pré-falta em 1 pu leva a um erro considerado aceitável dentro do estudo de Áreas de Risco.

\subsection{Coordenação dos dispositivos de proteção}

Conforme mencionado anteriormente, a duração da VTCDs é obtida como função dos tempos de atuação dos dispositivos de proteção instalados na da rede de distribuição, que são excitados pela corrente de Curto-Circuito.

Em função da curva de proteção de cada equipamento e do tempo de extinção natural da falta, alguns dispositivos podem ser acionados permitindo o isolamento de grandes blocos de carga.

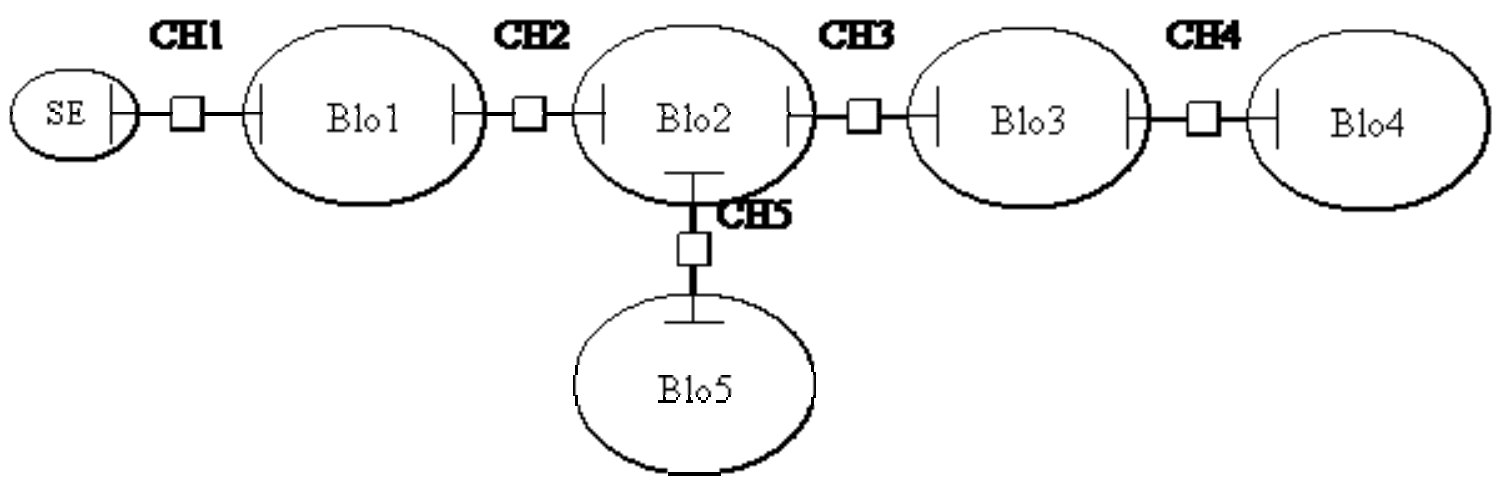

Figura 5-1 - Representação da Rede: Blocos de carga e Dispositivos de Proteção

Na Figura 5-1 pode-se observar o relacionamento e a disposição dos elementos de proteção e dos blocos de carga correspondentes para análise da atuação da proteção em uma falta na rede de distribuição.

Para iniciar a análise da coordenação de proteção, primeiro estrutura-se uma matriz de coordenação, que armazena todos os blocos e elementos de proteção. 
Tabela 5-1 Tabela de Coordenação da Proteção

\begin{tabular}{|c|c|c|c|c|c|}
\hline & Blo1 & Blo2 & Blo3 & Blo4 & Blo5 \\
\hline CH1 & 1 & 1 & 1 & 1 & 1 \\
\hline CH2 & 0 & 2 & 2 & 2 & 2 \\
\hline CH3 & 0 & 0 & 3 & 3 & 0 \\
\hline CH4 & 0 & 0 & 0 & 4 & 0 \\
\hline CH5 & 0 & 0 & 0 & 0 & 3 \\
\hline
\end{tabular}

Na Tabela 5-1 de coordenação, pode-se observar a relação dos dispositivos de proteção e os blocos que eles protegem. Esta tabela também mostra em ordem ascendente os dispositivos de proteção que deveriam ter a prioridade para o acionamento durante uma falta ocorrida na rede.

Analisando um caso, se uma falta acontecesse-se no bloco 3 (Blo3), as chaves analisadas seriam (em função da coluna correspondente na tabela de coordenação), CH1, $\mathrm{CH} 2, \mathrm{CH} 3$. Conhecendo agora os dispositivos de proteção candidatos, analisa-se qual deles será acionado seguindo a sua respectiva curva tempo-corrente de proteção. Para manter a seletividade dos dispositivos de proteção, terá que ser considerado como dispositivo de proteção atuante aquele que possui menor tempo de atuação no caminho da corrente de curtocircuito. Teoricamente o dispositivo de proteção atuante estaria localizado o mais próximo do ponto de falta, visando isolar o menor número de consumidores, mas na prática isto não é sempre é cumprido.

Conhecido o dispositivo de proteção que atua para isolar os blocos de carga durante a falta, procede-se a conhecer quais blocos foram isolados. Para isto, da tabela de coordenação, procura-se a chave atuante nas linhas da matriz e os blocos cujos elementos da matriz forem diferentes de zero, que representam os blocos de carga que esta chave protege.

Do exemplo, para uma falta no bloco 3 (Blo3), se a chave atuante fosse a $\mathrm{CH} 2$, os blocos isolados seriam Blo2, Blo3, Blo4 e Blo5. Se a chave atuante fosse $\mathrm{CH} 3$, os blocos isolados seriam Blo3 e Blo4. 


\subsection{Distribuição de probabilidade do tempo da extinção da falta}

Neste estudo, os defeitos são modelados considerando a possibilidade de ocorrência de extinção natural. Será assumida uma distribuição equiprovável com tempo de extinção natural entre 0 e $100 \mathrm{~ms}$, com $80 \%$ da probabilidade de ocorrer. Os outros $20 \%$ representam a probabilidade de ocorrer tempo de extinção natural superior a $100 \mathrm{~ms}$ até 5 segundos como é apresentada na Figura 5-2. Estes valores foram tomados a partir de conhecimentos práticos de especialistas, podendo ser alterado em função do caso.

Deste modo, consegue-se modelar situações em que as faltas são extintas antes da atuação dos dispositivos de proteção bem como situações em que as faltas são interrompidas pelos dispositivos de proteção, quando o tempo de atuação for inferior ao tempo de extinção natural do defeito. Esta modelagem pode ser aplicada quando é utilizada junto com dispositivos de proteção tais como: fusíveis, relés, disjuntores, chaves seccionadoras. No caso dos religadores a abordagem é diferente já que torna a análise mais complexa. No desenvolvimento deste trabalho não será considerado os religadores dentro do conjunto de dispositivos de proteção existentes nas redes elétricas, deixando para trabalhos futuros a inclusão desta variável na análise de Áreas de Risco.

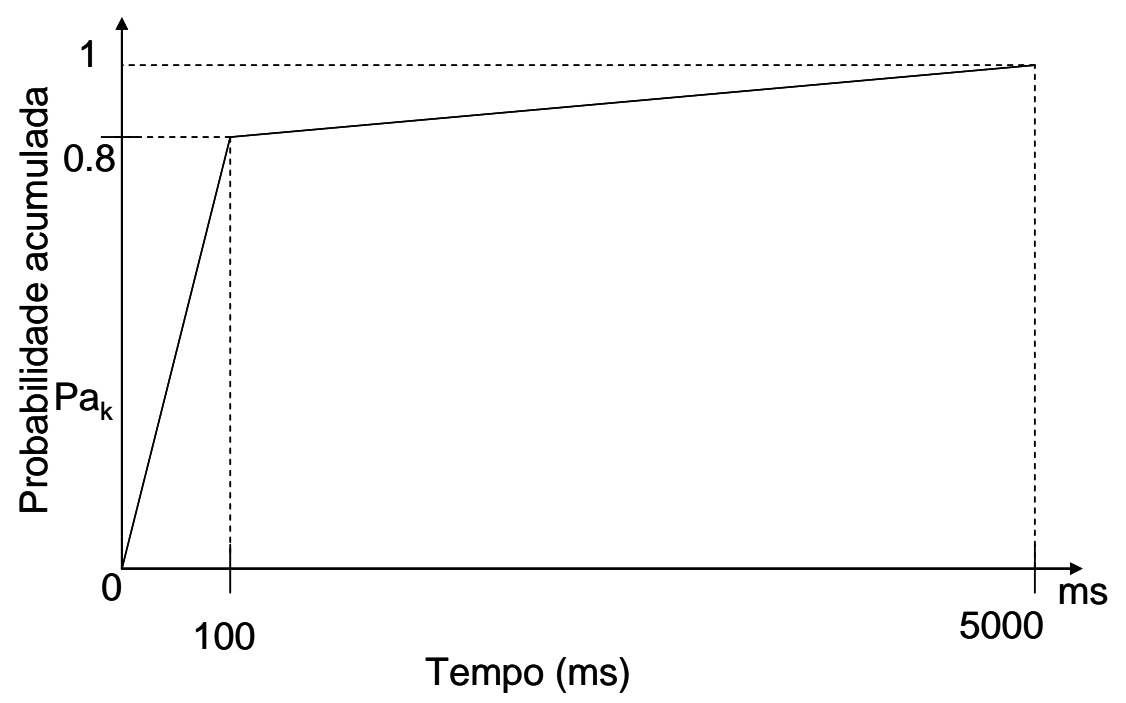

Figura 5-2 - Distribuição Acumulada vs Tempo de Extinção da Falta 


\subsection{Determinação da Probabilidade de ocorrência VTCDs ou Interrupções}

Uns dos pontos importantes na análise de áreas de risco frente às VTCDs é verificar se o fenômeno de Curto-Circuito originado na rede pode causar uma interrupção do fornecimento de energia para diferentes consumidores. Este fato é dependente da corrente de Curto-Circuito que provoca a VTCDs, evidenciada pela sua magnitude e duração. Os trabalhos apresentados por Camilo et al 2007 [ 18], Kagan et al 2004 [ 55] e Cebrian et al 2005 [ 21], comparam dois diferentes tempos para realizar esta análise, que são: i) O Tempo de Extinção natural da falta $\left(T_{e x N}\right)$, que representa a duração do fenômeno de Curto-Circuito atuante na rede, desde seu inicio até a sua extinção natural, sem a atuação de algum dispositivo de proteção e ii) $\mathrm{O}$ tempo de atuação do dispositivo de proteção $\left(T_{D P}\right)$, que é dependente do tipo de dispositivo, refletido na sua respectiva curva tempo-corrente de proteção, e do valor da corrente de Curto-Circuito nos dispositivos. Para analisar se o fenômeno de Curto-Circuito provocou uma interrupção ou não, são seguidos os seguintes critérios:

(a) Se $T_{e x N} \leq T_{D P}$, então não é produzida interrupção, porém, VTCDs são passíveis de ocorrer para todos os consumidores da rede com duração $T_{\text {exN }}$.

(b) Se $T_{e x N}>T_{D P}$, então é produzida uma interrupção para os consumidores a juntante do dispositivo de proteção. Os demais consumidores podem ser afetados por VTCDs de duração igual a $T_{D P}$.

Estes critérios foram utilizados para definir aqueles blocos de consumidores que podem suportar Interrupções ou VTCDs, frente a diferentes condições de Curto-Circuito. A desvantagem principal centra-se em que, dada a utilização do Método de Monte Carlo para determinar as Áreas de risco, este critério introduz mais uma variável a ser sorteada e analisada, o que aumenta o número de simulações necessário ao método de Monte Carlo para alcançar a sua estabilidade.

Neste trabalho, visando diminuir o número de variáveis aleatória o que se reflete na diminuição no número de simulações, foi concebido um novo critério que permite calcular a probabilidade de um evento de Curto-Circuito produzir uma VTCDs ou interrupção.

Para iniciar este processo, é necessário calcular o valor da corrente de Curto-Circuito atuante durante a falta. Este valor é possível de ser calculado, já que inicialmente foram obtidos seus parâmetros (tipo de Curtos-Circuitos, trecho de Curtos-Circuitos, ponto de falta, impedância de falta) pelas diferentes metodologias apresentados no Item 4.1. 
O segundo passo é identificar o caminho da corrente de Curto-Circuito. Considerando o sistema radial, este caminho é considerado desde o ponto de falta até a subestação principal que alimenta todos os alimentadores da rede. Conhecendo o caminho e utilizando o critério de coordenação de proteção apresentado no item 5.2, é possível identificar os dispositivos de proteção que podem atuar para eliminação da falta.

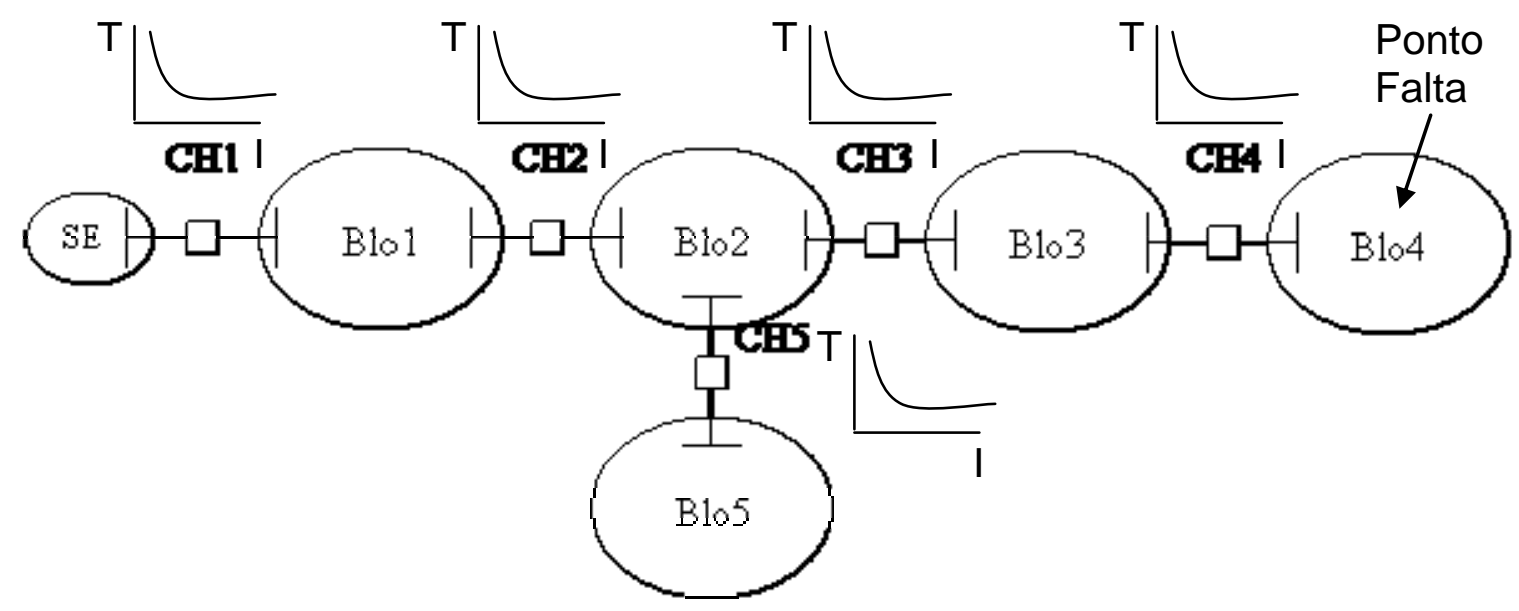

Figura 5-3 - Representação da Rede: Ponto de Falta e as respectivas curvas de proteção

Da Figura 5-3, pode ser observado que, se o ponto de falha acontecer em algum trecho do Bloco 4, as chaves envolvidas na proteção dos sistema seriam: $\mathrm{CH} 1, \mathrm{CH} 2, \mathrm{CH} 3$ e CH4. Admite-se que cada elemento de proteção de sobre-corrente possui uma curva de proteção especificada pelo fabricante de equipamento. Estas curvas possuem dois parâmetros para comparação: Tempo e Corrente.

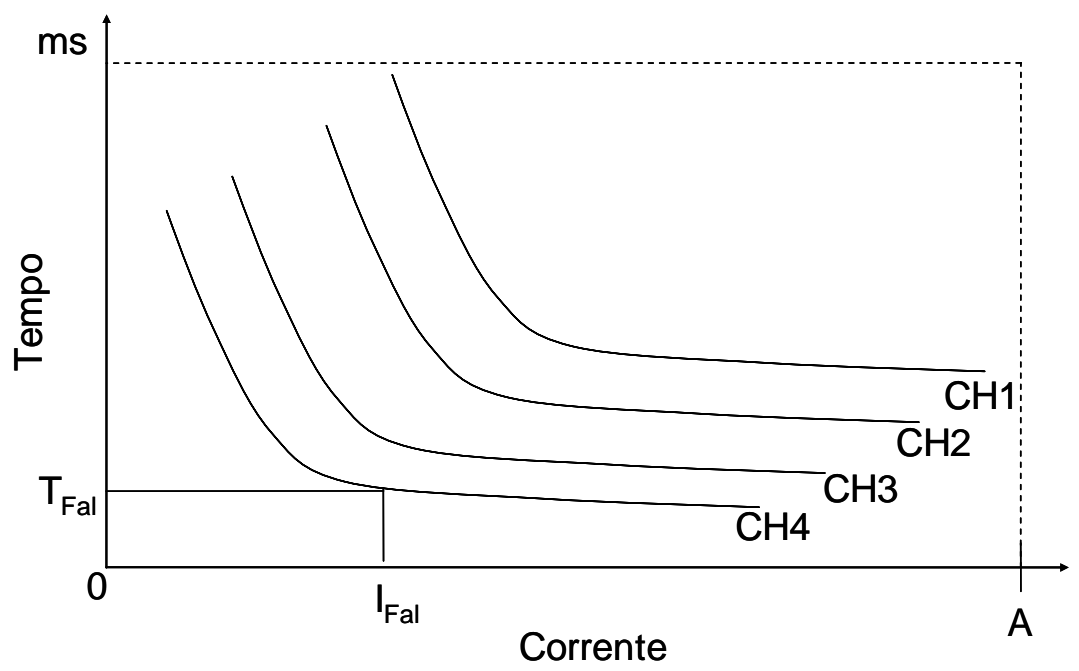

Figura 5-4 - Dispositivos de proteção envolvidos durante uma falta 
Na Figura 5-4, podem ser observadas as curvas de proteção dos vários dispositivos de proteção envolvidos no caminho da falta. Se a coordenação dos dispositivos de proteção estiver bem planejada, então a disposição das curvas de proteção terá a mesma tendência da Figura 5-4. Mas existem muitos casos em que, por condições práticas, esta coordenação não é respeitada ou não é possível, comprometendo o acionamento coordenado de dispositivos de proteção, o que pode promover desligamento desnecessário de alguns consumidores.

Para a escolha do dispositivo de proteção que isola a falta, seleciona-se aquele que possui o menor tempo de atuação para uma determinada corrente da falha. Para o caso de uma falta a como a apresentada na Figura 5-3, e observando a proteção apresentadas na Figura 5-4, a curva de proteção a atuar seria a correspondente à da chave $\mathrm{CH} 4$. Desta maneira, mediante uma interpolação simples, para o valor da corrente de Curto-Circuito, pode-se obter o valor do tempo de atuação da proteção durante a falta.

O terceiro passo parte do conhecimento do tempo de proteção para uma determinada falta. Assim, utilizando a Distribuição de probabilidade apresentada no item 5.3, é possível obter a probabilidade de acontecer uma VTCDs ou uma interrupção.

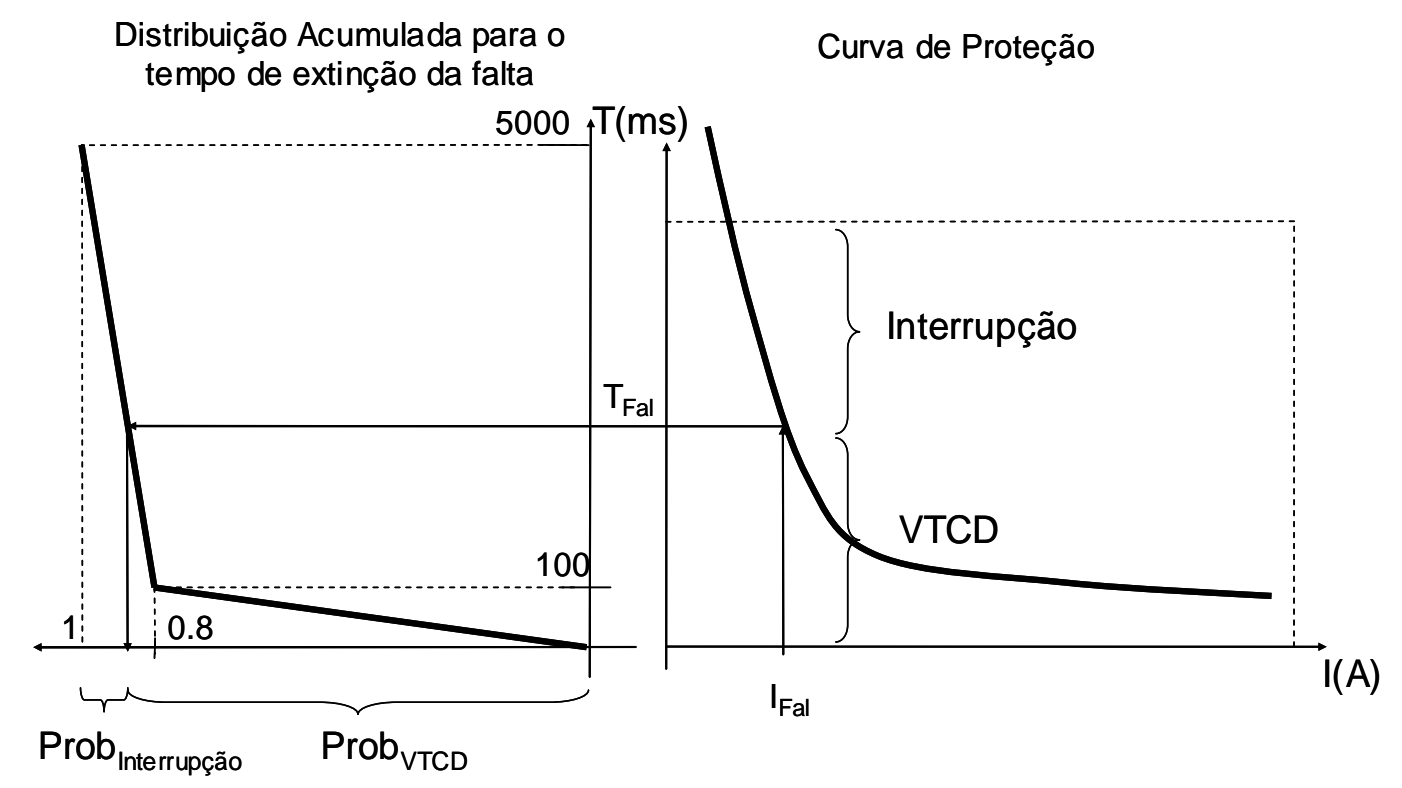

Figura 5-5 - Obtenção da Probabilidade de VTCD e interrupção utilizando as curvas de proteção e probabilidade acumulada dada uma corrente de falta

Da Figura 5-5, pode ser observado que, dada uma corrente de falta $\left(I_{F a l}\right)$, é possível obter a probabilidade de acontecer uma VTCD e uma interrupção de longa duração. A probabilidade de acontecer uma VTCD é obtida por $\left(\operatorname{Prob}_{V T C D}\right)$ e a interrupção seria obtida 
pelo seu complemento $\left(\operatorname{Prob}_{\text {Interr }}=1-\operatorname{Prob}_{V T C D}\right)$. Cabe observar que a distribuição de probabilidade acumulada adotada tem como limite $5000 \mathrm{~ms}$. Neste caso, para correntes de Curto-Circuito muito baixas, com tempos de atuação da proteção acima de $5000 \mathrm{~ms}$, será considerado como unitária a probabilidade de VTCD e nula a probabilidade de interrupção.

O quarto passo é identificar os blocos de consumidores que se encontram a jusante e a montante do dispositivo de proteção escolhido no segundo passo do procedimento.

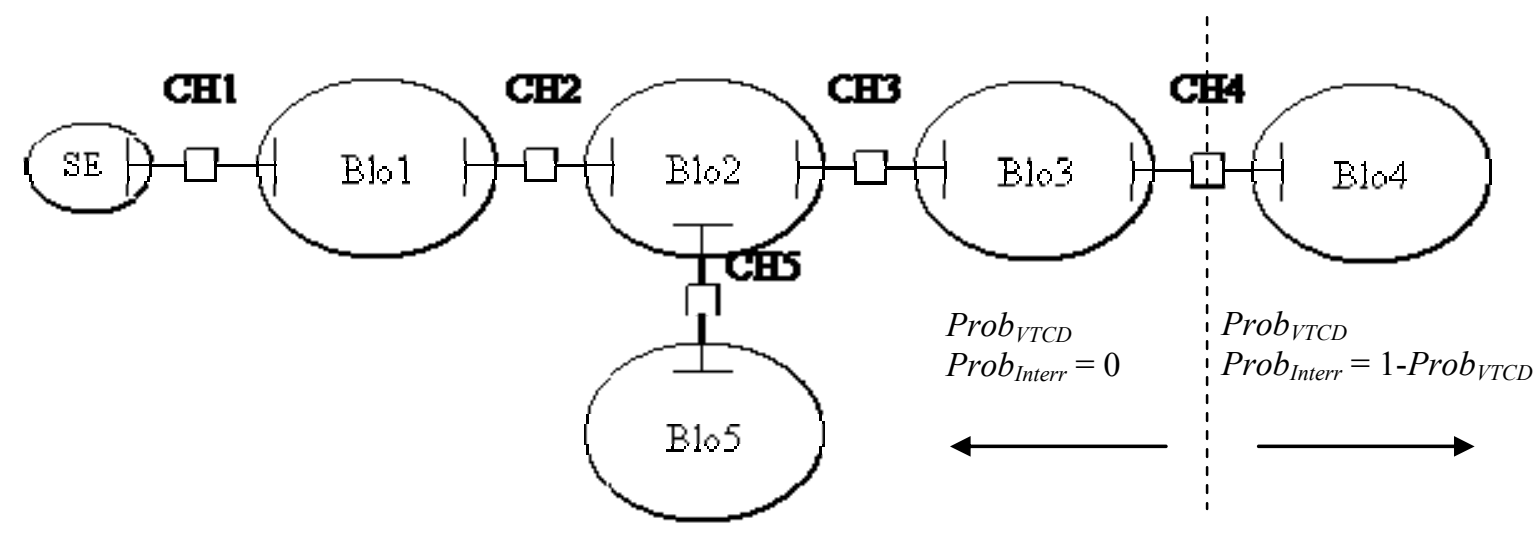

Figura 5-6 - Valor das Probabilidades de VTCD e interrupção para diferentes blocos de consumidores em função da sua posição

Da Figura 5-6, é possível observar que em função da posição do bloco de consumidores em relação ao dispositivo de proteção escolhido, os valores das Probabilidades de VTCD e interrupção muda. Isto é devido a que os blocos de consumidores a montante da chave escolhida (CH4 da Figura 5-6) são imunes a Interrupções o que faz o valor de Prob ${ }_{\text {Interr }}$ ser nula . Nos casos dos blocos de consumidores a jusante da chave escolhida, os valores de

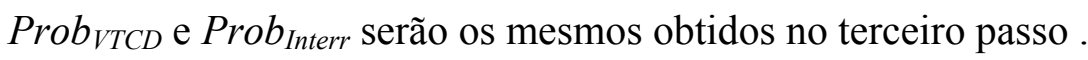

\subsection{Caracterização e classificação das VTCDs}

Para realizar a caracterização e classificação de VTCDs, visando a Análise de áreas de Risco é utilizada a geração de histogramas que leva em consideração o comportamento do perfil de tensão de cada barra durante a falta, assim como a duração do defeito.

A classificação das informações será realizada a partir dos seguintes parâmetros: 
- Magnitude (valor da tensão): valor eficaz da tensão em pu considerando o valor mínimo valor de tensão remanescente entre as três fases (agregação de fases) na condição de falta;

- Duração: Este valor é obtido em função do critério apresentado no item 5.3 e corresponde ao tempo obtido da interpolação da curva de tempo corrente do dispositivo de proteção utilizando o valor da corrente de Curto-Circuito para a condição de falta sorteada.

As faixas para a classificação das VTCDs foram adotadas de acordo com a Tabela 5-2 e a Tabela 5-3, para afundamentos de tensão e elevação de tensão, respectivamente em cada barra da rede elétrica analisada.

Tabela 5-2 Faixas de magnitudes e durações para a classificação dos afundamentos de tensão

\begin{tabular}{|c|c|c|c|c|c|c|c|c|c|}
\hline \multirow{2}{*}{$\begin{array}{c}\text { Faixas de } \\
\text { Amplitude de } \\
\text { tensão em PU }\end{array}$} & \multicolumn{9}{|c|}{ Faixas de Tempo (ms) } \\
\hline & $<0 ; 16,67]$ & $<16,67 ; 50]$ & $<50 ; 100]$ & $<100 ; 200]$ & $<200 ; 300]$ & $<300 ; 500]$ & $<500 ; 1000]$ & $<1000 ; 3000]$ & $<3000$; 1 $1 \mathrm{~min}]$ \\
\hline \multicolumn{10}{|l|}{$0,9>V \geq 0,85$} \\
\hline \multicolumn{10}{|l|}{$0,85>\mathrm{V} \geq 0,8$} \\
\hline \multicolumn{10}{|l|}{$0,8>\mathrm{V} \geq 0,7$} \\
\hline \multicolumn{10}{|l|}{$0,7>V \geq 0,6$} \\
\hline \multicolumn{10}{|l|}{$0,6>V \geq 0,5$} \\
\hline \multicolumn{10}{|l|}{$0,5>V \geq 0,4$} \\
\hline \multicolumn{10}{|l|}{$0,4>V \geq 0,3$} \\
\hline \multicolumn{10}{|l|}{$0,3>V \geq 0,2$} \\
\hline \multicolumn{10}{|l|}{$0,2>V \geq 0,1$} \\
\hline $0,1>V \geq 0,0$ & & & & & & & & & \\
\hline
\end{tabular}

Tabela 5-3 Faixas de magnitudes e durações para a classificação das elevações

\begin{tabular}{|c|c|c|c|c|c|c|c|c|c|}
\hline \multirow{2}{*}{$\begin{array}{c}\text { Faixas de } \\
\text { Amplitude de } \\
\text { tensão em PU }\end{array}$} & \multicolumn{9}{|c|}{ Faixas de Tempo (ms) } \\
\hline & $<0 ; 16,67]$ & $<16,67 ; 50]$ & $<50 ; 100]$ & $<100 ; 200]$ & $<200 ; 300]$ & $<300 ; 500]$ & $<500 ; 1000]$ & $<1000 ; 3000]$ & $<3000 ; 1 \mathrm{~min}]$ \\
\hline \multicolumn{10}{|l|}{$1,1<\mathrm{V} \leq 1,2$} \\
\hline \multicolumn{10}{|l|}{$1,2<\mathrm{V} \leq 1,3$} \\
\hline \multicolumn{10}{|l|}{$1,3<\mathrm{V} \leq 1,4$} \\
\hline \multicolumn{10}{|l|}{$1,4<\mathrm{V} \leq 1,5$} \\
\hline \multicolumn{10}{|l|}{$1,5<\mathrm{V} \leq 2,0$} \\
\hline $\mathrm{V}>2,0$ & & & & & & & & & \\
\hline
\end{tabular}

As células formadas na Tabela 5-2 e a Tabela 5-3 são preenchidas com os valores do número de ocorrências de afundamentos ou elevações de tensão conforme o valor obtido no Item $5.3\left(\right.$ Prob $\left._{V T C D}\right)$. 
Deve ser ressaltado que o valor da probabilidade $\left(\operatorname{Prob}_{V T C D}\right)$ não pode ser inserido diretamente na tabela, já que este valor representa o valor acumulado desde o tempo 0 até o tempo limite dado pela curva de proteção, no qual é considerado região de VTCD, como é mostrado na Figura 5-5.

O seguinte procedimento será aplicado para todas as barras existentes na rede elétrica. Para realizar o preenchimento de cada faixa de tensão e tempo é utilizando o seguinte critério: (a) Para iniciar o preenchimento é necessário conhecer a fila dentro da Tabela 5-2 ou Tabela 5-3. Para isso obtém-se o valor da Magnitude da tensão em pu da fase de maior afundamento de tensão $\left(V_{a f}\right)$ ou maior elevação de tensão $\left(V_{e l}\right)$, estes valores são obtidos seguindo o módulo de cálculo de Curto-Circuito explicado com mais detalhe no ANEXO A. O valor de $\left(V_{a f}\right)$ ou $\left(V_{e l}\right)$ definirá a fila que terá que ser preenchida.

(b) Sendo conhecidas a filas para preenchimento das Tabela 5-2 e Tabela 5-3 pelo passo (a), o seguinte passo é realizar o preenchimento dos valores para cada coluna destas tabelas, ou seja, por faixa de tempo. Antes de realizar o preenchimento é necessário conhecer o tempo limite de $\operatorname{VTCD}\left(T_{F a l}\right)$. Este valor é obtido seguindo o procedimento explicado no item 5.4. Assim as colunas ou faixas de tempo que serão preenchidas serão somente aquelas com valor inferior a $\left(T_{F a l}\right)$. Cada faixa de tempo terá um valor de tempo mínimo $\left(T_{\text {faxMIN }}\right)$ e valor de tempo máximo $\left(T_{f a x M A X}\right)$. Para estes valores será obtido seu correspondente valor de probabilidade de VTCDs em função da distribuição de probabilidade acumulada do tempo de extinção da falta (Item 5.3). Com isto o valor a ser inserido na faixa seria $\operatorname{Prob}_{V T C D}\left(T_{\text {faxMAX }}\right)-\operatorname{Prob}_{V T C D}\left(T_{\text {faxMIN }}\right)$. Para o caso em que a faixa de tempo possua um valor $T_{f a x M A X}$ maior a $T_{a f}$ o valor inserido será $\operatorname{Prob}_{V T C D}\left(T_{a f}\right)-\operatorname{Prob}_{V T C D}\left(T_{f a x M I N}\right)$. Para casos com valor inicial de $\operatorname{Prob}_{V T C D}\left(T_{a f}\right)=1$ o valor para o preenchimento de cada faixa será o resultado de $\operatorname{Prob}_{V T C D}\left(T_{\text {faxMAX }}\right)-\operatorname{Prob}_{V T C D}\left(T_{\text {faxMIN }}\right)$. Para casos em que o valor de $T_{a f}$ for maior que 5000 ms será considerando que o valor de $\operatorname{Prob}_{V T C D}\left(T_{a f}\right)$ sempre será 1.

(c) Finalmente, o valor obtido em cada faixa será acumulado ao valor já existente na mesma, para cada condição de curto-circuito obtida pelos métodos apresentados no Item 4.1. 


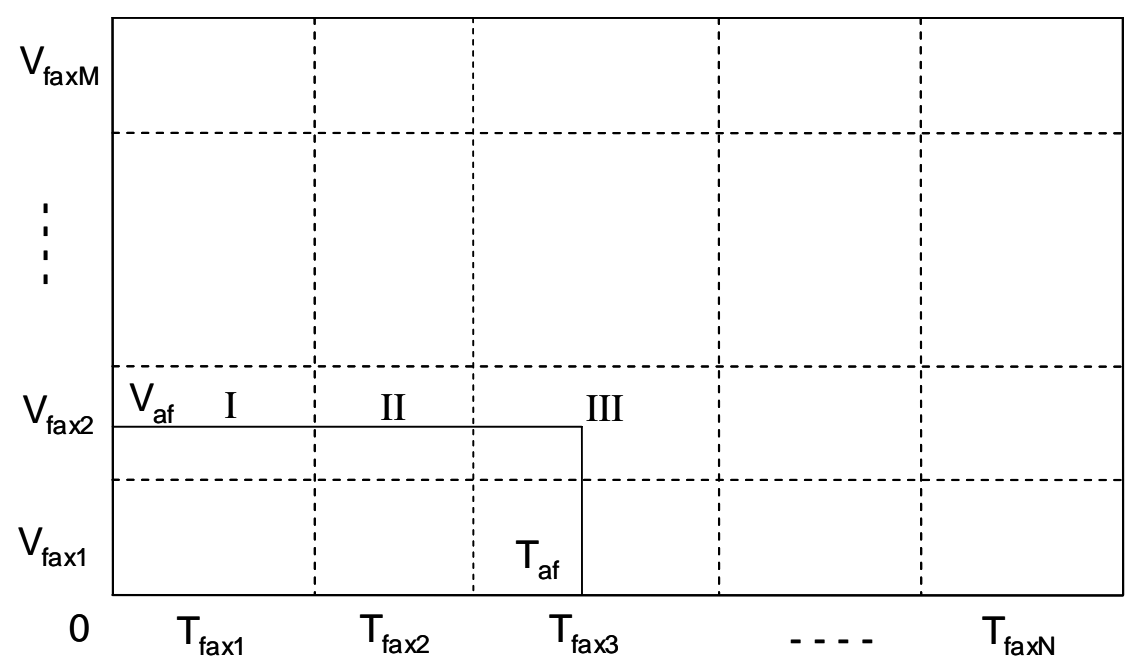

Figura 5-7 - Faixas de tensão e tempo, $\mathrm{N}$ faixas de tempo e $M$ faixas de tensão.

Da Figura 5-7, $V_{a f}$ encontrasse entre a faixa de tensão $V_{f a x 2}$, já que:

$V_{\text {fax2Min }} \leq V_{a f}<V_{\text {fax } 2 \operatorname{Max}}$

Assim também $T_{a f}$ encontrasse entre a faixa de tempo $T_{f a x 3}$, já que:

$T_{\text {fax } 3 \text { Min }} \leq T_{a f}<T_{\text {fax } 3 \text { Max }}$

O valor para o preenchimento em cada faixa será obtido da seguinte forma:

Posição I $\left(V_{2}, T_{1}\right)$ : Valor da Faixa I $=\operatorname{Prob}_{V T C D}\left(T_{\text {faxlMAX }}\right)-\operatorname{Prob}_{V T C D}\left(T_{\text {faxlMIN }}\right)$;

Posição II $\left(V_{2}, T_{2}\right)$ : Valor da Faixa II $=\operatorname{Prob}_{V T C D}\left(T_{\text {fax } 2 M A X}\right)-\operatorname{Prob}_{V T C D}\left(T_{\text {fax } 2 M I N}\right)$;

Posição III $\left(V_{2}, T_{3}\right)$ : Valor da Faixa III $=\operatorname{Prob}_{V T C D}\left(T_{a f}\right)-\operatorname{Prob}_{V T C D}\left(T_{\text {fax } 3 M I N}\right)$;

\subsection{Caracterização e classificação das Disrupções de equipamentos eletro-eletrônicos}

Considera-se que ocorre disrupção em equipamentos eletroeletrônicos, quando uma falta elétrica produz um afundamentos de tensão cujo valor da tensão fica "abaixo" de uma determinada curva de sensibilidade.

Visando possibilitar avaliações para diferentes curvas de sensibilidade, a determinação do número de disrupções pode ser realizada a partir de dados estatísticos (histograma) de afundamentos durante as simulações para cada evento sorteado. Com isso evitam-se possíveis excessos de carga computacional resultante.

Para realizar a classificação das Disrupções são também utilizadas as faixas apresentadas na Tabela 5-2 e na Tabela 5-3. O critério de preenchimento será o mesmo 
apresentado no Item 5.5, com a observação que neste caso será incluída a curva de sensibilidade da carga ou cargas que estão dispostas na barra em análise.

Neste caso as faixas nas quais será calculado o valor de $\operatorname{Prob}_{V T C D}\left(T_{\text {faxMAX }}\right)$ $\operatorname{Prob}_{V T C D}\left(T_{f a x M I N}\right)$ serão somente aquelas em que o nível da tensão $\left(\mathrm{V}_{\mathrm{af}}\right)$ fique abaixo da curva de sensibilidade.

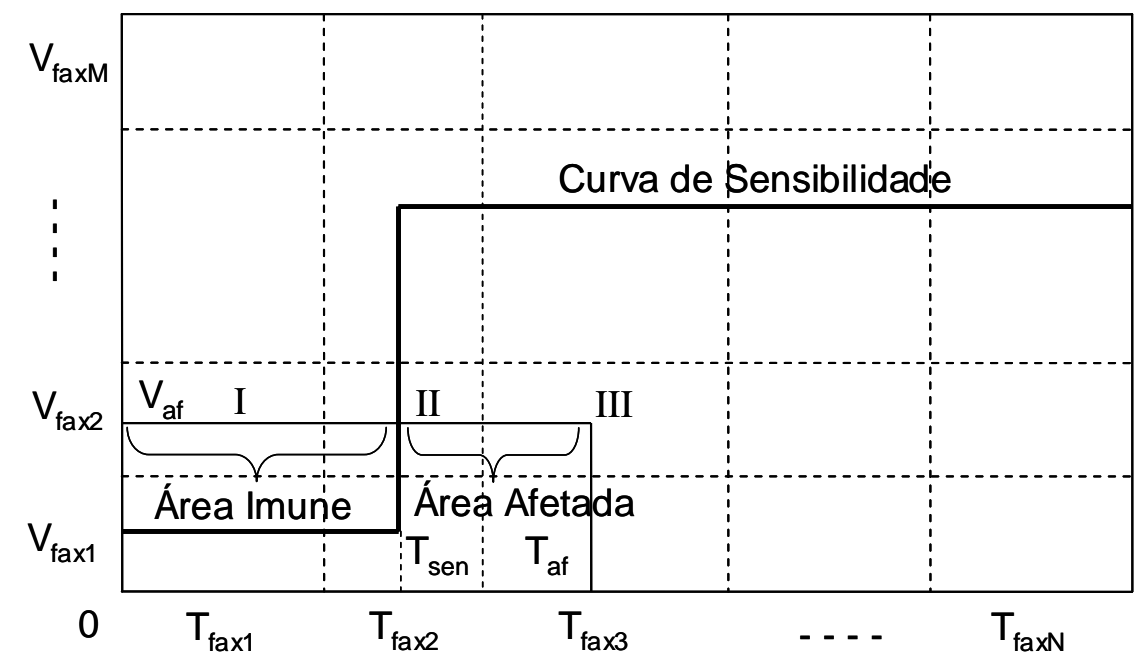

Figura 5-8 - Faixas de tensão e tempo para análise de Disrupções, $\mathbf{N}$ faixas de tempo e M faixas de tensão.

Da Figura 5-8, $V_{a f}$ encontrasse entre a faixa de tensão $V_{f a x 2}$, já que:

$V_{\text {fax } 2 \text { Min }} \leq V_{a f}<V_{\text {fax } 2 \text { Max }}$

Assim também $T_{a f}$ encontrasse entre a faixa de tempo $T_{f a x 3}$, já que:

$T_{\text {fax3Min }} \leq T_{a f}<T_{\text {fax } 3 \text { Max }}$

Considerando a curva de sensibilidade o valor das faixas será obtido da seguinte maneira:

Posição I $\left(V_{2}, T_{1}\right)$ : Área Imune,

$$
\text { Valor da Faixa } \mathrm{I}=0 \text {; }
$$

Posição II $\left(V_{2}, T_{2}\right)$ : Área parcialmente Imune,

$$
\text { Valor da Faixa II = } \operatorname{Prob}_{V T C D}\left(T_{f a x 2 M A X}\right)-\operatorname{Prob}_{V T C D}\left(T_{\text {sen }}\right) \text {; }
$$

Posição III $\left(V_{2}, T_{3}\right)$ : Área afetada,

$$
\text { Valor da Faixa III }=\operatorname{Prob}_{V T C D}\left(T_{a f}\right)-\operatorname{Prob}_{V T C D}\left(T_{f a x 3 M I N}\right) \text {; }
$$

Sendo que $T_{\text {sen }}$ da Figura 5-8 é o valor de um dos tempos da curva de sensibilidade localizado dentro de uma das faixas de tempo $\left(T_{f a x 2}\right)$ da tabela. 


\subsection{Contribuição de outros alimentadores nas VTCDs}

Os consumidores estão sujeitos a VTCDs causadas por faltas não só do próprio alimentador onde estão ligados, mas também de outras partes do sistema, principalmente de outros alimentadores ligados à mesma barra da subestação, conforme ilustrado na Figura 5-9.

Caso a rede considerada nas simulações não inclua todos os alimentadores derivados da mesma barra da subestação, a contribuição dos outros alimentadores pode ser calculada também através de simulações similares feitas para cada um dos outros alimentadores, mas determinando as VTCDs na barra de MT da subestação.

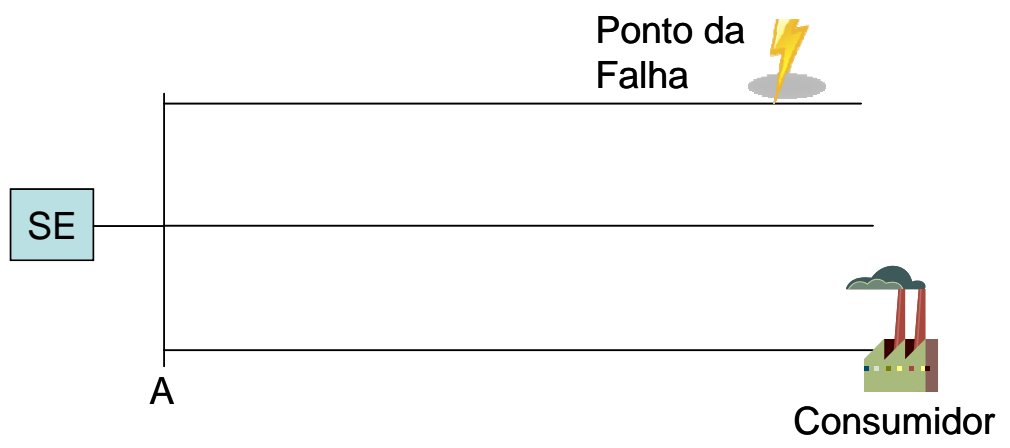

Figura 5-9 - Contribuição de Faltas em outros alimentadores

Se os efeitos das cargas e as tensões pré-faltas forem desprezados, pode-se considerar que as mesmas variações de tensão que ocorrem na barra da subestação em conseqüência de faltas nos outros alimentadores são verificadas em todos os pontos do alimentador sob análise. Na Figura 5-9, pode-se observar que a barra da subestação A terá uma Variação no seu nível de tensão provocada por uma falta em um dos alimentadores. Algum consumidor instalado em outro alimentador também sofrerá as conseqüências da variação da tensão na barra de alimentação A.

As ocorrências de VTCDs assim determinadas podem ser incluídas às ocorrências de VTCDs originárias do próprio alimentador, ou seja, o efeito destas ocorrências tem que ser acumulados na Tabela 5-2 e Tabela 5-3, mantendo os mesmos critérios explicado no Item 5.5 e 5.6.

Caso todos os outros alimentadores tenham configurações similares ao alimentador em estudo, as quantidades de VTCDs originárias daqueles alimentadores podem ser estimadas de uma forma simplificada usando a mesma quantidade de VTCDs provocadas pelo próprio alimentador na barra da subestação e multiplicando-a pelo número de alimentadores ligados 
na mesma barra do alimentador estudado. Esta consideração obviamente representa uma séria simplificação, e somente pode ser adotada se não forem disponíveis informações elétricas dos outros alimentadores tais como: impedância dos trechos, número e tipos de transformadores, número de consumidores cadastrados no alimentador, etc.

As VTCDs originárias de outras partes distantes do sistema (por exemplo, sistema de transmissão) não são necessariamente incluídas nas simulações. Normalmente é esperado que a maioria das VTCDs que afetam os consumidores alimentados em tensões de distribuição seja originária do próprio sistema de distribuição.

\subsection{Determinação da freqüência anual de ocorrência de VTCDs e Interrupções}

Dos sorteios das faltas, resultam números de ocorrências de VTCDs e de Interrupções nos pontos de avaliação, bem como o número de casos que resultam em interrupção no alimentador. Esses números variam praticamente de forma direta com o número de sorteios efetuados.

É necessário referir os números obtidos a uma base que permita uma comparação mais direta com os índices comumente usados na prática. O índice a ser adotado é o número de ocorrências (de VTCDs e Interrupções) por ano.

Esse índice pode ser obtido desde que sejam conhecidos os seguintes parâmetros:

- Taxa de falha por km por ano do alimentador

- Extensão total do alimentador (tronco + ramais)

A obtenção desse índice é realizada usando o seguinte equacionamento:

$$
N_{\text {anos }}=\frac{N_{\text {prot }}}{\lambda_{A l} \times d_{A l}}
$$

Em que:

$\lambda_{A l}:$ Taxa de falha por km por ano do alimentador analisado;

$d_{A l}$ : Extensão em km do alimentador analisado, considerando a soma do comprimento do tronco e ramais; 
$N_{\text {prot }}$ : Número de casos simulados nos quais aconteceu à atuação de algum dispositivo de proteção;

Para realizar a anualização dos índices de afundamento, interrupção, elevação e disrupção, devem seguir os seguintes equacionamentos:

$$
\begin{aligned}
& N_{A f u_{i} / \text { ano }}=\frac{N_{\text {afundamentos }_{i}}}{N_{\text {anos }}} \\
& N_{E l_{i} / \text { ano }}=\frac{N_{\text {Elevações }_{i}}}{N_{\text {anos }}} \\
& N_{\text {Int }_{i} / \text { ano }}=\frac{N_{\text {Interrupções }_{i}}}{N_{\text {anos }}} \\
& N_{\text {Disis } / \text { ano }}=\frac{N_{\text {Disrupcões }}}{N_{\text {anos }}}
\end{aligned}
$$

Em que:

$N_{A f u_{i} / a n o}:$ Número de Afundamentos por ano na $i$-ésima barra;

$N_{E l v_{i} / a n o}$ : Número de Elevações por ano na $i$-ésima barra;

$N_{\text {Int } / \text { ano }}:$ Número de Interrupções por ano na $i$-ésima barra;

$N_{D i s_{i} / \text { ano }}$ : Número de Disrupções por ano na $i$-ésima barra;

$N_{\text {Afundamentos }_{i}}$ : Número de casos simulados nos quais aconteceu afundamento de tensão na $i$ ésima barra;

$N_{\text {Elevações }_{i}}$ : Número de casos simulados nos quais aconteceu elevação de tensão na $i$-ésima barra;

$N_{\text {Interrupcões }_{i}}$ Número de casos simulados nos quais aconteceu interrupção de tensão na $i$-ésima barra;

$N_{\text {Disrup̧ões }_{i}}$ : Número de casos simulados nos quais aconteceu disrupção de tensão na $i$-ésima barra;

A taxa de falha por km por ano $\left(\lambda_{A l}\right)$ do alimentador é um dado cujo valor pode ser obtido na prática a partir dos dados de ocorrência de desligamentos de alimentador causados por defeitos. Para as simulações, essa taxa é um dado de entrada, devendo ser usado um valor apropriado para o alimentador simulado. Como valor "default" será usado o valor unitário isto 
é $\lambda=1\left(\mathrm{~km}^{-1} / \mathrm{ano}\right)$. Para uma taxa $\lambda$ diferente, os resultados podem ser obtidos simplesmente aplicando um fator de proporção.

\subsection{Determinação dos Custos de Interrupção e Disrupção}

Como descrito na revisão bibliográfica, muitos autores descrevem diferentes métodos para a avaliação econômica da qualidade de energia. Todas as referências visam analisar os transtornos e prejuízos provocados ao consumidor. Em geral é avaliado o custo da interrupção do fornecimento em diferentes indústrias, já que cada indústria apresenta processos sensíveis relacionados à perda de produção e serviço.

Neste trabalho além das Interrupções de longa duração, consideram-se também as disrupções na avaliação econômica do prejuízo aos consumidores. Como as VTCDs produzem paradas de produção de caráter não planejado, em muitos casos o prejuízo é muito maior que uma interrupção.

Tabela 5-4 - Custos de Interrupção para cada evento em diferentes categorias de consumidor

\begin{tabular}{|c|c|c|}
\hline classe & nome & $\begin{array}{c}\text { Custo Unitário } \\
\text { Interrupção }(\$ / \mathrm{kWh})\end{array}$ \\
\hline 1 & residencial & 1,15 \\
\hline 2 & comercial & 3,07 \\
\hline 3 & industrial & 1,27 \\
\hline 4 & rural & 1,00 \\
\hline 5 & outros & 1,00 \\
\hline 6 & IP & 0,03 \\
\hline 8 & Equivalente & 1,14 \\
\hline 9 & Hospitais & 0,47 \\
\hline
\end{tabular}

Na Tabela 5-4 são apresentados os valores dos custos unitários da interrupção utilizados para o desenvolvimento deste trabalho. Os valores do custo unitário de interrupção para os consumidores de tipo: residencial, comercial, industrial, foram obtidos como resultado dos valores médios apresentados no trabalho de Massaud et al (1994) [ 71].

Para os consumidores de tipo rural e outros foi considerado custo de 1,0 $\$ / \mathrm{kWh}$. Nas cargas de tipo Iluminação Pública (IP) e consumidores de tipo Hospital, os valores do custo unitário das interrupções foram obtidos do trabalho de Munasinghe e Gellerson (1979)[ 80].

A categoria de consumidor equivalente é representativa de um conjunto de cargas. Isto é muito útil quando se trabalha com redução de redes, onde um bloco de rede é reduzido a 
uma barra equivalente. Nesta categoria o valor da interrupção representa o valor médio das categorias envolvidas, ponderado pelo valor de demanda máxima e energia correspondente.

O valor do custo unitário da disrupção referenciado a demanda de ponta do consumidor, neste trabalho, é assumido 3,0 \$/kW, obtido do trabalho de Motoki (2007)[ 79]. Este valor será considerado o mesmo para todos os tipos de consumidor existentes na Tabela 5-4, porém a metodologia é genérica para inclusão de diferentes valores disponibilizados.

Para o cálculo do custo da interrupção além da demanda média é necessário o período em horas que o consumidor ficou sem suprimento. Em função de dados históricos levantados pela empresa, estes valos médios podem ser obtidos.

Conhecendo então o número de disrupções e Interrupções por ano calculado conforme Item 5.8 e multiplicado pelo seu respectivo custo, é possível obter, para cada consumidor o seu custo por ano, frente a fenômenos relativos às VTCDs e Interrupções de longa duração, seguindo o equacionamento descrito a seguir:

$$
\begin{aligned}
& \text { Custo }_{\text {Disrupcao }(k)}=\left(\text { Cto }_{\text {Disrup }(k)}\right)\left(\operatorname{Dem}_{\text {Pico }(k)}\right)\left(N_{\text {Dis }(k) / \text { ano }}\right) \\
& \text { Custo }_{\text {Interr }(k)}=\left(\text { Cto }_{\text {Interr }(k)}\right)\left(\text { Dem }_{\text {Media }(k)}\right)\left(\operatorname{NHoras}_{\text {Interr }(k)}\right)\left(N_{\text {Int }(k) / \text { ano }}\right) \\
& \text { Custo }_{\text {total }(k)}=\text { Custo }_{\text {Interr }(k)}+\text { Custo }_{\text {Disrupsão }_{(k)}} \\
& \text { Custo }_{\text {total }-\mathrm{Re} d e}=\sum_{i=1}^{n} \text { Custo }_{\text {total }(i)}
\end{aligned}
$$

Em que:

$n$ : Número de consumidores existentes na rede;

$C_{\text {toisrup }(k)}$ : Custo unitário por Disrupção para o k-ésimo consumidor $(\$ / \mathrm{kW})$;

$\operatorname{Dem}_{P i c o(k)}$ : Demanda de pico para uma curva de carga para o k-ésimo consumidor(kW);

$N_{\text {Dis }(k) / a n o}$ : Número de Discupções por ano para o k-ésimo consumidor;

Custo $_{\text {Disrupcao(k): }}$ Custo total da Disrupção para o k-ésimo consumidor (\$);

$C_{\text {tonterr }(k)}$ : Custo unitário por Interrupção para o k-ésimo consumidor $(\$ / \mathrm{kWh})$;

$\operatorname{Dem}_{\text {Media(k) }}$ : Demanda media para uma curva de demanda típica de 24 horas para o k-ésimo consumidor $(\mathrm{kW})$;

NHoras $_{\text {Interr }(k)}$ : Duração média por interrupção para o k-ésimo consumidor (horas);

$N_{\text {Int(k)/ano }}$ : Número de Interrupções por ano para o k-ésimo consumidor;

Custo $_{\text {Interr }(k)}$ : Custo total da Interrupção para o k-ésimo consumidor (\$);

Custo $_{\text {total }(k)}$ : Custo total de Disrupção e Interrupção para o k-ésimo consumidor (\$);

Custo $_{\text {total-Rede }}$ : Custo total das Disrupções e Interrupções existentes na rede (\$); 


\subsection{Algoritmo Utilizado para análise de Áreas de Risco}

Para realizar o cálculo dos índices de VTCDs (afundamentos, elevações e disrupções de tensão) e assim poder analisar as áreas de risco, é realizado o seguinte fluxo de processamento:

1. Armazenar dados da Rede: barras, trechos, cabos, fusíveis, disjuntores, transformadores, cargas, etc.;

2. Escolher um dos métodos de simulação: Monte Carlo, de Enumeração de estados ou Híbrido;

3. Calcular o número de simulações (número de Curtos-Circuitos) em função do método escolhido no passo 2;

4. Obter o conjunto de combinações de Curto-Circuito $\left(\right.$ Conj $\left._{C C}\right)$;

5. Obter o valor da corrente de curto (Icc), utilizando o módulo de Cálculo de CurtoCircuito para o elemento $\left(\right.$ Elem $\left._{C C}\right)$ pertencente ao conjunto $\left(\operatorname{Conj}_{C C}\right)$;

6. Selecionar o equipamento de proteção com a menor curva de proteção $\left(C_{\text {prot }}\right) \mathrm{em}$ função da seletividade considerando a localização do trecho de falta;

7. Obter o tempo de proteção limite para VTCD $\left(T_{V T C D}\right)$ utilizando a curva de proteção $\left(C_{\text {prot }}\right)$ em função da corrente de curto-circuito $(I c c)$;

8. Obter a probabilidade de VTCD ( $\left.\operatorname{Prob}_{V T C D}\right)$ utilizado a distribuição acumulada do tempo de Extinção da Falha em função do tempo $\left(T_{V T C D}\right)$. Obter também a probabilidade de interrupção $\left(\operatorname{Prob}_{\text {Interr }}=1-\operatorname{Prob}_{V T C D}\right)$;

9. Obter o valor do afundamento ou elevação de tensão, para todas as barras utilizando o módulo de Cálculo de Curto-Circuito para as condições de falta $\left(\right.$ Elem $\left._{C C}\right)$;

10. Armazenar estatisticamente o número de ocorrências de interrupções, VTCDs e Disrupções a partir dos valores de $\left(\right.$ Prob $\left._{V T C D}\right)$ nas faixas correspondentes em função do nível de tensão e do tempo até o tempo de duração $T_{V T C D}$. Realizar a análise de sensibilidade utilizando das curvas de sensibilidade do equipamento para cada consumidor analisado.

11. Testar se foram analisadas todas as combinações de Curto-Circuito do conjunto $\left(\operatorname{Conj}_{C C}\right)$. Se não, voltar para o passo 5; caso contrário, ir para o passo 12;

12. Anualizar as Interrupções, afundamentos, elevações e Disrupções de tensão em todas as barras da rede; 
13. Calcular o custo das Interrupções e das Disrupções para cada consumidor existente na rede;

14. Executar a visualização gráfica da rede com os índices anualizados.

15. Imprimir Relatórios dos resultados para todas as barras.

O diagrama de blocos da Figura 5-10 ilustra o procedimento descrito. 


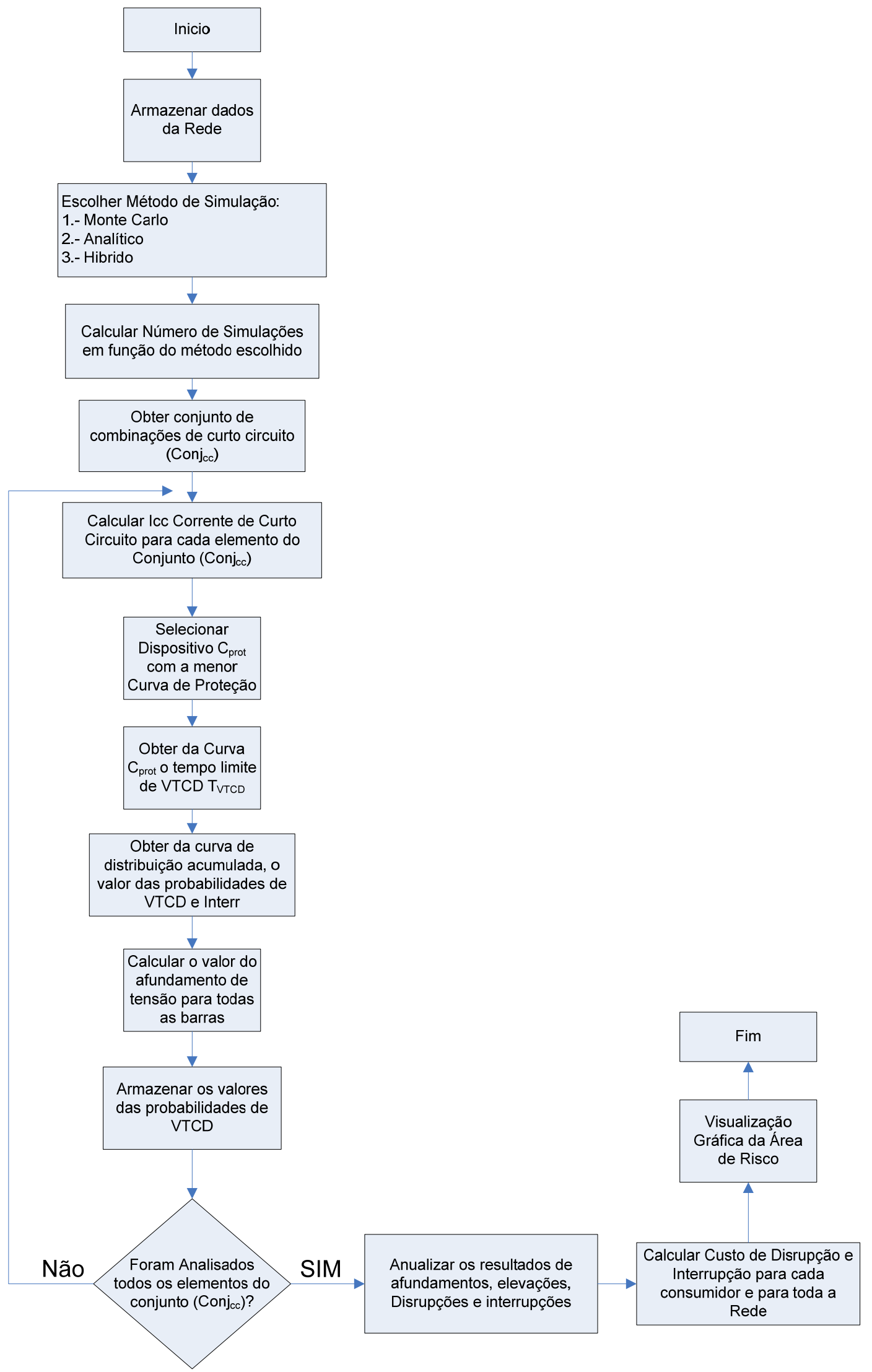

Figura 5-10 - Diagrama de blocos Utilizado na obtenção de índices de VTCDs e Análise de Área de risco 


\section{6 - PLANEJAMENTO DE SISTEMAS DE CONSIDERANDO CUSTOS DA QEE}

O planejamento de sistemas de distribuição de energia elétrica pode ser dividido em três categorias, a saber:

- O planejamento estratégico, de longo prazo, que determina basicamente os investimentos necessários para a expansão do sistema de distribuição, considerando aspectos de incertezas no mercado e demais variáveis do planejamento. Em geral, este tipo de enfoque é baseado em informações agregadas, como é o caso do sistema SISPAI, desenvolvido para este tipo de estudo[ 43][ 44]. Este tipo de estudo apresenta, em geral, horizonte de 5 a 20 anos.

- O planejamento tático, de médio prazo, que determina os planos de obras para expansão do sistema de distribuição, congregando problemas de alocação de novas subestações, novos alimentadores, recondutoramento e determinação da melhor configuração da rede para atendimento do mercado crescente. Este tipo de estudo apresenta, em geral, horizonte de 3 a 5 anos.

- O planejamento operacional, de curto prazo, quando são determinadas ações necessárias para atendimento de algumas condições de curto prazo, como é o caso de planos de manobras para o atendimento de contingências no sistema de distribuição, determinação da melhor configuração da rede para a minimização de determinados objetivos, como é o caso de minimização das perdas, alívio e balanceamento de cargas entre alimentadores, dentre outros.

Os estudos acima têm evoluído muito nos últimos 20 anos, através da utilização de ferramentas que possibilitam o tratamento de redes de grande porte e análise de diversos cenários possíveis, contemplando os aspectos de incerteza nos dados dos problemas. Quanto aos objetivos almejados, destacam-se, principalmente para os planos de expansão, a determinação de alternativas que minimizam os custos de investimento em obras no sistema e custos variáveis, englobando as perdas técnicas no sistema de distribuição. Nas restrições do problema, considera-se o atendimento às restrições técnicas do problema, que constituem 
balanço de demanda, carregamento máximo dos componentes de rede, níveis de tensão em faixas aceitáveis, dentre outros.

O problema de configuração das redes é aplicável para as situações de estudos de planejamento de médio e longo prazo[ 7][ 25][ 68]. A evolução dos métodos mostra a utilização de técnicas convencionais de otimização, como a utilização de programação linear, programação linear inteira mista, programação quadrática, programação dinâmica, dentre outros. No entanto, dada a natureza combinatória do problema, estes métodos apresentam dificuldades para o tratamento de redes de distribuição de médio e grande porte. Com isso, algoritmos baseados em meta-heurísticas vêm ganhando espaço, por sua enorme capacidade de determinar boas soluções para esses problemas. Em particular, pode-se citar os algoritmos evolutivos [ 20][ 62], que foram aplicados para a solução dos problemas com bastante sucesso.

Deve-se salientar que os modelos não consideram explicitamente na função objetivo aspectos relativos às interrupções e variações de tensão de curta duração. Alguns métodos, no entanto, já levam em conta a minimização da energia não distribuída, através de formulações simplificadas do problema [7]. Os modelos desenvolvidos nos capítulos anteriores permitem a comparação de alternativas de planejamento de curto e médio prazo, considerando os custos decorrentes de interrupções de longa duração e das disrupções em processos causadas por variações de tensão de curta duração. Estes custos podem ser incorporados à função objetivo, como será visto neste capítulo, permitindo que os modelos de planejamento sejam mais robustos, levando em conta estes importantes aspectos de qualidade de energia elétrica (QEE) na comparação de alternativas de configuração de redes.

\subsection{Inclusão do Custo da QEE no Planejamento de Operação}

Os sistemas aéreos de distribuição de energia elétrica por sua característica radial apresentam possibilidades de alteração da topologia através da abertura/fechamento de chaves seccionadoras localizadas em pontos estratégicos. A alteração da topologia, mantendo-se a radialidade, é realizada de modo a reduzir as perdas ativas nos alimentadores, melhorar o perfil de tensão para os consumidores, aumentar os níveis de confiabilidade e, em situações de manutenção programada ou manutenção corretiva (defeitos) eliminar e/ou isolar áreas em manutenção, e serem utilizadas para restaurar o fornecimento de energia em áreas desenergizadas. Reconfiguração de redes aéreas de distribuição de energia elétrica constitui-se 
em um problema que pode ser modelado através de Programação Não-linear Inteiro Mista (PNLIM). Tal formulação gera espaços de busca muito grandes, em que a exigência de radialidade da rede elétrica (principalmente nos sistemas de distribuição aéreos) é uma dificuldade adicional e, dada sua natureza combinatória, resulta num problema de difícil tratamento. Em conseqüência dessas dificuldades para resolução de problemas com essas características, além das técnicas de otimização clássica e combinatorial são propostos por alguns pesquisadores os algoritmos heurísticos.

Com o objetivo de reduzir o espaço de busca, muitos autores têm proposto, para a solução do problema de reconfiguração de redes de distribuição, as técnicas heurísticas que consistem em um conjunto de procedimentos simples, muitas vezes baseados em procedimentos práticos retirados da experiência dos operadores, que encontram soluções de boa qualidade para problemas complexos com esforço computacional relativamente pequeno sem, entretanto, garantirem a determinação da solução ótima. Na literatura são propostas várias técnicas heurísticas para reconfiguração de rede de distribuição dentre as quais destacase a técnica do importante trabalho de Cinvalar et al. (1988)[ 25], que propõe uma metodologia heurística para ser utilizada como ferramenta tanto de planejamento como de controle em tempo real (operação on-line) na reconfiguração de alimentadores primários, objetivando a redução de perdas. A técnica de solução proposta tem a capacidade de estimar, com mínimo esforço computacional, as mudanças nas perdas que resultam da reconfiguração dos alimentadores. Utilizam como critério para reduzir o número de reconfigurações candidatas, uma fórmula interessante e de uso simples que exclui opções indesejadas de chaveamentos sem a necessidade de se efetuar numerosos cálculos de fluxo de potência, reduzindo significativamente o esforço computacional. Baran e Wu et al.(1989)[7] tratam o problema de reconfiguração de redes em sistemas de distribuição para redução de perdas e balanceamento de cargas, utilizando a aproximação proposta por Cinvalar et al. (1988)[ 25] para abertura dos laços, quando da realização das operações de chaveamento, para a reconfiguração da rede.

\subsubsection{Formulação Clássica do Problema de Reconfiguração}

Os sistemas aéreos de distribuição de energia elétrica são, na grande maioria, configurados radialmente com o propósito de facilitar fatores inerentes à proteção, tais como: coordenação e atenuação de correntes de curto-circuito visando diminuir custos com equipamentos. Em geral, esses sistemas apresentam possibilidades de alteração da topologia, 
através da abertura/fechamento de chaves seccionadoras localizadas em pontos estratégicos. Em condição normal, a alteração da topologia mantendo-se a radialidade é realizada de modo a reduzir as perdas ativas nos alimentadores, melhorar o perfil de tensão para os consumidores e aumentar os níveis de confiabilidade.

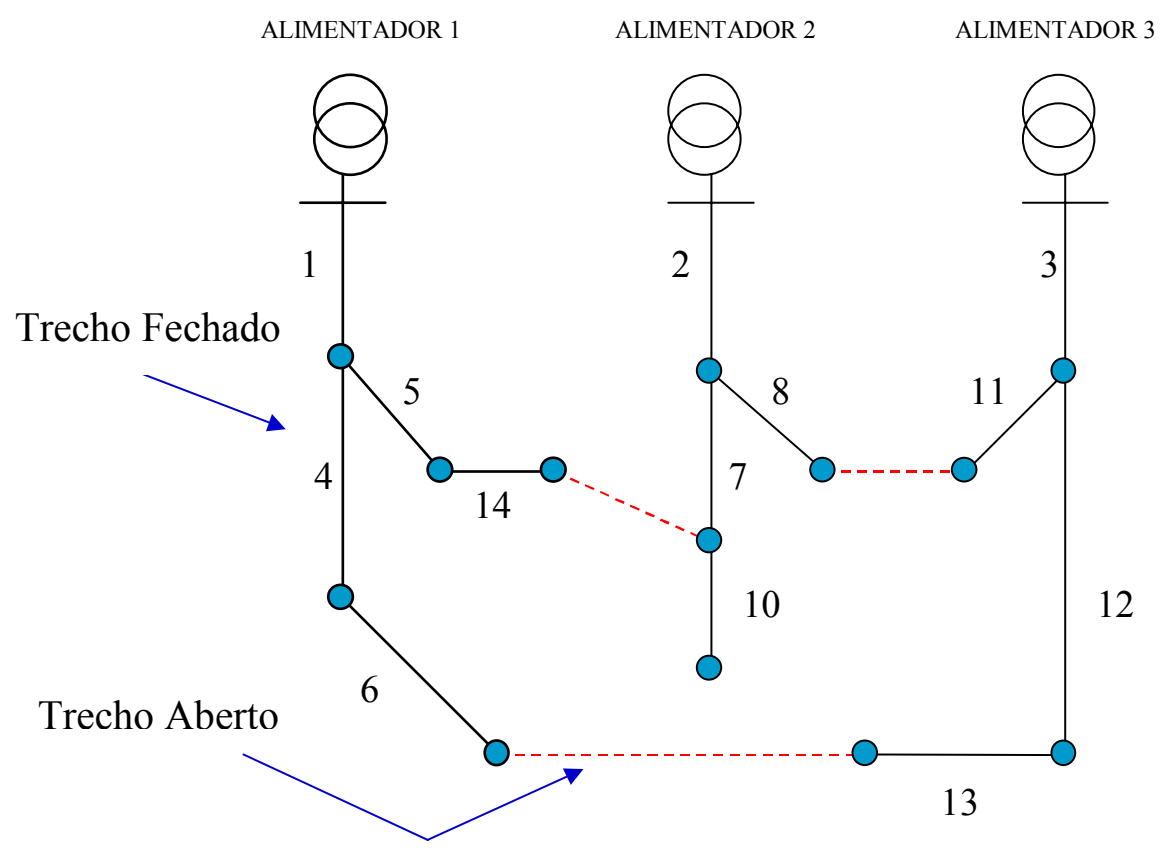

Figura 6.1- Diagrama unifilar de um sistema de distribuição simples

Na Figura 6-1, pode ser observada uma pequena rede de distribuição representativa. Uma troca adequada de trechos entre alimentadores leva a outra configuração radial. Portanto, o problema de reconfiguração ótima de um sistema de distribuição consiste em encontrar aquela configuração radial, do espaço de configurações radiais possíveis, que produza perdas mínimas de potência. Este processo de busca ótima implica analisar implícita ou explicitamente todas as configurações radiais possíveis.

Sendo um problema de otimização, cuja solução envolve a seleção dentre todas as configurações possíveis daquela alternativa que minimiza uma função objetivo sujeito ao atendimento de um conjunto de critérios técnicos, de forma geral, o problema de reconfiguração de sistema radiais, para minimização das perdas, pode ser formulado como:

$$
\text { Mimimizar } \quad f a_{k F}=\sum_{i=1}^{N_{\text {Tre }}} R_{i} \times I_{i}^{2}
$$

Sujeito às restrições:

-Restrições de fluxo de carga;

-Radialidade;

-Restrições de níveis de tensão; 
-Confiabilidade do Sistema;

-Balanço de carga entre os alimentadores;

-Restrições de carregamento nos trechos.

Em que:

$\mathrm{k} \varepsilon \mathrm{K}: \mathrm{K}$ conjunto de todas as configurações radiais factíveis para o sistema;

$f_{a k F}$ : Função Objetivo dos ramos da k-ésima configuração;

$R_{i}$ : Resistência do i-ésimo ramo da k-ésima configuração;

$I_{i}$ : Corrente do i-ésimo ramo da k-ésima configuração;

$N_{\text {Tre }}$ : Número de trechos da k-ésima configuração;

$N_{b}$ : Número de barras da k-ésima configuração.

\subsubsection{Restrições de fluxo de Potência}

As Restrições de fluxo de potência determinam o estado da rede, em que as leis de Kirchhoff ("lei dos nós" e "lei das malhas") devem-se ser respeitadas para qualquer condição ou configuração de rede. Para cumprir estas restrições, geralmente é utilizado um algoritmo de fluxo de potência (principalmente em procedimentos que analisam soluções completas do problema, como é o caso de métodos de solução por algoritmos genéticos e por busca heurística) ou as equações correspondentes são incorporadas na formulação de programação matemática como restrições explícitas.

\subsubsection{Restrição de Radialidade}

Por questões da viabilidade técnica/operacional, é comum que as redes de distribuição (especialmente urbanas) apresentem estruturas malhadas, sendo a operação do sistema feita radialmente. Assim, são permitidas reconfigurações do sistema em caso de contingência (por exemplo, saída de serviço de um ramo ou transformador), em que se busca encontrar uma configuração que possua características radiais dependendo da localização geográfica da rede e dos critérios da companhia distribuidora, normalmente relacionados com a segurança do serviço.

No problema de reconfiguração de redes, considera-se que, em cada trecho, existe uma chave seccionadora. Nos trechos energizados, as chaves estão fechadas (NF) e nos trechos não energizados as chaves estão abertas (NA). Assim, uma operação de chaveamento será a que envolve a troca de posições de diferentes trechos pela abertura e fechamento das suas 
respectivas chaves seccionadoras, de forma a minimizar as perdas de potência e manter a radialidade do sistema.

\subsubsection{Restrição do Nível de tensão}

O nível de tensão no consumidor é determinado pela tensão na subestação e pelas quedas de tensão nas linhas de distribuição (pontos de consumo) e transformadores, variando com flutuações nos níveis de consumo.

Normalmente, dividem-se as quedas de tensão em dois grupos: flutuações rápidas e flutuações lentas. As variações lentas são causadas, principalmente, por variações graduais nas demandas e por flutuações na tensão dos barramentos das subestações. Este tipo de variação, também chamado de variação de tensão de longa duração, tem um efeito considerável na eficiência e tempo de vida útil dos equipamentos dos consumidores. Normalmente é imposto um limite máximo de desvio em relação à tensão nominal durante as flutuações de tensão nas redes de distribuição [ 4].

As flutuações lentas de tensão têm, então, uma grande importância na qualidade de serviço e, consequentemente, consistem em um fator a considerar no planejamento e na operação dos sistemas de distribuição. Dessa forma, alternativas de reconfiguração do sistema que apresentam uma barra ou conjunto de barras abaixo de um valor pré-estabelecido em relação à tensão nominal devem ser penalizadas. A restrição de máxima queda de tensão pode ser escrita como a seguir:

$$
V_{i} \geq V_{\text {nom }}\left(1-\frac{\% \Delta V}{100}\right)
$$

Em que:

$V_{i}$ : Tensão avaliada da $i$-ésima barra do sistema;

$V_{\text {nom }}:$ Tensão nominal de operação;

$\% \Delta V:$ Porcentagem máxima permitida de queda de tensão, sobre a tensão nominal.

\subsubsection{Restrições de confiabilidade}

A maioria dos sistemas de distribuição são projetados para operar de forma radial. As redes radiais têm algumas vantagens sobre as redes malhadas tais como baixas correntes de 
curto-circuito, equipamentos de proteção e chaveamento simples e, conseqüentemente, baixos custos de manutenção, construção e operação. Por outro lado, a estrutura radial por si só confere baixa confiabilidade aos sistemas. Portanto, para fazer uso dos benefícios da estrutura radial e ao mesmo tempo controlar as dificuldades decorrentes do baixo índice de confiabilidade, os sistemas de distribuição são construídos com chaves de interconexão localizadas em pontos estratégicos que, sob diferentes condições de operação, podem ser usadas tanto para a proteção (isolamento de faltas) quanto para o gerenciamento da topologia da rede (reconfiguração). A reconfiguração pode ser realizada pela mudança do estado (aberta/fechada) das chaves da rede de tal modo que a radialidade é sempre restabelecida depois de feitas as manobras. Modelos simples de avaliação de confiabilidade podem ser incorporados ao modelo de planejamento, como é o caso de se levar em conta a minimização da energia não distribuída.

Este trabalho permite uma avaliação precisa dos indicadores relacionados às interrupções de longa duração, e é proposta uma maneira de custear o seu impacto sobre os consumidores.

\subsubsection{Restrições de balanço de carga entre os alimentadores}

A modificação da topologia da rede dinamicamente, pela reconfiguração da rede, transferindo cargas entre alimentadores pode melhorar de modo significativo as condições de operação de todo o sistema. Essa modificação pode ocorrer diariamente em horários de pico, semanalmente em conseqüência do consumo irregular durante os dias da semana ou ainda de acordo com a sazonalidade. Como os alimentadores do sistema de distribuição possuem diferentes tipos de cargas (residencial, comercial, industrial, etc.), os picos de carga em transformadores, alimentadores individuais, ou em partes de alguns alimentadores ocorrem em horários diferentes. Isto possibilita a transferência de carga de um alimentador ou transformador mais carregado para um outro relativamente menos carregado, de modo que o remanejamento de carga seja eficiente na melhoria do perfil de tensão de toda a rede, com significativa redução nas perdas globais do sistema de distribuição de energia elétrica.

De modo geral, em condições normais, a reconfiguração da rede é realizada visando a redução das perdas ativas nos alimentadores, melhoria do perfil de tensão para os consumidores, aumento da confiabilidade, isto é, buscar uma condição ótima de operação das redes de distribuição sem nenhuma violação nos limites de carregamento dos trechos e do limites de queda de tensão nas barras dos consumidores. 


\subsubsection{Restrições de fluxo de potência nos Trechos}

O máximo valor do fluxo de potência nos trechos está associado à máxima corrente (intensidade) que pode circular por um condutor elétrico dependendo de sua seção nominal, nível de isolação, condições de operação (regime permanente, temperatura do ambiente, condutores aéreos ou subterrâneos), etc. de forma que não se produza uma elevação da temperatura além da admissível. Esta intensidade máxima chama-se intensidade máxima admissível ou simplesmente capacidade admissível. Os componentes de rede que possuam fluxos maiores do que sua capacidade admissível devem ser penalizados. A restrição aplicável a um componente de rede $i j$ é dada por:

$$
\left|f_{i j}\right| \leq \bar{f}_{i j}
$$

Em que:

$f_{i j}$ : Fluxo no ramo i-j;

$\bar{f}_{i j}$ : Capacidade admissível do ramo i-j.

\subsubsection{Formulação do Problema de Reconfiguração considerando Custos da QEE}

A partir da formulação clássica do problema de reconfiguração, exposta no Item 6.1.1, pode-se ampliar tal formulação para a inclusão dos efeitos das interrupções e dos índices de VTCDs sobre os consumidores do sistema, que são incorporados na função objetivo a ser minimizada. Desta maneira, o modelo leva em conta não somente o efeito das perdas na rede estudada, mas também o efeito das interrupções de longa duração e das disrupções por afundamentos e elevações de tensão em todos os consumidores da rede.

A nova função objetivo, nestas condições, pode ser dada por:

$\operatorname{Mim} f a_{(i)}=$ Cto $_{\text {Perda }} \times$ Perdas $_{(i)} \times H_{\text {ano }}+\sum_{k=1}^{N_{\text {Cons }}}\left(\right.$ Custo $_{\operatorname{Interr}(k)(i)}+$ Custo $\left._{\text {Disrup }(k)(i)}\right)$

Em que:

$i$ : Índice da configuração da rede;

$k$ : Índice do consumidor pertencente à rede;

$N_{\text {Cons: }}$ : Número total de consumidores;

$f a_{(i)}$ : Função objetivo, considerando interrupções e disrupções para uma configuração i;

$C$ to $_{P e r d a}$ : Custo unitário da perda nas redes $(\$ / \mathrm{kWh})$; 
$\operatorname{Perdas}_{(i)}$ : Perdas Ativas totais na rede para a configuração i $(\mathrm{kW})$;

Hano: Número de horas existentes em um ano;

Custo $_{\text {Interr }(k)(i)}$ : Custo da interrupção no consumidor k, para a configuração i (\$/ano);

Custo $_{\text {Disrup(k)(i): }}$ : Custo da disrupção no consumidor k, para a configuração i (\$/ano).

As restrições do problema são basicamente as mesmas, ou seja:

-Restrições de fluxo de carga;

-Radialidade;

-Restrições de níveis de tensão;

-Confiabilidade do sistema;

-Balanço de carga entre os alimentadores;

-Restrições de carregamento nos trechos.

Sabe-se que, durante a execução de algoritmos de busca heurística, na procura da minimização da função objetivo, o processo de reconfiguração gera muitos casos de configurações inviáveis ou infactíveis. Para estas configurações, obviamente não é necessário obter o custo das interrupções e disrupções, já que estas configurações serão penalizadas por não cumprirem das restrições operacionais.

\subsubsection{Inclusão Prática dos Custos da QEE no Problema de Reconfiguração}

Muitos autores, encontrados na bibliografia, entre eles Qin et al (1997) [ 89], Young et al (2002) [ 111], Kuo et al (1994) [ 58], resolvem o problema clássico de Reconfiguração utilizando diferentes métodos e técnicas. A maioria destes métodos obtêm uma lista soluções durante o processamento ou como resultado do processamento, que representa o conjunto de configurações que obtiveram melhor função objetivo do ponto de vista de diminuição de perdas, todas elas cumprindo as restrições preestabelecidas.

Uma forma muito simples e prática para considerar o custo da QEE nas soluções obtidas por diferentes algoritmos consiste em aplicar o equacionamento do Item 6.1.2 para cada configuração obtida. Desta maneira, pode-se realizar outro tipo de ordenação, não somente considerando a menor perda ativa, e sim o menor custo monetário incluído, além do custo das perdas, o custo da energia não distribuída (por interrupções de longa duração) e o custo da disrupção de processos nos consumidores (por variações de tensão de curta duração). 
Como exemplo, sejam 2 configurações geradas por um algoritmo de reconfiguração de

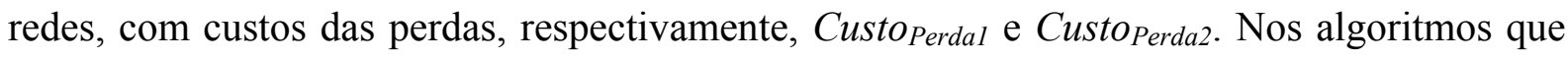
minimizam o custo das perdas, bastaria comparar os dois custos para ordenar estas duas alternativas.

Para realizar a inclusão prática do custo da QEE, o valor do custo das interrupções e das disrupções para cada configuração (obtido por um dos métodos descrito no capítulo 4 desta tese) deve ser obtido de forma a serem comparados os aqui denominados custos totais:

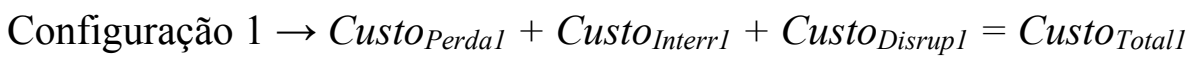

Configuração $2 \rightarrow$ Custo $_{\text {Perda2 }}+$ Custo $_{\text {Interr2 }}+$ Custo $_{\text {Disrup } 2}=$ Custo $_{\text {Total } 2}$

A inclusão do custo da QEE na reconfiguração das redes de distribuição se dá de forma bastante simples, podendo ser realizada de duas formas:

- pós-otimização, quando o modelo determina um conjunto das melhorias alternativas que reduzem as perdas ativas do sistema e atendem os critérios técnicos e só então são considerados os custos de interrupção e disrupção. Esta alternativa apresenta a vantagem de serem avaliadas poucas alternativas (configurações) durante a obtenção dos custos da QEE;

- durante a otimização do problema de reconfiguração de redes, cada alternativa de topologia proposta é submetida a: i) um programa de fluxo de potência para obtenção dos parâmetros elétricos (perdas, carregamentos, níveis de tensão) e seu impacto na função objetivo e nas restrições do problema e ii) um programa de análise de QEE, para obtenção dos custos de interrupção e disrupção sobre os consumidores do sistema. Esta alternativa apresenta desvantagem quanto ao tempo de processamento, pois todas as configurações factíveis são submetidas no programa de análise de QEE, porém a alternativa a ser obtida apresenta maior chance de ser uma alternativa de ótimo global do sistema.

\subsection{Inclusão do Custo da QEE no Planejamento da Expansão}

O problema clássico de planejamento da expansão em sistemas de distribuição de energia elétrica, em horizonte de médio prazo, consiste em determinar a capacidade, a localização e o instante de instalação dos novos equipamentos de distribuição, considerando as restrições de capacidade das linhas, queda de tensão e segurança no atendimento da demanda, como foi tratada nos trabalhos de Lakervi e Holmes (1995)[ 59]; Temraz e Quintana (1993) [ 106], Romero et al (2002) [ 94]. 
Inicialmente, diversos autores tentaram resolver este problema de forma simplificada, considerando um modelo de planejamento estático para um determinado horizonte, como apresentado por, Sun et al (1982) [ 104]; Aoki et al (1990) [ 5]. Destes trabalhos, resultou a formalização do problema em um único estágio, no qual os recursos necessários para o horizonte de planejamento são introduzidos de uma só vez. Geralmente utiliza-se um horizonte de curto/médio prazo para que sejam selecionados os investimentos que correspondam às reais necessidades da rede, pois as incertezas nas previsões tendem a aumentar quando o horizonte se amplia.

Posteriormente, o problema foi adequado para considerar um horizonte de médio/longo prazo, como foi apresentado no trabalho de Nara et al (1992) [ 81]. Esta abordagem deu origem à formulação do problema em múltiplos estágios, nos quais os recursos necessários para o horizonte de planejamento podem ser distribuídos de acordo com as necessidades previstas para cada estágio. Desta forma, as concessionárias podem acompanhar o crescimento gradual da demanda e realizar o planejamento a mínimo custo, considerando um horizonte maior. Os investimentos definidos para as etapas iniciais são efetivamente executados enquanto os investimentos definidos para as etapas finais são reavaliados no futuro considerando previsões atualizadas. Assim, o horizonte de planejamento desloca-se dinamicamente, de modo que o estágio inicial sempre coincida com o período (mês ou ano) de execução.

Os métodos de solução usados para resolver o problema de expansão podem ser divididos em duas categorias: métodos de programação matemática e métodos heurísticos, incluindo sistemas especialistas e algoritmos evolucionários. Entre os métodos de programação matemática destaca-se a programação inteira mista, a programação linear, a programação não-linear e a programação dinâmica. Com esta abordagem é possível representar explicitamente as principais restrições (Leis de Kirchhoff, capacidade dos equipamentos, queda de tensão e orçamento) e minimizar os custos fixos e variáveis relacionadas com a instalação e substituição de equipamentos. Nas abordagens via programação inteira mista, a introdução de considerações práticas freqüentemente limita o número de soluções e torna os problemas combinatoriais associados computacionalmente tratáveis. Este fato, associado à possibilidade de garantia de otimalidade e a capacidade de processamento dos computadores disponíveis atualmente, torna esta abordagem muito atrativa.

Desde 1980, grandes esforços têm sido investidos na solução do problema de planejamento da distribuição empregando algoritmos heurísticos, que se tornaram uma 
alternativa aos métodos de programação matemática. Os métodos heurísticos ganharam espaço pela facilidade em considerar restrições e funções objetivos não-lineares, embora não existam garantias de que a solução ótima do problema seja obtida. Ainda, com esta abordagem é possível introduzir mais facilmente aspectos como perdas, confiabilidade e incertezas. Entre os métodos heurísticos destacam-se os algoritmos denominados "branch exchange" apresentados por Aoki et al (1990) [ 5] e Míguez et al, (2002) [ 78] e os algoritmos baseados em computação evolucionária apresentado por Díaz-Dorado et al (2002) [ 26]. Outros métodos heurísticos também têm sido empregados na solução deste problema tais como os sistemas especialistas em Ranjan et al (2002) [ 90], colônia de formigas em Gómez et al (2004) [ 41], "simulated annealing” em Parada et al (2004) [ 86] e busca tabu em Bazan et al (2003) [ 8].

\subsubsection{Planejamento Estático}

É conhecido como planejamento estático quando as obras de construção de um sistema são realizados em um único estágio. Este planejamento é realizado quando as obras a serem executadas são pequenas, ou seja, o montante dos investimentos é baixo não necessitando de mais de uma fase para a construção.

No planejamento estático é assumido que todos os investimentos são realizados no início do horizonte de planejamento. Neste tipo de planejamento, o objetivo é encontrar a solução na qual os custos fixos e custos de operação sejam mínimos para o período de tempo considerado. Assim todos os investimentos são realizados no início do horizonte de planejamento.

\subsubsection{Planejamento Multi-Estágios (Dinâmico)}

O período de planejamento é geralmente dividido em vários estágios, por exemplo, períodos de um ano. Isto é normalmente realizado em modelos em que a demanda é considerada constante durante cada estágio. O problema de planejamento de sistemas de distribuição é tipicamente multi-estágios porque a expansão do sistema é uma função temporal. A construção de um sistema quando apenas um estágio é considerado é um caso especial do problema de planejamento multi-estágios. O planejamento multi-estágios aumenta o tamanho do problema e como conseqüência o esforço computacional. 
Este modelo de planejamento também é conhecido como problema dinâmico. As decisões de investimento de um sistema são realizadas simultaneamente no horizonte que é realizado o planejamento. O sistema é construído por fases tentando fazer os investimentos conforme sejam necessários, dependendo de estudos de crescimento da carga. Neste tipo de planejamento é determinado onde e quantos componentes para a rede devem ser instalados, assim como quando novos investimentos devem ser realizados.

Como o planejamento é realizado em diferentes etapas, é lógico pensar que os custos dos investimentos mudam nos diferentes estágios. Surge então a necessidade de atualização destes custos, ou seja, os custos de investimento dos diferentes horizontes de planejamento devem ser avaliados para um instante de tempo determinado, sendo afetados por uma taxa de atualização do capital.

No exemplo seguinte é considerado um problema de investimento com $\boldsymbol{n}$ estágios em $\boldsymbol{t}_{\boldsymbol{n}}$ anos, com uma taxa de atualização do capital $\boldsymbol{I}$.

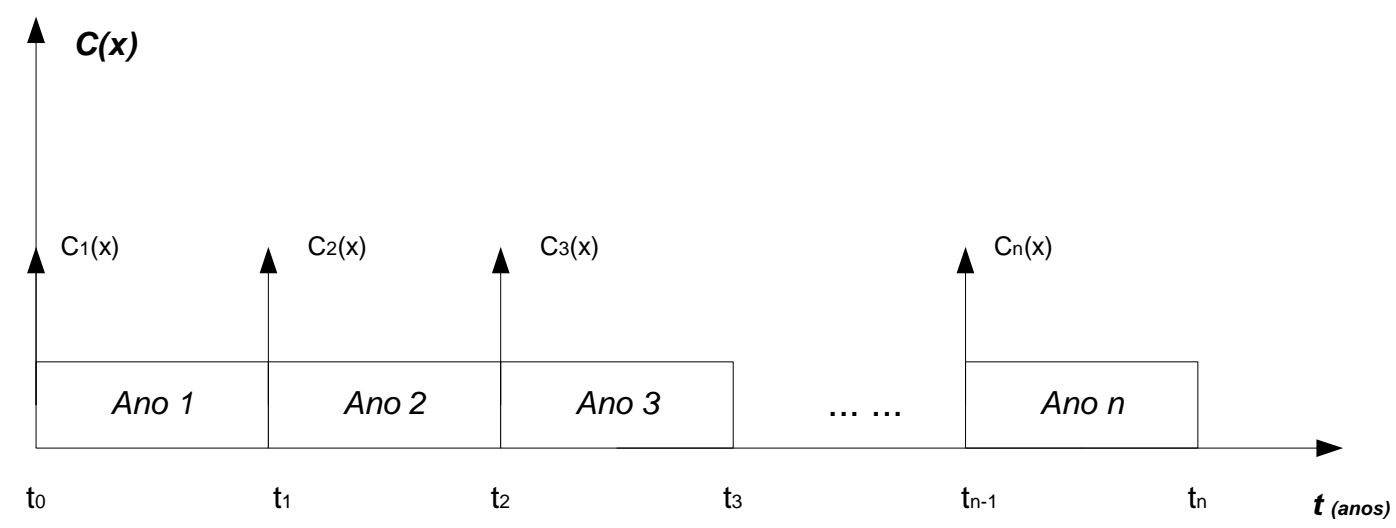

Figura 6-1 - Exemplo do planejamento de investimentos com n estágios

O custo atualizado para o ano $t_{0}$ será:

$$
C(x)=C_{1}(x) /(1+I)^{t 1-t 0}+C_{2}(x) /(1+I)^{t 2-t 0}+C_{3}(x) /(1+I)^{t 3-t 0}+\ldots \ldots+C_{n}(x) /(1+I)^{t n-t 0}
$$

Em que:

$C i(x)$ : Custo de investimento no estágio $i$

I: Taxa de amortização (em anos);

$t_{i}$ : Tempo do estágio em que são construídas as linhas e as subestações do sistema;

$t_{0}$ : Tempo inicial do horizonte de planejamento. 


\subsubsection{Planejamento Pseudo-dinâmico}

O planejamento pseudo-dinâmico consiste em utilizar o planejamento estático várias vezes. Para cada estágio do horizonte de planejamento são utilizados os resultados do planejamento estático do estágio anterior para iniciar o processo de um novo planejamento estático. O planejamento estático é chamado tantas vezes quanto for o número de estágios, mas considerando que para cada novo estágio o processo é iniciado com o sistema resultante proposto pelo planejamento anterior.

Uma opção mais interessante do planejamento pseudo-dinâmico é proposta em Kagan (1992) [ 53] e por Bazan (2003) [ 8], quando um planejamento estático é realizado inicialmente para a obtenção da rede para o horizonte de estudo, o que é denominado de rede alvo. O processo volta então ao início, conforme a alternativa anterior, para avaliar o planejamento estático para cada estágio. A diferença básica é que somente aquelas obras da rede alvo são consideradas nos processos intermediários de otimização.

\subsubsection{Formulação Clássica do Problema de Planejamento de Expansão}

O problema básico do planejamento de expansão de sistemas de distribuição consiste na minimização dos custos totais da expansão do sistema, considerando basicamente a construção de linhas, construção de novas subestações e ampliação das existentes e a mudança da bitola de alimentadores existentes (recondutoramento). Os principais aspectos técnicos e econômicos envolvidos no planejamento da expansão de em redes de distribuição são os seguintes:

i) Economia: Minimizar os custos de investimentos, operação e as perdas elétricas.

ii) Confiabilidade: Maximizar a flexibilidade do sistema, para garantir sua confiabilidade.

iii)Segurança: Tem o objetivo de preservar a integridade física e elétrica dos condutores e equipamentos do sistema. A avaliação do estado físico dos condutores e equipamentos é efetuada através da observação de normas mínimas de segurança.

iv) Qualidade de serviço: Este aspecto está relacionando com os níveis de tensão e variações máximas e mínimas especificadas pelas normas de cada país.

As restrições consideradas serão as mesmas apresentadas no Item 6.1.1: leis de Kirchhoff, limites de tensão e carregamento e radialidade da rede. 


\subsubsection{Função objetivo - Planejamento ótimo estático Clássico}

Esse modelo considera uma função objetivo que representa os custos de expansão fixos e variáveis. Os custos fixos são correspondentes às linhas e subestações do sistema de energia elétrica, representando os investimentos na instalação de novos equipamentos nos sistemas. Os custos variáveis correspondem aos custos de operação, ou dispêndios necessários para operar o sistema elétrico, que consideram as perdas nas linhas. A função objetivo é representada pela seguinte equação matemática:

$$
F O=\sum_{i=1}^{N S} C S_{i} X_{S}+\sum_{j=1}^{N L} C F_{L j} X_{L j} d_{L j}+\sum_{j=1}^{N L} C V_{M V A j} p\left(R_{L j} S_{L j}^{2}\right) d_{L j}
$$

Em que :

$C S_{i}$ : $\quad$ Custo da Subestação i $(\mathrm{R} \$)$;

$X_{s}$ : $\quad$ Variável que define a existência da subestação i (1 subestação é construída, 0 subestação não é construída);

$C F_{L j}: \quad$ Custo fixo do trecho $\mathrm{j}(\mathrm{R} \$ / \mathrm{km})$;

$X_{L j}$ : $\quad$ Variável que define a existência da linha j (1 linha é construída, 0 linha não é construída);

$P\left(\right.$. ): $\quad$ Perda por comprimento do trecho j, função da resistência $R_{L j}$ e do quadrado do fluxo $S_{L j}(\mathrm{MW} / \mathrm{km})$;

$C V_{M V j}$ : Custo variável, em função das perdas na linha $j$ (Unid/MW);

$S_{L j}: \quad \quad \quad \quad$ Fluxo de potência na linha j (MVA);

$d_{L j}$ : $\quad$ Comprimento da linha $\mathrm{j}(\mathrm{km})$;

NS: $\quad$ Número de subestações totais;

NL: $\quad$ Número de Trechos totais.

\subsubsection{Função objetivo - Planejamento ótimo Dinâmico clássico}

No planejamento dinâmico, existe uma variável adicional que é o tempo. Assim, determinam-se os estágios do planejamento quando serão construídos os diferentes reforços no sistema elétrico, sejam eles novas linhas, novas subestações, assim como a troca dos condutores por outro(s) de maior capacidade (recondutoramento). Desta forma, no planejamento dinâmico a função objetivo pode ser representada como: 


$$
\begin{gathered}
F O_{\text {dinamico }}=\left(C F_{E s t 1}+C V_{E s t 1}\right)+\left(C F_{E s t 2}+C V_{E s t 2}\right)(1+I)^{t 1-t 0}+ \\
\left(C F_{E s t 3}+C V_{E s t 3}\right)(1+I)^{t 2-t 0}+\ldots \ldots+\left(C F_{E s t n}+C V_{E s t n}\right)(1+I)^{t n-t 0}
\end{gathered}
$$

Em que:

$C F_{E s t i}:$ Custo fixo no estágio $i$, incluindo custo de novos alimentadores, custo de novas subestações e custo de recondutoramento;

$C V_{E s t i}$ : Custo variável do estágio $i$, incluindo custos de perdas no sistema;

I: $\quad$ Taxa de atualização do capital;

$t_{i}$ : $\quad$ Tempo para o estágio $i$;

$t_{0}: \quad$ Tempo inicial do horizonte do planejamento.

\subsubsection{Ações durante o Planejamento de Expansão}

No desenvolvimento deste trabalho, são considerados os seguintes reforços para o planejamento da expansão: Novos trechos de rede e chaves de manobra, novos alimentadores em subestações existentes, novas subestações, ampliação de subestações existentes e recondutoramento de trechos de rede.

\section{i) Novos trechos de rede e chaves de manobra}

Este tipo de ação de planejamento analisa dois tipos distintos de proposição de reforços a serem instalados na rede. Tanto para a instalação de novos trechos como de novas chaves de manobra, o valor do custo fixo será igual à soma do custo do investimento e do custo de instalação (mão de obra) destes equipamentos. O valor dos custos variáveis são determinados pelo produto entre o custo unitário das perdas e as perdas determinadas por um algoritmo de fluxo de potência, para a configuração que contempla equipamentos novos e existentes.

\section{ii) Novos alimentadores em subestações existentes}

Uma obra bastante comum em sistemas de distribuição consiste na ampliação do número de alimentadores em subestações existentes. Obviamente, este reforço pode ser instalado no sistema, desde que exista possibilidade de instalação de um bay adicional de saída (em alguns casos, os bays em uma subestação já estão disponíveis.) e exista acesso físico (aéreo ou subterrâneo) para saída do alimentador do terreno da subestação. 
A instalação de um novo alimentador tem por objetivo aliviar o carregamento dos demais alimentadores da subestação e, dependendo da configuração da rede, permite também reduzir o carregamento de alimentadores de outras subestações e, por conseqüência, reduzir o carregamento destas outras subestações.

Quando é considerado este tipo de Ação de planejamento, o valor dos custos fixos deverá incluir, quando necessário, o custo do bay de saída e demais custos relativos à saída do alimentador da subestação. Também, em novos trechos de rede, o custo fixo relativo a este reforço só será incluído ao custo total quando o fluxo de potência neste elemento for não nulo.

\section{iii) Novas Subestações}

Quando é realizada uma ação de planejamento que considera uma nova subestação, o planejador deve também propor os novos alimentadores que se derivam da barra de média tensão. O tratamento destes novos alimentadores é análogo ao exposto no item anterior, relativo aos alimentadores novos em subestações existentes.

Da mesma forma que os reforços de trechos de rede ou novos alimentadores, o custo fixo da subestação será incorporado ao custo total somente quando o correspondente fluxo de potência for não nulo.

\section{iv) Ampliação de Subestações Existentes}

Uma outra forma de suprir um possível déficit global de demanda na região de estudo de planejamento é através do aumento de capacidade em subestações existentes. Esta operação pode ser realizada de duas formas distintas: (i) através de instalação de unidade transformadora adicional na SE e (ii) através de substituição de uma unidade transformadora por outra de capacidade superior. A primeira forma depende, obviamente, da subestação ter espaço físico para instalação da nova unidade. A substituição depende de haver um transformador de capacidade maior que o existente, em geral nos padrões utilizados na empresa. Para os dois casos, deve-se verificar se os equipamentos da subestação comportam este aumento de capacidade; por exemplo, a potência de curto circuito sofre aumento quando a capacidade é ampliada e, obviamente, os disjuntores da SE devem estar dimensionados para o novo valor.

Para esta ação de planejamento não há a necessidade de chaves de manobra adicionais. Basta tão somente monitorar o carregamento na subestação após o procedimento de fluxo de potência. Quando o carregamento da SE existente exceder o valor máximo de fluxo e houver 
possibilidade de aumento de capacidade suficiente, o reforço da unidade transformadora é incorporado ao sistema, bem como o correspondente custo fixo adicional.

\section{v) Recondutoramento de Trechos de Rede}

Da mesma forma que a troca por um transformador de maior capacidade deve ser realizada em função do carregamento da subestação, o mesmo deve ocorrer com o recondutoramento de um trecho de rede por um condutor de seção nominal maior.

Para realizar o Recondutoramento de alguns trechos é necessário considerar a violação de carregamento no trecho e dos intervalos de capacidade máxima entre os vários condutores. Para esta ação de planejamento, obviamente, o custo fixo a ser considerado será função do condutor escolhido, dado que o custo de material é diferenciado por seção nominal.

\subsubsection{Formulação considerando Custo da QEE no Planejamento de Expansão}

Como foi comentando nos capítulos anteriores, fenômenos de VTCDs são basicamente relacionados ao mau funcionamento de equipamentos sensíveis de consumidores, o que geralmente causa interrupção em processos produtivos. Este conceito foi considerado neste trabalho como disrupção do consumidor. Processos contínuos, quando interrompidos devido a afundamentos ou elevações de tensão, normalmente demandam um longo período para o restabelecimento dos procedimentos de produção. As disrupções ocorrem quando a variação de tensão é mais severa que a suportada pelo equipamento ou processo.

No Capítulo 4 - foram apresentadas diferentes metodologias que permitem obter, para toda a rede elétrica, indicadores de VTCDs esperados para cada barra do sistema, de cada alimentador e subestação. A média da freqüência de VTCDs indica o número esperado de afundamentos, elevações e ainda das disrupções, levando em consideração as curvas de sensibilidade para cada consumidor.

Com isto, é possível acrescentar o efeito da qualidade da energia frente a fenômenos de VTCDs, dentro dos principais aspectos técnicos e econômicos envolvidos nos modelos de planejamento de expansão clássica.

\subsubsection{Função objetivo - Planejamento ótimo estático incluindo custo da QEE}

Este modelo considera na função objetivo, além dos custos de novas ações de planejamento, os custos referentes à energia não distribuída (interrupções de longa duração) e 
as disrupções por VTCDs nos consumidores. A função objetivo é representada pela seguinte equação matemática:

$$
F O_{\text {sstatico }}=\text { Custo }_{C F x-r f(i)}+\text { Custo }_{C V-r f(i)}+\text { Custo }_{E N D(i)}+\text { Custo }_{\text {Disrupৎões }(i)}
$$

Em que:

$i$ : Índice do conjunto de reforços realizado (construção de novas subestações e alimentadores,

troca de cabos, chaves de interconexão, ramais para interconexão entre alimentadores, etc.);

Custo $_{C F x-r f(i)}$ : Custo fixo para o conjunto de reforços i na rede de distribuição;

Custo $_{C V-r f(i)}$ : Custo variável para o sistema com o conjunto i de reforços na rede primária (perdas na rede primária);

Custo $_{E N D(i)}$ : Custo da energia não distribuída (interrupções de longa duração) com o conjunto de reforços i;

Custo $_{\text {Disrup̧̧ão(i): }}$ Custo das Disrupções nos consumidores existentes na rede de distribuição (parada de produção) após reforços i.

As restrições serão as mesmas apresentadas no item 6.1.1. Desta forma, o objetivo do planejamento ótimo estático corresponde à minimização da FO, respeitando todas estas restrições.

\subsubsection{Função objetivo - Planejamento ótimo Dinâmico incluindo custo da QEE}

Como foi descrito anteriormente, no planejamento dinâmico existe uma variável adicional que é o tempo. Assim, deve ser definido não só se determinado reforço deve ser construído, mas também o estágio que deve ser instalado. Na nova formulação proposta, são incluídos os custos das interrupções e das disrupções, para cada estágio de planejamento. Desta forma, a seguinte função objetivo pode ser formulada para o planejamento dinâmico considerando o custo da QEE:

$$
\begin{aligned}
F O_{\text {dinamico }}=\left(C F_{E s t(0)}+C V_{E s t(0)}+\right. & \left.C_{\text {Interr }(0)+\operatorname{Disrup}(0)}\right)+\left(C F_{E s t(1)}+C V_{E s t(1)}+C_{\text {Interr }(I)+\operatorname{Disrup}(1)}\right)(1+I)^{t l-t 0}+ \\
( & C F_{E s t(2)}+C V_{E s t(2)}+C_{\text {Interr }(2)+\operatorname{Disrup}(2))(1+I)^{t-t 0}+\ldots}+\ldots \\
& +\left(C F_{E s t(n)}+C V_{E s t(n)}+C_{\text {Interrn }+\operatorname{Disrup}(n))(1+I)^{t n-t 0}}\right.
\end{aligned}
$$




$$
F O_{\text {dinamico }}=\sum_{k=0}^{n}\left(\left(C F_{\text {Est }(k)}+C V_{E s t(k)}+C_{\operatorname{Interr}(k)+\operatorname{Disrup}(k)}\right) \times(1+I)^{t_{k}-t_{0}}\right)
$$

Em que:

$C F_{E s t(k)}$ : Custo fixo no estágio $k$, incluindo custo de novos alimentadores, custo de novas subestações e custo de recondutoramento;

$C V_{E s t(k)}$ : Custo variável do estágio $k$, incluindo custos de perdas no sistema;

$C_{\text {Interr }(k)+\text { Disrup }(k)}$ : Custo das interrupções e das disrupções no estágio $k$;

I: $\quad$ Taxa de atualização do capital;

$n: \quad$ Horizonte de planejamento.

$t_{k}$ : Tempo do estágio $k$ em que são construídas as linhas e as subestações do sistema, em anos;

$t_{0}$ : Tempo inicial do horizonte do planejamento.

Do mesmo modo que o planejamento estático, as restrições serão as mesmas apresentadas no item 6.1.1. Com isto o objetivo do planejamento ótimo dinâmico seria a minimização da FO, respeitando todas estas restrições.

\subsubsection{Inclusão Prática do custo da QEE no Problema de Planejamento da Expansão}

Já foi comentado, nos itens anteriores, que o problema da expansão em sistemas de distribuição, assim como o problema de reconfiguração de rede, pode ser solucionado utilizando diferentes técnicas, apresentadas por diferentes autores. As técnicas de planejamento estático, dinâmico e pseudo-dinâmico, são muitas vezes utilizadas, com resultados interessantes. Todas elas possibilitam a obtenção de uma série de ações de planejamento ao longo do horizonte estudado.

Para a solução deste problema, com a inclusão do custo da QEE, pode ser utilizada a formulação apresentada no Item 6.2.5, na qual é incluído, para cada opção obtida, o valor dos custos fixos e variáveis da ação de planejamento, somado aos custos das interrupções de longa duração e das disrupções por VTCDs. Muitas destas alternativas de planejamento são infactíveis, ou seja, não cumprem as restrições do problema e, portanto, não necessitam a obtenção destes custos adicionais de qualidade de energia.

Assim como o problema de reconfiguração, uma forma muito simples e prática pra realizar a inclusão do efeito do custo da QEE, no âmbito do planejamento de expansão, seria 
com a execução de dois procedimentos. Primeiro, obter o conjunto de soluções ótimas, após a minimização da função objetivo convencional (custos de investimento e de perdas) para o planejamento estático, dinâmico ou pseudo-dinâmico. Assim, cada solução representa um conjunto de ações de planejamento a serem executadas.

O segundo procedimento seria calcular, para cada solução encontrada, os custos de interrupção e de disrupção, sendo adicionadas para o valor do custo total.

Depois da inclusão do novo custo (interrupção e disrupção), a melhor solução representará aquela que, além de cumprir as restrições operacionais, também atende a de melhor custo total, contemplando custos de investimento, custos de perdas, custos de interrupção de longa duração e custos das disrupções em processos por VTCDs.

Como exemplo, considerando 5 anos de planejamento, sejam duas alternativas de solução de expansão do sistema:

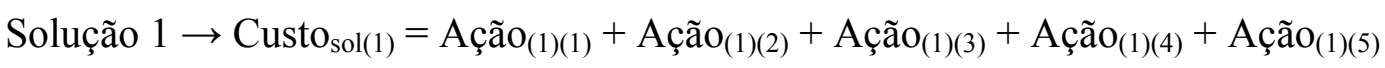

Solução $2 \rightarrow$ Custo $_{\operatorname{sol}(2)}=\mathrm{Açcão}_{(2)(1)}+\mathrm{Ação}_{(2)(2)}+\mathrm{Accaão}_{(2)(3)}+\mathrm{Ação}_{(2)(4)}+\mathrm{Acção}_{(2)(5)}$

onde o termo $\operatorname{Ação}_{(2)(4)}$ representa a ação de planejamento a ser realizada pela solução 2 no

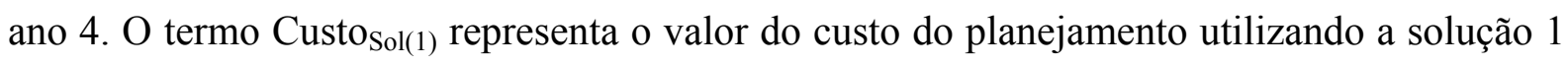
sem a inclusão do custo da QEE. Para realizar a inclusão prática do custo da QEE, devem ser determinados para as duas alternativas os custos das interrupções e das disrupções para cada solução.

Então:

Solução $1 \rightarrow$ Custo $_{\text {sol(1) }}=\mathrm{Ação}_{(1)(1)}+\mathrm{C}_{\operatorname{Inter}(1)(1)+\operatorname{Disrup}(1)(1)}+\mathrm{Ação}_{(1)(2)}+\mathrm{C}_{\operatorname{Inter(1)(2)+Disrup(1)(2)}}+$ $\mathrm{Açãao(1)(3)}^{+} \mathrm{C}_{\text {Inter(1)(3)+Disrup(1)(3) }}+\mathrm{Açãão}_{(1)(4)}+\mathrm{C}_{\text {Inter(1)(4)+Disrup(1)(4) }}{ }^{+}$

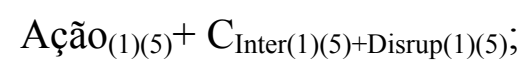

Solução $2 \rightarrow$ Custo $_{\text {sol(2) }}=\mathrm{Ação}_{(2)(1)}+\mathrm{C}_{\operatorname{Inter}(2)(1)+\operatorname{Disrup}(2)(1)}+\mathrm{Ação}_{(2)(2)}+\mathrm{C}_{\operatorname{Inter}(2)(2)+\operatorname{Disrup}(2)(2)}+$

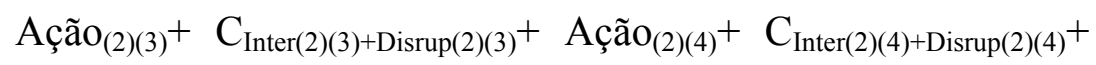

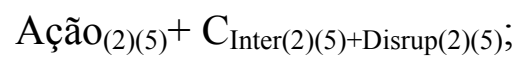

Desta maneira, com a inclusão do custo da QEE, aquela solução i de melhor custo Custo $_{\text {sol(i) }}$ será a escolhida. A inclusão do custo da QEE no planejamento das redes de distribuição pode ser realizada de duas formas (de forma análoga ao já apresentado para o problema de reconfiguração de redes):

- pós-otimização, quando o modelo determina uma série de alternativas de expansão de forma convencional (minimização dos custos de investimento e das perdas ativas do sistema, atendendo aos critérios técnicos) e só então são considerados os custos de 
interrupção e disrupção. Esta alternativa apresenta a vantagem de serem avaliadas poucas alternativas pelos modelos que permitem obter o custo da QEE;

- durante a otimização da expansão, cada alternativa de conjunto de reforços proposta, isto é, cada configuração é também submetida a um programa de análise de custo de QEE, para obtenção dos custos de interrupção e disrupção sobre os consumidores do sistema. Obviamente, esta opção demanda maior esforço computacional, mas o modelo se direciona para obtenção do ótimo global. 


\section{7 - RESULTADOS}

Para a apresentação dos resultados no presente trabalho, este capítulo será dividido em duas partes. A primeira parte apresentará o comportamento de cada método de simulação (Monte Carlo, Enumeração de estados e Híbrido) para a obtenção dos índices de interrupção de longa duração e de VTCDs, para duas redes de distribuição: uma rede ilustrativa com 27 barras e uma rede maior, com 609 barras. Serão apresentadas comparações dos métodos de simulação, com respeito à sua eficiência na qualidade dos resultados e no tempo de processamento. $\mathrm{Na}$ segunda parte do capítulo, serão apresentados resultados obtidos em exemplos de consideração dos índices de VTCDs em problemas de planejamento da operação e da expansão de sistemas de distribuição de energia elétrica.

Todos os métodos foram implementados utilizando a linguagem de programação $\mathrm{C}++$. O sistema computacional utilizado em todos os testes apresenta CPU Intel Pentium M 740 de 1,73 GHz com 512 MB de memória RAM.

\subsection{Análise de Áreas de Risco}

\subsubsection{Rede de 27 barras}

O estudo das áreas de risco foi aplicado numa rede de distribuição de energia elétrica ilustrativa, constituída por:

i) 2 alimentadores;

ii) 27 barras;

iii) 6 transformadores: $1 \times 138 \mathrm{kV} / 13,8 \mathrm{kV} ; \quad 2 \times 13,8 \mathrm{kV} / 23 \mathrm{kV} ; \quad 1 \times 13,8 \mathrm{kV} / 0,22 \mathrm{kV}$; e $2 \mathrm{x} 23 \mathrm{kV} / 0,22 \mathrm{kV}$;

iv) 5 chaves de proteção, ao longo de toda a rede;

v) 3300 metros de rede: 10x200metro $(13,8 \mathrm{kV}) ; \quad 1 \times 100$ metros $(13,8 \mathrm{kV})$; $3 \times 200$ metros $(23 \mathrm{kV})$ e $6 \times 100$ metros $(0,22 \mathrm{kV})$. 
vi) 6 consumidores de diferentes tipos: 3 Comercial $(80,10$ e $80 \mathrm{~kW})$ com tensão nominal de $0,22 \mathrm{kV}, 2$ Industrial $(5000,4000 \mathrm{~kW})$ com tensão nominal de $23 \mathrm{kV}$ e 1 Industrial $(6000 \mathrm{~kW})$ com tensão nominal de $13,8 \mathrm{kV}$

Considera-se que as cargas dos consumidores são alimentadas por um transformador (possuem seu próprio transformador na entrada) com conexão $D-Y t$ (Delta-Estrela aterrado), apesar de não terem sido representados no diagrama unifilar.

O diagrama unifilar da rede estudada pode ser observado na Figura 7-1.

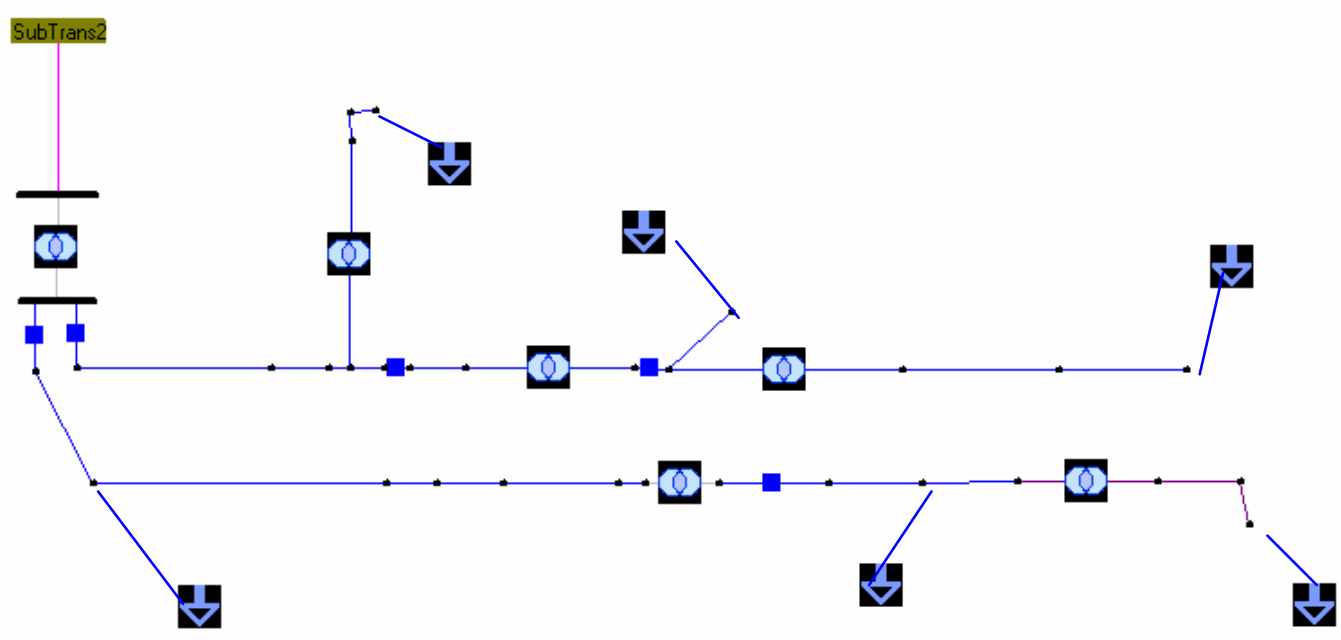

Figura 7-1 -Diagrama Unifilar - Rede de 27 barras

\subsubsection{Rede de 609 barras}

O estudo das áreas de risco foi aplicado a uma rede de distribuição real, constituída por:

i) 1 alimentador;

ii) 609 barras;

iii) 3 transformadores: $330 \mathrm{kV} / 138 \mathrm{kV}, 138 \mathrm{kV} / 13,8 \mathrm{kV}$ e $13,8 \mathrm{kV} / 0,22 \mathrm{kV}$;

iv) 23 chaves de proteção, ao longo de toda a rede;

v) 18774 metros de rede: 10.000 metros $(138 \mathrm{kV}), \quad 8.754$ metros $(13,8 \mathrm{kV}) \quad$ e $20 \mathrm{metros}(0,22 \mathrm{kV})$.

vi) 118 consumidores de diferentes tipos: 5 Comercial, 2 Industrial, 2 Outros, e 109 equivalentes, todas com tensão nominal de alimentação de13,8 kV. 
Como no caso anterior, as cargas dos consumidores são alimentados por um transformador (possuem seu próprio transformador MT/BT) com conexão D-Yt (Delta-Estrela aterrado), não representados no diagrama unifilar que encontra-se na Figura 7-2.

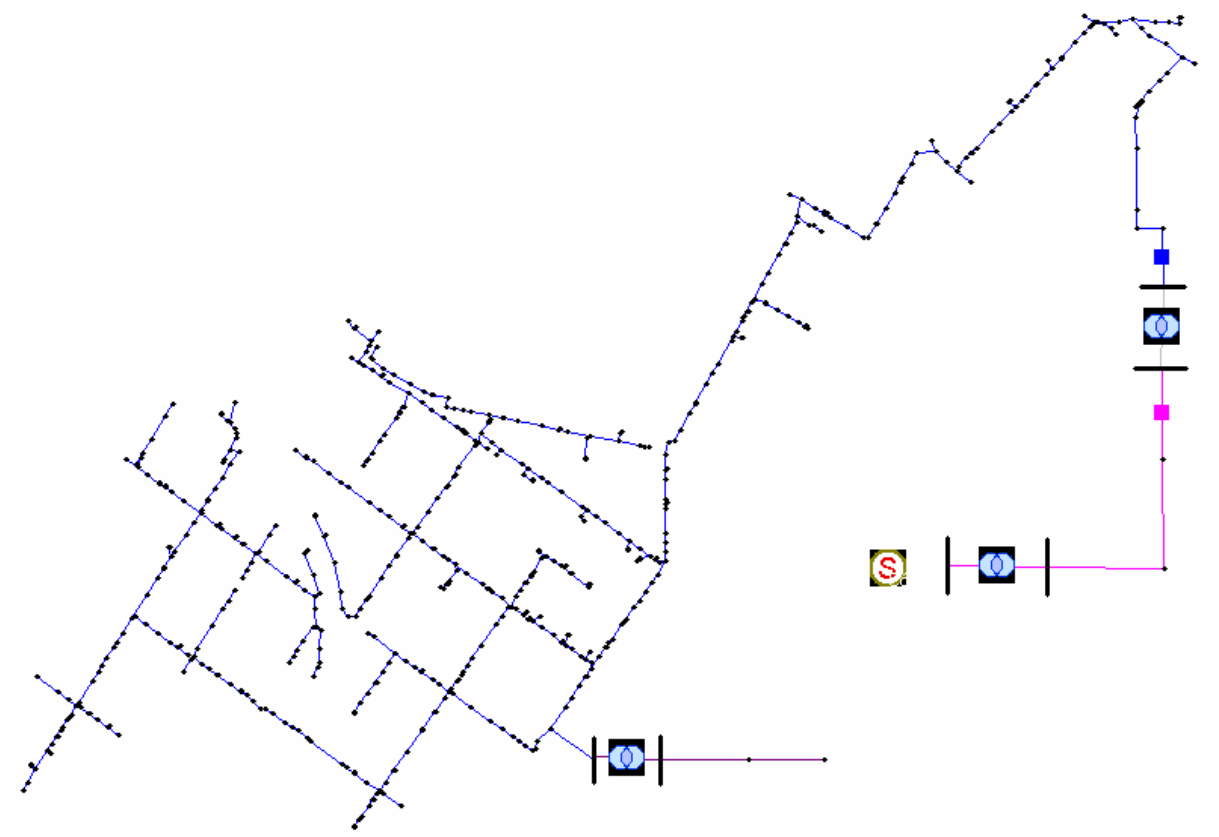

Figura 7-2 - Diagrama Unifilar - Rede de 609 barras utilizada nas simulações

\subsubsection{Parâmetros Para as Simulações}

Para a execução dos diferentes modelos, serão utilizados os seguintes parâmetros:

(a) Para a escolha do trecho em falta na rede de 27 barras, será considerado que a taxa de falha para cada trecho é de $T x=0,303$ (falha/ $\mathrm{km} / \mathrm{ano}$ ). Com isto a taxa de falha para todo o sistema resulta em $T_{A L}=1$ (falha/km/ano). Para a rede de 609 barras, será considerado que a taxa de falha para cada trecho é de $T x=0,0533$ (falha $/ \mathrm{km} / \mathrm{ano}$ ). Com isto a taxa de falha para todo o sistema resulta em $T_{A L}=1$ (falha/km/ano).

(b) Para a escolha do tipo de falta, será considerada a seguinte distribuição de probabilidades: Faltas trifásicas 10\%, Faltas dupla fase $20 \%$, Faltas dupla-fase-terra $20 \%$, Faltas fase-terra $50 \%$.

(c) Para a escolha da impedância de falta, serão considerados os seguintes valores máximos em função do tipo de curto-circuito: falta trifásica $10 \Omega$ (impedância por fase), falta fase-terra $30 \Omega$, falta fase-fase $20 \Omega$ (impedância entre fases) e falta dupla fase-terra $10 \Omega$ (impedância 
entre fases) e $30 \Omega$ (impedância para terra), dados referenciais fornecidos dados por uma concessionária.

(d) Os valores dos custos unitários para interrupção e disrupção serão obtidos da Tabela 5-4.

(e) Para todas as redes, as potências de curto-circuito utilizadas são:

$$
\begin{aligned}
& \text { Trifásica }=300,2 \underline{\lfloor+88,09} \text { MVA; } \\
& \text { Monofásica }=250,2\left\lfloor \_87,7\right. \text { MVA. }
\end{aligned}
$$

Também serão feitas as seguintes considerações:

(a) $\mathrm{Na}$ análise estatística dos resultados de VTCDs, considera-se o valor mínimo de tensão entre as três fases para os afundamentos de tensão, e o valor máximo entre as três fases para as elevações de tensão.

(b) Os eventos considerados nessas simulações restringem-se àqueles originários de faltas na rede primária de distribuição $(13,8 \mathrm{kV})$.

(c) As interrupções serão consideradas como sendo de longa duração, pois não é considerado o efeito dos religadores (interrupções de curta duração).

(d) $\mathrm{O}$ valor de $T_{A L}$ representa o número de ocorrências contabilizadas pela concessionária de energia durante a abertura de algum dispositivo de proteção, ou seja, representa interrupções de longa duração.

(e) Para a análise de disrupções em consumidores ocasionadas por VTCDs, nas redes de 27 e 609 barras, serão consideradas nas simulações que as curvas de sensibilidade dos processos serão as mesmas para todos os consumidores envolvidos e será aquela mostrada na Figura 7-3. 


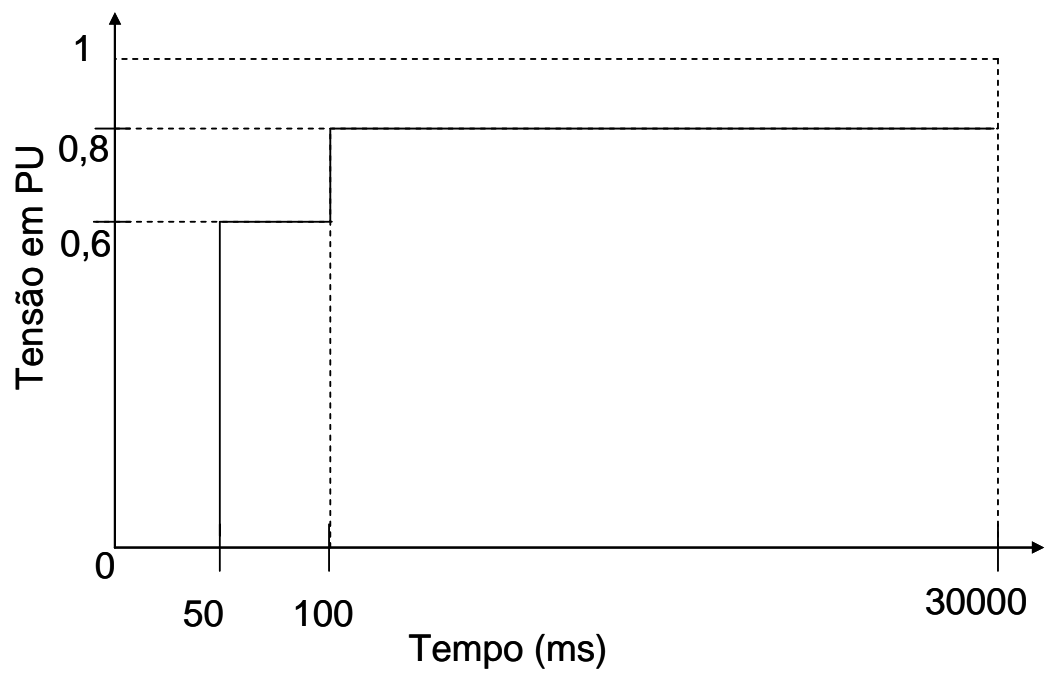

Figura 7-3 - Curva de sensibilidade representativa utilizada na análise de áreas de risco para os diferentes métodos de simulação

\subsubsection{Comportamento dos Métodos de simulação}

Nesta seção serão apresentados resultados para os três métodos propostos nesta tese (Monte Carlo, Enumeração de estados e Híbrido). Serão feitas variações em alguns parâmetros, visando obter uma análise de sensibilidade do comportamento e eficiência para cada método. Como parâmetros de comparação, serão utilizados os valores dos custos das interrupções de longa duração, custo das disrupções, e o custo total da soma dos dois valores.

Dado que o método de Monte Carlo e Híbrido possuem variáveis com comportamento aleatório, serão realizadas 5 execuções sucessivas, de forma a obter a média do custos, seu respectivo desvio padrão e coeficiente de variação (relação entre o desvio padrão e o valor médio). O valor do desvio padrão também será utilizado como parâmetro de comparação.

Com o método de Enumeração de estados, serão feitas variações no número de faixas para cada variável, obtendo diferentes valores de custos. Assim, o parâmetro de comparação será o valor obtido dos custos, em relação àqueles obtidos pelo método de Monte Carlo.

Para os três métodos, o tempo de processamento também será um parâmetro de comparação, para medir a eficiência na obtenção dos resultados. 


\subsubsection{Caso 1 - Rede de 27 barras}

\subsection{Método de Monte Carlo}

Na Tabela 7-1, são apresentados os resultados dos custos das disrupções por VTCDs e interrupções de longa duração, com seus respectivos desvios, variando o número total de faltas em: $1.000,10.000$ e 100.000. Consideram-se 5 execuções para cada conjunto de número total de faltas, para a obtenção do desvio padrão.

Tabela 7-1 - Resultados para diferentes números totais de faltas-Método Monte Carlo - Rede 27 Barras

\begin{tabular}{|c|c|c|c|c|c|c|c|c|c|c|}
\hline \multirow{2}{*}{$\begin{array}{c}\text { No de Curtos } \\
\text { Circuitos }\end{array}$} & \multirow{2}{*}{$\begin{array}{c}\text { Tempo Médio } \\
\text { (s) }\end{array}$} & \multicolumn{8}{|c|}{ Unidade (\$/ano) } & \multirow[b]{3}{*}{$\begin{array}{c}\text { \%Coeficiente } \\
\text { de variação }\end{array}$} \\
\hline & & & & & Simulaçã & & & & & \\
\hline \multirow{4}{*}{1000} & \multirow{4}{*}{0,344} & Custos & 1 & 2 & 3 & 4 & 5 & Media & Desvio Padrão & \\
\hline & & Disrupção & 81.874 & 90.678 & 93.090 & 76.947 & 88.977 & 86.313 & 6.699 & 7,76 \\
\hline & & Interrupção & 86.495 & 89.739 & 86.686 & 89.405 & 85.854 & 87.636 & 1.798 & 2,05 \\
\hline & & Total & 168.369 & 180.417 & 179.776 & 166.352 & 174.831 & 173.949 & 6.431 & 3,70 \\
\hline \multirow{4}{*}{10000} & \multirow{4}{*}{1} & Custos & 1 & 2 & 3 & 4 & 5 & & & \\
\hline & & Disrupção & 86.483 & 92.806 & 86.760 & 88.467 & 87.757 & 88.455 & 2.558 & 2,89 \\
\hline & & Interrupção & 86.989 & 87.850 & 88.902 & 87.219 & 88.392 & 87.870 & 797 & 0,91 \\
\hline & & \begin{tabular}{|l|} 
Total \\
\end{tabular} & 173.472 & 180.656 & 175.662 & 175.686 & 176.149 & 176.325 & 2.635 & 1,49 \\
\hline \multirow{4}{*}{100000} & \multirow{4}{*}{9} & Custos & 1 & 2 & 3 & 4 & 5 & & & \\
\hline & & Disrupção & 88.156 & 89.547 & 87.130 & 89.227 & 88.996 & 88.611 & 975 & 1,10 \\
\hline & & Interrupção & 87.701 & 87.527 & 87.656 & 87.865 & 87.608 & 87.671 & 126 & 0,14 \\
\hline & & \begin{tabular}{|l|} 
Total \\
\end{tabular} & 175.857 & 177.074 & 174.786 & 177.092 & 176.604 & 176.283 & 975 & 0,55 \\
\hline
\end{tabular}

Pode-se observar da Tabela 7-1 que o desvio padrão diminui quando é aumentado o número total de faltas, o que coincide com a teoria de Monte Carlo, já que quanto maior o número de simulações, maior a tendência em se alcançar a "Estabilidade de Monte Carlo". O menor desvio padrão obtido corresponde a 100.000 faltas no total, com custo médio total de $\$ 176.283$ por ano, para um coeficiente de variação de $0,55 \%$ e um tempo de processamento de 9 segundos.

\subsection{Método de Enumeração de estados}

Os resultados usando o método de Enumeração de estados são apresentados para diferentes condições, variando o número de faixas: $N_{F x \text { Comp }}, N_{F x I m p}, N_{F x I m p F F T-T}$ relativos, respectivamente, ao número de subdivisões de cada trecho de rede e número de faixas de impedâncias (faltas trifásicas, dupla-fase, fase-terra, dupla fase-terra entre fases) e número de faixas de impedância para faltas dupla fase-terra, para a terra. 
Tabela 7-2 - Resultados para diferentes números de faixas - Método de Enumeração de estados - Rede 27 Barras

\begin{tabular}{|c|c|c|c|c|c|c|c|}
\hline \multirow{2}{*}{$N_{\text {Fx Comp }}$} & \multirow{2}{*}{$N_{\text {FxImp }}$} & \multirow{2}{*}{$N_{\text {FxImpFFT-T }}$} & \multirow{2}{*}{$\begin{array}{c}\text { No de Curtos } \\
\text { Circuitos }\end{array}$} & \multirow{2}{*}{ Tempo (s) } & \multicolumn{3}{|c|}{ Custo (\$/ano) } \\
\cline { 5 - 8 } & & 2 & 520 & $<1$ & 263.288 & 90.143 & 353.431 \\
\hline 2 & 2 & 2 & 5.200 & $<1$ & 137.555 & 87.891 & 225.446 \\
\hline 5 & 5 & 5 & 33.800 & 1 & 90.418 & 87.152 & 177.570 \\
\hline 10 & 10 & 10 & &
\end{tabular}

Pode ser observar na Tabela 7-2 os resultados obtidos variando as faixas de: 2, 5, 10 de forma para todas as variáveis envolvidas no método de Enumeração de estados. Para obtenção de maior precisão, nota-se a necessidade de se aumentar o número das faixas, o que produz um aumento no número de faltas simuladas e, por conseqüência, um aumento no tempo de processamento. Para esta rede de 27 barras, o tempo de processamento é relativamente baixo, mas para redes maiores o tempo de processamento representará um fator limitante. Esta observação ficará mais clara na análise da rede de 609 barras.

\subsection{Método Híbrido}

Para analisar o comportamento do método Híbrido, a rede utilizada será a mesma apresentada na Figura 7-1. A execução será realizada em duas formas. A primeira execução realiza variações do parâmetro $N_{F x-M i n}$ (Faixa Mínima) em valores de 1, 3, 5, 7, 11, 13. Com estes valores, será obtido o número de faltas necessário para a simulação por este método.

Para a segunda execução, será fixxado o número de faltas em diferentes valores: 1.000, 10.000, 100.000. Com isto, o método realiza a melhor distribuição do número de faltas ao longo da rede, mantendo as distribuições de probabilidade para cada variável. 
Tabela 7-3-Resultados para diferentes faixas mínimas - Método Híbrido - Rede 27 Barras

\begin{tabular}{|c|c|c|c|c|c|c|c|c|c|c|c|}
\hline \multirow{2}{*}{$\begin{array}{c}\text { No de Curtos } \\
\text { Circuitos }\end{array}$} & \multirow{2}{*}{$\begin{array}{c}\text { Faixa } \\
\text { Mínima }\end{array}$} & \multirow{2}{*}{$\begin{array}{c}\text { Tempo } \\
\text { Médio (s) } \\
\end{array}$} & \multicolumn{8}{|c|}{ Unidade (\$/ano) } & \multirow[b]{3}{*}{$\begin{array}{c}\text { \%Coeficiente } \\
\text { de variação }\end{array}$} \\
\hline & & & & & & Simulaçãc & & & & & \\
\hline \multirow{4}{*}{55} & \multirow{4}{*}{1} & \multirow{4}{*}{$<1$} & Custos & 1 & 2 & 3 & 4 & 5 & Media & Desvio Padrão & \\
\hline & & & Disrupção & 136.985 & 79.801 & 130.684 & 108.296 & 108.948 & 112.943 & 22.521 & 19,94 \\
\hline & & & Interrupção & 95.886 & 95.229 & 90.470 & 90.683 & 90.746 & 92.603 & 2.709 & 2,93 \\
\hline & & & Total & 232.871 & 175.030 & 221.154 & 198.979 & 199.694 & 205.546 & 22.354 & 10,88 \\
\hline \multirow{4}{*}{165} & \multirow{4}{*}{3} & \multirow{4}{*}{$<1$} & Custos & 1 & 2 & 3 & 4 & 5 & & & \\
\hline & & & Disrupção & 114.500 & 100.837 & 74.760 & 90.039 & 96.008 & 95.229 & 14.572 & 15,30 \\
\hline & & & Interrupção & 89.931 & 91.901 & 88.745 & 89.934 & 93.038 & 90.710 & 1.725 & 1,90 \\
\hline & & & Total & 204.431 & 192.738 & 163.505 & 179.973 & 189.046 & 185.939 & 15.303 & 8,23 \\
\hline \multirow{4}{*}{275} & \multirow{4}{*}{5} & \multirow{4}{*}{$<1$} & Custos & 1 & 2 & 3 & 4 & 5 & & & \\
\hline & & & Disrupção & 82.789 & 89.664 & 104.747 & 94.867 & 93.142 & 93.042 & 8.014 & 8,61 \\
\hline & & & Interrupção & 90.096 & 88.234 & 86.293 & 90.287 & 90.678 & 89.118 & 1.838 & 2,06 \\
\hline & & & Total & 172.885 & 177.898 & 191.040 & 185.154 & 183.820 & 182.159 & 6.978 & 3,83 \\
\hline \multirow{4}{*}{385} & \multirow{4}{*}{7} & \multirow{4}{*}{$<1$} & Custos & 1 & 2 & 3 & 4 & 5 & & & \\
\hline & & & Disrupção & 100.009 & 94.994 & 90.511 & 100.767 & 86.924 & 94.641 & 5.981 & 6,32 \\
\hline & & & Interrupção & 85.773 & 89.094 & 89.628 & 85.478 & 92.179 & 88.430 & 2.815 & 3,18 \\
\hline & & & Total & 185.782 & 184.088 & 180.139 & 186.245 & 179.103 & 183.071 & 3.271 & 1,79 \\
\hline \multirow{4}{*}{605} & \multirow{4}{*}{11} & \multirow{4}{*}{$<1$} & Custos & 1 & 2 & 3 & 4 & 5 & & & \\
\hline & & & Disrupção & 89.995 & 88.335 & 91.451 & 93.112 & 90.571 & 90.693 & 1.767 & 1,95 \\
\hline & & & Interrupção & 86.240 & 86.532 & 88.852 & 87.112 & 85.816 & 86.910 & 1.183 & 1,36 \\
\hline & & & Total & 176.235 & 174.867 & 180.303 & 180.224 & 176.387 & 177.603 & 2.500 & 1,41 \\
\hline \multirow{4}{*}{715} & \multirow{4}{*}{13} & \multirow{4}{*}{$<1$} & Custos & 1 & 2 & 3 & 4 & 5 & & & \\
\hline & & & Disrupção & 91.696 & 90.239 & 91.354 & 93.592 & 93.256 & 92.027 & 1.389 & 1,51 \\
\hline & & & Interrupção & 88.293 & 87.978 & 87.520 & 87.217 & 88.694 & 87.940 & 590 & 0,67 \\
\hline & & & Total & 179.989 & 178.217 & 178.874 & 180.809 & 181.950 & 179.968 & 1.492 & 0,83 \\
\hline
\end{tabular}

Tabela 7-4 - Resultados para diferentes números de faltas - Método Híbrido - Rede 27 Barras

\begin{tabular}{|c|c|c|c|c|c|c|c|c|c|c|}
\hline \multirow{2}{*}{\begin{tabular}{|c}
$\begin{array}{c}\text { No de Curtos } \\
\text { Circuitos }\end{array}$ \\
\end{tabular}} & \multirow{2}{*}{$\begin{array}{c}\text { Tempo } \\
\text { Médio (s) }\end{array}$} & \multicolumn{8}{|c|}{ Unidade (\$/ano) } & \multirow[b]{3}{*}{$\begin{array}{c}\text { \%Coeficiente } \\
\text { de variação }\end{array}$} \\
\hline & & & & & Simulaçã & & & & & \\
\hline \multirow{4}{*}{1000} & \multirow{4}{*}{0,25} & Custos & 1 & 2 & 3 & 4 & 5 & Media & Desvio Padrão & \\
\hline & & Disrupção & 98.311 & 81.182 & 88.664 & 90.783 & 93.727 & 90.533 & 6.358 & 7,02 \\
\hline & & Interrupção & 89.250 & 88.398 & 87.540 & 88.202 & 86.017 & 87.881 & 1.208 & 1,37 \\
\hline & & Total & 187.561 & 169.580 & 176.204 & 178.985 & 179.744 & 178.415 & 6.494 & 3,64 \\
\hline \multirow{4}{*}{10000} & \multirow{4}{*}{1} & Custos & 1 & 2 & 3 & 4 & 5 & & & \\
\hline & & Disrupção & 87.789 & 89.236 & 89.678 & 89.273 & 90.254 & 89.246 & 912 & 1,02 \\
\hline & & Interrupção & 87.652 & 87.643 & 87.867 & 87.839 & 87.998 & 87.800 & 151 & 0,17 \\
\hline & & Total & 175.441 & 176.879 & 177.545 & 177.112 & 178.252 & 177.046 & 1.038 & 0,59 \\
\hline \multirow{4}{*}{100000} & \multirow{4}{*}{5} & Custos & 1 & 2 & 3 & 4 & 5 & & & \\
\hline & & Disrupção & 89.618 & 88.654 & 89.141 & 88.809 & 88.908 & 89.026 & 375 & 0,42 \\
\hline & & Interrupção & 87.604 & 87.580 & 87.648 & 87.724 & 87.645 & 87.640 & 55 & 0,06 \\
\hline & & Total & 177.222 & 176.234 & 176.789 & 176.533 & 176.553 & 176.666 & 368 & 0,21 \\
\hline
\end{tabular}

Os resultados obtidos na Tabela 7-3 e na Tabela 7-4 mostram os resultados para diferentes números de faltas, em 5 execuções diferentes. Assim, é possível obter os valores das médias e dos desvios padrão para cada condição.

Sendo realizada a primeira parte, correspondente à variação do número de faixas mínimo, o valor com faixa mínima igual a 13 já reflete valores com desvios padrão muito baixos (para o custo total, coeficiente de variação abaixo de 1\%). Na segunda parte, os resultados podem ser observados na Tabela 7-4, para números de faltas com valores relativamente maiores, sendo possível observar a diminuição dos desvios padrão com o aumento do número de faltas. A Tabela 7-4 será posteriormente analisada junto com a Tabela 7-1, para efeito de comparação com o método de Monte Carlo, com relação aos resultados das médias e dos desvios padrão obtidos. 


\subsubsection{Caso 2 - Rede de 609 barras}

\subsection{Método de Monte Carlo}

$\mathrm{Na}$ Tabela 7-5 são apresentados os resultados dos custos das disrupções por VTCDs e interrupções de longa duração e seus respectivos desvios padrão, variando o número de faltas em: $1.000,10000$ e 100.000. Consideram-se 5 simulações para cada conjunto de faltas, para a obtenção do desvio padrão.

Tabela 7-5 - Resultados Para diferentes Números de Curtos-Circuitos - Método Monte Carlo

\begin{tabular}{|c|c|c|c|c|c|c|c|c|c|c|}
\hline \multirow{2}{*}{$\begin{array}{c}\text { No de Curtos } \\
\text { Circuitos }\end{array}$} & \multirow{2}{*}{\begin{tabular}{|c|} 
Tempo Médio \\
(s) \\
\end{tabular}} & \multicolumn{8}{|c|}{ Unidade (\$/ano) } & \multirow[b]{3}{*}{$\begin{array}{c}\text { \%Coeficiente } \\
\text { de variação }\end{array}$} \\
\hline & & & & & Simulaç & & & & & \\
\hline \multirow{4}{*}{1000} & \multirow{4}{*}{4} & Custos & 1 & 2 & 3 & 4 & 5 & Media & Desvio Padrão & \\
\hline & & Disrupção & 396.670 & 438.489 & 349.975 & 360.234 & 386.255 & 386.325 & 34.750 & 8,99 \\
\hline & & Interrupção & 333.997 & 343.982 & 318.187 & 312.428 & 348.556 & 331.430 & 15.763 & 4,76 \\
\hline & & Total & 730.667 & 782.471 & 668.162 & 672.662 & 734.811 & 717.755 & 47.798 & 6,66 \\
\hline \multirow{4}{*}{10000} & \multirow{4}{*}{27} & Custos & 1 & 2 & 3 & 4 & 5 & & & \\
\hline & & Disrupção & 381.384 & 384.899 & 383.766 & 374.746 & 378.903 & 380.740 & 4.067 & 1,07 \\
\hline & & Interrupção & 330.317 & 322.906 & 324.108 & 326.452 & 326.493 & 326.055 & 2.838 & 0,87 \\
\hline & & Total & 711.701 & 707.805 & 707.874 & 701.198 & 705.396 & 706.795 & 3.858 & 0,55 \\
\hline \multirow{4}{*}{100000} & \multirow{4}{*}{390} & Custos & 1 & 2 & 3 & 4 & 5 & & & \\
\hline & & Disrupção & 379.221 & 378.786 & 379.650 & 377.889 & 381.385 & 379.386 & 1.294 & 0,34 \\
\hline & & Interrupção & 327.252 & 327.896 & 327.207 & 328.123 & 325.645 & 327.225 & 969 & 0,30 \\
\hline & & Total & 706.473 & 706.682 & 706.857 & 706.012 & 707.030 & 706.611 & 393 & 0,06 \\
\hline
\end{tabular}

Dos resultados obtidos na Tabela 7-5, a chamada estabilidade de Monte Carlo é obtida para 100.000 faltas, com custo médio total de $\$ 706.611$ por ano, e um coeficiente de variação de $0,06 \%$, em tempo de processamento de 390 segundos.

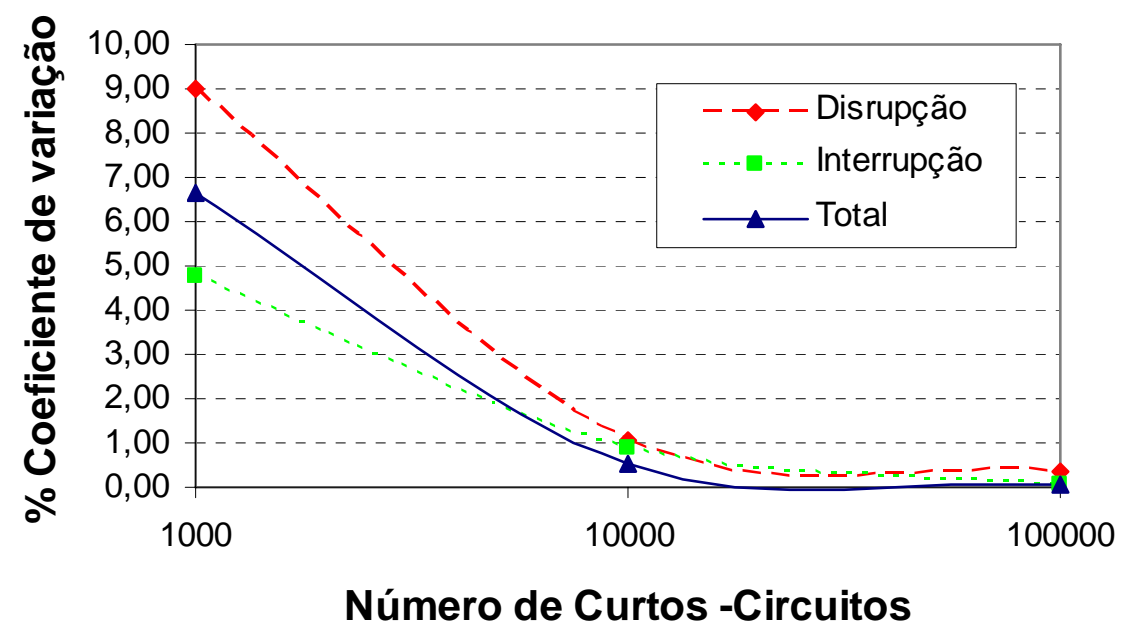

Figura 7-4 - \% Coeficiente de variação vs Número de Faltas- Método Monte Carlo 


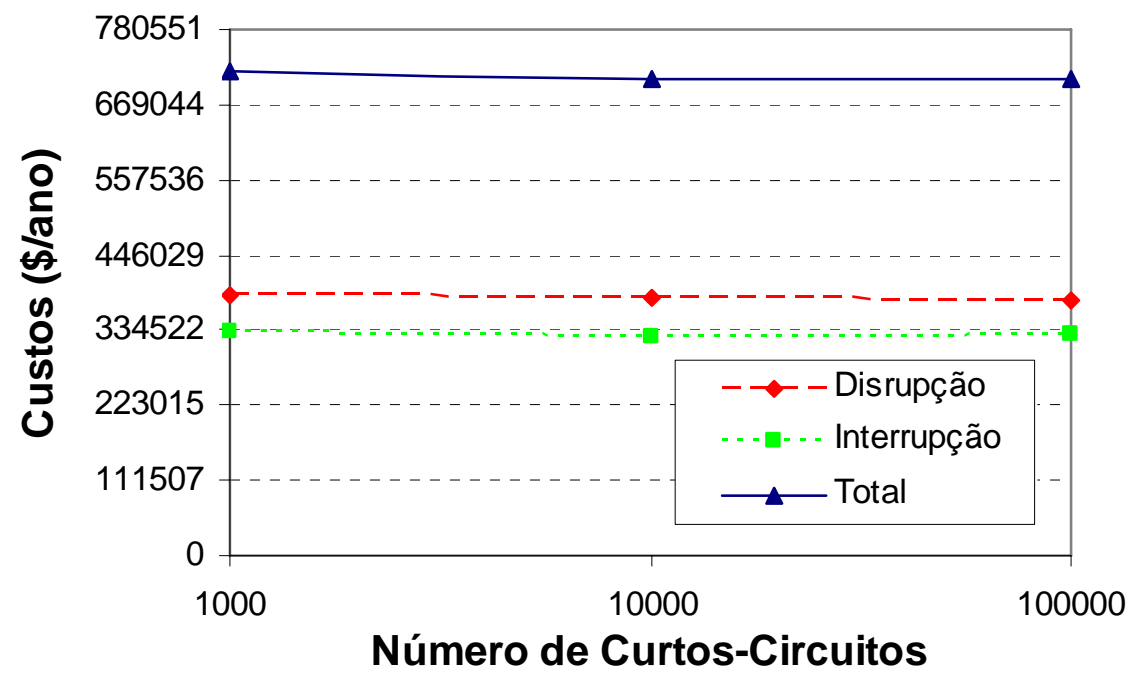

Figura 7-5 - Custos anualizados vs Número de Faltas - Método Monte Carlo

Pode ser observado na Figura 7-4 a tendência do coeficiente de variação dos custos (interrupção, disrupção e total) em função do número de faltas. Da figura, para 100.000 faltas, os valores dos coeficientes de variação ficam embaixo de $0,5 \%$.

Também pode ser observado na Figura 7-5 que os valores dos custos não sofrem muita variação nos seus valores médios, quando varia-se o número total de faltas de 1.000 para 100.000 .

\subsection{Método de Enumeração de estados}

Serão apresentados resultados usando o método de Enumeração de estados para diferentes condições, variando o número de faixas das variáveis aleatórias $\left(N_{F x \text { Comp }}, N_{F x I m p}\right.$, $N_{\text {FxImpFFT-T). }}$.

Tabela 7-6 - Resultados para diferentes números de faixas - Método de Enumeração de estados

\begin{tabular}{|c|c|c|c|c|r|r|r|}
\hline \multirow{2}{*}{$N_{\text {Fx Comp }}$} & \multirow{2}{*}{$N_{\text {FxImp }}$} & \multirow{2}{*}{$N_{\text {FxImpFFT-T }}$} & No de Curtos & \multirow{2}{*}{ Circuitos } & Tempo (s) & \multicolumn{3}{|c|}{ Custo (\$/ano) } \\
\cline { 6 - 8 } & & & & & Disrupção & Interrupção & Total \\
\hline 2 & 2 & 2 & 12.160 & 31 & 645.062 & 337.830 & 982.892 \\
\hline 5 & 5 & 5 & 121.600 & 677 & 567.995 & 330.725 & 898.720 \\
\hline 10 & 10 & 10 & 790.400 & 2993 & 564.767 & 328.411 & 893.178 \\
\hline
\end{tabular}

Pode-se observar na Figura 7-6 os resultados obtidos variando a simulação para 2, 5 e 10 faixas. Conforme já explicitado no caso anterior, para se obter maior precisão é necessário aumentar o número de faixas, o que produz um aumento no número de faltas e no tempo de processamento. 
Para diminuir o tempo de processamento sem comprometer a qualidade dos resultados, determina-se a rede reduzida da Figura 7-6, aplicando o critério de redução de rede apresentado no item 4.1.3.1.

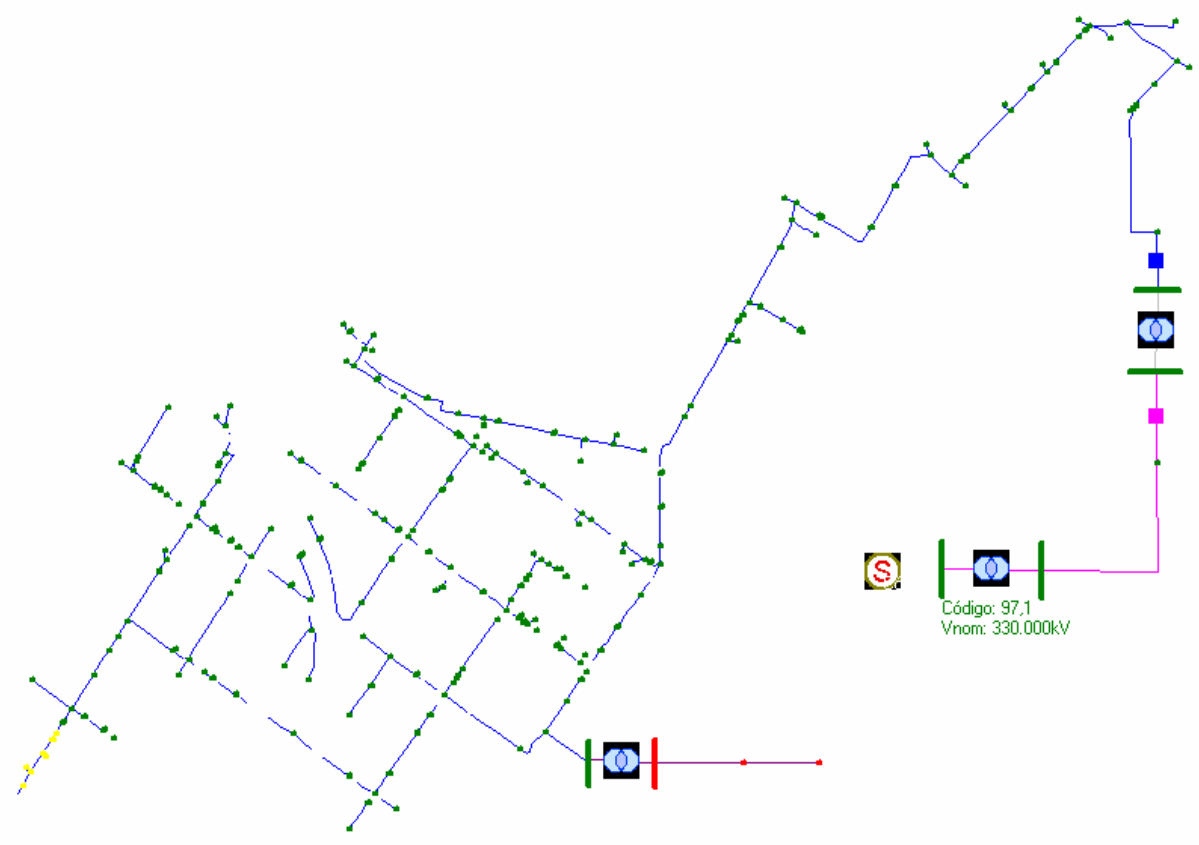

Figura 7-6 - Rede de 609 barras (reduzida para 323 barras)

A Figura 7-6 apresenta o diagrama unifilar da rede reduzida. O número de transformadores, consumidores, chaves e comprimento da rede serão os mesmos da rede original mostrada no Figura 7-2, porém a rede apresenta 323 barras.

Para realizar as novas simulações com esta nova rede reduzida, são atribuídos valores diferentes para os números de faixas $N_{\text {FxComp }}, N_{\text {FxImp }}, N_{\text {FxImpFFT-T. }}$.

Tabela 7-7 - Resultados para diferentes valores de faixas de comprimento, utilizando uma rede reduzida Método de Enumeração de estados

\begin{tabular}{|c|c|c|c|c|c|c|c|}
\hline \multirow{2}{*}{$N_{\text {FxComp }}$} & \multirow{2}{*}{$N_{\text {FxImp }}$} & \multirow{2}{*}{$N_{\text {FxImpFFT-T }}$} & No de Curtos & \multirow{2}{*}{ Tempo (s) } & \multicolumn{3}{|c|}{ Custo (\$/ano) } \\
\cline { 6 - 8 } & & & & Disrupçãos & Interrupção & Total \\
\hline 100 & 2 & 2 & 323.000 & 485 & 639.349 & 337.937 & 977.286 \\
\hline 200 & 2 & 2 & 646.000 & 1155 & 639.349 & 337.937 & 977.286 \\
\hline 800 & 2 & 2 & 2.584 .000 & 4161 & 639.348 & 337.942 & 977.290 \\
\hline
\end{tabular}

Tabela 7-8 - Resultados Para diferentes valores de faixas de impedância de falta, utilizando uma rede reduzida - Método de Enumeração de estados

\begin{tabular}{|c|c|c|c|c|c|c|c|}
\hline \multirow{2}{*}{$N_{\text {FxComp }}$} & \multirow{2}{*}{$N_{\text {FxImp }}$} & \multirow{2}{*}{$N_{F x I m p F F T-T}$} & \multirow{2}{*}{$\begin{array}{c}\text { No de Curtos } \\
\text { Circuitos }\end{array}$} & \multirow{2}{*}{ Tempo (s) } & \multicolumn{3}{|c|}{ Custo (\$/ano) } \\
\hline & & & & & Disrupção & Interrupção & Total \\
\hline 2 & 100 & 2 & 323.000 & 655 & 537.508 & 326.506 & 864.014 \\
\hline 2 & 200 & 2 & 646.000 & 1231 & 537.038 & 326.451 & 863.489 \\
\hline 2 & 800 & 2 & 2.584 .000 & 6061 & 536.896 & 326.408 & 863.304 \\
\hline
\end{tabular}


Tabela 7-9 - Resultados Para diferentes valores de faixas de impedância de falta terra, utilizando uma rede reduzida - Método de Enumeração de estados

\begin{tabular}{|c|c|c|c|c|c|c|c|}
\hline \multirow{2}{*}{$N_{\text {FxComp }}$} & \multirow{2}{*}{$N_{\text {FxImp }}$} & \multirow{2}{*}{$N_{\text {FxImpFFT-T }}$} & No de Curtos & \multirow{2}{*}{ Circuitos } & \multirow{2}{*}{ Tempo (s) } & \multicolumn{3}{|c|}{ Custo (\$/ano) } \\
\cline { 6 - 8 } & 2 & 100 & 133.076 & 218 & Disrupção & Interrupção & Total \\
\hline 2 & 2 & 200 & 262.276 & 545 & 638.265 & 337.684 & 975.955 \\
\hline 2 & 2 & 800 & 1.037 .476 & 2690 & 638.259 & 337.684 & 975.949 \\
\hline 2 & 2 & 8084 & 975.943 \\
\hline
\end{tabular}

Das Tabela 7-7, Tabela 7-8 e Tabela 7-9, são apresentados resultados variando o número de faixas para cada variável envolvida. Assim, pode-se observar que a influência nos resultados para o aumento no número de faixas da variável impedância de falta $\left(N_{F x I m p}\right)$ é muito maior em comparação com as outras variáveis. Isto pode ser explicado, dado que o valor da impedância de falta é muito maior do que as impedâncias de trecho, o que se reflete no cálculo da corrente de curto-circuito e no valor dos afundamentos de tensão.

Dos resultados, pode-se observar que mesmo utilizando uma rede reduzida e variando as faixas, o desempenho ainda do método de Enumeração de estados é bastante aquém do método de Monte Carlo. Comparando o número de faltas calculados e o tempo de processamento, pode-se concluir que, para esta rede. é necessário aumentar em forma significativa o número das faixas para cada variável, o que resultará num número de cálculo de faltas muito grande. É dado como observação que para realizar simulações maiores, para esta rede 609 barras, é necessário de enormes recursos computacionais, o que limita o desempenho deste método para redes reais.

\subsection{Método Híbrido}

Para analisar o comportamento do método Híbrido, a rede utilizada será a mesma apresentada na Figura 7-2. A execução será realizada em duas formas. Na primeira execução, realiza-se variações do parâmetro $N_{F x-M i n}$ (Faixa Mínima) para valores de 1, 3, 5, 7. Com estes valores será obtido o número de faltas necessário para a simulação deste método.

Para a segunda execução, será fixado o número de faltas, para diferentes valores: 1000,10000 e 100000. Assim, o método realizará a melhor distribuição do número de faltas ao longo da rede, mantendo as distribuições de probabilidade mostrada no Item 7.1.3. 


\section{(a) Primeira execução:}

Tabela 7-10-Resultados para diferentes números de faixas mínimas - Método Híbrido

\begin{tabular}{|c|c|c|c|c|c|c|c|c|c|c|c|}
\hline \multirow{2}{*}{$\begin{array}{l}\text { No de Curtos } \\
\text { Circuitos }\end{array}$} & \multirow{2}{*}{$\begin{array}{c}\text { Faixa } \\
\text { Mínima }\end{array}$} & \multirow{2}{*}{$\begin{array}{c}\text { Tempo } \\
\text { Médio (s) } \\
\end{array}$} & \multicolumn{8}{|c|}{ Unidade (\$/ano) } & \multirow[b]{3}{*}{$\begin{array}{c}\text { \%Coeficiente } \\
\text { de variação }\end{array}$} \\
\hline & & & & & & Simulação & & & & & \\
\hline \multirow{4}{*}{988} & \multirow{4}{*}{1} & \multirow{4}{*}{3} & Custos & 1 & 2 & 3 & 4 & 5 & Media & Desvio Padrão & \\
\hline & & & Disrupção & 384.036 & 378.986 & 379.081 & 390.456 & 383.126 & 383.137 & 4.692 & 1,22 \\
\hline & & & Interrupção & 314.881 & 326.944 & 339.712 & 312.633 & 356.352 & 330.104 & 18.222 & 5,52 \\
\hline & & & Total & 698.917 & 705.930 & 718.793 & 703.089 & 739.478 & 713.241 & 16.438 & 2,30 \\
\hline \multirow{4}{*}{2964} & \multirow{4}{*}{3} & \multirow{4}{*}{8} & Custos & 1 & 2 & 3 & 4 & 5 & & & \\
\hline & & & Disrupção & 389.044 & 378.999 & 385.791 & 383.138 & 380.565 & 383.507 & 4.031 & 1,05 \\
\hline & & & Interrupção & 332.983 & 327.673 & 330.705 & 330.913 & 328.723 & 330.199 & 2.066 & 0,63 \\
\hline & & & Total & 722.027 & 706.672 & 716.496 & 714.051 & 709.288 & 713.707 & 6.044 & 0,85 \\
\hline \multirow{4}{*}{4941} & \multirow{4}{*}{5} & \multirow{4}{*}{13} & Custos & 1 & 2 & 3 & 4 & 5 & & & \\
\hline & & & Disrupção & 381.500 & 380.890 & 380.931 & 384.022 & 383.743 & 382.217 & 1.542 & 0,40 \\
\hline & & & Interrupção & 320.075 & 333.613 & 323.809 & 327.370 & 328.072 & 326.588 & 5.057 & 1,55 \\
\hline & & & Total & 701.575 & 714.503 & 704.740 & 711.392 & 711.815 & 708.805 & 5.409 & 0,76 \\
\hline \multirow{4}{*}{6917} & \multirow{4}{*}{7} & \multirow{4}{*}{18} & Custos & 1 & 2 & 3 & 4 & 5 & & & \\
\hline & & & Disrupção & 381.969 & 384.861 & 380.440 & 379.454 & 377.931 & 380.931 & 2.643 & 0,69 \\
\hline & & & Interrupção & 324.465 & 329.156 & 326.502 & 328.151 & 334.370 & 328.529 & 3.717 & 1,13 \\
\hline & & & Total & 706.434 & 714.017 & 706.942 & 707.605 & 712.301 & 709.460 & 3.456 & 0,49 \\
\hline
\end{tabular}

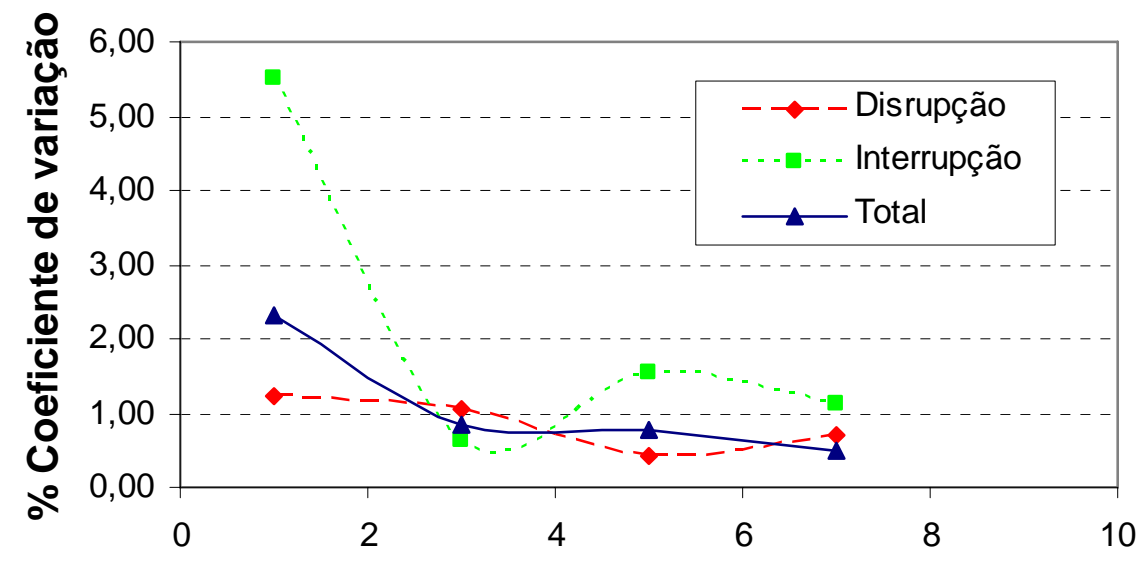

Número de Faixas Mínimas

Figura 7-7 - \% coeficiente de variação vs Número de faixas mínimas - Método Híbrido 


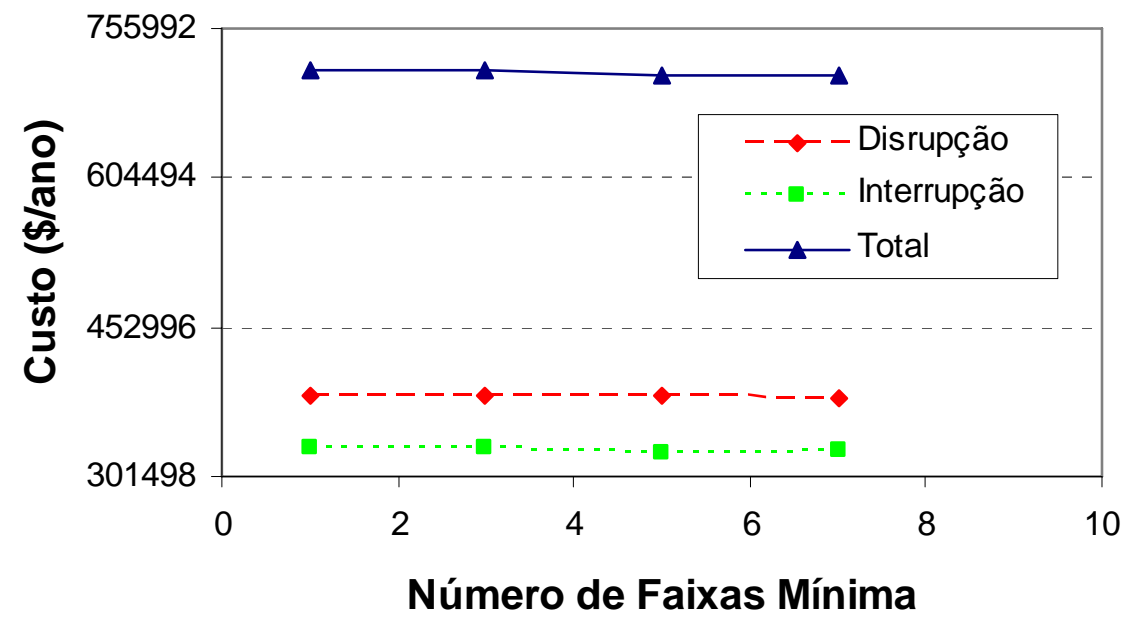

Figura 7-8 - Custo anualizados vs Número de faixas mínimas - Método Híbrido

Sendo realizada a primeira execução, variando o número de faixas mínimo, nota-se que o valor com faixa mínima de 3 já reflete valores com desvios muito baixos. É importante observar que, no caso das interrupções de longa duração, os desvios padrão obtidos para 5 e 7 faixas mínimas aumenta em relação à 3 faixas mínimas. Este incremento pode ser explicado dado que o método Híbrido possui variáveis de natureza aleatória que influenciam na variação do número de interrupções. Por outro lado, sendo comparado o valor total (Custo das Interrupções mais disrupções), os desvios padrão diminuem com o aumento das faixas.

\section{(b) Segunda execução:}

Tabela 7-11 - Resultados para diferentes Números de faltas - Método Híbrido

\begin{tabular}{|c|c|c|c|c|c|c|c|c|c|c|}
\hline \multirow{2}{*}{$\begin{array}{l}\text { No de } \\
\text { Curtos }\end{array}$} & \multirow{2}{*}{$\begin{array}{c}\text { Tempo } \\
\text { Médio (s) } \\
\end{array}$} & \multicolumn{8}{|c|}{ Unidade (\$/ano) } & \multirow[b]{3}{*}{$\begin{array}{c}\text { \%Coeficiente } \\
\text { de variação }\end{array}$} \\
\hline & & & & & Simulação & & & & & \\
\hline \multirow{4}{*}{1000} & \multirow{4}{*}{4} & Custos & 1 & 2 & 3 & 4 & 5 & Media & Desvio Padrão & \\
\hline & & Disrupção & 379.710 & 374.892 & 379.953 & 381.987 & 381.220 & 379.552 & 2.766 & 0,73 \\
\hline & & Interrupção & 352.814 & 353.800 & 331.032 & 331.756 & 338.802 & 341.641 & 11.079 & 3,24 \\
\hline & & Total & 732.524 & 728.692 & 710.985 & 713.743 & 720.022 & 721.193 & 9.297 & 1,29 \\
\hline \multirow{4}{*}{10000} & \multirow{4}{*}{27} & Custos & 1 & 2 & 3 & 4 & 5 & & & \\
\hline & & Disrupção & 378.321 & 377.979 & 377.901 & 380.092 & 376.804 & 378.219 & 1.192 & 0,32 \\
\hline & & Interrupção & 324.939 & 330.017 & 327.403 & 324.835 & 331.499 & 327.739 & 2.988 & 0,91 \\
\hline & & Total & 703.260 & 707.996 & 705.304 & 704.927 & 708.303 & 705.958 & 2.146 & 0,30 \\
\hline \multirow{4}{*}{100000} & \multirow{4}{*}{390} & Custos & 1 & 2 & 3 & 4 & 5 & & & \\
\hline & & Disrupção & 379.194 & 378.633 & 379.307 & 379.706 & 380.022 & 379.372 & 528 & 0,14 \\
\hline & & Interrupção & 325.313 & 326.827 & 328.005 & 327.787 & 327.486 & 327.084 & 1.085 & 0,33 \\
\hline & & Total & 704.507 & 705.460 & 707.312 & 707.493 & 707.508 & 706.456 & 1.388 & 0,20 \\
\hline
\end{tabular}




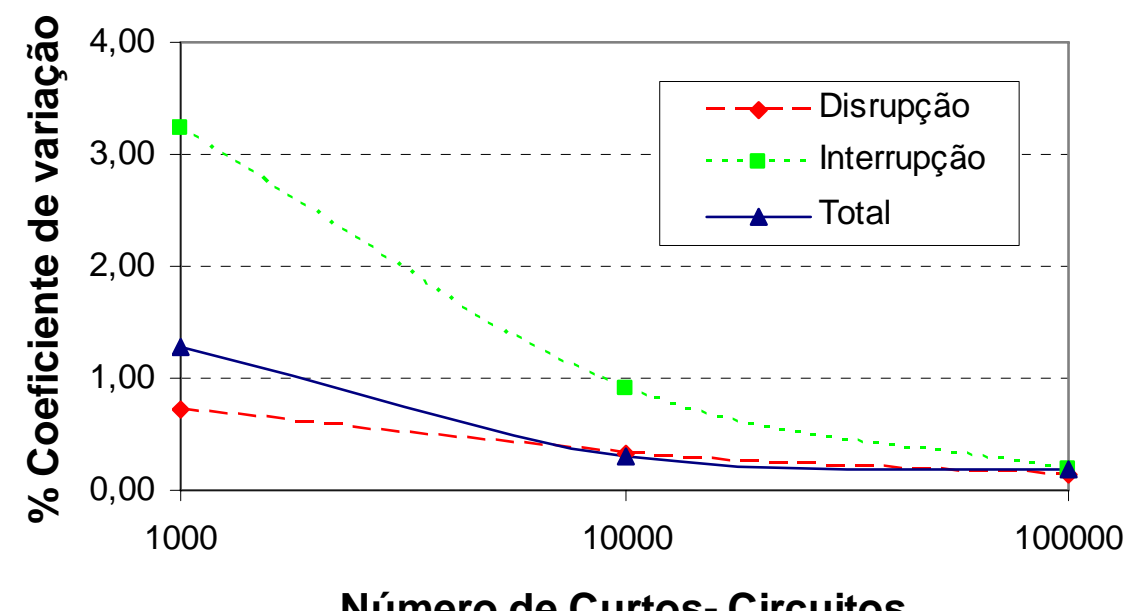

Figura 7-9 - \% coeficiente de variação vs Número de Curtos-Circuitos - Método Híbrido

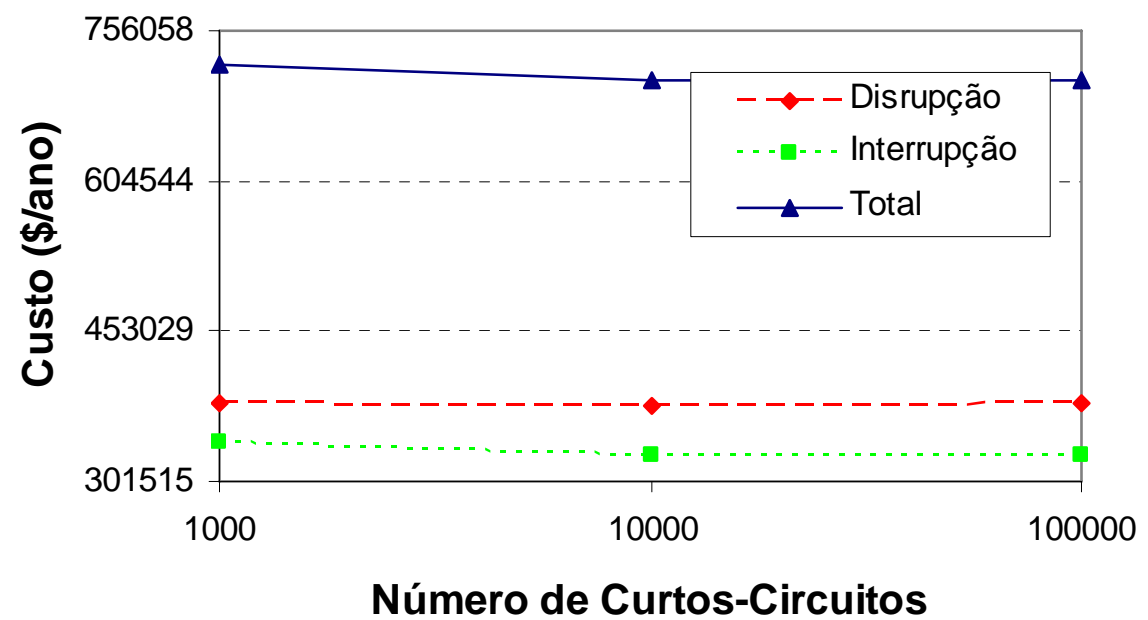

Figura 7-10 - Custos Anualizados vs Número de Curtos-circuitos - Método Híbrido

Os resultados da segunda execução podem ser observados na Tabela 7-11. Para relativamente maior número de faltas, é possível observar a diminuição do coeficiente de variação dos custos. A Figura 7-9 e a Figura 7-10 mostram a tendência do coeficiente de variação e do valor do custo anualizado, respectivamente. Pode-se observar das figuras que a tendência é praticamente a mesma para 1.000 e 100.000 faltas simuladas.

\subsubsection{Comparação dos Métodos}

Nesta seção serão realizadas diferentes comparações para medir a eficiência de cada método estudado. As comparações abrangem valores médios, desvio padrão e tempo computacional. 


\subsubsection{Primeira Comparação}

Para realizar a primeira comparação, serão utilizados os valores médios obtidos, conforme apresentados nas Tabela 7-1, Tabela 7-2 e Tabela 7-3 para a rede de 27 barras e Tabela 7-5, Tabela 7-6 e Tabela 7-10 para a rede de 609 barras. Os valores extraídos serão aqueles que apresentam as seguintes condições:

(a) Para o Método de Monte Carlo e Híbrido, o número de faltas simuladas considerado é de 100.000;

(b) Para o Método de Enumeração de estados, serão considerados os resultados obtidos para 10 faixas por variável;

Tabela 7-12 - Comparação dos Três Métodos de simulação - Rede 27 Barras

\begin{tabular}{|l|c|c|c|r|r|}
\hline \multicolumn{4}{|c|}{} & \multicolumn{3}{|c|}{ Métodos de Simulação } & \\
\cline { 2 - 5 } & \multicolumn{3}{|c|}{ Custos (\$/ano) } & \%Coeficiente de \\
\cline { 2 - 5 } & Monte Carlo & Analítico & Híbrido & Desvão dos Métodos \\
\hline visrupção & 88.611 & 90.418 & 89.026 & 946 & 1,06 \\
\hline Interrupção & 87.671 & 87.152 & 87.640 & 291 & 0,33 \\
\hline Total & 176.283 & 177.570 & 176.666 & 661 & 0,37 \\
\hline
\end{tabular}

Tabela 7-13 - Comparação dos Três Métodos de simulação - Rede 609 Barras

\begin{tabular}{|c|c|c|c|c|c|}
\hline & \multicolumn{3}{|c|}{ Métodos de Simulação } & & \\
\hline & \multicolumn{4}{|c|}{ Custos (\$/ano) } & \multirow{2}{*}{$\begin{array}{c}\text { \%Coeficiente de } \\
\text { variação dos Métodos }\end{array}$} \\
\hline & Monte Carlo & Analítico & Híbrido & Desvio & \\
\hline Disrupção & 379386 & 564767 & 379372 & 107034 & 24,26 \\
\hline Interrupção & 327225 & 328411 & 327084 & 729 & 0,22 \\
\hline Total & 706611 & 893178 & 706456 & 107759 & 14,02 \\
\hline
\end{tabular}

Para as duas redes simuladas, como referência, são utilizados os valores dos custos médios obtidos com o método de Monte Carlo para obter o coeficiente de variação da Tabela 7-12 e na Tabela 7-13. Pode-se observar que os valores obtidos nos três métodos, para a rede de 27 barras, ficam muito próximos, e seus coeficientes de variação, são inferiores a 1,1 \%.

Para a rede maior, de 609 barras, os valores dos custos médios para interrupções apresentam um coeficiente de variação inferior a $0,5 \%$, mas para o caso do custo médio das disrupções, o valor do coeficiente de variação é muito maior, chegando a $24,26 \%$. Isto pode ser explicado pelo fato de que o método de Enumeração de estados ainda precisa de mais simulações para chegar a uma solução próxima do método de Monte Carlo.

Por outro lado, se somente forem comparados os métodos Monte Carlo e Híbrido para a rede de 609 barras, os resultados são muito próximos, já que apresentam coeficientes de variação inferiores a $0,03 \%$ o que demonstra que estes dois métodos chegam a resultados praticamente iguais, como pode ser observado na Tabela 7-14. 
Tabela 7-14 - Comparação do Método Monte Carlo e Híbrido - Rede 609 Barras

\begin{tabular}{|l|r|r|r|r|}
\hline \multirow{2}{*}{} & \multicolumn{3}{|c|}{ Métodos de Simulação } & \\
\cline { 2 - 4 } & \multicolumn{2}{|c|}{ Custos (\$/ano) } & \%Coeficiente \\
& Monte Carlo & Híbrido & \multicolumn{1}{c|}{ Desvio } & variação \\
\hline Disrupção & 379.386 & 379.372 & 10 & 0,00 \\
\hline Interrupção & 327.225 & 327.084 & 100 & 0,03 \\
\hline Total & 706.611 & 706.456 & 109 & 0,02 \\
\hline
\end{tabular}

\subsubsection{Segunda Comparação}

Esta segunda comparação analisa a qualidade dos resultados em função do tempo de processamento para os 3 métodos estudados. Para esta comparação, serão utilizados os resultados aplicados à rede de 609 barras, já que no caso da rede de 27 barras os tempos computacionais são muito pequenos, dificultando o objetivo desta comparação.

Para esta comparação, será somente utilizado o valor médio do custo total, tanto para o método de Monte Carlo como para o método Híbrido. Serão extraídos da Tabela 7-5 e da Tabela 7-11 os resultados para as simulações de 1.000, 10.000 e 100.000 faltas. No caso do método de Enumeração de estados, será considerado o valor do custo total obtido para as 2, 5 e 10 faixas da Tabela 7-6.

Tabela 7-15 - Custo Total médio vs tempo para os três métodos

\begin{tabular}{|c|c|c|c|c|}
\hline \multirow{2}{*}{ Monte Carlo } & $\begin{array}{c}\text { No de curtos- } \\
\text { circuitos }\end{array}$ & No de faixas & Tempo(s) & Monte Carlo \\
\cline { 2 - 4 } & 1.000 & & 4 & 717.755 \\
\cline { 2 - 5 } Analítico & 10.000 & & 27 & 706.795 \\
\cline { 4 - 5 } & & 2 & 390 & 706.611 \\
\hline \multirow{3}{*}{ Híbrido } & 10000 & 5 & 677 & 892.892 \\
\cline { 2 - 5 } & 10.000 & 10 & 2993 & 893.178 \\
\cline { 2 - 4 } & 100.000 & & 4 & 721.193 \\
\hline
\end{tabular}




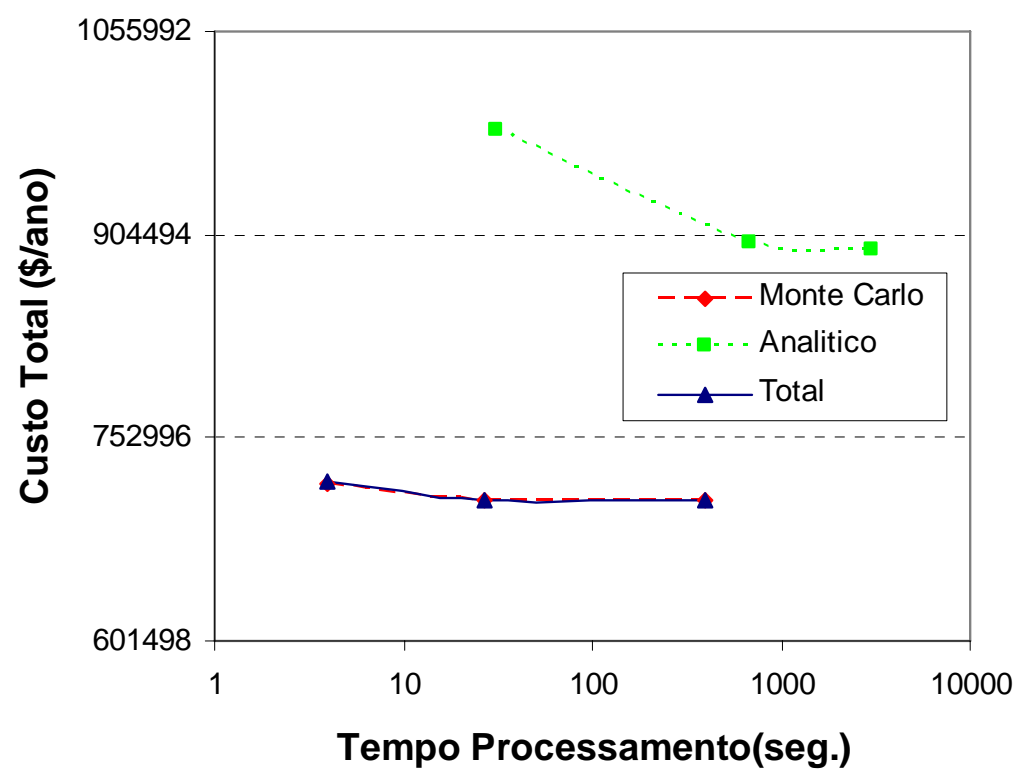

Figura 7-11 - Custo total médio vs tempo de processamento para os três métodos.

A partir das informações da Tabela 7-15, foi gerada a Figura 7-11, onde fica evidente que os tempos de processamento obtidos pelo método de Enumeração de estados são muito maiores em relação aos outros dois métodos. Como foi comentado anteriormente, o método de Enumeração de estados ainda não alcançou a sua convergência, já que precisaria de mais faltas simuladas, o que resultaria em tempo de processamento ainda maior. No caso dos métodos de Monte Carlo e Híbrido, a estabilidade é obtida para tempo inferior a $400 \mathrm{~s}$.

Estes resultados mostram a eficiência marcante dos métodos de Monte Carlo e Híbrido em relação ao Método de Enumeração de estados, tanto em tempo de processamento como em qualidade dos resultados obtidos.

\subsubsection{Terceira Comparação}

No item 7.1.5.2, foi possível observar que os métodos Monte Carlo e Híbrido mantêm tendências muito parecidas, o que não acontece com o método de Enumeração de estados. É por isso que nesta terceira comparação não será considerado o Método de Enumeração de estados.

A finalidade desta comparação visa avaliar o desempenho do método Monte Carlo frente ao método Híbrido, tanto em tempo computacional como na eficiência na obtenção dos resultados. A rede analisada para esta comparação será a de 609 barras, e será analisado o custo total resultante da soma dos custos de Disrupção por VTCDs e de Interrupção de longa duração. 


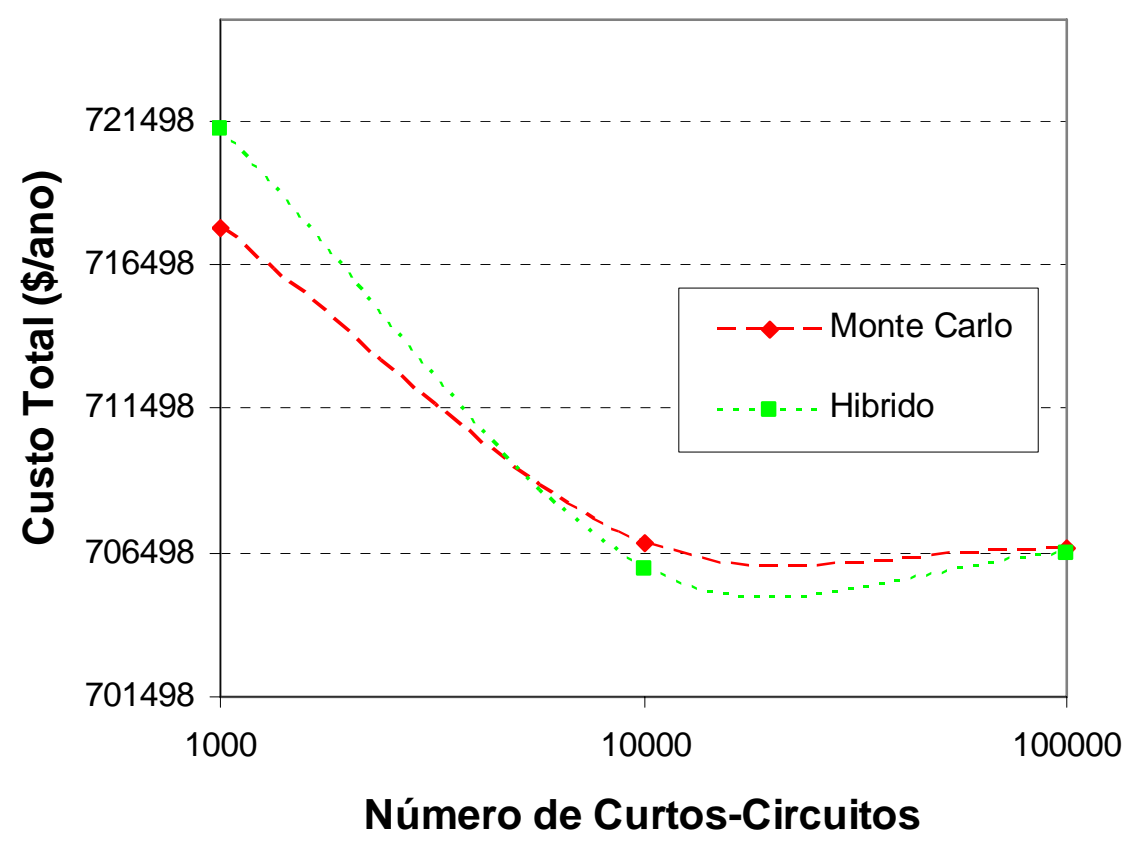

Figura 7-12 - Custo Anualizado vs Tempo de Número de Curtos-Circuitos

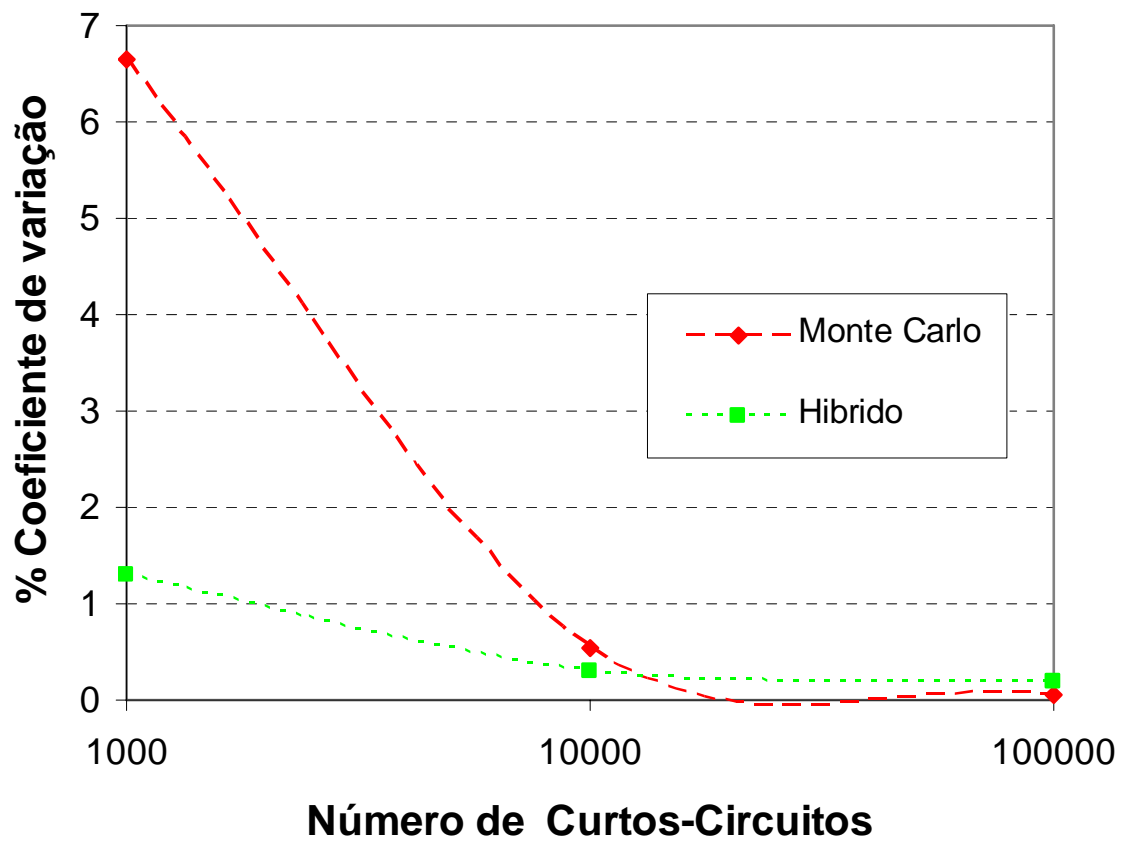

Figura 7-13 - \% Coeficiente de variação vs Número de Curtos-Circuitos.

Da Figura 7-13 pode-se observar que para 1.000 faltas simuladas, o método Híbrido possui um coeficiente de variação menor em comparação ao método de Monte Carlo. Para maiores faltas, os dois métodos convergem para um mesmo ponto.

Dado que ambos os métodos utilizam os mesmos módulos computacionais para cálculo de curto-circuito e para análise estatística, ambos os métodos terão os mesmos tempos de processamento para o mesmo número de faltas simuladas. 
A Tabela 7-16 apresenta resultados derivados da Tabela 7-10, para diferentes condições de faixa mínima. Com isto é possível analisar o valor da faixa mínima necessária para poder obter um número de faltas simuladas que daria como resultado um coeficiente de variação inferior a $0,5 \%$, considerado razoável para garantir que o método Híbrido alcançou a sua estabilidade.

Tabela 7-16 - Comparação Método Híbrido e Monte Carlo - custo médio total e \% coeficiente de variação

\begin{tabular}{|c|c|c|c|}
\hline \multirow{3}{*}{ Híbrido } & $\begin{array}{c}\text { No de Curtos } \\
\text { Circuitos }\end{array}$ & $\begin{array}{c}\text { Custo Total } \\
(\$ / \text { ano })\end{array}$ & $\begin{array}{c}\text { \% Coeficiente } \\
\text { de variação }\end{array}$ \\
\cline { 2 - 4 } & 988 & 713.241 & 2,30 \\
\cline { 2 - 4 } & 2.964 & 713.707 & 0,85 \\
\cline { 2 - 4 } & 4.941 & 708.805 & 0,76 \\
\hline \multirow{3}{*}{ Monte Carlo } & 6.917 & 709.460 & 0,49 \\
\cline { 2 - 4 } & 1.000 & 717.755 & 6,66 \\
\cline { 2 - 4 } & 10.000 & 706.795 & 0,55 \\
\hline
\end{tabular}

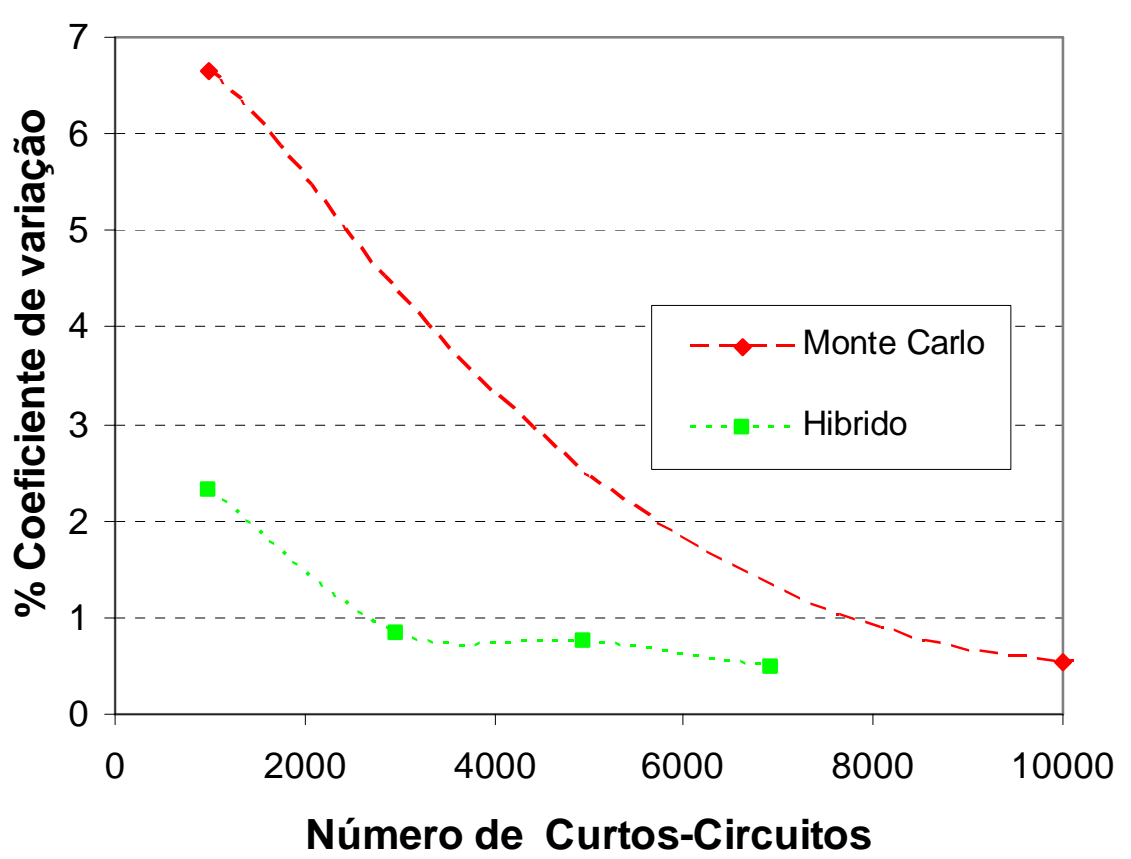

Figura 7-14 - \% Coeficiente de variação vs Número de curtos-circuitos para o método Monte Carlo e Híbrido

Da Figura 7-14, observa-se que o Método Híbrido com 6.917 faltas simuladas (faixa mínima 7) obtém resultado com valor do coeficiente de variação inferior a $0,5 \%$. O Método de Monte Carlo precisa de mais de 10.000 faltas simuladas para obter este mesmo desvio padrão.

Desta análise, pode-se concluir que o método Híbrido se mostrou mais eficiente, já que consegue encontrar com menor número de faltas simuladas, e portanto menor tempo de 
processamento, melhores resultados na obtenção dos custos anualizados para as interrupções de longa duração e disrupções por VTCDs.

\subsection{6 Áreas de Risco utilizando os diferentes métodos de simulação}

Nesta seção serão apresentadas, em forma gráfica, as áreas de risco para a rede de 609 barras mostrada na Figura 7-2. As áreas de risco apresentam os seguintes índices: Afundamento de tensão, Interrupção de longa duração, Afundamento de tensão com Interrupção, Elevações de tensão e Disrupções por VTCDs. Os resultados serão divididos em 3 cores em função do nível de severidade: verde (menor), amarelo (médio), vermelho (máximo).

No caso da área de risco obtida pelo método de Monte Carlo, foram utilizados 100.000 faltas simuladas para a obtenção dos seus índices. Com o Método de Enumeração de estados foram utilizadas as seguintes faixas: $N_{F x \text { Com }}=2, N_{\text {FxImp }}=800$ e $N_{\text {FxImpFFT-T. }}=2$ (o que resulta em 2.584.000 faltas simuladas). Finalmente, com o método Híbrido, foi utilizado o valor da faixa mínima $N_{F x-M i n}=5$ (4941 faltas simuladas).

Será apresentada na Figura 7-15, Figura 7-16, Figura 7-17, Figura 7-18, Figura 7-19, as Áreas de Risco frente a afundamentos de tensão, Interrupções de longa duração, Afundamentos mais Interrupções de longa duração, Elevações e Disrupções de tensão, em todas as barras para o sistema de 609 barras, para cada método de simulação (Monte Carlo, Enumeração de estados e Híbrido). 


\subsubsection{Análise de Afundamentos de Tensão}

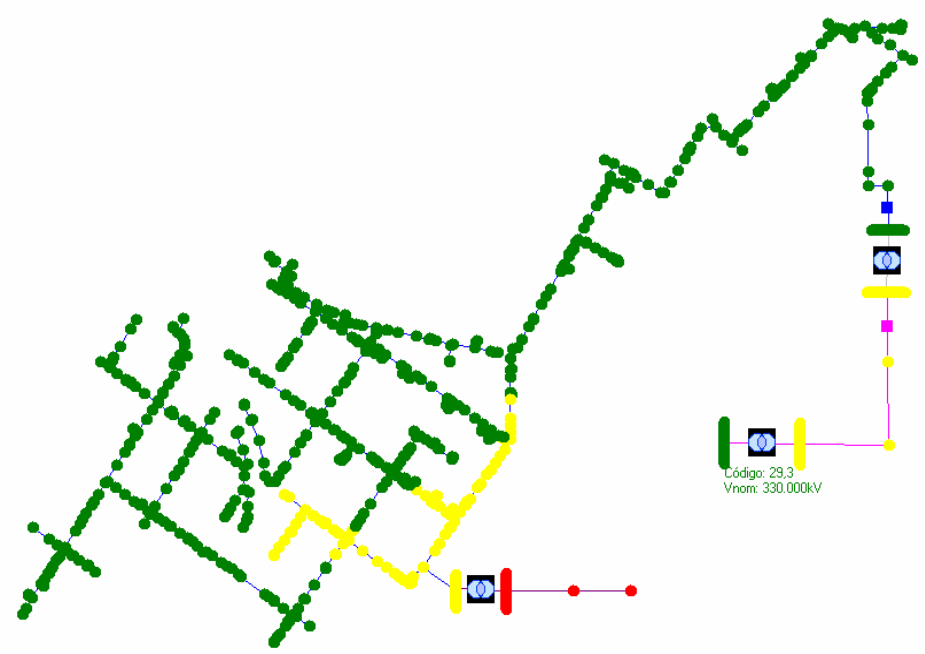

(a)

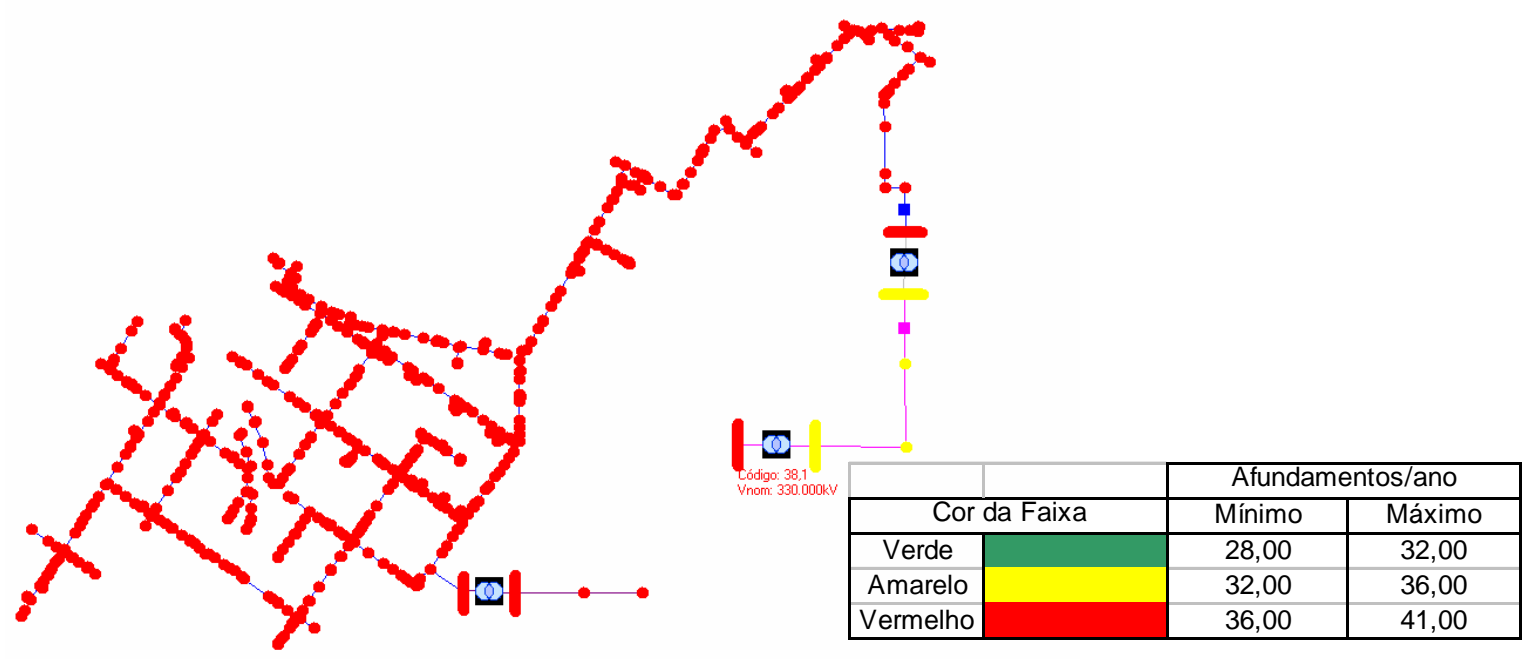

(b)

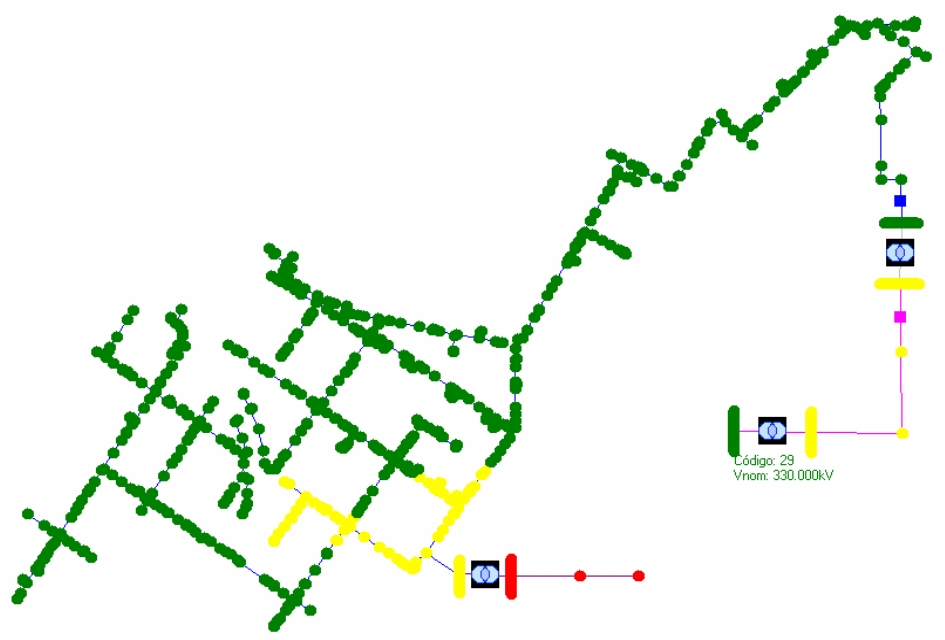

(c)

Figura 7-15- Áreas de Risco referente a afundamentos de tensão: (a) Método Monte Carlo, (b) Método Enumeração de estados, (c) Método Híbrido. 


\subsubsection{Análise de Interrupções de longa duração}

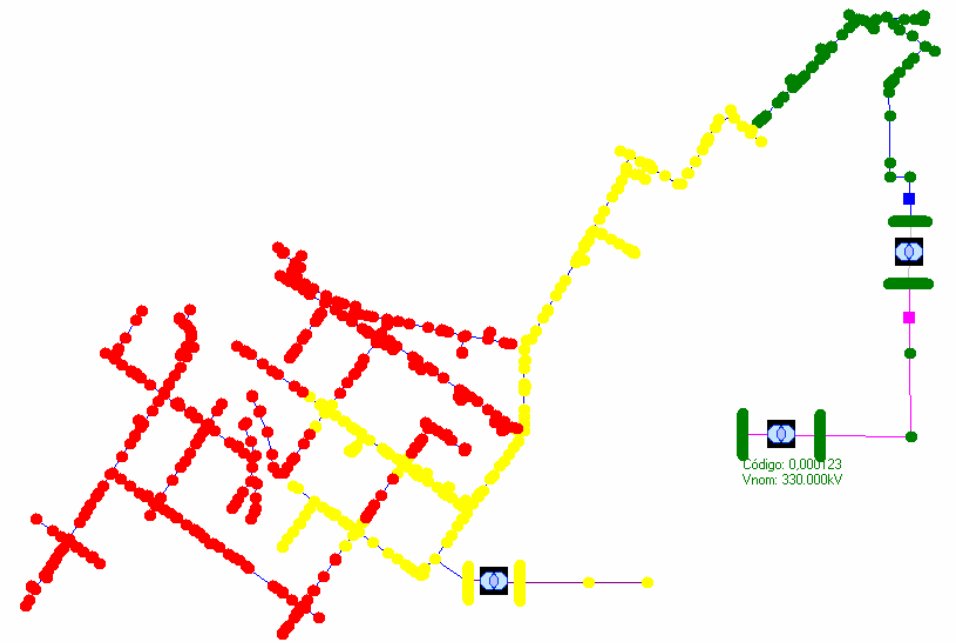

(a)
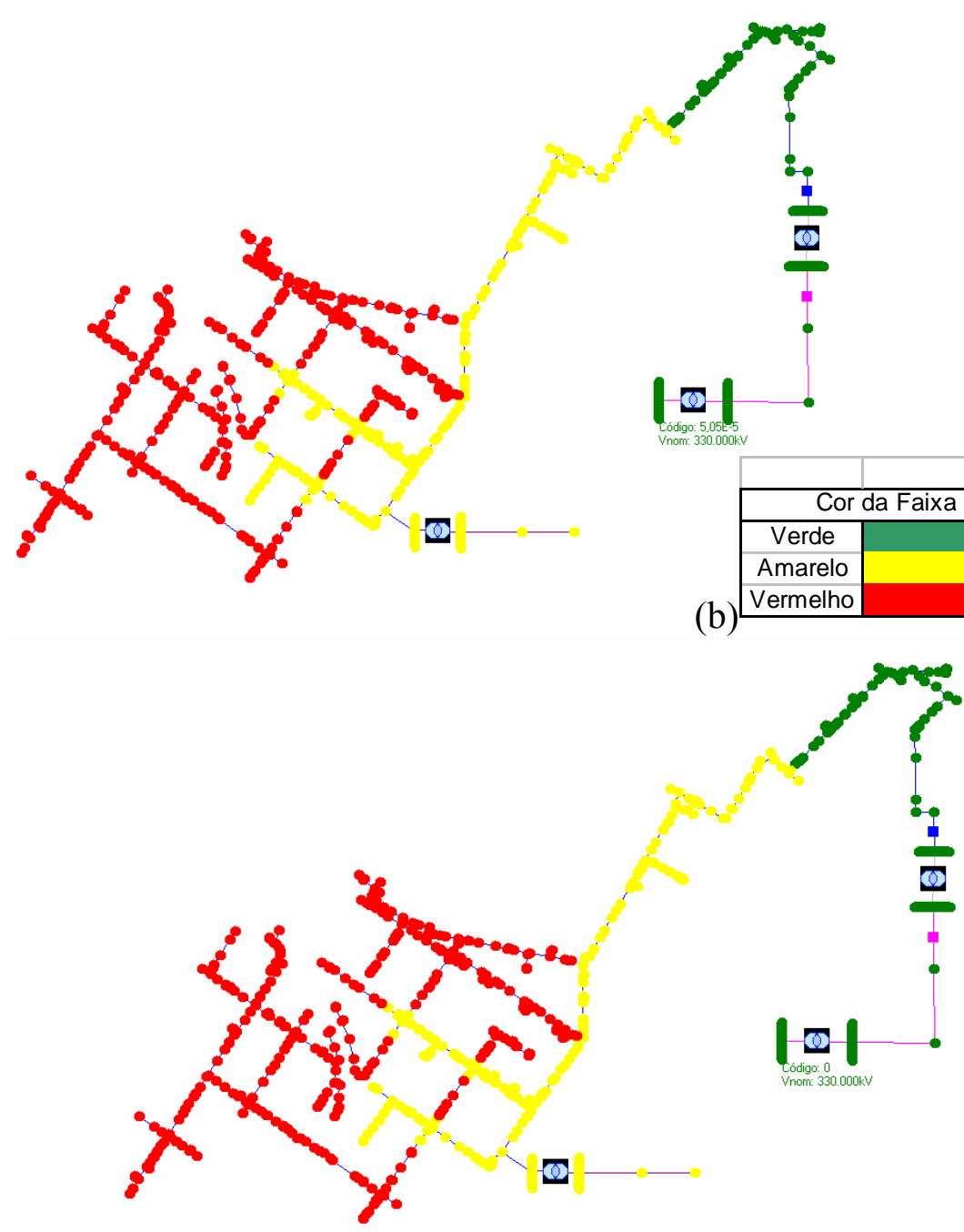

b) Vermelho

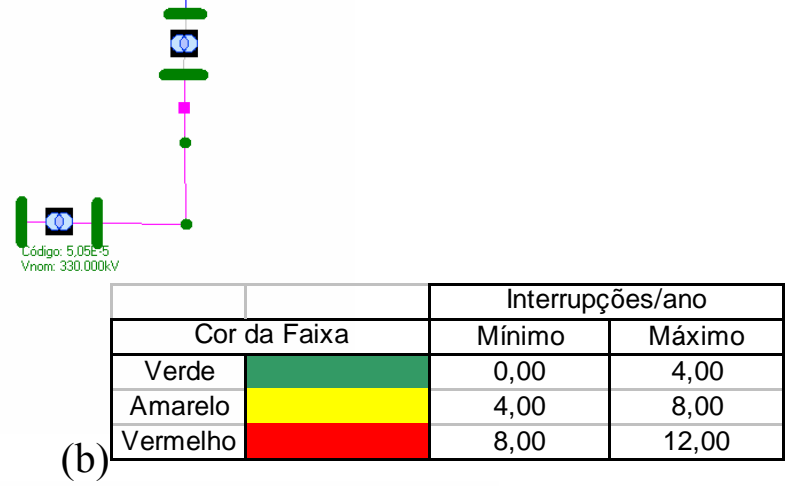

(c)

Figura 7-16 - Áreas de Risco referente a Interrupções: (a) Método Monte Carlo, (b) Método de Enumeração de estados, (c) Método Híbrido. 


\subsubsection{Análise de Afundamentos mais Interrupções}
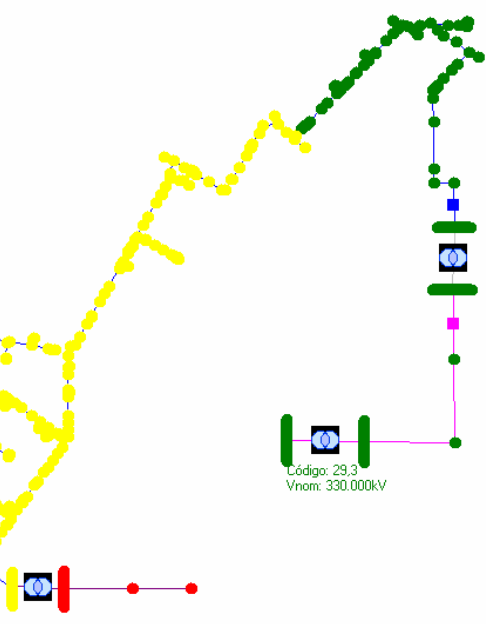

(a)

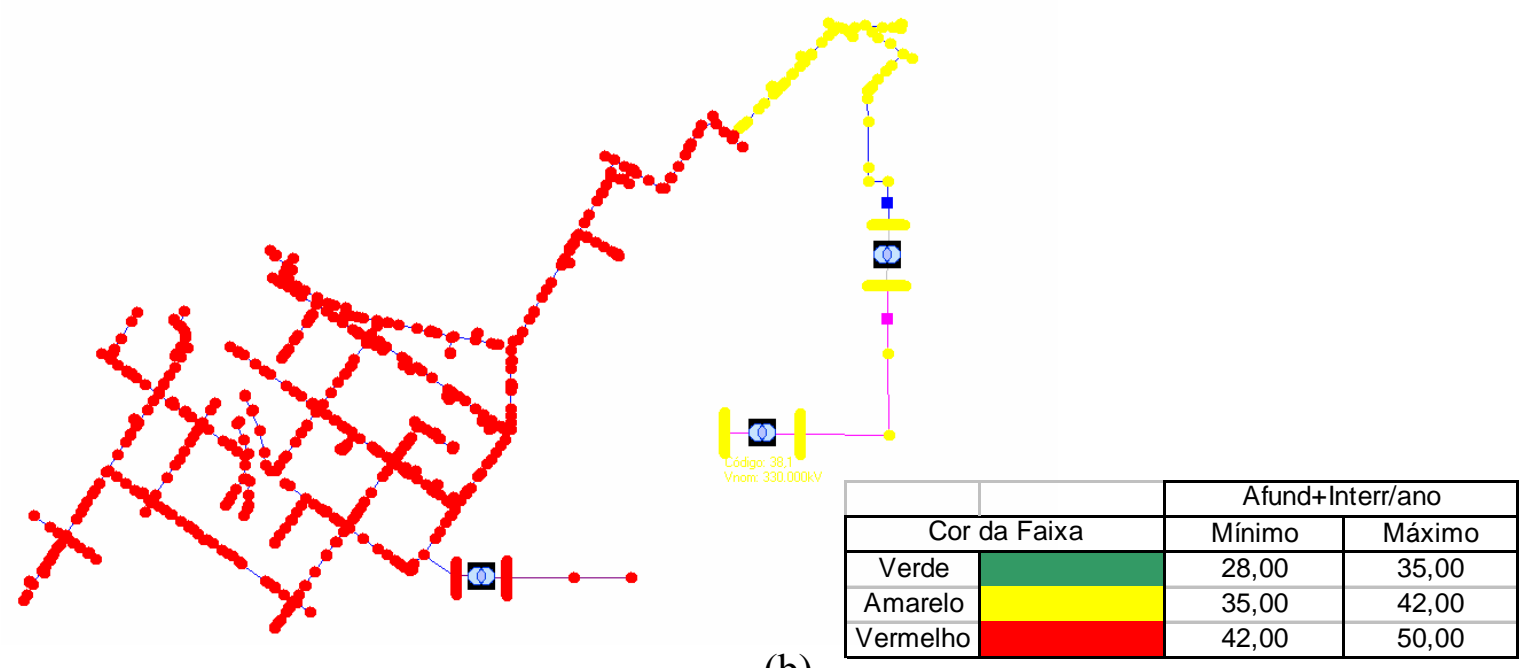

(b)
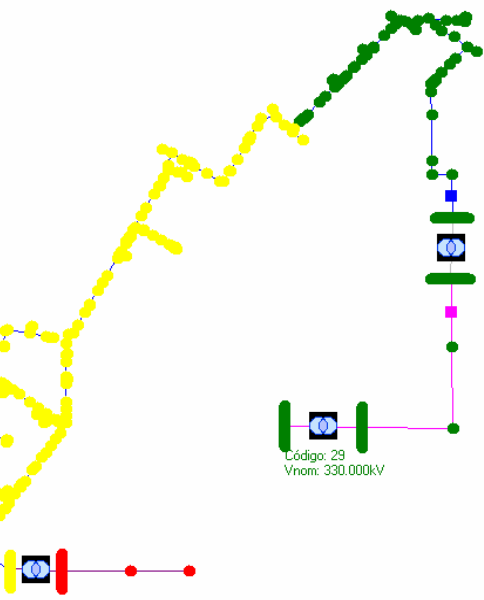

(c)

Figura 7-17 - Áreas de Risco referente a afundamentos de tensão mais Interrupções: (a) Método Monte Carlo, (b) Método de Enumeração de estados, (c) Método Híbrido 


\subsubsection{Análise de Elevações de tensão}

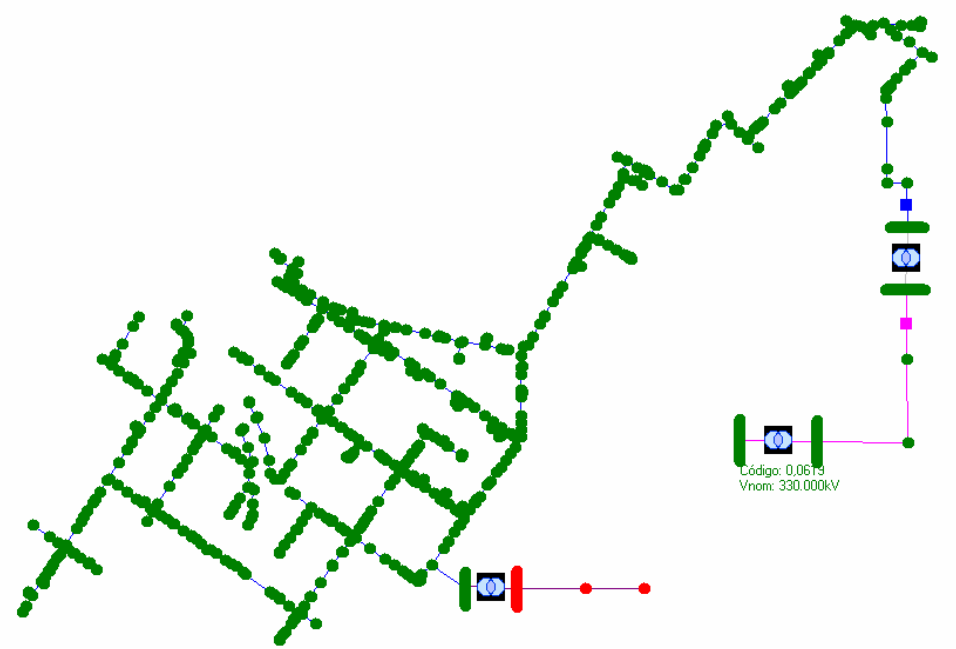

(a)

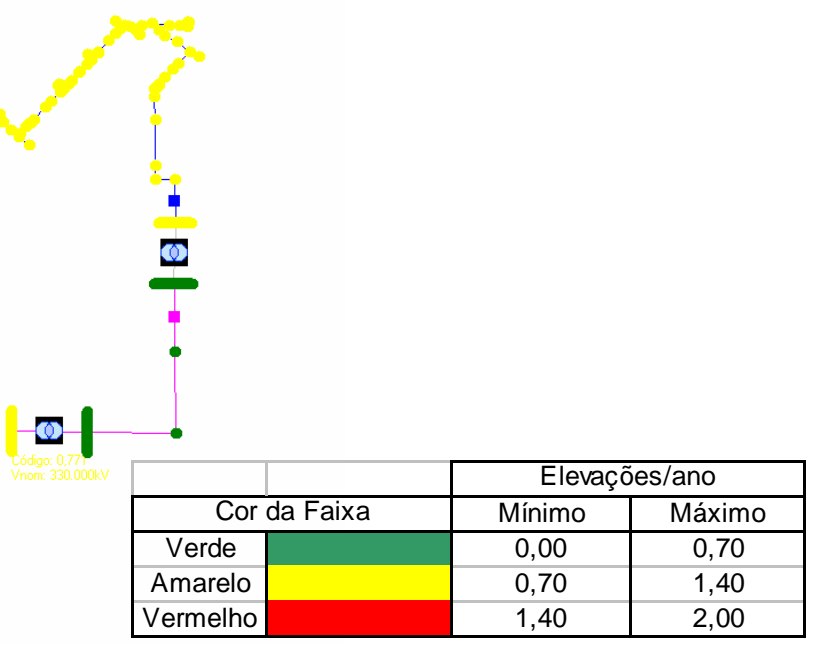

(b)

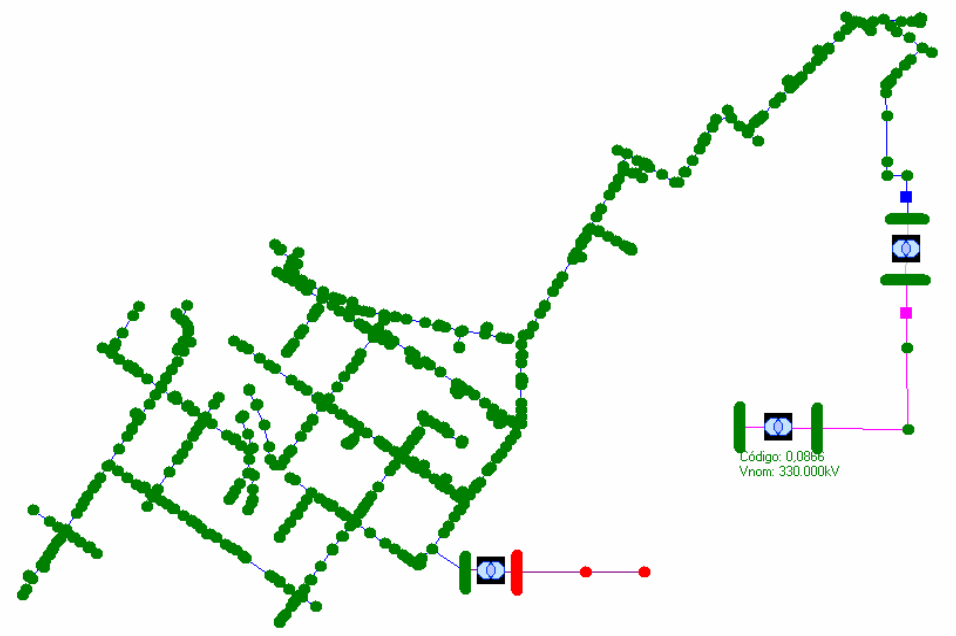

(c)

Figura 7-18 - Áreas de Risco referente a elevações de tensão: (a) Método Monte Carlo, (b) Método de Enumeração de estados, (c) Método Híbrido 


\subsubsection{Análise de Disrupções por VTCDs}

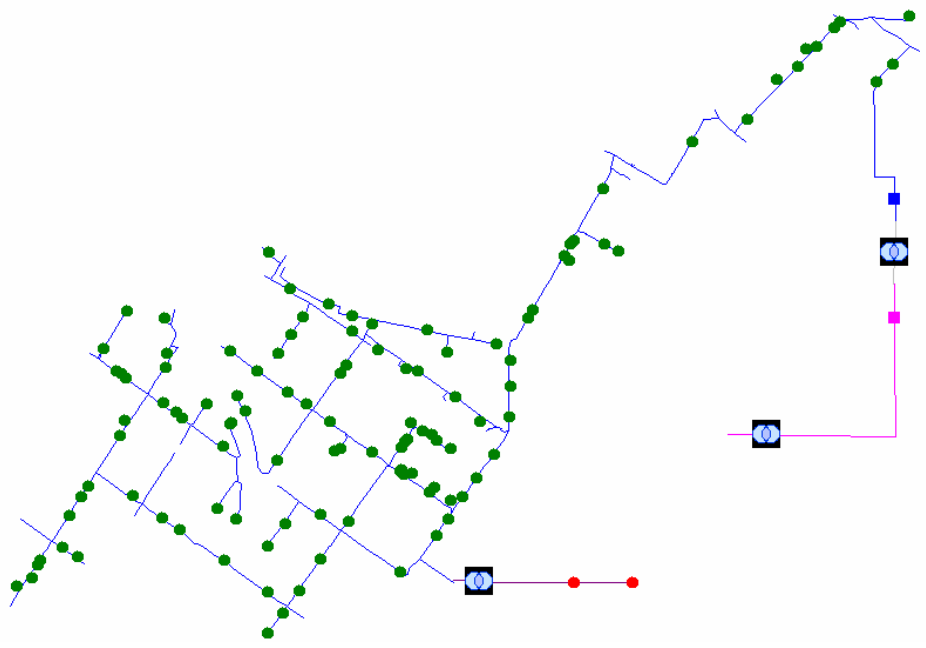

(a)

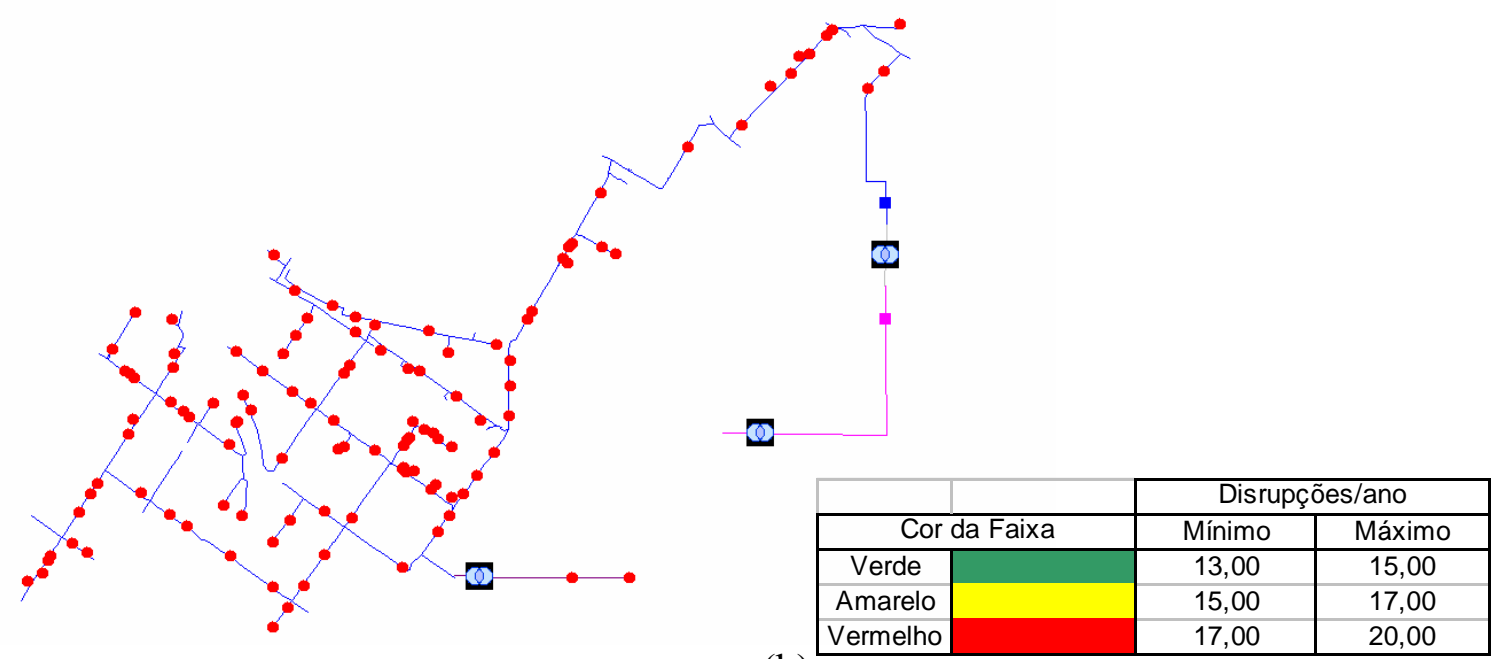

(b)

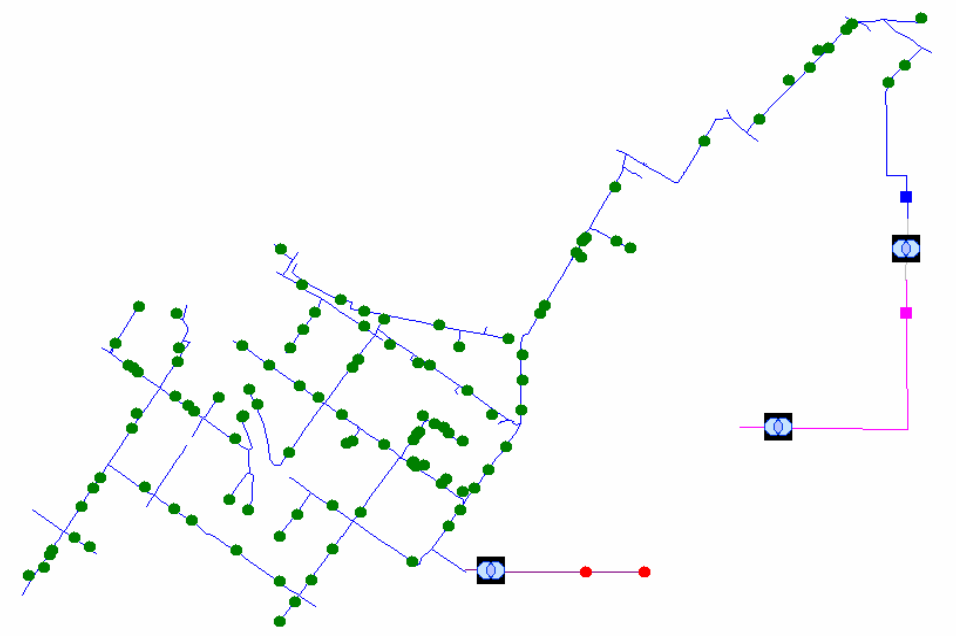

(c)

Figura 7-19 - Áreas de Risco referente à Disrupções de tensão: (a) Método Monte Carlo, (b) Método de Enumeração de estados, (c) Método Híbrido. 


\section{Comentário dos Resultados das Áreas de Risco}

Na Figura 7-15, foram apresentados os resultados obtidos das Áreas de Risco frente fenômenos de VTCDs utilizando os três métodos de simulação explicados no Item 4.1. Destes resultados pode-se observar graficamente que as Áreas de risco obtidas pelo Método de Monte Carlo e Hibrido são muito similares. No caso do Método de Enumeração de estados, seus resultados são um tanto diferentes, isto é dado por que o método de Enumeração de estados ainda precisaria de mais iterações (número de faixas) para melhorar a qualidade dos seus resultados.

Assim também pode ser observado na Figura 7-16 os resultados obtidos das Áreas de Risco frente a interrupções de longa duração. Para este tipo de gráfico os três métodos de simulação obtiveram resultados muito similares na disposição das cores nas barras. O que valida os resultados dos três métodos quando é analisado as interrupções de longa duração.

No caso das Figura 7-17, Figura 7-18, Figura 7-19, pode se observar que, os resultados obtidos pelos métodos Monte Carlo e Híbrido tiveram resultados muito similares na disposição das cores. Isto não acorre para o Método de Enumeração de estados, já que como foi comentado este método precisa de mais simulações.

De todos estes resultados pode-se concluir que tanto o Método de Monte Carlo e Híbrido podem ser utilizado para avaliar as Áreas de Risco frente a fenômenos de VTCDs. Dado que ambos os métodos conseguem chegar a valores similares, a escolha do melhor método dentre eles foi avaliado em função do esforço computacional na obtenção dos resultados. Com este parâmetro de comparação pode-se concluir que o Método Hibrido apresenta melhor comportamento, já que consegue obter resultados de boa qualidade em menor tempo de processamento. 


\subsection{Inclusão do Custo de QEE no Planejamento de Operação - Reconfiguração de Redes}

Para incorporar os efeitos dos custos de QEE em problemas de planejamento da operação, será utilizada uma rede de distribuição de energia elétrica conhecida na literatura (Civanlar et al,1988), constituída por 14 barras, 3 chaves de interconexão e tensão de $23 \mathrm{kV}$.

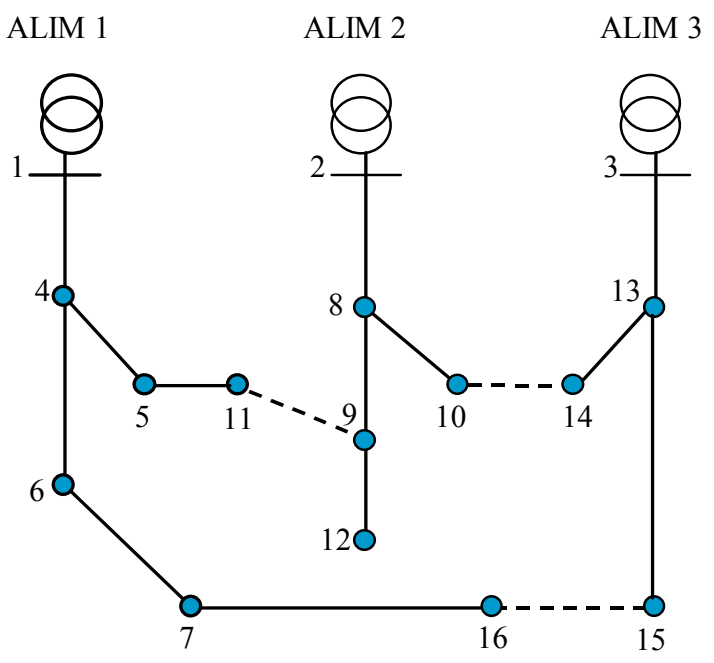

Figura 7-20 - Rede de 14 barras

No trabalho apresentado por Cebrian (2003) [ 21], são apresentados resultados com configurações que cumprem as restrições operacionais clássicas do problema de reconfiguração com os menores valores de perdas de potência.

Tabela 7-17- Configurações com menores valores de Perdas de Potência - Rede 14 barras

\begin{tabular}{|c|c|c|}
\hline $\begin{array}{c}\text { Configuração } \\
\text { No. }\end{array}$ & Chaves Abertas & $\begin{array}{c}\text { Perdas } \\
\text { (kW) }\end{array}$ \\
\hline 01 & $7-8-15$ & 466,12 \\
\hline 02 & $7-8-4$ & 479,29 \\
\hline 03 & $7-13-15$ & 483,87 \\
\hline 04 & $7-8-12$ & 492,83 \\
\hline
\end{tabular}




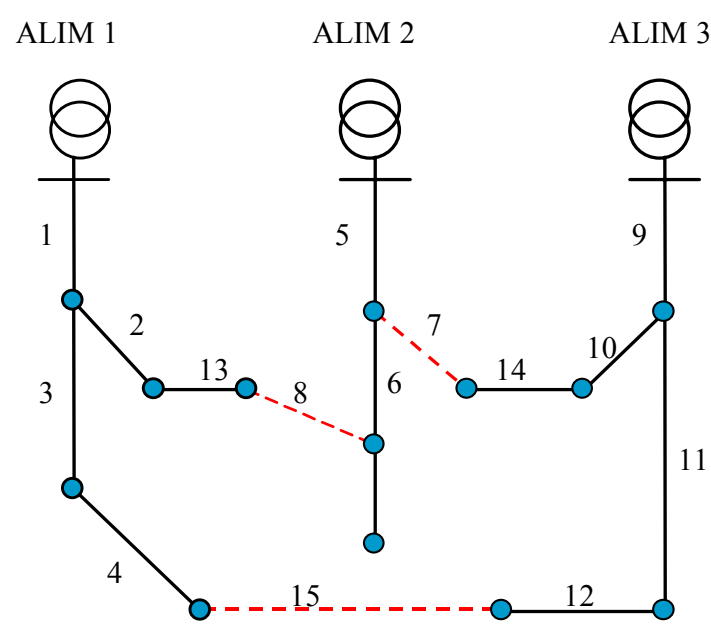

(a)

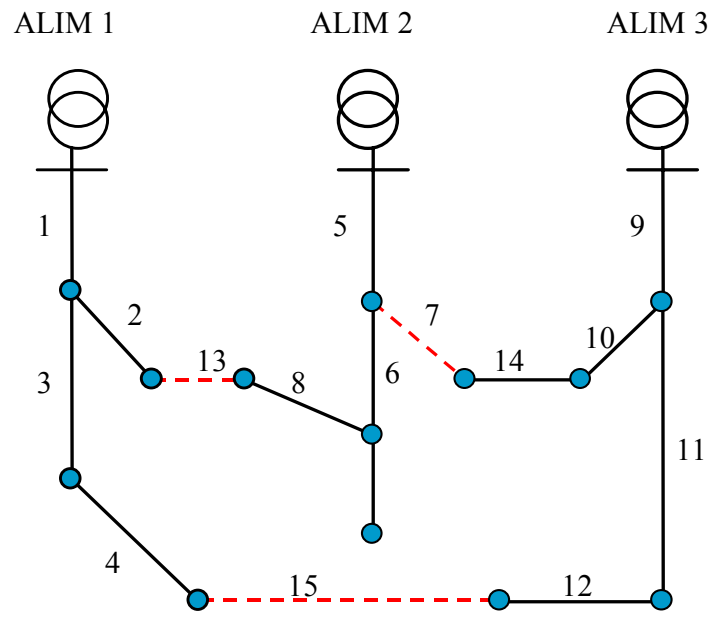

(c)

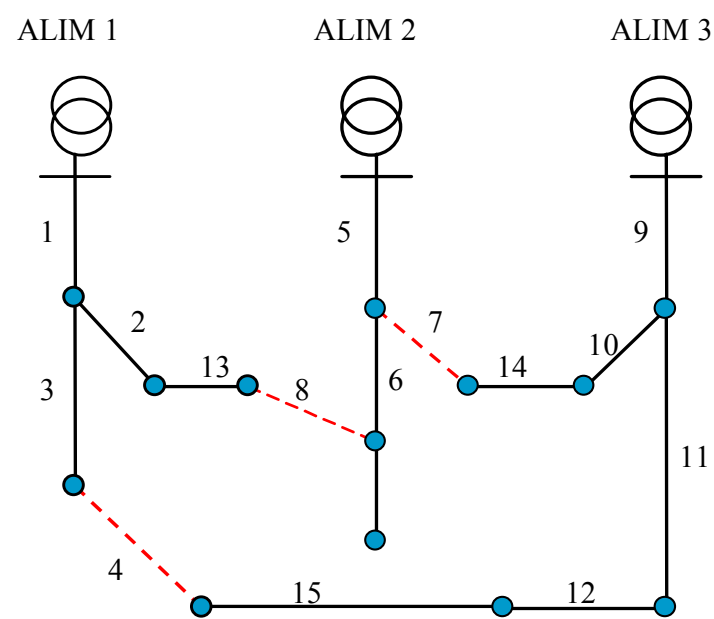

(b)

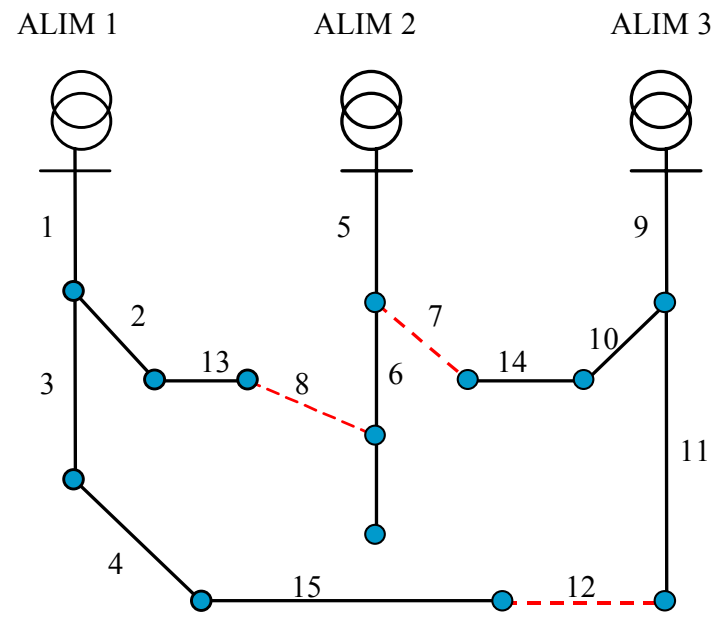

(d)

Figura 7-21 - Melhores Configurações - Rede 14 barras.

Para as configurações apresentadas na Figura 7-21, que representam aquelas como menor valor de perdas, serão avaliados os valores do custo das interrupções de longa duração e do custo de disrupções por VTCDs para os consumidores existentes nestas redes. Estes valores, adicionados ao valor do custo das perdas possibilitam obter o custo total da alternativa, com a consideração dos custos de QEE frente a um problema de reconfiguração de redes.

Para iniciar a o cálculo do custo da QEE nesta rede, é assumido que todos os consumidores são do tipo industrial. Portanto, a curva de sensibilidade utilizada para todos os consumidores será a mesma, como mostrado na Figura 7-22.

Para o cálculo dos custos da QEE, somente será considerado a curva de sensibilidade, com análise das disrupções provocadas por afundamentos de tensão. 


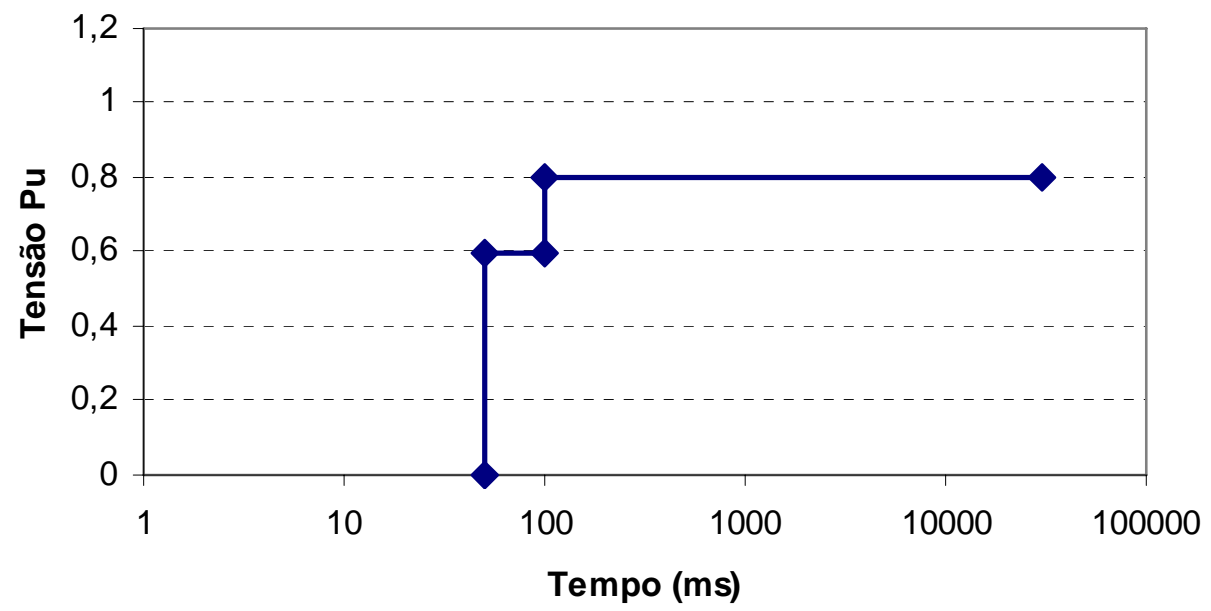

Figura 7-22 - Curva de sensibilidade para os consumidores do exemplo

Considera-se também que existe um dispositivo de proteção em cada saída de alimentador. Estes dispositivos possuem a mesma curva de proteção, como mostrado na Figura 7-23.

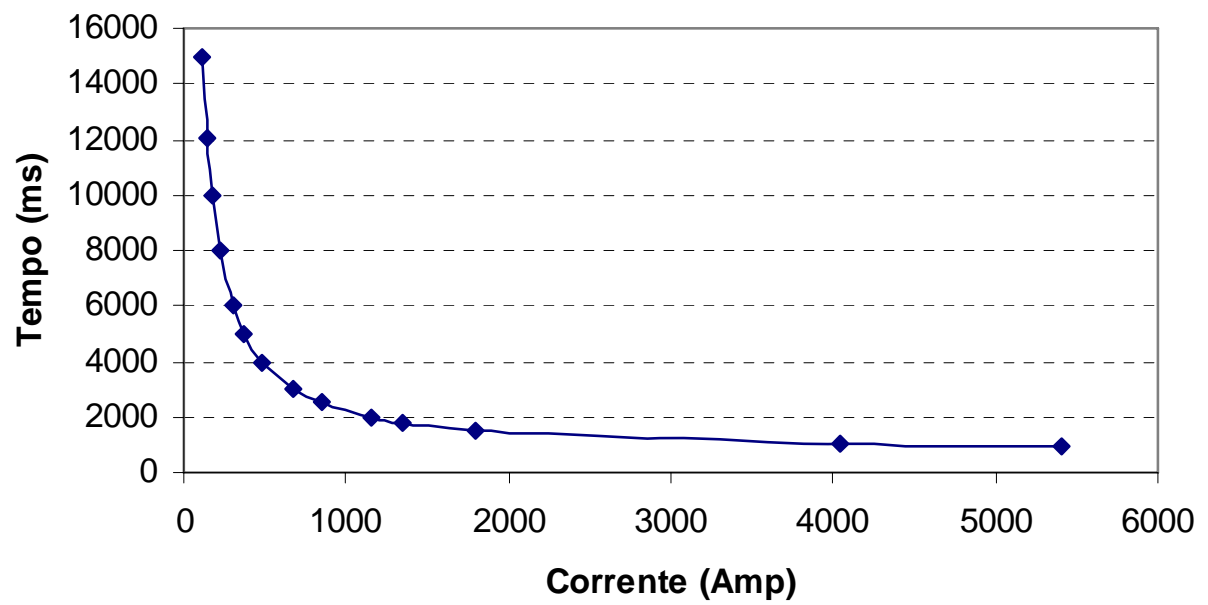

Figura 7-23 - Curva de dispositivo de Proteção

As potências de curto-circuito utilizadas são: Trifásica $=300,2 \underline{\mid+88,09}$ MVA e Monofásica $=250,2\lfloor\underline{-87,7}$ MVA.

Para a avaliação do custo da interrupção e Disrupção, adotam-se os valores Cto $_{\text {Inter }}=$ $1,27 \$ / \mathrm{kWh}$ e Cto $_{\text {Disrup }}=3,0 \$ / \mathrm{kW}$. Para todos os consumidores, o valor de duração da interrupção é de NHoras $_{\text {Interr }}=3$ horas. Para avaliar o custo das perdas, considera-se Cto $_{P e r}=$ $0,145 \$ / \mathrm{kWh}$ para um período de 8760 horas por ano.

Será considerado que os valores das potências ativas e reativas das cargas serão as mesmas durante o período de 24 horas. Assim, o valor da demanda de ponta será igual ao valor da demanda média para todas as cargas. O comprimento para todos os trechos será considerado de $1 \mathrm{~km}$. 


\subsubsection{Inclusão dos Custos de interrupção de longa duração e de disrupção por VTCDs nas configurações com menores perdas}

Para a obtenção dos resultados, será utilizado o Método Híbrido, utilizando simulação de 100.000 curtos-circuitos. Os resultados obtidos paras as 4 configurações do conjunto são apresentados na Tabela 7-18 e Tabela 7-19. Na Tabela 7-18 são apresentados os índices de freqüências de ocorrências anuais de disrupção por barras e correspondentes custos anuais. $\mathrm{Na}$ Tabela 7-19 são apresentados os índices de freqüências de ocorrências anuais de interrupções de longa duração por barra e os correspondentes custos anuais.

Tabela 7-18 - Resultados dos Custos de Disrupção por barra para as 4 Configurações

\begin{tabular}{|c|c|c|c|c|c|c|c|c|}
\hline & \multicolumn{2}{|c|}{ Configuração 1} & \multicolumn{2}{|c|}{ Configuração 2} & \multicolumn{2}{|c|}{ Configuração 3} & \multicolumn{2}{|c|}{ Configuração 4} \\
\hline Barra No & $\begin{array}{c}\text { NDisru } \\
\text { /ano }\end{array}$ & $\begin{array}{c}\text { Custo }_{\text {Disrups }} \\
\text { (\$/ano) }\end{array}$ & $\begin{array}{c}\text { NDisru } \\
\text { lano }\end{array}$ & $\begin{array}{c}\text { Custo }_{\text {Disrups }} \\
\text { (\$/ano) }\end{array}$ & $\begin{array}{c}\text { NDisru } \\
\text { lano }\end{array}$ & $\begin{array}{c}\text { Custo }_{\text {Disrups }} \\
\text { (\$/ano) }\end{array}$ & $\begin{array}{c}\text { NDisru } \\
\text { lano }\end{array}$ & $\begin{array}{c}\text { Custo }_{\text {Disrups }} \\
\text { (\$/ano) }\end{array}$ \\
\hline 4 & 15,26 & 91.531 & 15,50 & 92.973 & 15,53 & 93.186 & 14,91 & 89.456 \\
\hline 5 & 15,46 & 139.182 & 15,71 & 141.347 & 15,59 & 140.315 & 15,13 & 136.189 \\
\hline 6 & 15,47 & 92.825 & 15,56 & 93.355 & 15,75 & 94.501 & 15,29 & 91.735 \\
\hline 7 & 15,52 & 69.848 & 15,61 & 70.224 & 15,80 & 71.121 & 15,48 & 69.680 \\
\hline 8 & 15,90 & 190.800 & 15,82 & 189.839 & 15,60 & 187.236 & 15,84 & 190.082 \\
\hline 9 & 16,11 & 241.686 & 16,02 & 240.358 & 15,99 & 239.913 & 16,04 & 240.592 \\
\hline 10 & 15,52 & 46.569 & 15,19 & 45.575 & 15,51 & 46.517 & 15,77 & 47.299 \\
\hline 11 & 15,51 & 27.926 & 15,75 & 28.348 & 16,05 & 28.892 & 15,18 & 27.322 \\
\hline 12 & 16,17 & 218.229 & 16,07 & 216.941 & 16,04 & 216.536 & 16,10 & 217.380 \\
\hline 13 & 15,25 & 45.759 & 14,93 & 44.776 & 15,25 & 45.746 & 15,48 & 46.450 \\
\hline 14 & 15,46 & 46.386 & 15,14 & 45.421 & 15,45 & 46.353 & 15,71 & 47.136 \\
\hline 15 & 15,47 & 46.403 & 15,35 & 46.061 & 15,46 & 46.371 & 15,54 & 46.617 \\
\hline 16 & 15,52 & 97.807 & 15,55 & 97.941 & 15,50 & 97.664 & 15,55 & 97.955 \\
\hline
\end{tabular}

Tabela 7-19 - Resultados dos Custos da interrupção por barra para as 4 Configurações

\begin{tabular}{|c|c|c|c|c|c|c|c|c|}
\hline & \multicolumn{2}{|c|}{ Configuração 1} & \multicolumn{2}{|c|}{ Configuração 2} & \multicolumn{2}{|c|}{ Configuração 3} & \multicolumn{2}{|c|}{ Configuração 4} \\
\hline Barra No & $\begin{array}{c}\text { NInterr } \\
\text { lano }\end{array}$ & $\begin{array}{c}\text { Custo }_{\text {interr }} \\
\text { (\$/ano) }\end{array}$ & $\begin{array}{c}\text { NInterr } \\
\text { /ano }\end{array}$ & $\begin{array}{c}\text { Custo }_{\text {interr }} \\
\text { (\$/ano) }\end{array}$ & $\begin{array}{c}\text { NInterr } \\
\text { lano }\end{array}$ & $\begin{array}{c}\text { Custo }_{\text {interr }} \\
\text { (\$/ano) }\end{array}$ & $\begin{array}{c}\text { NInterr } \\
\text { lano }\end{array}$ & $\begin{array}{c}\text { Custo }_{\text {interr }} \\
\text { (\$/ano) }\end{array}$ \\
\hline 4 & 5,04 & 38.309 & 3,99 & 30.353 & 4,03 & 30.615 & 6,01 & 45.650 \\
\hline 5 & 5,04 & 57.463 & 3,99 & 45.529 & 4,03 & 45.923 & 6,01 & 68.476 \\
\hline 6 & 5,04 & 38.309 & 3,99 & 30.353 & 4,03 & 30.615 & 6,01 & 45.650 \\
\hline 7 & 5,04 & 28.732 & 6,04 & 34.426 & 4,03 & 22.962 & 6,01 & 34.238 \\
\hline 8 & 3,00 & 45.547 & 3,00 & 45.628 & 4,00 & 60.879 & 3,03 & 46.020 \\
\hline 9 & 3,00 & 56.933 & 3,00 & 57.035 & 4,00 & 76.099 & 3,03 & 57.525 \\
\hline 10 & 5,00 & 18.991 & 6,04 & 22.951 & 5,00 & 19.009 & 4,00 & 15.206 \\
\hline 11 & 5,04 & 11.493 & 3,99 & 9.106 & 4,00 & 9.132 & 6,01 & 13.695 \\
\hline 12 & 3,00 & 51.240 & 3,00 & 51.331 & 4,00 & 68.489 & 3,03 & 51.772 \\
\hline 13 & 5,00 & 18.991 & 6,04 & 22.951 & 5,00 & 19.009 & 4,00 & 15.206 \\
\hline 14 & 5,00 & 18.991 & 6,04 & 22.951 & 5,00 & 19.009 & 4,00 & 15.206 \\
\hline 15 & 5,00 & 18.991 & 6,04 & 22.951 & 5,00 & 19.009 & 4,00 & 15.206 \\
\hline 16 & 5,00 & 39.880 & 6,04 & 48.197 & 5,00 & 39.920 & 6,01 & 47.933 \\
\hline
\end{tabular}


Da Tabela 7-20, pode-se observar os resultados obtidos, relativos aos custos de interrupções de longa duração e das disrupções por VTCDs, e compará-los com o custo das perdas para as 4 melhores configurações obtidas pelos algoritmos de busca heurísticos clássicos.

Tabela 7-20 - Comparação dos Custos para as Melhores configurações

\begin{tabular}{|c|c|c|c|}
\hline $\begin{array}{c}\text { Configuração } \\
\text { No }\end{array}$ & $\begin{array}{c}\text { Custo das } \\
\text { Perdas (\$/ano) }\end{array}$ & $\begin{array}{c}\text { Custo da Interrupção } \\
\text { + Disrupção (\$/ano) }\end{array}$ & $\begin{array}{c}\text { Custo Total } \\
\text { (\$/ano) }\end{array}$ \\
\hline 1 & 592.066 & 1.798 .816 & 2.390 .882 \\
2 & 608.794 & 1.796 .922 & 2.405 .716 \\
3 & 614.612 & 1.815 .024 & 2.429 .636 \\
4 & 625.993 & 1.819 .675 & 2.445 .668 \\
\hline
\end{tabular}

Realizando esta comparação, a Figura 7-24 permite observar que os valores obtidos dos custos referentes à qualidade de energia são relativamente maiores do que os custos das perdas, o que mostra a importância da inclusão desta condição dentro da função de avaliação na procura das configurações ótimas.

Mesmo assim, para a rede de 14 barras, a ordenação de forma crescente ao valor das perdas de potência apresentada na Tabela 7-17 é mantida com a consideração dos custos de perdas e dos custos da qualidade de energia (interrupção de longa duração e Disrupção por VTCD), como mostra a Figura 7-25.

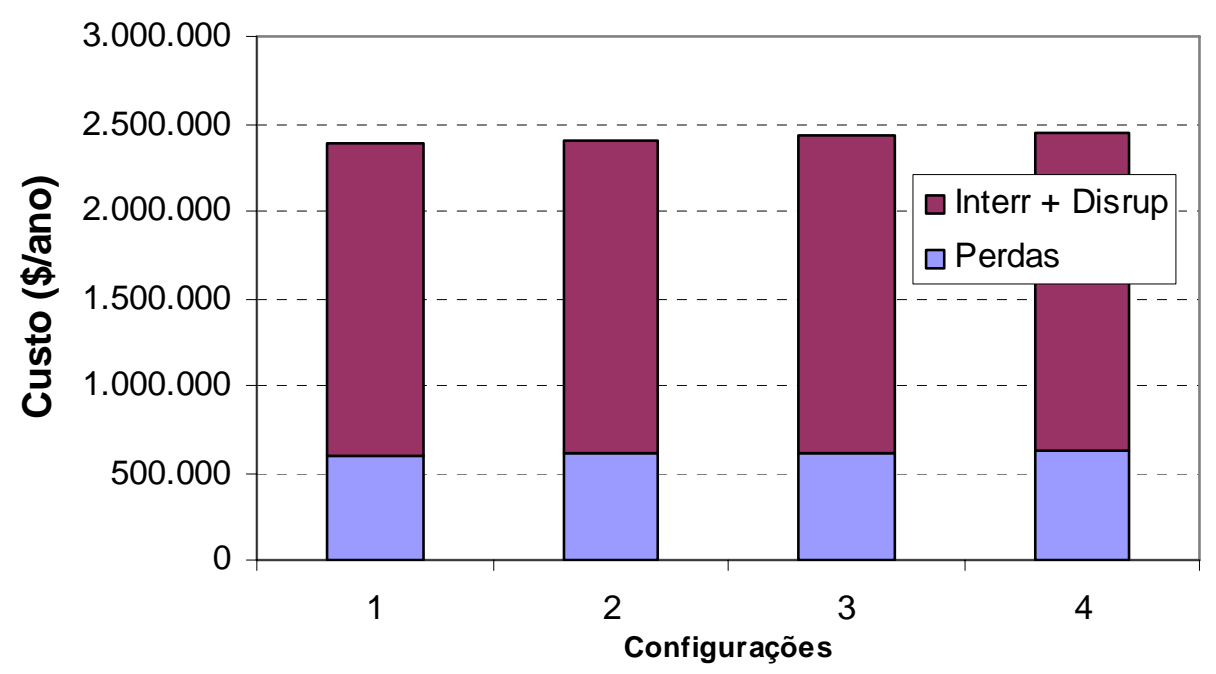

Figura 7-24 - Contribuição de cada custo por categoria vs melhores configurações 


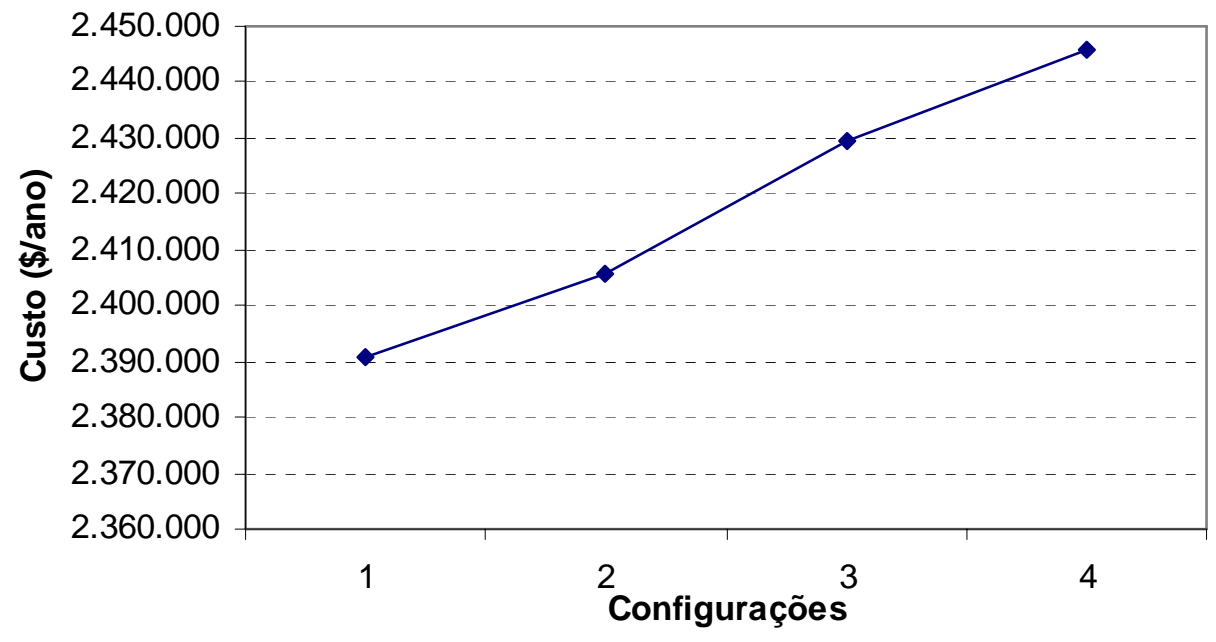

Figura 7-25 - Resultados do custo total vs melhores configurações

\subsubsection{Análise de VTCDs para um consumidor particular}

Para esta análise, será escolhido o consumidor com maior consumo na rede de 14 barras. A configuração utilizada será aquela da Figura 7-21 (a). Esta configuração é utilizada, uma vez que representa o menor custo total, conforme obtido na Tabela 7-18 e Tabela 7-19. O consumidor mais carregado encontra-se conectado na barra 9 da Figura 7-20. A seguir serão mostrados os resultados obtidos relativos aos índices de afundamentos e elevações de tensão e bem como das disrupções, em função da curva de sensibilidade do processo do consumidor, conforme Figura 7-22. Para a simulação, serão utilizados os resultados obtidos aplicando o Método Híbrido, considerando 100.000 faltas simuladas. Os resultados serão apresentados em forma de histogramas, para cada índice de VTCDs, de forma a serem analisados as freqüências de ocorrência para cada faixa de amplitude e duração.

Na Figura 7-26, Figura 7-27 e Figura 7-28 são apresentados os seguintes resultados relativos aos índices de afundamentos de tensão, elevações de tensão e disrupções por VTCDs, respectivamente:

a) histograma de freqüência de ocorrências por ano do índice, em função das faixas de amplitude e de duração das VTCDs

b) histograma de freqüência de ocorrências em função das faixas de amplitude de VTCDs e histograma de freqüência de ocorrências em função das faixas de duração de VTCDs

c) valores numéricos das freqüências de ocorrências dos histogramas 


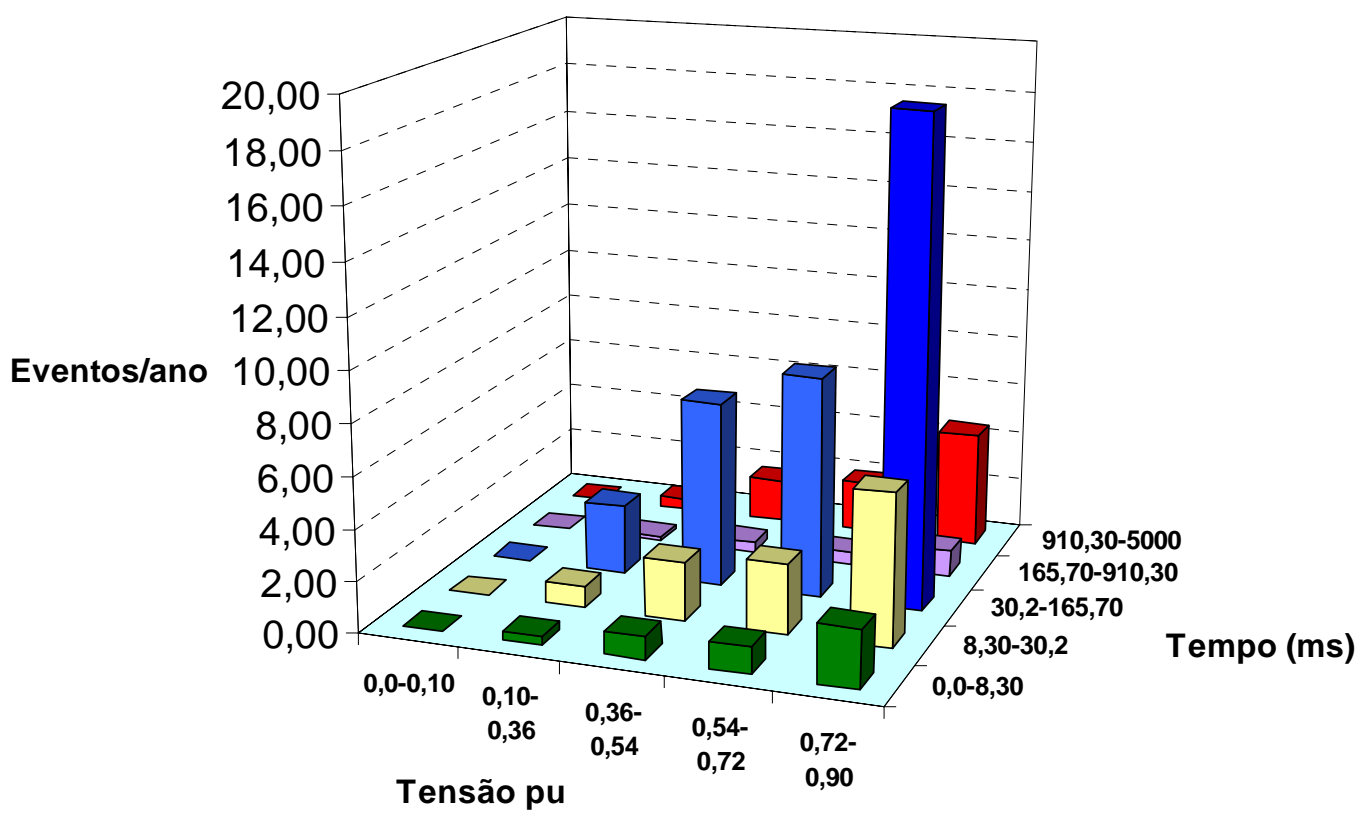

(a)
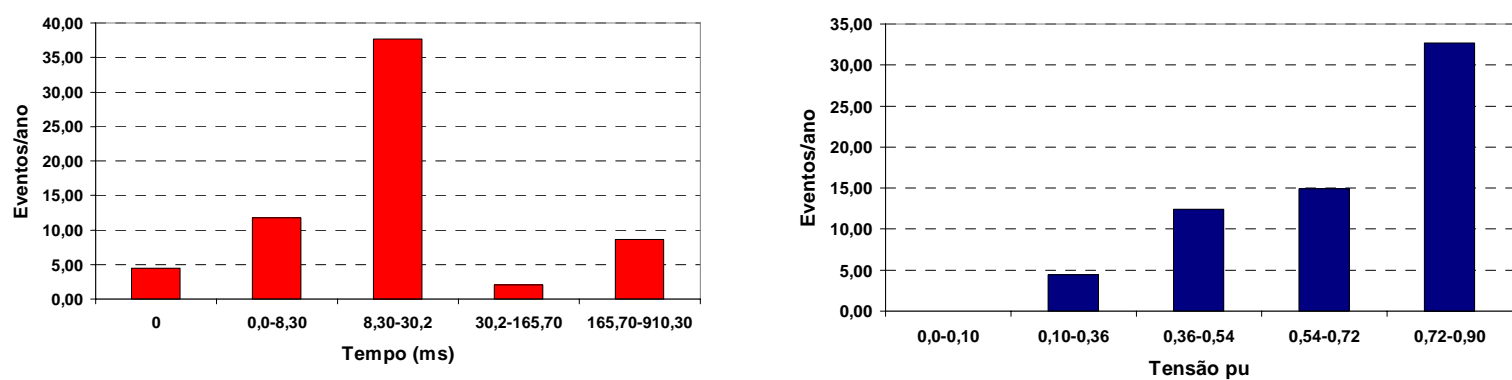

(b)

\begin{tabular}{|c|c|c|c|c|c|c|}
\hline & \multicolumn{5}{|c|}{ Faixas de Tensão } \\
\hline & & $0,0-0,10$ & $0,10-0,36$ & $0,36-0,54$ & $0,54-0,72$ & $0,72-0,90$ \\
\hline \multirow{5}{*}{ 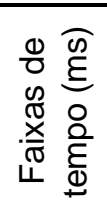 } & $0,0-8,30$ & 0,00 & 0,32 & 0,86 & 1,03 & 2,25 \\
\hline & $8,30-30,2$ & 0,00 & 0,85 & 2,27 & 2,71 & 5,93 \\
\hline & $30,2-165,70$ & 0,00 & 2,72 & 7,27 & 8,68 & 18,99 \\
\hline & $165,70-910,30$ & 0,00 & 0,14 & 0,38 & 0,46 & 1,00 \\
\hline & $910,30-5000$ & 0,00 & 0,40 & 1,70 & 2,00 & 4,53 \\
\hline
\end{tabular}

(c)

Figura 7-26 - Histograma dos índices de Afundamentos: (a) Histograma, (b) Eventos/ano vs tempo(ms) e Eventos/ano vs tensão pu, (c) Dados do histograma. 


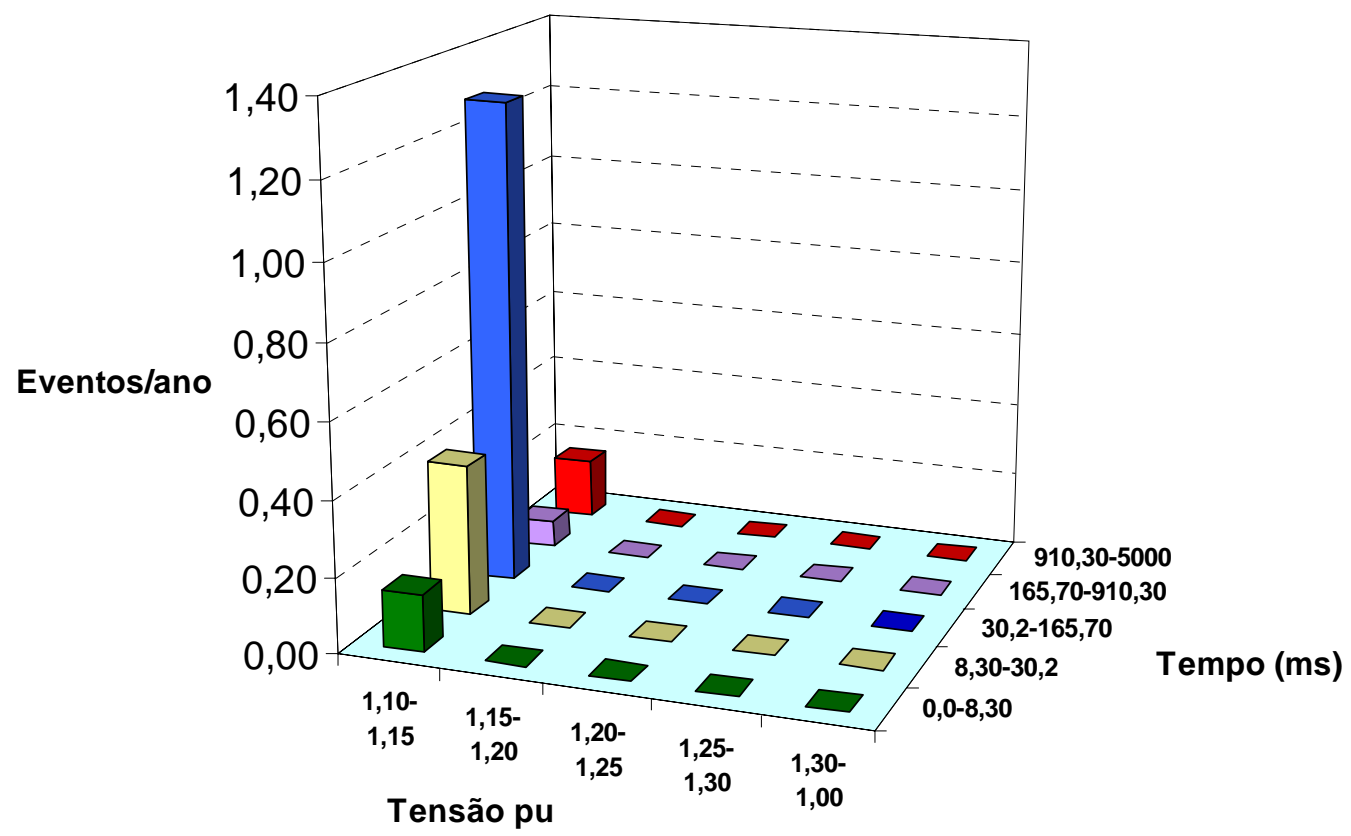

(a)
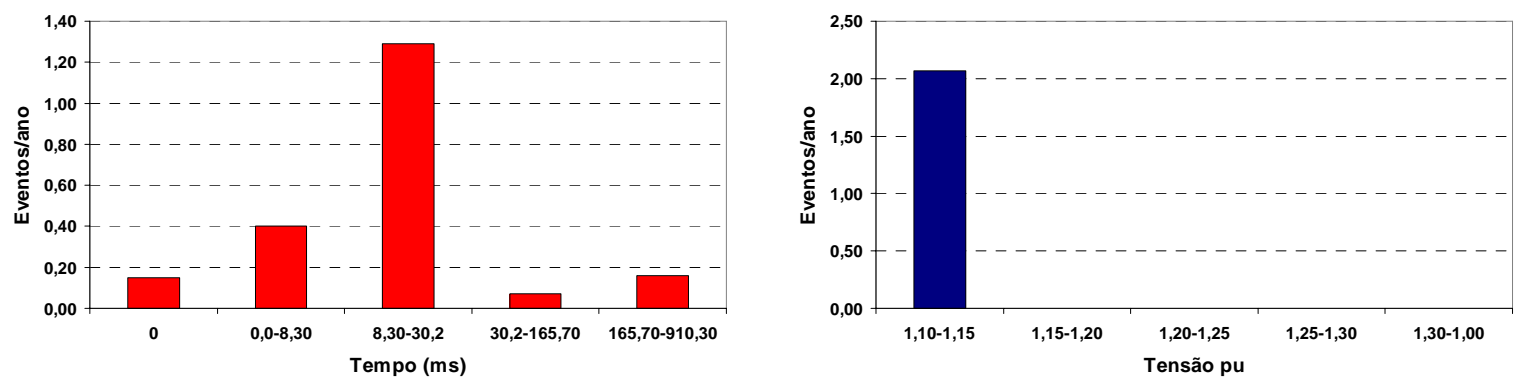

(b)

\begin{tabular}{|c|c|c|c|c|c|c|}
\hline & \multicolumn{5}{|c|}{ Faixas de Tensão } \\
\hline & & $1,10-1,15$ & $1,15-1,20$ & $1,20-1,25$ & $1,25-1,30$ & $1,30-1,00$ \\
\hline \multirow{5}{*}{ 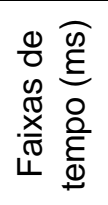 } & $0,0-8,30$ & 0,15 & 0,00 & 0,00 & 0,00 & 0,00 \\
\hline & $8,30-30,2$ & 0,40 & 0,00 & 0,00 & 0,00 & 0,00 \\
\hline & $30,2-165,70$ & 1,29 & 0,00 & 0,00 & 0,00 & 0,00 \\
\hline & $165,70-910,30$ & 0,07 & 0,00 & 0,00 & 0,00 & 0,00 \\
\hline & $910,30-5000$ & 0,16 & 0,00 & 0,00 & 0,00 & 0,00 \\
\hline
\end{tabular}

(c)

Figura 7-27 - Histograma dos índices de Elevação: (a) Histograma, (b) Eventos/ano vs tempo(ms) e Eventos/ano vs tensão pu, (c) Dados do histograma. 


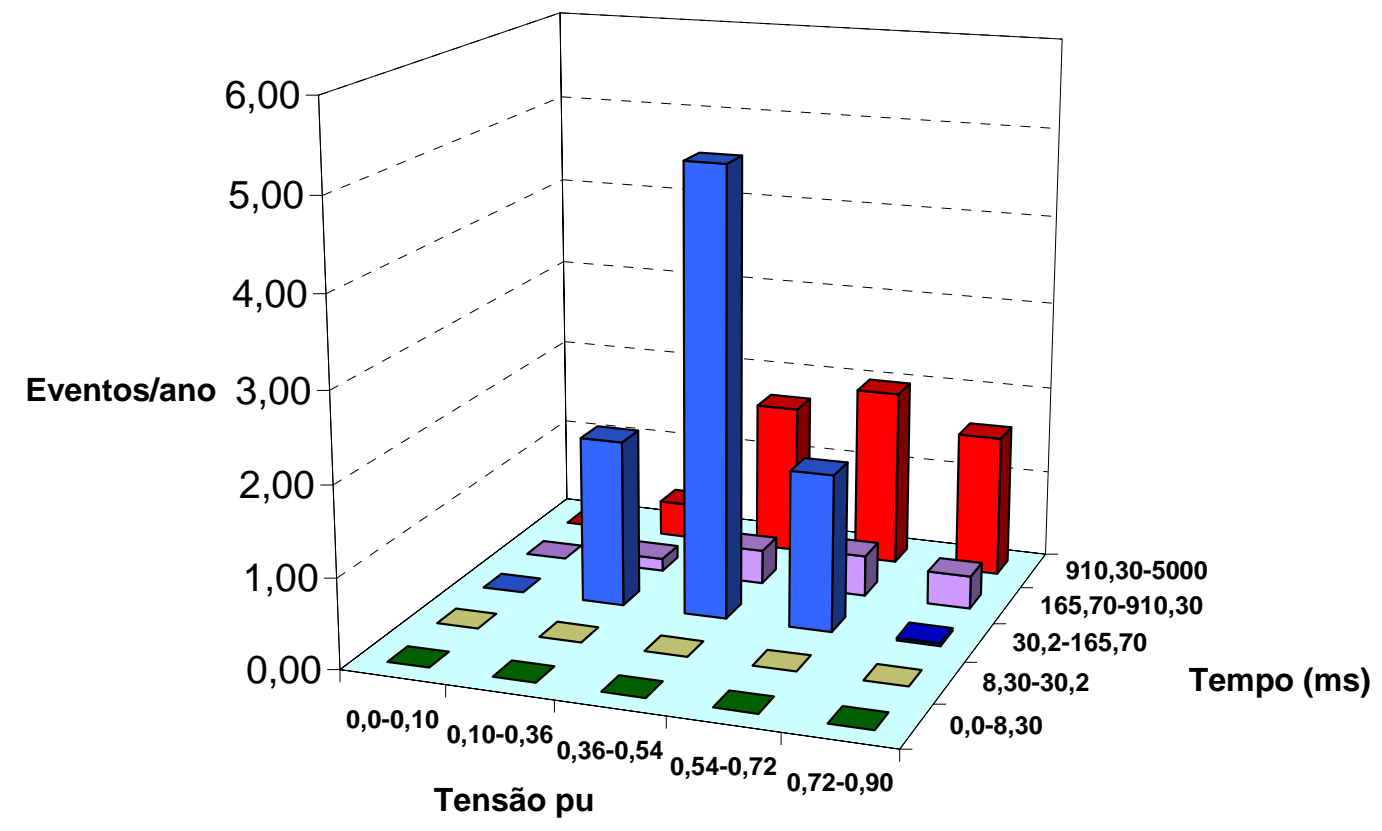

(a)
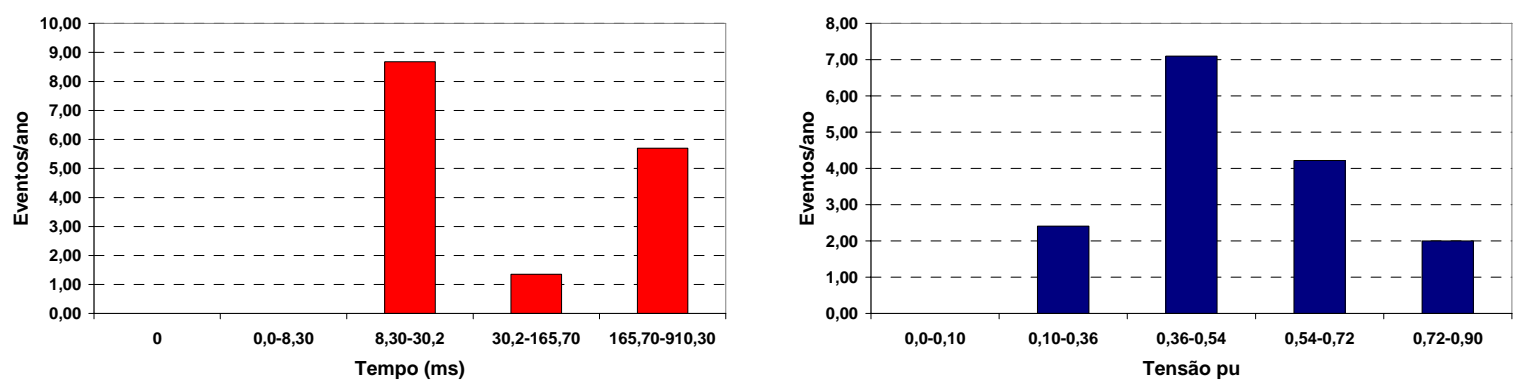

(b)

\begin{tabular}{|c|c|c|c|c|c|c|}
\hline & \multicolumn{5}{|c|}{ Faixas de Tensão } \\
\hline & & $0,0-0,10$ & $0,10-0,36$ & $0,36-0,54$ & $0,54-0,72$ & $0,72-0,90$ \\
\hline \multirow{5}{*}{ 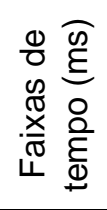 } & $0,0-8,30$ & 0,00 & 0,00 & 0,00 & 0,00 & 0,00 \\
\hline & $8,30-30,2$ & 0,00 & 0,00 & 0,00 & 0,00 & 0,00 \\
\hline & $30,2-165,70$ & 0,00 & 1,87 & 5,02 & 1,76 & 0,03 \\
\hline & $165,70-910,30$ & 0,00 & 0,14 & 0,38 & 0,46 & 0,37 \\
\hline & $910,30-5000$ & 0,00 & 0,40 & 1,70 & 2,00 & 1,60 \\
\hline
\end{tabular}

(c)

Figura 7-28 - Histograma dos índices de disrupção por afundamentos de tensão: (a) Histograma, (b) Eventos/ano vs tempo(ms) e Eventos/ano vs tensão pu, (c) Dados do histograma. 


\subsection{Inclusão do custo da QEE no Planejamento de Expansão}

Nesta seção, são considerados o efeitos dos índices de VTCDs sobre modelos clássicos para tratamento do problema de planejamento de expansão. Para tal finalidade, será utilizada uma rede ilustrativa encontrada na literatura, utilizada por Kagan (1992)[53]. Serão utilizados os resultados obtidos no trabalho de Bazan (2003)[ 8], utilizando modelo de planejamento dinâmico. Este trabalho utiliza uma técnica heurística de Busca Tabu para a solução do problema clássico do planejamento de expansão.

A rede a ser analisada é constituída por 3 trechos existentes e 13 trechos candidatos, uma subestação existente (barra 10) e uma subestação candidata (barra 12), num total de 12 barras. São considerados 3 estágios para o horizonte de planejamento.

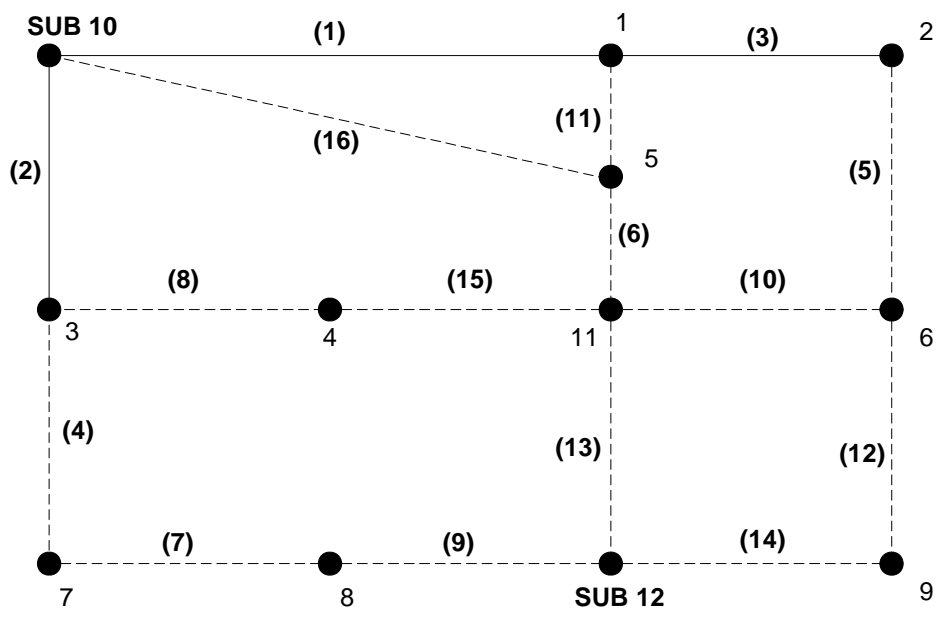

Figura 7-29- Rede de 12 barras para análise da inclusão do custo da QEE no planejamento de expansão

Nas Tabela 7-21, Tabela 7-22, Tabela 7-23 e Tabela 7-24 encontram-se as características elétricas da rede de 12 barras. A Figura 7-25 apresenta os valores dos custos unitários para as interrupções de longa duração e as Disrupções de tensão, estes valores serão utilizados durante a obtenção do custo da QEE para a rede de 12 barras. A Figura 7-29 mostra a topologia inicial deste sistema e o conjunto de trechos candidatos. Durante as simulações será considerado que existe um dispositivo de proteção em cada alimentador existente nas subestações SUB10 e SUB12. A curva de sensibilidade utilizada será a mesma para todos os consumidores existentes nas barras e será aquela apresentada na Figura 7-22. A curva de proteção será a mesma para todos os dispositivos de proteção e terão o comportamento da Figura 7-23. 
Tabela 7-21 - Dados das Demandas dos nós para três estágios de planejamento

\begin{tabular}{|c|c|c|c|}
\hline \multirow{2}{*}{ Barra No } & \multicolumn{3}{|c|}{ Demanda das Barras (MW) } \\
\cline { 2 - 4 } & Estágio 1 & Estágio 2 & Estágio 3 \\
\hline 1 & 5,00 & 6,00 & 6,90 \\
2 & 5,00 & 5,75 & 6,33 \\
3 & 2,00 & 2,20 & 2,64 \\
4 & 5,00 & 6,00 & 6,60 \\
5 & 4,00 & 4,40 & 5,06 \\
6 & 5,00 & 6,50 & 7,15 \\
7 & 6,70 & 7,71 & 9,25 \\
8 & 5,00 & 6,00 & 6,90 \\
9 & 5,00 & 5,75 & 6,90 \\
11 & 5,00 & 5,00 & 5,00 \\
\hline
\end{tabular}

Tabela 7-22 - Dados das Subestações

\begin{tabular}{|l|c|c|c|}
\cline { 3 - 4 } \multicolumn{1}{c|}{} & Subestação & $\begin{array}{c}\text { Capacidade } \\
\text { (MW) }\end{array}$ & $\begin{array}{c}\text { Custo fixo } \\
\text { (unidades) }\end{array}$ \\
\hline Existente & 10 & 45,00 & 0 \\
Futura & 12 & 35,00 & 1500 \\
\hline
\end{tabular}

Tabela 7-23 - Dados dos Trechos

\begin{tabular}{|c|c|c|c|}
\hline Trecho & Barra Inicial & Barra Final & $\begin{array}{c}\text { Comprimento } \\
(\mathrm{km})\end{array}$ \\
\hline 1 & 1 & 10 & 2,00 \\
\hline 2 & 3 & 10 & 2,00 \\
\hline 3 & 2 & 1 & 1,00 \\
\hline 4 & 7 & 3 & 1,00 \\
\hline 5 & 6 & 2 & 2,00 \\
\hline 6 & 5 & 11 & 1,00 \\
\hline 7 & 7 & 8 & 1,00 \\
\hline 8 & 3 & 4 & 1,00 \\
\hline 9 & 8 & 12 & 1,00 \\
\hline 10 & 11 & 6 & 1,00 \\
\hline 11 & 1 & 5 & 1,00 \\
\hline 12 & 6 & 9 & 1,00 \\
\hline 13 & 12 & 11 & 1,00 \\
\hline 14 & 9 & 12 & 1,00 \\
\hline 15 & 4 & 11 & 1,00 \\
\hline 16 & 10 & 5 & 2,30 \\
\hline
\end{tabular}

Tabela 7-24 - Dados dos tipos de cabo

\begin{tabular}{|c|c|c|c|c|c|}
\hline $\begin{array}{c}\text { Tipo de } \\
\text { Cabo }\end{array}$ & MW max & $\mathrm{R}(\mathrm{pu} / \mathrm{km})$ & $\mathrm{X}(\mathrm{pu} / \mathrm{km})$ & $\begin{array}{c}\mathrm{CF} \\
\text { (unit/km) }\end{array}$ & $\begin{array}{c}\mathrm{CV} \\
(\mathrm{unit} / \mathrm{Km} / \mathrm{MW})\end{array}$ \\
\hline 1 & 10 & 0,0285 & 0,0365 & 20 & 1 \\
\hline 2 & 20 & 0,0285 & 0,0365 & 30 & 2 \\
\hline 3 & 25 & 0,0285 & 0,0365 & 40 & 4 \\
\hline
\end{tabular}

Tabela 7-25 - Custo Unitário das Interrupções e Disrupções

\begin{tabular}{|c|c|}
\hline $\begin{array}{c}\text { CtoDisrup } \\
\text { (unit/MW) }\end{array}$ & $\begin{array}{c}\text { Ctolnterr } \\
\text { (unit/MWh) }\end{array}$ \\
\hline 0,75 & 0,315 \\
\hline
\end{tabular}


Para ilustração da metodologia, será tomada a solução ótima obtida considerando os custos de perdas e custos de investimento relativos à expansão do sistema nos três estágios até o horizonte de estudo. Sobre estas configurações, serão obtidos, utilizando o Método Híbrido, os custos de interrupções de longa duração e os custos de disrupções por VTCDs.

As potências de curto-circuito utilizadas são: Trifásica $=300,2 \underline{\mid+88,09}$ MVA e Monofásica $=250,2 \underline{\mid-87,7}$ MVA.

As configurações obtidas pelo método de Bazan (2003)[ 8], utilizando o modelo dinâmico, são apresentadas na Figura 7-30.

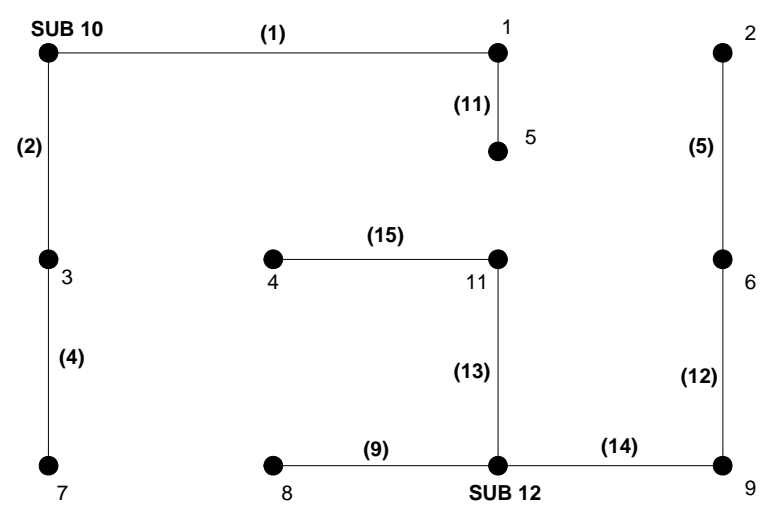

(a)

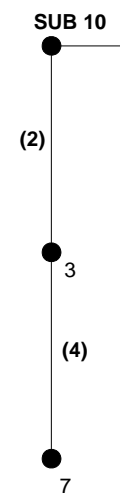

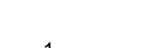

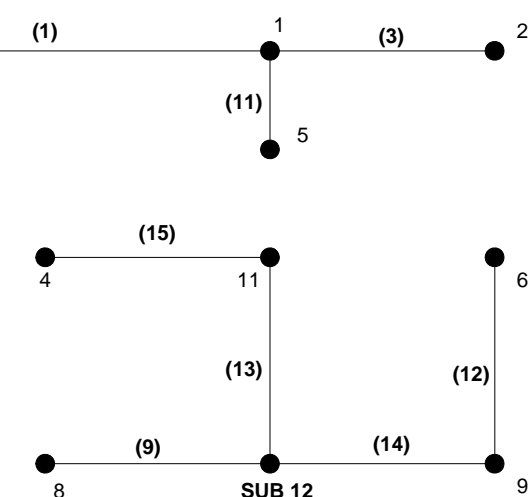

(b)

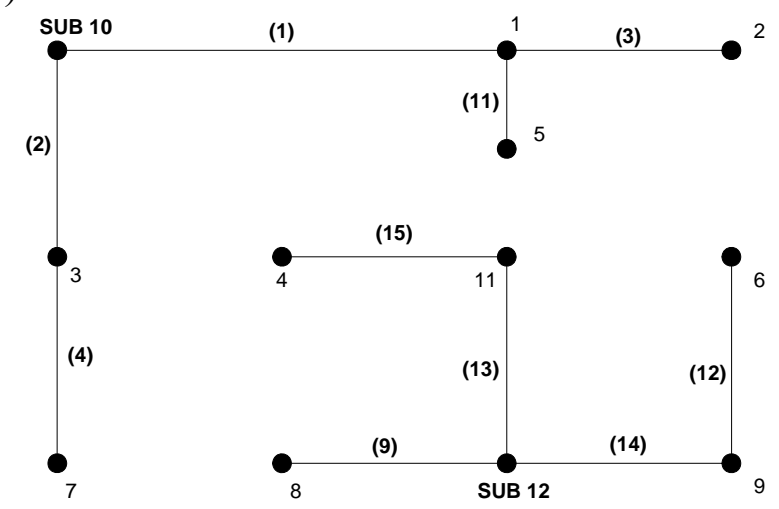

(c)

Figura 7-30 - Configurações para os três estágios do planejamento dinâmico: (a) Primeiro Estágio, (b) Segundo Estágio, (c) Terceiro Estágio

Utilizando o método híbrido, são obtidos os custos de interrupção de longa duração e os custos de disrupções por VTCDs para cada um dos três estágios de planejamento, utilizando as configurações e dados de mercado correspondentes. Estes resultados globais são apresentados na Tabela 7-26. 
Tabela 7-26 - Custos de investimento, perdas, interrupção e disrupção para cada estágio de planejamento

\begin{tabular}{|c|c|c|c|}
\hline Estágio No & $\begin{array}{c}\text { Custo do Investimento } \\
\text { + Perdas (unit/ano) }\end{array}$ & $\begin{array}{c}\text { Custo da Interrupção + } \\
\text { Disrupção (unit/ano) }\end{array}$ & $\begin{array}{c}\text { Custo Total por } \\
\text { estágio (unit/ano) }\end{array}$ \\
\hline 1 & 1.850 & 404,40 & 2.254 \\
2 & 255 & 467,46 & 722 \\
3 & 282 & 531,76 & 814 \\
\hline
\end{tabular}

Nas Tabela 7-27 e Tabela 7-28 são apresentados, respectivamente, os custos de disrupção por VTCDs e custos de interrupção de longa duração para cada uma das barras do sistema.

Tabela 7-27 - Resultados dos Custos de Disrupção por barra para os três estágios de planejamento

\begin{tabular}{|r|r|r|r|r|r|r|}
\cline { 2 - 7 } \multicolumn{1}{c|}{} & \multicolumn{2}{c|}{ Estágio 1 } & \multicolumn{2}{c|}{ Estágio 2 } & \multicolumn{2}{c|}{ Estágio 3 } \\
\hline Barra No & $\begin{array}{c}\text { NDisru } \\
\text { Iano }\end{array}$ & $\begin{array}{c}\text { Custo }_{\text {Disrups }} \\
\text { (unit/ano) }\end{array}$ & $\begin{array}{c}\text { NDisru/ } \\
\text { ano }\end{array}$ & $\begin{array}{c}\text { Custo } \\
\text { Disrups } \\
\text { (unit/ano) }\end{array}$ & $\begin{array}{c}\text { NDisru } \\
\text { lano }\end{array}$ & $\begin{array}{c}\text { Custo }_{\text {Disrups }} \\
\text { (unit/ano) }\end{array}$ \\
\hline 1 & 8,14 & 30,5 & 9,69 & 43,6 & 9,69 & 50,1 \\
2 & 8,18 & 30,7 & 9,80 & 42,3 & 9,80 & 46,5 \\
3 & 8,10 & 12,2 & 9,50 & 15,7 & 9,50 & 18,8 \\
4 & 7,92 & 29,7 & 6,52 & 29,3 & 6,52 & 32,3 \\
5 & 8,26 & 24,8 & 9,78 & 32,3 & 9,78 & 37,1 \\
6 & 8,07 & 30,3 & 6,53 & 31,8 & 6,53 & 35,0 \\
7 & 8,19 & 41,2 & 9,60 & 55,5 & 9,60 & 66,6 \\
8 & 7,91 & 29,7 & 6,52 & 29,3 & 6,52 & 33,7 \\
9 & 7,75 & 29,1 & 6,43 & 27,7 & 6,43 & 33,3 \\
11 & 7,82 & 29,3 & 6,42 & 24,1 & 6,42 & 24,1 \\
\hline
\end{tabular}

Tabela 7-28 - Resultados dos Custos de Interrupção por barra para os três estágios de planejamento

\begin{tabular}{|r|c|r|r|r|r|r|}
\cline { 2 - 7 } \multicolumn{1}{c|}{} & \multicolumn{2}{|c|}{ Estágio 1 } & \multicolumn{2}{c|}{ Estágio 2 } & \multicolumn{2}{c|}{ Estágio 3 } \\
\hline \multirow{2}{*}{ Barra No } & $\begin{array}{c}\text { NInterr } \\
\text { lano }\end{array}$ & $\begin{array}{r}\text { Custo }_{\text {interr }} \\
\text { (unit/ano) }\end{array}$ & $\begin{array}{c}\text { NInterr/ } \\
\text { ano }\end{array}$ & $\begin{array}{r}\text { Custo } \\
\text { (unterr } \\
\text { (unit/ano) }\end{array}$ & $\begin{array}{c}\text { NInterr } \\
\text { /ano }\end{array}$ & $\begin{array}{c}\text { Custo }_{\text {interr }} \\
\text { (unit/ano) }\end{array}$ \\
\hline 1 & 2,98 & 14,2 & 3,98 & 22,7 & 3,98 & 26,2 \\
2 & 3,02 & 5,8 & 3,02 & 16,5 & 3,02 & 18,2 \\
3 & 2,98 & 11,4 & 3,98 & 8,3 & 3,98 & 10,0 \\
4 & 3,02 & 19,3 & 3,98 & 22,7 & 3,98 & 25,0 \\
5 & 1,03 & 4,9 & 3,02 & 12,7 & 3,02 & 14,6 \\
6 & 2,98 & 14,2 & 1,02 & 6,3 & 1,02 & 6,9 \\
7 & 2,00 & 9,5 & 1,99 & 14,6 & 1,99 & 17,5 \\
8 & 2,98 & 14,2 & 2,00 & 11,4 & 2,00 & 13,1 \\
9 & 2,00 & 9,5 & 1,99 & 10,9 & 1,99 & 13,1 \\
11 & 2,98 & 14,2 & 2,00 & 9,5 & 2,00 & 9,5 \\
\hline
\end{tabular}

Nas avaliações dos custos das interrupções de longa duração e disrupções por VTCDs, os valores obtidos sofrem aumentos para cada estágio, já que estes valores estão diretamente ligados a demanda (crescente) de cada barra. 
Na Figura 7-31, pode-se observar o alto valor dos custos das interrupções de longa duração e das disrupções por VTCDs, quando comparados com os custos de investimento e de perdas, para os 3 estágios do período de planejamento.

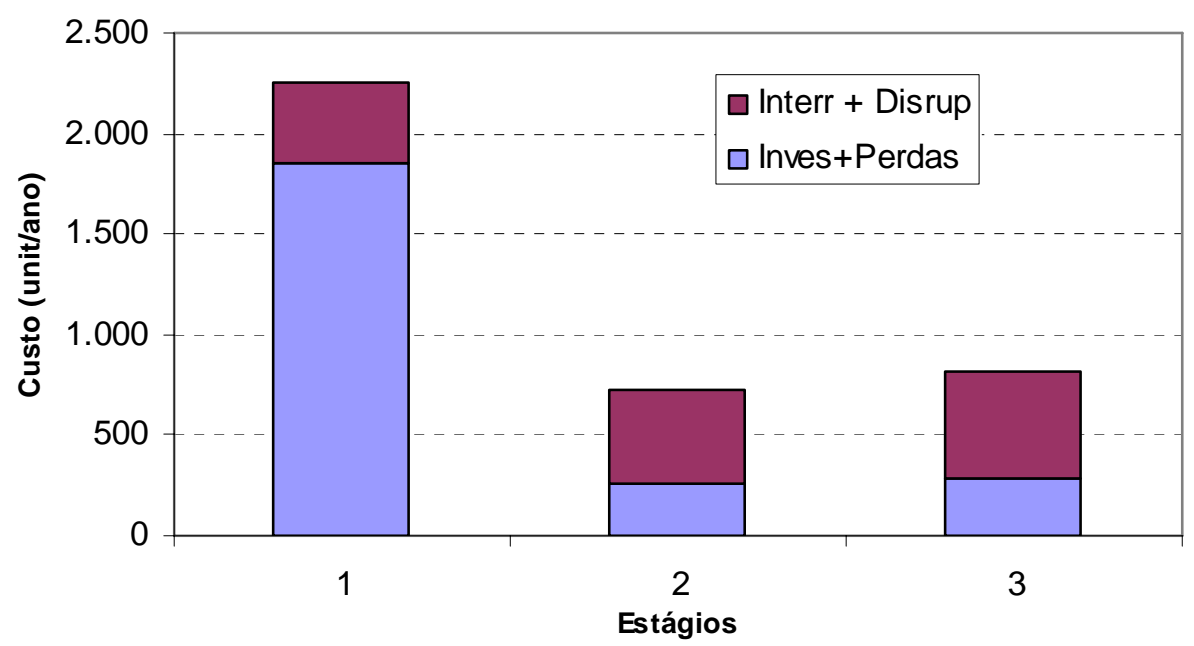

Figura 7-31 - Custos totais para cada estágio

O exemplo ilustrativo apresenta como os custos de qualidade de energia elétrica, quais sejam interrupções de longa duração e disrupções por VTCDs, podem ser facilmente considerados sobre uma dada alternativa de expansão do sistema de potência.

Apesar de não mostrado neste exemplo, a consideração dos custos de qualidade de energia elétrica pode definitivamente alterar as configurações do sistema elétrico para a solução ótima de expansão do sistema de distribuição de energia elétrica. Ou seja, dados os altos valores de custos de QEE que incidem sobre os consumidores, podem ser obtidas alternativas de planejamento que determinem a instalação de reforços específicos para minimizar o custo total de expansão do sistema, considerando os efeitos das interrupções e das disrupções por VTCDs. 
8 - CONCLUSÕES

Neste trabalho foram desenvolvidas, três metodologias para Análise de Riscos de Interrupções de Processos eletro-eletrônicos devido a variações de tensão de curta duração (VTCDs). Estas metodologias são: Monte Carlo, Enumeração de estados e Híbrido.

Com a utilização destas metodologias, é possível obter índices relativos às VTCDs (Afundamentos, Elevações, Interrupções e Disrupções de tensão) em cada consumidor existente na rede de distribuição elétrica.

A partir da avaliação destes índices, na segunda parte deste trabalho a preocupação foi desenvolver uma formulação matemática que permita considerar o efeito destes fenômenos de QEE nos modelos clássicos para tratamento dos problemas de reconfiguração de redes distribuição e de planejamento de expansão de sistemas de distribuição. Desta maneira é concebido um novo modelo de planejamento de sistema de distribuição, para horizontes de curto e médio prazo, contemplando os custos de qualidade de energia relativos às interrupções de longa duração e VCTDs.

\subsection{Discussão Geral}

Nesta seção são comentados e discutidos os tópicos apresentados ao longo dos diferentes capítulos que constituem este trabalho de tese.

No capítulo 2 foi apresentada uma revisão bibliográfica dos diferentes trabalhos encontrados na literatura científica, referentes à qualidade de energia e seu efeito nos consumidores. Para o desenvolvimento deste trabalho foram utilizados critérios vindos de normas existentes no panorama mundial, assim como as normas atualmente existentes no Brasil. Com isto foi possível caracterizar os fenômenos referentes à qualidade de energia, aos quais os consumidores são submetidos. Limites são estabelecidos pelas normas, no intuito de restringir o impacto destes fenômenos nos consumidores existentes nas redes de distribuição elétrica.

Neste mesmo capítulo, foram observados trabalhos que analisam o impacto da qualidade da energia nas cargas dos consumidores. Os diferentes trabalhos comentados 
permitem entender a importância do impacto das VTCDs sobre os equipamentos utilizados nos processos industriais, principalmente provocados por faltas no sistema elétrico.

Diferentes trabalhos, também apresentados neste capítulo, avaliam os custos da qualidade do fornecimento da energia envolvendo os consumidores. Estes custos referem-se aos transtornos e prejuízos pela perda de produção, oportunidades de negócio, de lazer e outros, cada vez que o consumidor é submetido uma VTCD que provoca uma parada de produção não programada ou outro tipo de transtorno. Estes custos chegam a ser muito maiores do que os custos da perdas por produção programada.

No capítulo 3, são apresentados diferentes aspectos relevantes para a análise das VTCDs. As Ocorrências de faltas elétricas e manobras de grandes blocos de cargas são apontadas como as causas principais de VTCDs e também apresentadas neste capítulo. Para o caso de partida de motores, a magnitude da VTCD depende da intensidade da corrente de partida do motor e das características da rede. Para estes tipos de afundamentos, existem métodos para compensar a queda de tensão como: instalação de partidas suaves nos motores, solicitação para a concessionária de uma rede de reforço ou utilizar restauradores dinâmicos de tensão (DVR- "Dynamic Voltage Regulator"), etc. No caso de VTCDs provocadas por curtos-circuitos, a abordagem é diferente, dado que são praticamente inevitáveis em um sistema elétrico de grande porte, o que motiva o desenvolvimento deste trabalho de tese.

Neste capítulo, também são apontados os fatores que influenciam às VTCDs provocados por faltas elétricas, com ênfase para: tipo de falta, localização da falta, impedância da falta, conexão dos transformadores, tensão pré-falta, desempenho dos sistemas de proteção, assim como outros fatores. Cada um deles representa um item a ser analisado e considerado durante a modelagem apresentada ao longo desta tese.

Um item importante, também apontado, refere-se à sensibilidade dos equipamentos e processos industriais, já que são estes que devem suportar as VTCDs provocados por faltas elétricas. Existem na bibliografia curvas de sensibilidade largamente utilizadas como a curva CBEMA, atualizada para a ITIC, representando o desempenho de alguns equipamentos eletro-eletrônicos. Estas curvas permitem observar as regiões de imunidade frente as VTCDs, tornando possível analisar o nível de severidade do afundamento de tensão (magnitude e duração) que poderia provocar uma Disrupção no equipamento analisado. Foi definido ao longo deste trabalho que Disrupção é um termo aplicado quando uma falta elétrica, provoca uma VTCD com um nível de afundamento inferior à curva de sensibilidade suportada do equipamento ou processo eletro-eletrônico. 
No capítulo 4, foram desenvolvidas três metodologias para avaliação de índices de VTCDs: O Modelo de Monte Carlo, Modelo de Enumeração de estados e Modelo Híbrido.

O modelo de Monte Carlo baseia-se em um processo de geração de números aleatórios para estabelecimento dos cenários a partir de distribuições de probabilidades relacionadas às variáveis do problema. Também se fundamenta em um processo de imitar a realidade. Este método permite simular as diferentes variáveis envolvidas no processo de análise, que no caso das VTCDs, ou seja, os fatores que influenciam os afundamentos de tensão nas rede de distribuição elétrica. Neste capítulo foi formulado, para cada variável envolvida, um equacionamento que caracteriza seu comportamento durante o processo de sorteio de números aleatórios. As variáveis envolvidas são: trecho de falta, ponto de falta, tipo de falta e resistência de falta. Para utilizar este método, é necessário realizar uma grande quantidade de sorteios,estabelecendo-se grande número de cenários de faltas na rede elétrica, obtendo-se, no final, resultados estatísticos das grandezas de interesse para o estudo de Áreas de Risco.

O modelo de Enumeração de estados é uma metodologia do tipo determinística, ao contrário do modelo de Monte Carlo (metodologia do tipo estatístico). Sua modelagem consiste em analisar todos os tipos de curtos circuitos, para todos os trechos existentes na rede. A variável relativa ao ponto de falta no trecho será obtida do fracionamento do comprimento total do trecho em faixas pré-estabelecidas. No caso da variável impedância de falta (tanto para fase-fase como para e fase-terra) o valor será obtido também do fracionamento do valor máximo (dependendo do tipo de falta) em faixas pré-estabelecidas. No final serão obtidas combinações local-tipo-impedância, cada uma delas associado a um peso final na contribuição do perfil da variação da tensão obtida.

O Método Híbrido apresenta uma abordagem conjunta dos métodos anteriores. Ou seja, durante a obtenção das combinações de curtos-circuitos, algumas variáveis serão obtidas de forma aleatória (trecho de falta, ponto de falta), e outras de forma determinística (impedância de falta). Este método permite, dado um número de combinações préestabelecido (número de curtos-circuitos), distribuir esta quantidade respeitando a distribuição de probabilidade de cada variável envolvida, sem comprometer o resultado final. Este método inicía com o agrupamento dos trechos existentes na rede em função dos comprimentos com valores semelhantes (considerando uma tolerância). Estes grupos são ainda classificados como: Grupos predominantes (grupos de maior comprimento) e Grupos menos predominantes (grupos de menor comprimento). Para manter a distribuição de probabilidades, cada grupo impõe-se uma participação na distribuição do número total de curtos-circuitos em função do valor total do comprimento de cada grupo. Conhecendo a quantidade de curtos-circuitos que 
cada Grupo possui, o passo seguinte é realizar uma segunda distribuição em função da probabilidade do tipo de falta, sendo assim possível conhecer a quantidade de curtos-circuitos por grupo e por tipo de falta.

O próximo passo é definir o valor de cada variável envolvida. Para a obtenção do valor da impedância de falta, é necessário o fracionamento em faixas, a quantidade de faixas será o valor obtido logo após da segunda distribuição. O trecho de falta será estabelecido aleatoriamente dentro do grupo que está sendo analisado. O ponto de falta também é escolhido aleatoriamente dentro do trecho de falta escolhido no passo anterior.

O capítulo 5 toma como base os conjuntos de condições de curto-circuito obtidos nas três metodologias, explicadas no capítulo anterior. O objetivo deste capítulo é caracterizar e classificar a severidade das VTCDs provocados em cada condição de curto-circuito, em função da magnitude da tensão e da duração da falta. Assim, é descrita uma formulação que permite anualizar cada índice de VTCD obtido (Afundamento, Elevação, Interrupção e Disrupção de tensão, para cada consumidor existente na rede elétrica. A partir dos índices de VTCD, é possível a obtenção dos custos, em valores monetários, relativos aos prejuízos que cada consumidor enfrenta ao ano, devido a fenômenos associados às VTCDs.

No capítulo 6, realiza-se uma revisão dos diferentes modelos existentes na bibliografia que estudam os problemas de planejamento de operação e planejamento de expansão de sistema de distribuição de energia elétrica. O objetivo deste capítulo é apresentar as formulações clássicas existentes para a obtenção de soluções ótimas destes problemas,. Mostrando como é possível incorporar o custo da qualidade de energia nestas formulações.

Nestes modelos, é usual, considerar a minimização dos custos dos investimentos e dos custos das perdas elétricas que as concessionárias de energia elétrica irão enfrentar durante o planejamento de operação ou expansão. Entretanto, tais modelos não consideram os prejuízos que os consumidores enfrentam frente a fenômenos associados às VTCDs. Tais prejuízos podem chegar a perdas substanciais que devem ser consideradas pelas concessionárias, já que de alguma forma elas são responsáveis pela qualidade do fornecimento da energia. Em alguns casos, os consumidores prejudicados irão refletir suas perdas monetárias, às concessionárias, usando vias judiciais que ao longo do tempo produzirão grandes prejuízos. Deve-se ressaltar também as medidas regulatórias que vem sendo realizadas, através de Resoluções e dos Procedimentos de Distribuição, que deverão regulamentar os índices como já é o caso das interrupções de longa duração, através da Resolução ANEEL 024/2000..

No capítulo 7, são apresentados diferentes resultados referentes aos índices de VTCDs (Afundamento e Elevação de tensão, Interrupção de longa duração e Disrupção por VTCDs), 
produzindo informações que possibilitam realizar um mapeamento da rede elétrica com respeito às Áreas de Risco associadas às faltas no sistema elétrico de distribuição.

Os resultados apresentados, obtidos pelas três metodologias descritas neste trabalho, possibilitam vislumbrar graficamente as situações em que os fenômenos relacionados à VTCDs devem ser levados em consideração, como nos casos que envolvem equipamentos ou processos industriais sensíveis a esse fenômeno. Assim, os índices obtidos podem ser utilizados futuramente para o suporte ao processo de análise de solicitações de consumidores, visto que conhecido a localização do cliente reclamante, e da característica dos seus equipamentos eletro-eletrônicos (curva de sensibilidade), é possível simular e analisar se aquele equipamento seria sensibilizado por faltas oriundas na rede de distribuição.

Utilizando o Modelo de simulação de Monte Carlo percebe-se que redes mais complexas demandam uma maior quantidade de Curtos-Circuitos, para que os resultados atinjam estabilidade. Desta forma mais simulações são necessárias para um resultado ainda mais preciso. No entanto, a metodologia de Monte Carlo mostrou ser significativamente mais rápida quando comparada com o Método de Enumeração de estados, mesmo para uma rede elétrica de grande porte.

Este comportamento é explicado, pois o Método de Enumeração de estados, para aumentar a sua precisão, necessita de um número maior de faixas nas suas variáveis, provocando o aumento polinomial do número de curtos-circuitos a serem simulados que, para uma rede de grande porte, supera em muito a quantidade utilizada pelo Método de Monte Carlo.

Durante a execução do Método de Enumeração de estados, pode-se observar que a variável que tem mais influência nos resultados é a variável impedância de falta, isto é explicado pelo fato de que o valor desta impedância, para redes de distribuição elétrica, é muito maior que valores de impedância de trechos que envolvem a falta.

O Método de Enumeração de estados, por ser um Método determinístico e não estatístico (Método de Monte Carlo), seria mais preciso, mas sua principal limitante é o esforço computacional, na obtenção dos resultados. Acredita-se que com o surgimento de novos sistemas computacionais mais eficientes e rápidos este Método pode-se mostrar muito interessante, dada a sua precisão na obtenção dos resultados.

O terceiro Método desenvolvido, chamado de Híbrido, apresenta um comportamento parecido ao de Monte Carlo, dado que algumas das suas variáveis também são de caráter aleatório. A principal diferença entre estes dois métodos consiste em que, no caso do Método Monte Carlo, é necessário estabelecer um número de curtos-circuitos muito grande e não 
previamente conhecido para alcançar a sua estabilidade. Com o Método Híbrido, é possível estabelecer um número de curtos-circuitos, não necessariamente muito grande, para obter resultados com a mesma qualidade que o Método de Monte Carlo.

O Método Híbrido distribui o número de Curtos-Circuitos simulados, respeitando o comportamento de cada variável, conseguindo resultados com menor desvio, quando comparados com o Método de Monte Carlo. Isto é possível dado que o Método Híbrido estabelece um conjunto de curtos-circuitos de forma mais racional, deixando a aleatoriedade às variáveis menos predominantes (trecho de falta e ponto de falta), e distribuindo em faixas as variáveis mais predominantes (impedância de falta).

Dado que o Método Híbrido consegue obter melhores resultados em um tempo de processamento relativamente menor em comparação aos Métodos de Monte Carlo e Enumeração de estados, pode-se concluir que o Método Híbrido é o mais eficiente na obtenção dos índices de VTCDs para afundamentos, elevações e disrupções de tensão nas barras existentes na rede de distribuição elétrica.

$\mathrm{Na}$ última parte do capítulo 7 foram analisadas algumas redes ilustrativas visando a solução dos problemas de planejamento de operação de planejamento de expansão ótimo. No caso do problema de reconfiguração de redes, configurações consideradas ótimas do ponto de vista de redução das perdas elétricas estavam disponibilizadas pelos autores. No caso do problema de expansão, estavam disponíveis as obras a serem realizadas ao longo do horizonte de planejamento visando a minimização do custo do investimento e do custo operacional.

Neste trabalho estas redes foram simuladas para obter os índices de VTCDs em cada condições de mercado, de forma a obter o custo relativo às Interrupções de longa duração e o custo relativo às Disrupções por VTCDs. Estes custos adicionados aos referenciados anteriormente, permitiram obter o valor total anualizado que a concessionária terá que enfrentar não somente pela operação e/ou expansão da sua rede, mas considerando também pelos prejuízos imputados aos consumidores existentes nas suas redes elétricas.

\subsection{Principais Contribuições}

\section{1) Contribuição na inclusão do tempo na Classificação das VTCDs}

Durante a classificação de severidade de afundamentos e elevações de tensão explicado no Item 5.5, não somente é utilizado a magnitude do afundamento de tensão para cada condição de curto-circuito, mas também é considerado a variável duração. Muito autores 
desconsideram esta variável durante as simulações, como por exemplo no trabalho de Olguin (2005)[ 83], já que a sua inclusão é de difícil tratamento. Este trabalho contribui para a na inclusão desta variável (tempo), além das outras (tipo de falta, ponto de falta, impedância de falta) que caracterizam uma determinada falta elétrica. Esta inclusão é de grande importância já que permite realizar uma melhor análise da severidade das VTCDs, em magnitude e duração frente à curva de sensibilidade de um determinado equipamento eletro-eletrônico. Assim, é possível contabilizar, além dos índices de ocorrências de Afundamentos e Elevações de tensão por ano, as frequências de ocorrências de Disrupções por ano para cada consumidor existente na rede de distribuição.

\section{2) Contribuição na diminuição do Número de Variáveis envolvidas}

Em alguns trabalhos encontrados na literatura, como por exemplo Camilo (2007) [ 18] e Kagan (2004) [ 55], a variável Tempo é incluída, de forma estatística ou determinística, no conjunto de variáveis que caracterizam um curto circuito, ou seja em alguns, casos ela é determinada por sorteio e em outras e fracionada em faixas definidas. De uma ou outra forma, a inclusão desta variável gera um grande aumento no número de combinações de curtocircuito necessário para obter índices de VTCDs para um rede de distribuição elétrica.

Uma das principais contribuições deste trabalho é obter a variável Tempo, de forma que não seja obtida por sorteios, nem fracionada em faixas definidas, e sim obtida em função das outras variáveis envolvidas na caracterização de um curto-circuito (tipo de falta, ponto de falta, impedância de falta). A obtenção da variável Tempo envolve os conceitos de probabilidade de VTCDs e probabilidade de interrupção, explicados em mais detalhe no capítulos desta tese.

Dado que a variável Tempo não é mais sorteada, como foi realizada nos modelos de Monte Carlo, ou fracionada em modelos analíticos existentes em trabalhos anteriores, o número de combinações de curtos-circuitos diminui drasticamente, o que reflete na qualidade dos resultados e em um menor esforço computacional, possibilitando a obtenção de índices de VTCDs caracterizadas por magnitude e duração para redes de grande porte.

\section{3) Contribuição na proposta de um Método Híbrido}

A metodologia mais utilizada para caracterizar variáveis estatísticas referentes a tipolocal-impedância de falta é a metodologia de Monte Carlo, já que permite modelar, de forma simples, a distribuição de probabilidade para cada variável. Esta metodologia realiza um 
número grande de sorteios, gerando um conjunto de combinações de condições de curtoscircuitos que permitem caracterizar estes fenômenos ao longo da rede de distribuição. A principal desvantagem deste método é a quantidade grande de sorteios de números aleatórias e análise dos cenários correspondentes necessários para que o método consiga chegar a sua estabilidade. Este número de sorteios é desconhecido, antes de se realizar a primeira simulação pelo método de Monte Carlo, dado que este valor somente é conhecido ao longo de diferentes simulações sucessivas, quando os resultados obtidos atingem um desvio muito baixo.

O método Híbrido apresentado neste trabalho apresenta uma abordagem diferente na obtenção do conjunto de combinações de curtos-circuitos. Com este método, pode-se fixar a priori o número de simulações, ou seja o número de condições de curtos-circuitos, já que o método realiza a distribuição das faltas nas variáveis envolvidas de forma racional, respeitando a distribuição de probabilidade de cada variável.

Os resultados obtidos neste trabalho indicaram que este método, em comparação com o Modelo de Monte Carlo, se mostram mais eficientes na obtenção dos resultados, dado que com menor número de simulações, ontem resultados mais precisos. Assim, o Método Híbrido representa outra importante contribuição no desenvolvimento deste trabalho.

\section{4) Contribuição para formulação do planejamento de operação e expansão utilizando índices de VTCDs.}

Os modelos clássicos de planejamento de operação e planejamento de expansão realizam a formulação de cada problema visando a diminuição de custos do ponto de vista da concessionária de energia elétrica. Outra contribuição deste trabalho é incorporar o custo do prejuízo dos consumidores referentes a fenômenos de VTCDs dentro da formulação da função objetivo, nos problemas de planejamento de operação e planejamento de expansão. $\mathrm{Na}$ minimização desta nova função objetivo, além dos custos de investimento e operação, são considerados os custos dos prejuízos referentes às interrupções de longa duração e disrupções por VTCDs nos consumidores existentes nas redes de distribuição de energia elétrica.

Assim também, a metodologia apresentada pode permitir identificar não só os recursos de planejamento (reconfiguração, novos reforços, etc.) como também introduzir na competição equipamentos mitigadores (DVRs, UPSs, Flywheel - volante, etc.), chaves de transferência rápida, alimentadores exclusivos, etc., que são alternativas especificas para diminuir os custos de qualidade de energia (afundamentos e interrupções). 


\subsection{Trabalhos Futuros}

\section{A. Impacto dos religadores na obtenção de índices de VTCDs e interrupções de curta duração.}

Uma consideração importante nos próximos trabalhos consiste na inclusão do efeito dos religadores existentes nos alimentadores na rede de distribuição elétrica. Os religadores, dado seu princípio de atuação, permitem o rápido restabelecimento do fornecimento da energia para os consumidores envolvidos em uma falta elétrica. Entretanto, a utilização destes dispositivos faz com que ocorram diversas VTCDs consecutivos para consumidores de outros ramais em caso de faltas permanentes. Isto pode influenciar na contagem na duração de Afundamentos, Elevações e Disrupções de tensão nos quais os consumidores ficarão submetidos, o que em geral é tratado por agregação temporal, a inclusão deste tipo de proteção é necessária, mas requer de uma abordagem diferente, pois o Método Híbrido deverá ter a concepção revista com relação à obtenção das probabilidades de VTCDs e interrupção, para cada condição de curto-circuito.

\section{B. Implementação de Técnicas de Otimização em modelos de planejamento de operação e expansão com a inclusão dos índices de VTCDs}

No presente trabalho foi apresentada uma formulação que inclui o custo do prejuízo nos consumidores referentes aos fenômenos de VTCDs dentro da função objetivo nos problemas clássicos de planejamento de operação e planejamento de expansão. Uma abordagem interessante para próximos trabalhos seria utilizar técnicas de otimização visando a minimização desta função objetivo.

Tendo em vista que o problema do planejamento de operação (reconfiguração) assim como o problema de planejamento de expansão são de natureza combinatorial, Técnicas Heurísticas podem ser aplicadas, entre elas: Algoritmos Evolutivos, Busca Tabu, Vizinhança variável, etc. A principal vantagem da utilização destas técnicas para resolver o problema de planejamento está na facilidade de se trabalhar com um modelo não linear do problema, atendendo-se requisitos técnicos e econômicos para obtenção de resultados compatíveis com a realidade das concessionárias de energia, e com a inclusão do índices de VTCD, com a realidade dos consumidores existentes nas suas redes. Cada configuração de rede, estabelecida explicitamente pelo método de otimização, pode ser submetido a um dos modelos para obtenção dos custos relativos à QEE propostos neste trabalho. 


\section{Execução de uma campanha de medição em diferentes pontos da rede elétrica de distribuição para validar os resultados obtidos pelos Métodos de simulação.}

Uma proposta interessante para futuros trabalhos consiste na realização de uma campanha de medições em diferentes pontos de redes reais de distribuição. Esta campanha de medições pode ser realizada instalando diferentes medidores ao longo da rede de distribuição, em pontos aleatórios ou específicos. Desta maneira, registrando a forma de onda das perturbações de tensão em cada ponto de monitoração durante um período longo de tempo (por exemplo, alguns meses até anos), de forma a validar e ainda calibrar os resultados obtidos pelos métodos de simulação apresentados neste trabalho de tese.

\section{Inclusão de indicadores de qualidade no planejamento}

Outra proposta interessante para trabalhos futuros seria a inclusão de indicadores de qualidade de longa duração, tais como DEC, DIC, FEC, FIC e DMIC, durante a análise de planejamento de operação ou expansão, sendo considerados seus limites como restrições ou penalidades incorporadas na formulação matemática. 


\section{9 - REFERÊNCIAS BIBLIOGRÁFICAS}

[ 1] Abreu, J. P. G.; "Qualidade de energia Elétrica", Grupo de qualidade da energia elétrica da Universidade Federal de Itajubá 2000.

[2] Abreu, J. P. G.; Filho, J. M de C., Vilas-Boas, F. M.; "Medidas preventivas e Corretivas para minimizar o impacto das Depressões de Tensão", II Seminário Brasileiro sobre qualidade de energia Elétrica, São Lourenço - MG, 1997.

[ 3] Alves, M. F.; Costa, J. G.; Fonseca, V. R. C.; "Impacto Econômico do Afundamento de Tensão na Indústria: Uma Metodologia Aplicada a Grandes Redes Elétricas". V SBQEE Seminário Brasileiro sobre Qualidade da Energia Elétrica.Tópico: Impacto Econômico e Responsabilidades, p. 483- 488, Aracajú, Sergipe, Brasil, 2003.

[4] Agencia Nacional de Energia Elétrica (ANEEL); "Procedimentos de Distribuição de Energia Elétrica no Sistema Elétrico Nacional - PRODIST", Módulo 8, Qualidade da Energia Elétrica, 2007.

[ 5] Aoki, K.; Nara, K.; Satoh, T.; Kitagawa, M.; Yamanaka, K.; "New approximate optimization method for distribution system planning". IEEE transactions on Power Systems,Vol. 5, No.1, pp. 126-132, 1990.

[ 6] Aung, M. T.; Milanovic, J. V.; Simmons, P. A.; "Automated Comprehensive Assessment and Visualization of Voltage Sag Performance". ICHQP 2004.

[7] Baran, M.E. and Wu, F.F., "Network reconfiguration in distribution systems for lossreduction and load balancing ", IEEE Transactions on Power Delivery, Volume: 4 No 2, April pp: $1401-1407,1989$.

[ 8] Bazan, F. A.; "Planejamento de sistemas de distribuição de energia elétrica utilizando algoritmo busca tabu". Dissertação de Mestrado, Universidade Estadual Paulista - campus Ilha Solteira, 2003.

[ 9] Becker, C. :"Proposed chapter 9 for predicting voltage sags (dips) in revision to IEEE std 493", the gold book. IEEE transactions on industry applications. vol. 30. no. 3. 1994.

[10] Billinton, R.; Tollefson, G.; Wacker G.; "Comprehensive bibliography on reliability worth and electrical service consumer interruption costs: 1980-1990". IEEE Transactions on Power Systems, v. 6, n. 4, p.1508-1514, Nov. 1991.

[11] Bollen, M H J; "Fast assessment method for sags in distribution systems". IEEE Trans on Industry applications. vol. 32. no. 6. November/December 1996.

[ 12] Bollen, M H J; "Additions to the method of critical distances for stochastic assessment of voltage sags". IEEE 1998.

[13] Bollen, M.H.J., Qade, M.R., Allan, R.N.; "Stochastical and statistical assessment of voltage dips", IEEE 1998. 
[14] Bollen, M. H. J.; "Understanding power Quality problems - voltage sags and interruptions", IEEE Press Series, p. 541,New York, 2000.

[15] Books, C. L.; Dugan, R. C.; Waclawiak, M.; Sudaram, A. - Indices for Assessing Utility Distribution System RMS Variation Performance - www.pqnet.electrotek.com\.

[16] Bhavaraju, M. P.; Hebson, J. D.; Wood, W.; "Emerging Issues in Power System Planning". IEEE Proceedings, v. 77, n. 6, p. 891-898, 1989.

[17] Burato, Marco V.; " Construção e Avaliação de um Modelo de Simulação de Monte Carlo para Analisar a Capacidade de Pagamento das Empresas em Financiamentos de Longo Prazo"- Tese de Mestrado - Orientador: Oscar Claudino Galli - Rio Grande do Sul Universidade federal do Rio Grande do Sul, 2005.

[ 18] Camilo e Silva, L. M.; "Simulação de Monte Carlo no cálculo de riscos de ocorrência de variação de tensão de curta duração em redes de distribuição de energia elétrica", Dissertação de Mestrado, Escola politécnica da Universidade de São Paulo, São Paulo, 2007.

[19] Carvalho, J. M..; "Uma Contribuição à Avaliação do atendimento a consumidores com cargas sensíveis - Proposta de novos indicadores". Tese de Doutorado, Escola Federal de Itajubá, 2000.

[20] Cebrian, J. C.; "Algoritmo Evolutivo Dedicado À Solução Do Problema De Reconfiguração De Sistemas De Distribuição Radias", Tese de mestrado,UNESP Ilha Solteira, 2003

[21] Cebrian, J. C. ;Kagan, N. ;Camilo, L. M.; "Consideration of voltage sags disruption risks in distribution planning studies", In: International Conference on Electricity Distribution, Turin. CIRED 2005.

[22] CED - Centro de Excelência em Distribuição de Energia Elétrica. "Apoio à SEE na Apuração e Avaliação da Qualidade do Produto - Terminologia, Conceituação e definições", QUEN-004 - Módulo II, Nota Técnica 1, março de 1998.

[23] CENELEC. "Voltage Characteristics of Electricity Supplied by Public Distribution Systems", 1994.

[24] Chen, S.L.; Chen, G.B.; Hsu, S.C.; Chen, A.Y.T.; Guo, T.Y.; Huang, F.F.; Huang, Y.C.; "Mitigation of voltage sags by network reconfiguration of a utility power system", Transmission and Distribution Conference and Exhibition: Asia Pacific. IEEE/PES, Volume 3, p. 2067 - 2072 vol.3, 2002.

[25] Civanlar, S.; Grainger, J.J.; Yin, H. and Lee, S.S.H., "Distribution feeder reconfiguration for loss reduction", IEEE Transactions on Power Delivery, Volume: 3 No 3, July, p. $1217-1223,1988$.

[26] Díaz-Dorado, E.; Cidrás, J.; Míguez, E.; "Application of Evolutionary Algorithms for the Planning of Urban Distribution Networks of Medium Voltage". IEEE transactions on Power Systems, Vol. 17, No. 3, p. 1151-1159, 2002.

[27] Colding, S.; "What quality can be demanded from the electricity supply". Elteknik med Aktuell Elektronik 25(2):20-2, 1982.

[28] Conrad, L.; Little, K.; Grigg, C.; "Predicting and Preventing Problems Associated Associated with Remote Fault-Clearing Voltage Dips". IEEE transactions on industry applications. vol. 27. Issue: 1, Part: 1, p. 167-172, 1991. 
[29] Correia, M. D.; Olivera, D.; "Pilot project for the evaluation of the sag performance of some Brazilian network busbars". CIGRE/IEEE PES International Symposium. Quality and Security of Electric Power Delivery Systems, Montreal, Canada, IEEE, 2003.

[30] Daniel, M.S.; “A 35-kV system voltage sag improvement”, Power Delivery, IEEE Transactions on, Volume 19, Issue 1, p. 261 - 265, 2004.

[31] Davenport, F.; "Voltage Dips and Short Interruptions in Medium Voltage Public Electricity Supply". Electricity Association, London. Group of Experts: F. W. T. Davenport (Chairman), D. Bose, U. Grape, M. Kasztler, J. N. Luttjehuizen, H. Seljeseth, M. Silvestri, D. J. Start, J-P Tete, J. Votsmeier, R. Tonon, 1991.

[32] Deloux, G.; "International Standardization and electric power supply network disturbances". International Conference on Sources and Effects of Power System Disturbance, London, UK, IEE, 1974.

[33] Dorr, D. S.: "Interpreting Recent Power Quality Surveys to Define the Electrical Environment", Conference Record of the 1996 IEEE Industry Applications conference. Thirty-first IAS Annual Meeting. p. 2251-2258 vol.4, 1996.

[34] Dorr, D. S.: "National Power Laboratory Power Quality Study Results Based on 600 Site-Months". Telecommunications Energy $14^{\text {th }}$ International Conference. INTELEC 92. p. 378-383, 1992.

[35] Dugan, R. C.; Mcgranaghan, M. F.; Santoso, S.; Wayney Beaty, H.; Eletric Power System Quality. McGraw-Hill. 568p, 2002.

[36] Dugan, R.C.; Brooks, D.L.; McDermott, T.E.; Sundaram, A.; "Using voltage sag and interruption indices in distribution planning", Power Engineering Society 1999 Winter Meeting, IEEE, Volume 2, p. 1164 - 1169 vol.2, 1999.

[37] Farqui, T. C..; “Afundamentos de tensão em industrias de papel e celulose”, Tese Mestrado, Escola politécnica da Universidade de São Paulo, São Paulo, 2005.

[ 38] Gates, J.; Wacker, G.; Billinton, R.; "Development of Customer Survey Instruments for Reliability Worth Evaluation in Electric Power Systems". IEEE Wescanex' 95 Proceedings, p. 12-17, 1995.

[ 39] Gomez da Costa, J. " Avaliação de impactos econômicos do afundamento de tensão na industria ". Dissertação de Mestrado, Pontifícia Universidade Católica de Minas Gerais, 2003.

[40] Gomez, J. C.; Campetelli, G. N.;" Voltage Sag mitigation by current limiting fuses". Proceedings of World Congress on Industrial Applications of Electrical Energy and $35^{\text {th }}$ IEEE-IAS Annual Meeting, Rome, Italy, IEEE, 2000.

[41] Gómez, J.F.; Khodr, H.M.; Oliveira, P.M.; Ocque, L.; Yusta, J.M.; Villasana, R.; Urdaneta, A.J.; "Ant colony system algorithm for the planning of primary distribution circuits". IEEE Trans. on Power Systems, Vol. 19, No. 2, p. 996- 1004, 2004.

[ 42] Gomes, P.; Schilling, M. Th.; "Custo de Interrupção: Conceituação, Metodologia de Avaliação, Valores Existentes e Aplicações". XIV SNPTEE - Seminário Nacional de Produção e Transmissão de Energia Elétrica. Grupo IV - Análise e Técnicas de Sistemas de Potência, p.1-6, Belém, Pará, Brasil, 1997.

[43] Gouvea, M. R.; Kagan, N.; "A Methodology For Planning Electricity Supply Systems On Aggregated Basis". In: International Conference On Electricity Distribution, 13. CIRED: reports. Bruxelas, Bélgica. v. 1. p. 6321-6326, 1995. 
[ 44] Gouvea, M. R. ; Valente, A ; Araújo, H. ; Kagan, N. . Modelo de Evolução de Redes No Planejamento Agregado de Investimentos. In: Seminário Nacional de Distribuição De Energia Elétrica, SENDI'94: contribuições técnicas. Recife. v. Disc10, 1994.

[45] Gruzs, T. M.; "Power quality-a shared responsibility". Power Quality 89. Official Proceedings of the first international conference, long beach, CA, USA, Intertec Commun, 1989.

[46] Heine, P.; Lehtonen, M.; Lakervi, E.; "Voltage Sag Analysis Taken into account in Distribution Network Design", IEEE Power Tech Conference. Porto, Portugal 2001.

[47] Heine, P.; Lehtonen, M.; "Voltage sag distributions caused by power system faults", Power Systems, IEEE Transactions on, Volume 18, Issue 4, p. 367 - 1373, 2003.

[ 48] Heine, P.; Pohjanheimo, P.; Lehtonen, M.; Lakervi, E.; "Estimating the annual frequency and cost of voltage sags for customers of five Finnish distribution companies", Electricity Distribution, 2001. Part 1: Contributions. CIRED. 16th International Conference and Exhibition on (IEE Conf. Publ No. 482), Volume 2, p. 5 vol.2, 2001.

[49] Hydro-Québec, CEA (Canadian Electricity Association) 220 D 711 - Power Quality Measurement Protocol CEA Guide to Performing Power Quality Surveys, Prepared by HidroQuébec, 1996.

[ 50] IEEE Std 493-1997, IEEE Golden Book, Capítulo 9, "Voltage Sag Analysis"

[ 51] IEEE 519-1992, "Recommended Practices and Requirements for Harmonic control in electrical Power systems".

[52] IEEE. "Recommended Practice for Monitoring Electric Power Quality", Std. 1159, 1995

[53] Kagan, N. "Electrical Distribution System Planning Using Multi objective and Fuzzy Mathematical Programming", PhD Thesis, University of London. 1992

[ 54] Kagan, N.; Matsuo, N. M.; Ferrari, E. L.; Duarte, S. X.; Cavaretti, J. L.; Castellano, U. F.; Tenório, A.; Antunes, A. U.; "Aplicação de ferramenta computacional para Análise estatística de VTMs e critérios para seleção dos pontos de medição", Seminário brasileiro sobre qualidade de energia elétrica, 4, Porto Alegre. p. 427-432, 2001.

[ 55] Kagan, N.; Matsuo, N.M.; Vasconcelos, G.; Castellano, U.F.; Cebrian, J.C.; Camilo, L.M.; Duarte, S.X.; Arango, H.; Bernartelli, W.H.; Marsulo, J.A.; "Evaluating the risk of equipment disruption related to voltage sags", Harmonics and Quality of Power, 2004. 11th International Conference on, p. 379 - 384, 2004.

[ 56] Kajihara, H. H.; “ Quality Power for electronics”, Electro-Technology, v. 82, n. 5, p. 46, 1968.

[ 57] Kindermann, Geraldo, Curto-Circuito, 2a . Edição - Porto Alegre - Sagra Luzzatto, 1997.

[58] Kuo, C. -C. and Chang, H.-C., "Applying a refined genetic algorithm to network reconfiguration for loss reduction”. IEE of Japan Power \& Energy, p. 37 - 42, 1994.

[ 59] Lakervi E.; Holmes, E.J.; "Electricity distribution network design". 2nded., IEE Power Series 21, London, Peter Peregrinus Ltd., p. 325, 1995.

[60] Lakervi, E.; "Voltage sag mitigation through distribution system design", Power Engineering Society Winter Meeting, 2000. IEEE, Volume 4, p. 2879 - 2880 vol.4, 2000. 
[61] Leitão, J. J. A. L.; "Impactos econômicos causados pelos distúrbios na rede básica de energia elétrica: Curtos-Circuitos, Interrupções de energia e afundamentos de tensão", Tese Doutorado, Escola politécnica da Universidade de São Paulo, São Paulo, 2002.

[62] Lin, W.M.; Cheng, F.S. and Tsay, M.T., "Distribution feeder reconfiguration with refined genetic algorithm". IEE Proceedings- Generation, Transmission and Distribution, Volume: 147 No 6, p. $349-354,2000$.

[63] Liu, E; Tu, L. G.; Hong, H. W.; Zhong, W.; "An integrated application for voltage sag analysis", IEEE Transactions on Power Systems. Vol. 13 no., 1998.

[64] Lonngren, K.; " Quality of electricity supply". Saehkeo 47(3): 118-123.

[ 65] Macken, K.J.P.; Bollen, M.H.J.; Belmans, R.J.M.; "Mitigation of voltage dips through distributed generation systems", Industry Applications, IEEE Transactions on, Volume 40, Issue 6, p. 1686 - 1693, 2004.

[ 66] Magalhães, C. H. N.; Gouvêa, M. R.; Silva, F. A. T.; Tahan, C. M. V.; Araujo Filho, L. G. C.; "Avaliação do custo social de interrupção de energia elétrica do lado da demanda no estado de são Paulo", SNPTEE, 16, p. 1-6, 2001.

[67] Mamede, Jurasy P.; "Previsão da manutenção de disjuntores dos alimentadores de distribuição de energia elétrica pelo método de Curto-Circuito probabilístico" - Tese de Mestrado - Orientador: Fujio Sato - Universidade Estadual de Campinas, Campinas, 2004.

[68] Mantovani, J. R. S.; Casari F. and Romero R. A., "Reconfiguração de sistemas de distribuição radiais utilizando o critério de queda de tensão". Revista Controle e Automação, Sociedade Brasileira de Automática, SBA. Vol.11 No. 03, 2000.

[69] Mantovani, J. R. S.;"Cálculo de fluxo de carga e Curto-Circuito em redes de distribuição de energia elétrica", Relatório do Projeto de Pesquisa, Outubro de 2001

[ 70] Marques, R. M. B.; "Ferramenta Computacional Para Avaliação do Impacto Econômico da Qualidade da Energia Elétrica no Setor de Produção das Indústrias", Dissertação de Mestrado, Universidade Federal de Ceará, 2006.

[71] Massaud, A.G.; Schilling, M.T.; Hernandez, J.P.; "Electricity restriction costs", Generation, Transmission and Distribution, IEE Proceedings, Volume 141, Issue 4, p. 299 - 304, 1994.

[72] McEachern, A.; "Power Quality: how bad is bad?", Electrical Construction and Maintenance 92(2): 26, 30, 32, 1993.

[73] McGranaghan, M.; Mueller, D.; Samotyj, M.: "Voltage Sags in Industrial Systems". Technical Conference on Industrial and Commercial Power Systems, p. 18-24, 1991.

[74] McGranaghan, M.: "Effect of Voltage Sags in processes Industrial application". Proceedings of Stockholm power tech international symposium on electric power engineering , Stockholm, Sweden, IEEE, 1995.

[ 75] Mcgranaghan, M.; Roettger, B.; "Economic Evaluation of Power Quality". IEEE Power Engineering Review, p. 8-12, 2002.

[ 76] McGranaghan, M.; Kennedy, B. W.; "Power Quality contracts in a competitive electric utility industry". Proceedings of 1998 International conference on Harmonics and Quality of power, 14-16, Athens, Greece, IEEE, 1998.

[77] Melo, M. O. B. C.; Cavalcanti, G. A.; "Avaliação do Impacto da Qualidade de Energia Elétrica no Mercado e na Produção Industrial, Análise e Metodologia". V SBQEE - Seminário 
Brasileiro sobre Qualidade da Energia Elétrica. Tópico: Impacto Econômico e Responsabilidades, Aracajú, Sergipe, Brasil, p. 483-488, 2003.

[ 78] Míguez, E.; Cidrás, J.; Díaz-Dorado, E.; García-Dornelas, J.L.; "An improved branchexchange algorithm for large-scale distribution network planning". IEEE Transactions on Power Systems, Vol. 17, No. 4, p. 931-936, 2002.

[79] Motoki, E. M.; "Procedimentos para mitigação e redução do impacto de qualidade de energia na indústria têxtil", Dissertação de Mestrado, Escola politécnica da Universidade de São Paulo, São Paulo, 2007.

[ 80] Munasinghe, M.; Gellerson, M; "Economic Criteria for Optimizing Power System Reliability Levels", Bell Journal of Economics, Volume 10, Issue 1, p. 353-365, 1979.

[ 81] Nara, K.; Satoh, T.; Kuwabara, H.; Aoki, K.; Kitagawa, M.; Ishihara, T.; "Distribution systems expansion planning by multi-stage branch exchange, IEEE Trans. on Power Systems, Vol. 7, No. 1, p. 208-214, 1992.

[ 82] Neudorf, E. G.; Kiguel, D. L.; Hamoud, G. A. et al.; "Cost-benefit analysis of power system reliability: Two utility case studies". IEEE Transactions on Power Systems, v. 10, n. 3, p. 1667-1675, 1995.

[ 83] Olguin, G.; "Voltage Dip(Sag) Estimation in Power Systems based on Stochastic Assessment and Optimal Monitoring", Thesis(PhD). Division of Electric Power engineering, Chalmers University of Technology, 2005.

[ 84] Oliveira, T. C.; Abreu, J. P. G.; Gomes, R. P; "Estimação de parâmetros de afundamentos de tensão". VI SBQEE. Pará. Brasil. 2005.

[ 85] Operador Nacional do Sistema Elétrico (ONS).; "Padrões de Desempenho da Rede Básica",Sub-módulo 2.2, Dezembro 2002.

[ 86] Parada, V.; Ferland, J.A.; Arias, M.; Daniels, K.; "Optimization of electrical distribution feeders using simulated annealing". IEEE Trans. on Power Delivery, Vol. 19, No. 3, pp. 1135-1141, 2004.

[ 87] Pohjanheimo, P.; Lehtonen, M; "Introducing Prob-A-Sag - A Probabilistic Method for Voltage Sag Management". ICHQP 2004.

[ 88] Qade, M.R.; Bollen, M.H.J.; Allan, R.N.; "Stochastic Prediction of Voltage Sags in a Large Transmission System", IEEE transactions on industry applications. vol. 35. no. 1., Page(s): 152-162, 1999.

[ 89] Qin, Z.; Shirmohammadi, D. and Liu, W.-H.E., "Distribution feeder reconfiguration for operation cost reduction". IEEE Transactions on Power Systems, Vol. 12 No. 2, May, p. 730 $-735,1997$.

[90] Ranjan, R.; Venkatesh, B.; Das, D.; "A new algorithm for power distribution system planning". Eletric Power System Research, Vol. 62, No. 1, p. 55-65, 2002.

[91] Radhakrishna, C.; Eshwardas, M.; Chebiyam, G.; "Impact of voltage sags in practical power system networks",Transmission and Distribution Conference and Exposition, 2001 IEEE/PES, Volume 1, p. 567 - 572 vol.1, 2001.

[ 92] Ramos, A. J. P.; Medeiros, R. K. D.; “Avaliação e mensuração da qualidade da energia através dos indicadores das normas Sul africanas: Análise conceitual, atributos e Análise de casos em sistemas reais", Seminário brasileiro sobre qualidade de energia elétrica, 4, Porto Alegre. Anais, p. 471-476, 2001. 
[ 93] Reis, L. B.; "Energia elétrica para o desenvolvimento sustentável”, São Paulo, EDUSP, p. 284, 2000.

[94] Romero, R.; Monticelli, A.; Garcia, A.; Haffner, S.; "Test systems and mathematical models for transmission network expansion planning". IEE Proc.-Gener. Transm Distrib., Vol. 1491, No. 1, p. 27-36, 2002.

[95] Sang-Yun Yun; Jung-Hwan Oh; Seong-Jeong Rim; Jae-Chul Kim; "Mitigation of voltage sag using feeder transfer in power distribution system", Power Engineering Society Summer Meeting, 2000. IEEE, Volume 3, p. 1421 - 1426 vol. 3, 2000.

[ 96] Santos, R. F. S.; Silva, S. R.; "Sensibilidade de Controlador Lógico programável frente a afundamentos de tensão", V Seminário brasileiro sobre qualidade de energia, Aracaju - SE Brasil, 2003.

[97] Santos, W.B; Silva,S. F ; Ferreira,S.M ; Mello,G.V ;Costa,S.M "Monitoração da Qualidade da Energia Elétrica de Fornecimento a Clientes com Cargas Sensíveis Identificação do Nível de Sensibilidade “IV SBQEE, Sessão 2D p. 309, Porto Alegre, 2001.

[98] Sarkar, A.; "Reliability Evaluation of a Generation-Resource Plan Using CustomerOutage Costs in India". Energy v. 21, n. 9, p. 795-803, 1996.

[99] Sato, Fujio; "Um estudo comparativo da análise de Curto-Circuito probabilístico utilizando ambiente paralelo e distribuído", Tese de Doutorado, Universidade Estadual de Campinas, 1995.

[ 100] Souza, L.F.W de, CEPEL - Centro de Pesquisas de Energia Elétrica. "Identificação e classificação de afundamentos momentâneos de tensão a partir de características e parâmetros de tensão durante o evento", Relatório do Projeto de Pesquisa, 2002.

[ 101] Subramaniam, R. K.; Billinton, R.; Wacker, G.; "Factors affecting the development of an industrial customer damage function". IEEE TPAS, v. 104, n. 11, p. 3209-3215, 1985.

[ 102] Sullivan, M. J.; Suddeth, B. N.; Vardell, T. et al.; "Interruption costs, customer satisfaction and expectations for service reliability". IEEE Transactions on Power Systems, v. 11, n. 2, p. 989-995, 1996.

[103] Sullivan, M. J.; Vardell, T.; Johnson, M.; "Power interruption costs to industrial and commercial consumers of electricity". IEEE Transactions on Industry Applications, v. 33, n. 6, p. 1448-1458, 1997.

[104] Sun, D.I.; Farris, D.R.; Cote, P.J.; Shoults, R.R.; Chen, M.S.; "Optimal distribution substation and primary feeder planning via the fixed charge network formulation". IEEE Trans. Power Apparatus and Systems, Vol. PAS- 101, No. 3, p. 602-609, 1982.

[ 105] Tahan, C. M. V.; Gouvea, M. R.; Dini, N. P.; Cunha, R. C.; "Avaliação de indicadores de continuidade por Análise amostral", Seminário brasileiro sobre qualidade de energia elétrica, 4, Porto Alegre. Anais, p. 445-450, 2001.

[ 106] Temraz, H.K.; Quintana, V.H.; "Distribution system expansion planning models: an overview". Electric Power Systems Research, Vol. 26, p. 61-70, 1993.

[ 107] Tosato, F.; Quaia, S.; "Equipment fault-clearing time reduction: an approach to utility voltage sag mitigation". Elektrotehniski Vestnik 67(5): 294-9, 2000.

[ 108] Tosato, F; "Voltage Sag mitigation on distribution utilities", European Transaction on Electric Power 11(1): 17-21, 2001. 
[109] Wacker, G.; Billinton, R.; "Customer costs of electric service interruptions", Proceedings of the IEEE, v. 77, n. 6, p. 919-930, 1989.

[110] Wacker, G.; Billinton, R.;“Farm losses resulting from electric service interruptions a Canadian survey", IEEE transactions, v. 4, n. 2, 1989

[111] Young, J.J.; Kim, J.-C.; Kim, J.O.; Shin, J.-R. and Lee, K.Y., “An efficient simulated annealing algorithm for network reconfiguration in large-scale distribution systems". IEEE Transactions on Power Delivery, Vol. 17, No: 4, p. 1070-1078, 2002. 


\section{0 - CÁLCULO DE CURTO-CIRCUITO}

Para faltas desequilibradas em redes trifásicas, a complexidade envolvida na análise do Curto-Circuito para sistemas desequilibrados pode ser consideravelmente reduzida utilizandose o método das componentes simétricas. A grande vantagem deste método é a decomposição das correntes e tensões de fase, assimétricas, em um conjunto de componentes com características simétricas [69].

Considerando-se $I_{A}, I_{B}$ e $I_{C}$ como sendo três correntes de fase desequilibradas, por definição, pode-se decompô-las em nove novos componentes, de acordo com o conjunto de equações a seguir:

$$
\begin{aligned}
& I_{A} \equiv I_{A 0}+I_{A+}+I_{A-} \\
& I_{B} \equiv I_{B 0}+I_{B+}+I_{B-} \\
& I_{C} \equiv I_{C 0}+I_{C+}+I_{C-}
\end{aligned}
$$

Para que o conjunto de equações (4.1) tenha solução única, é necessário impor as seguintes restrições adicionais aos componentes deste conjunto de equações, como, por exemplo, as do conjunto de equações a seguir:

$$
\begin{gathered}
I_{A}=I_{A+}+I_{A-}+I_{A 0} \\
I_{B}=\alpha^{2} I_{A+}+\alpha I_{A+}+I_{A 0} \\
I_{C}=\alpha I_{A+}+\alpha^{2} I_{A+}+I_{A 0}
\end{gathered}
$$

Sendo $\alpha \equiv e^{j 120^{\circ}}$ : A equação a seguir, corresponde ao conjunto de equações (4.2) escrito na forma matricial:

$$
I_{p}=T I_{s}
$$

Sendo a matriz: 
$T \equiv\left[\begin{array}{ccc}1 & 1 & 1 \\ 1 & \alpha^{2} & \alpha \\ 1 & \alpha & \alpha^{2}\end{array}\right]$

Denominada matriz de transformação de componentes simétricas. Os vetores correntes:

$I_{p} \equiv\left[\begin{array}{c}I_{A} \\ I_{B} \\ I_{C}\end{array}\right]$

E:

$I_{s} \equiv\left[\begin{array}{c}I_{A 0} \\ I_{A+} \\ I_{A-}\end{array}\right]$ ou para simplificar ${ }^{1} \quad I_{s} \equiv\left[\begin{array}{l}I_{0} \\ I_{+} \\ I_{-}\end{array}\right]$

Representam as correntes de fase e os componentes simétricos, respectivamente. Invertendo-se a equação (4.3), obtém-se:

$I_{s}=T^{-1} I_{p}$

Sendo:

$T^{-1}=\frac{1}{3}\left[\begin{array}{ccc}1 & 1 & 1 \\ 1 & \alpha & \alpha^{2} \\ 1 & \alpha^{2} & \alpha\end{array}\right]$

Os vetores do conjunto de equações a seguir:

$V_{p} \equiv\left[\begin{array}{l}V_{A} \\ V_{B} \\ V_{C}\end{array}\right]$ e $V_{s} \equiv\left[\begin{array}{l}V_{A 0} \\ V_{A+} \\ V_{A-}\end{array}\right]$ ou para simplificar $V_{s} \equiv\left[\begin{array}{l}V_{0} \\ V_{+} \\ V_{-}\end{array}\right]$

Representam as tensões reais de fase e os componentes simétricos da tensão, respectivamente, e aplicando-se a transformação aos fasores de tensão, tem-se:

$V_{p}=T V_{s}$

\footnotetext{
${ }^{1}$ Deve-se lembrar sempre que os componentes $I_{0}$ e $I_{+}, I_{-}$referisse á fase A.
} 
$V_{s}=T^{-1} V_{p}$

Conforme o tipo de falta é estabelecido condições de contorno nos pontos de falta, determinando uma forma conveniente de interligar as redes de seqüência de modo a satisfazer as restrições, gerando um circuito equivalente para o defeito, possibilitando obter as correntes e tensões de seqüência resultantes da falta. Os valores de fase são obtidos pela transformação inversa das componentes simétricas.

As tensões de seqüência na barra de falta (barra i) são obtidas de:

$V_{i}^{s}=V^{s}{ }_{i}{ }^{\prime}-z_{i i}^{s} x I_{f_{i}}^{s}$

Em que: $\mathrm{s} \in\{0,1$ e 2$\}$, índices referentes às seqüências zero, positiva e negativa respectivamente.

As tensões de seqüência em outras barras da rede (barra genérica k) resultantes da falta no ponto i são obtidas de:

$V_{k}^{s}=V^{s}{ }_{k}^{\prime}-z_{i k}^{s} x I_{f_{i}}^{s}$

Para redes trifásicas com tensões bem equilibradas, as tensões pré-faltas de seqüências negativas e zero são desprezadas.

As impedâncias $z^{S_{i i}}$ e $z^{S_{i k}}$ são elementos da matriz de impedâncias nodais, que podem ser obtidas da inversão da matriz de admitâncias nodais, para cada seqüência: $\left[Z^{s}\right]=\left[Y^{s}\right]^{-1}$

Em que:

$\left[Y^{s}\right]=\left[\begin{array}{ccccc}y_{11}^{s} & \cdot & \cdot & \cdot & y_{1 n}^{s} \\ \cdot & \cdot & \cdot & \cdot & \cdot \\ \cdot & \cdot & \cdot & \cdot & \cdot \\ \cdot & \cdot & \cdot & \cdot & \cdot \\ y_{n 1}^{s} & \cdot & \cdot & \cdot & y_{n n}^{s}\end{array}\right]$

$y_{i i}^{s}=\sum_{k \neq i} Y_{i k}^{s}$

$y_{i k}^{s}=-Y_{i k}^{s}$

A forma expandida da matriz de impedâncias nodais é: 


$$
\left[Z^{s}\right]=\left[\begin{array}{ccccc}
z_{11}^{s} & \cdot & \cdot & \cdot & z_{1 n}^{s} \\
\cdot & \cdot & \cdot & \cdot & \cdot \\
\cdot & \cdot & \cdot & \cdot & \cdot \\
\cdot & \cdot & \cdot & \cdot & \cdot \\
z_{n 1}^{s} & \cdot & \cdot & \cdot & z_{n n}^{s}
\end{array}\right]
$$

\subsection{Curto-Circuito Trifásico}

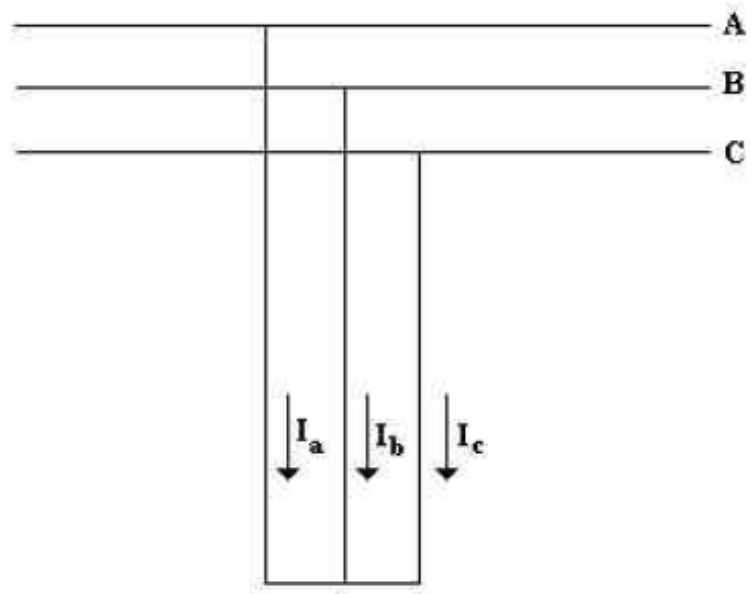

Figura 10-1 - Curto-Circuito Trifásico.

$\left|V_{A N}\right|=\left|V_{B N}\right|=\left|V_{C N}\right|=0$

Decompondo em componentes simétricas:

$$
\begin{aligned}
& {\left[\begin{array}{l}
V_{A N 0} \\
V_{A N 1} \\
V_{A N 2}
\end{array}\right]=\frac{1}{3}\left[\begin{array}{ccc}
1 & 1 & 1 \\
1 & \alpha & \alpha^{2} \\
1 & \alpha^{2} & \alpha
\end{array}\right]\left[\begin{array}{l}
V_{A N} \\
V_{B N} \\
V_{C N}
\end{array}\right]} \\
& V_{A N 0}=\frac{1}{3}\left(V_{A N}+V_{B N}+V_{C N}\right) \\
& V_{A N 1}=\frac{1}{3}\left(V_{A N}+\alpha V_{B N}+\alpha^{2} V_{C N}\right) \\
& V_{A N 2}=\frac{1}{3}\left(V_{A N}+\alpha^{2} V_{B N}+\alpha V_{C N}\right) \\
& V_{A N 0}=V_{A N 1}=V_{A N 2}=0
\end{aligned}
$$




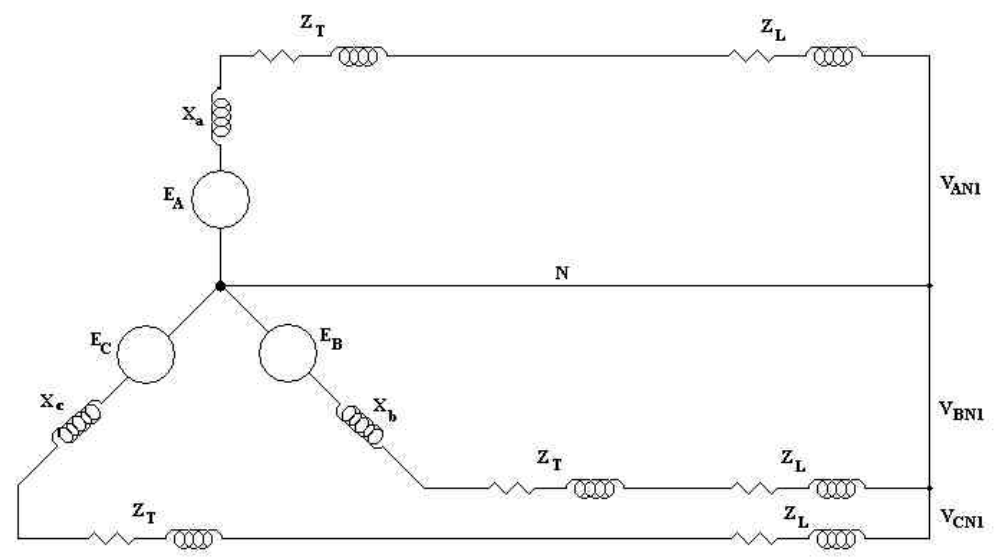

Figura 10-2 - Diagrama Trifilar - Curto-Circuito trifásico

Para a seqüência positiva, tem-se:

$V_{A N 1}=E_{a}-Z_{A 1} \cdot I_{A 1}$

Para a seqüência negativa, tem-se:

$V_{A N 2}=0-Z_{A 2} \cdot I_{A 2}$

Para a seqüência zero, tem-se:

$V_{A N 0}=0-Z_{A 0} . I_{A 0}$

Colocando na forma matricial:

$\left[\begin{array}{c}V_{A N 0} \\ V_{A N 1} \\ V_{A N 2}\end{array}\right]=\left[\begin{array}{c}0 \\ E_{a} \\ 0\end{array}\right]-\left[\begin{array}{ccc}Z_{0} & 0 & 0 \\ 0 & Z_{1} & 0 \\ 0 & 0 & Z_{2}\end{array}\right] \cdot\left[\begin{array}{c}I_{A 0} \\ I_{A 1} \\ I_{A 2}\end{array}\right]$

$V_{A N 1}=E_{a}-Z_{1} \cdot I_{A 1}$

$0=E_{a}-Z_{1} \cdot I_{A 1} \Rightarrow I_{A 1}=\frac{E_{0}}{Z_{1}}$

Como:

$I_{A}=I_{A 1}+I_{A 2}+I_{A 0}$

$I_{B}=I_{B 1}+I_{B 2}+I_{B 0}$

$I_{C}=I_{C 1}+I_{C 2}+I_{C 0}$

e considerando ainda:

$I_{B 1}=\alpha^{2} \cdot I_{A 1}$

$I_{C 1}=\alpha \cdot I_{A 1}$

Que leva a: 
$\left|I_{A}\right|=\left|I_{B}\right|=\left|I_{C}\right|=E_{0} / Z_{1}$

\subsection{Curto-Circuito Fase - Terra}

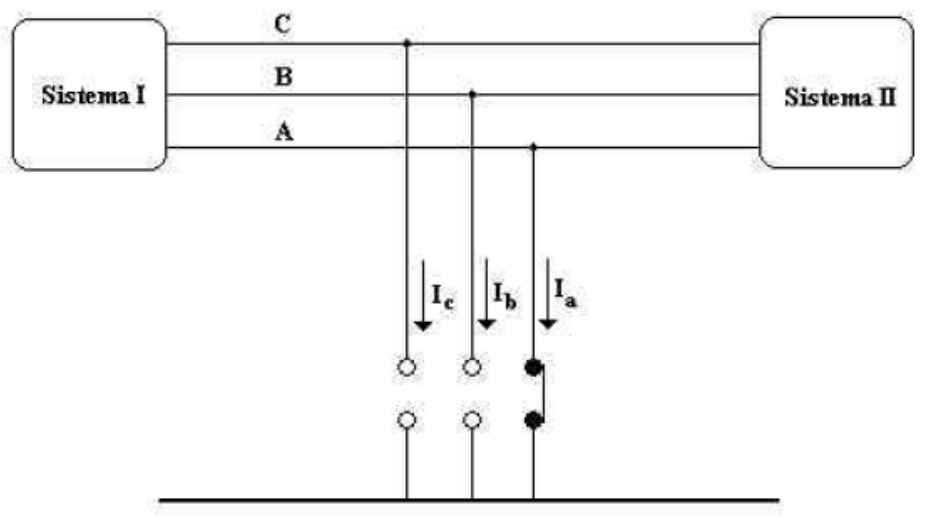

Figura 10-3 - Curto-Circuito Fase-Terra.

$I_{A} \neq 0, I_{B}=0, I_{C}=0$ Correntes de falta

$V_{A}=0, V_{B} \neq 0, V_{C} \neq 0$ tensões de falta

Decompondo a corrente $\mathrm{I}_{\mathrm{A}}$ em componentes simétricas:

$$
\begin{aligned}
& {\left[\begin{array}{c}
I_{A 0} \\
I_{A 1} \\
I_{A 2}
\end{array}\right]=\frac{1}{3}\left[\begin{array}{ccc}
1 & 1 & 1 \\
1 & \alpha & \alpha^{2} \\
1 & \alpha^{2} & \alpha
\end{array}\right]\left[\begin{array}{c}
I_{A} \\
0 \\
0
\end{array}\right]} \\
& I_{A 0}=\frac{1}{3} \cdot I_{A}, I_{A 1}=\frac{1}{3} \cdot I_{A}, I_{A 2}=\frac{1}{3} \cdot I_{A}
\end{aligned}
$$

Isto é:

$$
I_{A 0}=I_{A 1}=I_{A 2}=\frac{1}{3} \cdot I_{A}
$$

Considerando agora no ponto de Curto-Circuito, o Thévenin equivalente para seqüência positiva, negativa e zero: 

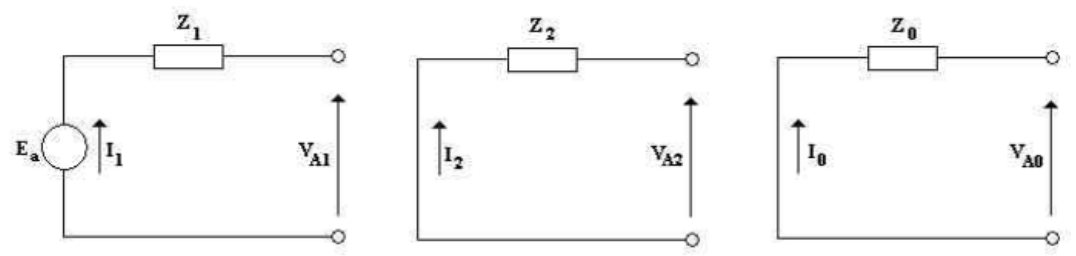

Figura 10-4 - Equivalente Thévenin para o Curto-Circuito fase-terra.

$$
\begin{aligned}
& V_{A 1}=E_{a}-Z_{1} \cdot I_{1} \\
& V_{A 2}=-Z_{2} \cdot I_{2} \\
& V_{A 0}=-Z_{0} \cdot I_{0} \\
& {\left[\begin{array}{c}
V_{A} \\
V_{B} \\
V_{C}
\end{array}\right]=\left[\begin{array}{ccc}
1 & 1 & 1 \\
1 & \alpha & \alpha \\
1 & \alpha & \alpha^{2}
\end{array}\right]\left[\begin{array}{c}
V_{A 0} \\
V_{A 1} \\
V_{A 2}
\end{array}\right]} \\
& V_{A}=V_{A 0}+V_{A 1}+V_{A 2} \\
& V_{A}=-Z_{0} \cdot I_{A 0}+E_{a}-Z_{1} I_{A 1}-Z_{2} I_{A 2} \\
& V_{A}=0 \quad I_{A 0}=I_{A 1}=I_{A 2}=\frac{1}{3} I_{A} \\
& I_{A 1}=\frac{E_{a}}{Z_{0}+Z_{1}+Z_{2}} \\
& I_{A}=\frac{3 E_{a}}{Z_{0}+Z_{1}+Z_{2}}
\end{aligned}
$$

Em que:

$E_{a}: \mathrm{V}_{\text {th }}$ de seqüência positiva (pré-falta) no ponto em Curto-Circuito;

$Z_{1}: Z_{\text {th }}$ de seqüência positiva no ponto;

$Z_{2}: Z_{\text {th }}$ de seqüência negativa no ponto;

$Z_{0}: Z_{\text {th }}$ de seqüência zero no ponto.

Conhecendo-se IA $0=$ IA $1=$ IA2, podem-se calcular as contribuições parciais para cada seqüência e depois decompô-las (pode-se desprezar ou não as correntes pré-falta). Os diagramas de seqüência positiva, negativa e zero são interligados em série: 


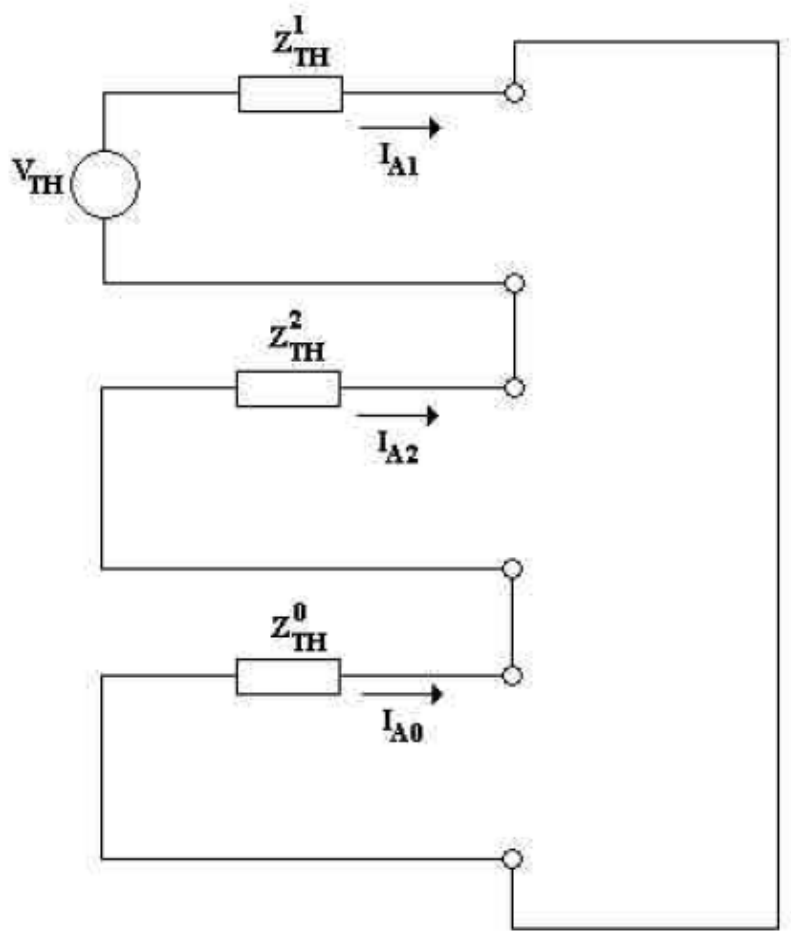

Figura 10-5 - Diagrama de seqüência para o Curto-Circuito fase-terra

\subsection{Curto-Circuito Fase-Fase (Fases B e C)}
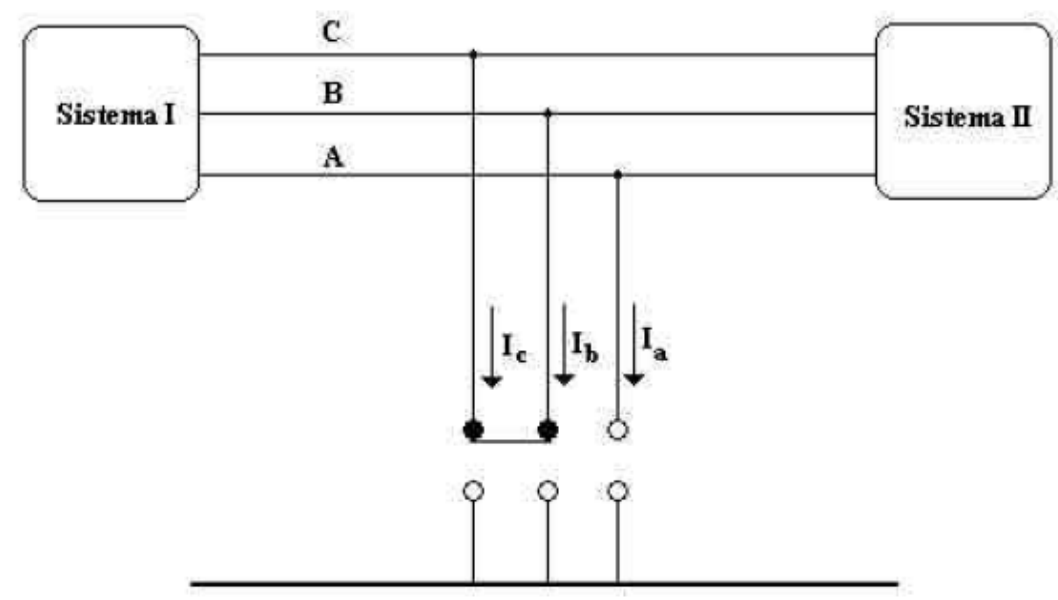

Figura 10-6 - Curto-Circuito Fase-Fase

Falta nas Fases B e C:

$$
I_{A}=0 \quad I_{C}=-I_{B} \Rightarrow I_{C}=I_{B} e^{j 180}
$$

Componentes simétricas: 


$$
\begin{aligned}
& {\left[\begin{array}{c}
I_{A 0} \\
I_{A 1} \\
I_{A 2}
\end{array}\right]=\frac{1}{3}\left[\begin{array}{ccc}
1 & 1 & 1 \\
1 & \alpha & \alpha^{2} \\
1 & \alpha^{2} & \alpha
\end{array}\right]\left[\begin{array}{c}
0 \\
I_{B} \\
I_{B} e^{j 180^{0}}
\end{array}\right]} \\
& I_{A 0}=\frac{1}{3}\left(I_{B}-I_{B} e^{j 180^{0}}\right) \\
& I_{A 1}=\frac{1}{3}\left(e^{j 120^{0}} I_{B}+e^{-j 120^{0}} I_{B} e^{j 180^{0}}\right) \\
& I_{A 1}=\frac{I_{B}}{3}\left(-\frac{1}{2}+j \frac{\sqrt{3}}{2}+\frac{1}{2}+j \frac{\sqrt{3}}{2}\right) \\
& I_{A 1}=\frac{I_{B} \sqrt{3}}{3} e^{j 90^{0}} \\
& I_{A 2}=\frac{I_{B} \sqrt{3}}{3} e^{-j 90^{0}}
\end{aligned}
$$

Conclusão:

$$
\begin{aligned}
& I_{A 0}=0 \\
& I_{A 2}=-I_{A 1} \neq 0
\end{aligned}
$$

As tensões, para o ponto de Curto-Circuito, em uma falta fase-fase são:

$V_{A N}=E_{a}$

$$
V_{B N}=V_{C N}
$$

Decompondo em componentes simétricas:

$$
\begin{aligned}
& {\left[\begin{array}{c}
V_{A N 0} \\
V_{A N 1} \\
V_{A N 2}
\end{array}\right]=\frac{1}{3}\left[\begin{array}{ccc}
1 & 1 & 1 \\
1 & \alpha & \alpha^{2} \\
1 & \alpha^{2} & \alpha
\end{array}\right]\left[\begin{array}{c}
E_{a} \\
V_{B N} \\
V_{B N}
\end{array}\right]} \\
& V_{A N 1}=\frac{1}{3}\left(E_{a}+V_{B N} e^{j 120^{0}}+V_{B N} e^{-j 120^{0}}\right) \\
& V_{A N 2}=\frac{1}{3}\left(E_{a}+V_{B N} e^{-j 120^{0}}+V_{B N} e^{j 120^{0}}\right) \\
& \therefore V_{A N 1}=V_{A N 2}
\end{aligned}
$$

Ponto de Curto-Circuito: Thévenin equivalente
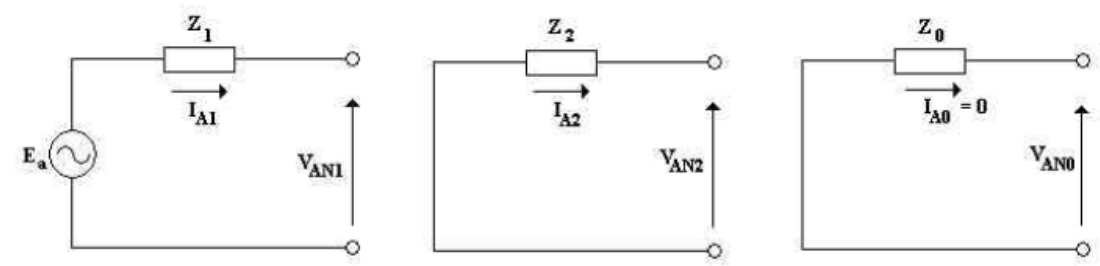
Figura 10-7 - Equivalente Thévenin para o Curto-Circuito fase-fase.

$$
\begin{aligned}
& V_{A N 1}=E_{a}-Z_{1} \cdot I_{A 1} \\
& V_{A N 2}=-Z_{2} \cdot I_{A 2}=Z_{2} I_{A 1}
\end{aligned}
$$

Como $V_{A N 1}=V_{A N 2}$ então:

$E_{a}-Z_{1} \cdot I_{A 1}=Z_{2} I_{A 1}$

$I_{A 1}=\frac{E_{a}}{Z_{1}+Z_{2}}$

As condições que devem ser obedecidas para a interligação dos Thévenin's equivalentes, para Curtos-Circuitos entre as linhas B e C são:

$I_{A 1}=-I_{A 2}$

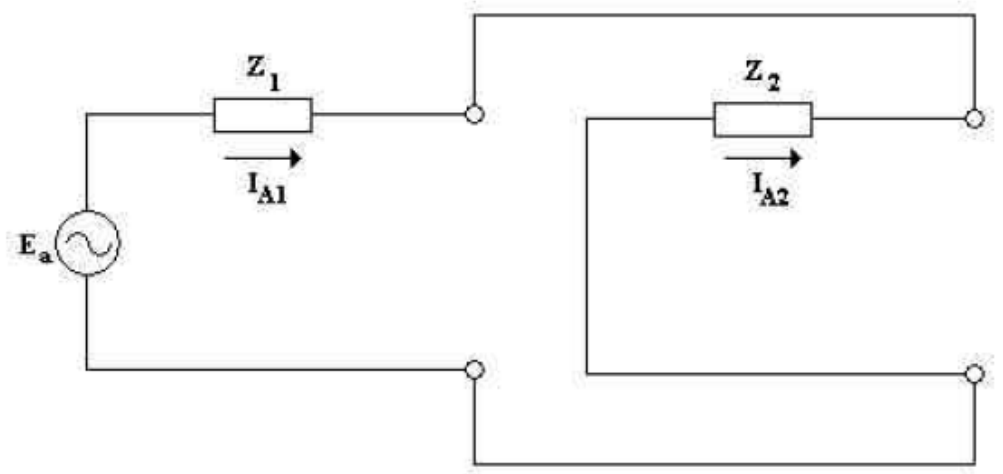

Figura 10-8 - Diagrama de seqüência para o Curto-Circuito fase-fase.

Usando componentes simétricas:

$$
\begin{aligned}
& {\left[\begin{array}{l}
I_{A} \\
I_{B} \\
I_{C}
\end{array}\right]=\left[\begin{array}{ccc}
1 & 1 & 1 \\
1 & \alpha^{2} & \alpha \\
1 & \alpha & \alpha^{2}
\end{array}\right]\left[\begin{array}{c}
0 \\
I_{A 1} \\
-I_{A 1}
\end{array}\right]} \\
& I_{A}=0 \\
& I_{B}=\left(\alpha^{2}-\alpha\right) I_{A 1}
\end{aligned}
$$




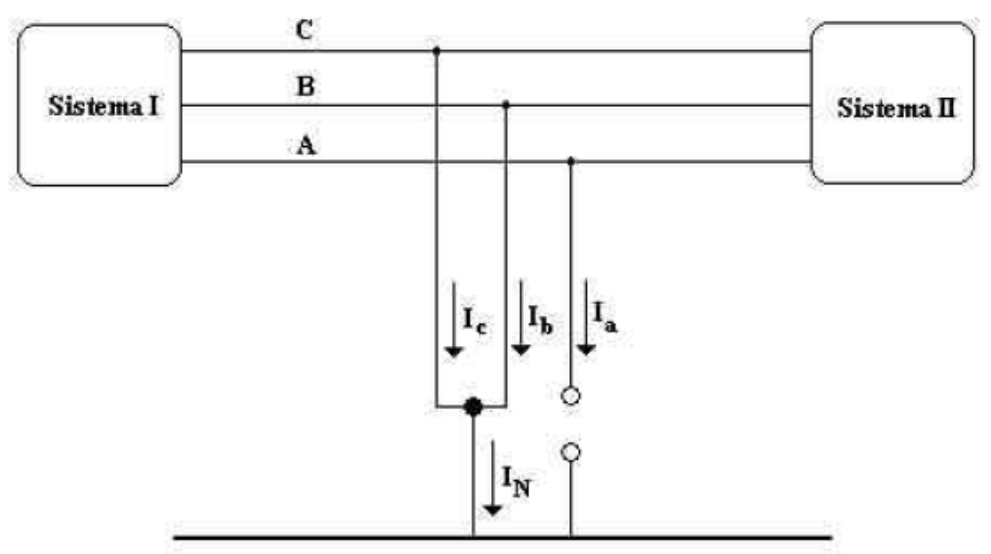

Figura 10-9 - Curto-Circuito Fase-Fase-Terra.

Curto-Circuito Fases B e C:

$I_{A}=0$

$\left[\begin{array}{l}I_{A} \\ I_{B} \\ I_{C}\end{array}\right]=\left[\begin{array}{ccc}1 & 1 & 1 \\ 1 & \alpha^{2} & \alpha \\ 1 & \alpha & \alpha^{2}\end{array}\right]\left[\begin{array}{l}I_{A 0} \\ I_{A 1} \\ I_{A 2}\end{array}\right]$

$I_{A 1}=-\left(I_{A 0}+I_{A 2}\right)$

$V_{A N} \neq 0$

$V_{B N}=V_{C N}=0$

$\left[\begin{array}{c}V_{A 0} \\ V_{A 1} \\ V_{A 2}\end{array}\right]=\frac{1}{3}\left[\begin{array}{ccc}1 & 1 & 1 \\ 1 & \alpha & \alpha^{2} \\ 1 & \alpha^{2} & \alpha\end{array}\right]\left[\begin{array}{c}V_{A N} \\ 0 \\ 0\end{array}\right]$

$V_{A 0}=\frac{1}{3} V_{A N} \quad V_{A 1}=\frac{1}{3} V_{A N} \quad V_{A 2}=\frac{1}{3} V_{A N}$

$V_{A 0}=V_{A 1}=V_{A 2}$

Thévenin equivalente:
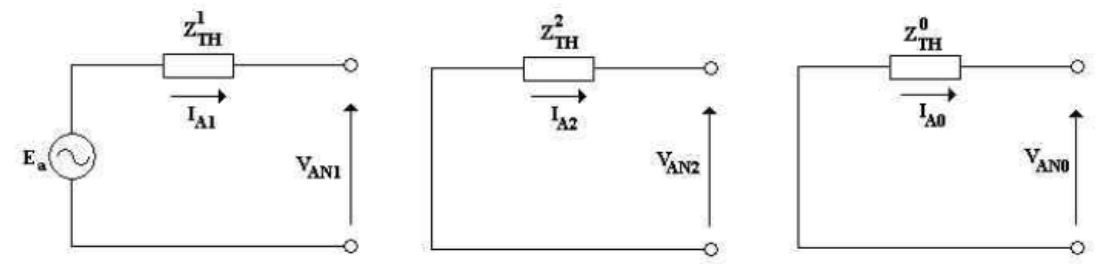

Figura 10-10 - Equivalente Thévenin para o Curto-Circuito fase-fase-terra. 


$$
\begin{aligned}
& V_{A N 1}=E_{a}-Z_{T H}^{1} \cdot I_{A 1} \\
& V_{A N 2}=-Z_{T H}^{2} \cdot I_{A 2} \\
& V_{A N 0}=-Z_{T H}^{0} \cdot I_{A 0} \\
& V_{A N 1}=V_{A N 2} \\
& E_{a}-Z_{T H}^{1} \cdot I_{A 1}=-Z_{T H}^{2} I_{A 2} \\
& V_{A N 1}=V_{A N 0} \\
& E_{a}-Z_{T H}^{1} \cdot I_{A 1}=-Z_{T H}^{0} I_{A 0} \\
& I_{A 0}=\frac{Z_{T H}^{1} I_{A 1}-E_{a}}{Z_{T H}^{0}} \\
& I_{A 0}+I_{A 1}+I_{A 2}=0 \Rightarrow I_{A 2}=-\left(I_{A 0}+I_{A 1}\right)
\end{aligned}
$$

Substituindo (4.5) em (4.6):

$$
I_{A 2}=-\left(\frac{Z_{T H}^{1} I_{A 1}-E_{a}}{Z_{T H}^{0}}\right)-I_{A 1}
$$

Substituindo (4.7) em (4.4):

$$
\begin{aligned}
& E_{a}-Z_{T H}^{1} \cdot I_{A 1}=Z_{T H}^{2}\left(\frac{Z_{T H}^{1} I_{A 1}-E_{a}}{Z_{T H}^{0}}\right)+Z_{T H}^{2} I_{A 1} \\
& E_{a}+\frac{Z_{T H}^{2} E_{a}}{Z_{T H}^{0}}=Z_{T H}^{1} I_{A 1}+\frac{Z_{T H}^{2} Z_{T H}^{1}}{Z_{T H}^{0}} I_{A 1}+Z_{T H}^{2} I_{A 1} \\
& E_{a}+\frac{Z_{T H}^{2} E_{a}}{Z_{T H}^{0}}=\left(Z_{T H}^{1}+\frac{Z_{T H}^{2} Z_{T H}^{1}}{Z_{T H}^{0}}+Z_{T H}^{2}\right) I_{A 1} \\
& \left(Z_{T H}^{0}+Z_{T H}^{2}\right) E_{a}=\left(Z_{T H}^{1} Z_{T H}^{0}+Z_{T H}^{2} Z_{T H}^{1}+Z_{T H}^{2} Z_{T H}^{0}\right) I_{A 1} \\
& I_{A 1}=\frac{E_{a}}{\frac{Z_{T H}^{1}\left(Z_{T H}^{0}+Z_{T H}^{2}\right)+Z_{T H}^{2} Z_{T H}^{0}}{\left(Z_{T H}^{0}+Z_{T H}^{2}\right)}} \\
& I_{A 1}=\frac{E_{a}}{Z_{T H}^{2} Z_{T H}^{0}} \\
& \left(Z_{T H}^{0}+Z_{T H}^{2}\right)
\end{aligned}
$$

Para a interligação dos diagramas deve-se obedecer:

$$
I_{A}=0 \quad I_{A 1}+I_{A 2}+I_{A 0}=0 \Rightarrow I_{A 1}=-\left(I_{A 2}+I_{A 0}\right)
$$




$$
I_{A 1}=\frac{E_{a}}{Z_{T H}^{1}+\frac{Z_{T H}^{2} Z_{T H}^{0}}{\left(Z_{T H}^{0}+Z_{T H}^{2}\right)}}
$$

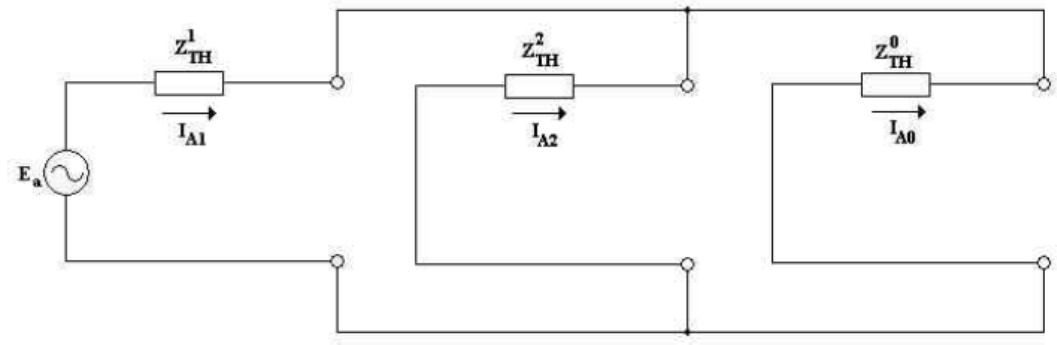

Figura 10-11 - Diagrama de seqüência para o Curto-Circuito fase-fase-terra. 